\title{
Effects of Particles and Bioflocculation on Ultraviolet Disinfection
}

\author{
By \\ Kerim Kollu, B.A.Sc. Env. Engineering
}

A thesis submitted to the Faculty of Graduate Studies and Research in partial fulfillment of the requirements for the degree of

\author{
Master of Applied Science \\ in \\ Environmental Engineering* \\ Department of Civil and Environmental Engineering \\ Carleton University \\ Ottawa, Ontario \\ Canada
}
*The Master of Applied Science in Environmental Engineering Program is a joint program with the University of Ottawa administrated by the
Ottawa-Carleton Institute for Environmental Engineering

(C) Kerim Kollu, 2008 


$\begin{array}{ll}\begin{array}{l}\text { Library and } \\ \text { Archives Canada }\end{array} & \begin{array}{l}\text { Bibliothèque et } \\ \text { Archives Canada }\end{array} \\ \begin{array}{l}\text { Published Heritage } \\ \text { Branch }\end{array} & \begin{array}{l}\text { Direction du } \\ \text { Patrimoine de l'édition }\end{array} \\ \begin{array}{l}\text { 395 Wellington Street } \\ \text { Ottawa ON K1A 0N4 } \\ \text { Canada }\end{array} & \begin{array}{l}\text { 395, rue Wellington } \\ \text { Ottawa ON K1A 0N4 } \\ \text { Canada }\end{array}\end{array}$

Your file Votre référence ISBN: 978-0-494-44047-6 Our file Notre référence ISBN: 978-0-494-44047-6

NOTICE:

The author has granted a nonexclusive license allowing Library and Archives Canada to reproduce, publish, archive, preserve, conserve, communicate to the public by telecommunication or on the Internet, loan, distribute and sell theses worldwide, for commercial or noncommercial purposes, in microform, paper, electronic and/or any other formats.

The author retains copyright ownership and moral rights in this thesis. Neither the thesis nor substantial extracts from it may be printed or otherwise reproduced without the author's permission.
AVIS:

L'auteur a accordé une licence non exclusive permettant à la Bibliothèque et Archives Canada de reproduire, publier, archiver, sauvegarder, conserver, transmettre au public par télécommunication ou par l'Internet, prêter, distribuer et vendre des thèses partout dans le monde, à des fins commerciales ou autres, sur support microforme, papier, électronique et/ou autres formats.

L'auteur conserve la propriété du droit d'auteur et des droits moraux qui protège cette thèse. $\mathrm{Ni}$ la thèse ni des extraits substantiels de celle-ci ne doivent être imprimés ou autrement reproduits sans son autorisation.
In compliance with the Canadian Privacy Act some supporting forms may have been removed from this thesis.

While these forms may be included in the document page count, their removal does not represent any loss of content from the thesis.
Conformément à la loi canadienne sur la protection de la vie privée, quelques formulaires secondaires ont été enlevés de cette thèse.

Bien que ces formulaires aient inclus dans la pagination, il n'y aura aucun contenu manquant.

\section{Canada}




\begin{abstract}
UV disinfection units are becoming increasingly popular in the wastewater treatment industry. However, the effectiveness of UV disinfection is closely related to the water quality parameters, and inactivation of microorganisms has been shown to decrease in presence of particles. Several studies have reported results on the effect of particle size on UV disinfection, but the importance of the bioflocculation process and the effect of final floc size and structure on UV disinfection have been largely ignored. This study is the first of its kind to study effects of flocs and flocculation on UV disinfection in a completely controlled synthetic system via induced bioflocculation. The study was divided into three phases. In the first phase, it was found that larger sized particles protected $E$. coli to a lesser extent from UV disinfection. In the second phase, flocculation was observed to decrease disinfection efficiency based on floc size and structure. Finally, the third phase showed that extracellular polymers played an important role in disinfection kinetics by absorbing UV light.
\end{abstract}




\section{ACKNOWLEDGMENTS}

Firstly, I would like to extend sincere thanks to my supervisor, Dr. Banu Örmeci, for her guidance and support throughout the course of my Master's work, and for her excellent supervision during the entirety of this thesis and her timely and comprehensive feedback. To the members of the committee, I thank you for your comments and your review of this work. Also, to the laboratory staff in the Environmental Engineering Laboratory at Carleton University, especially to Dr. Marie-Josee Tudoret, for all her help. I would also like to extend thanks to every person in the Environmental Engineering Department at Carleton University that I have had the joy of getting to know over the past two years.

To those who are part of my everyday life: my roommate; Kim Hair, and to all my amazing friends all around the world, especially to Audrey Murray and Erol Ozbakir for their everlasting encouragement. Finally to my parents and sister, for their infinite love and support. 


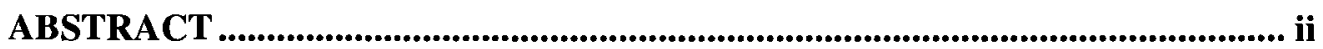

ACKNOWLEDGMENTS ................................................................................. ii

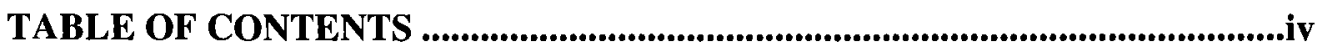

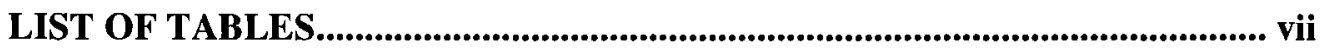

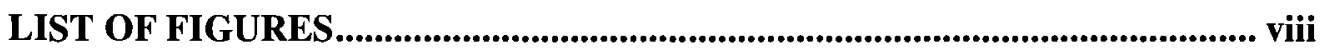

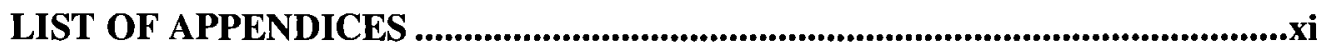

LIST OF ACRONYMS AND NOMENCLATURE ............................................ xii

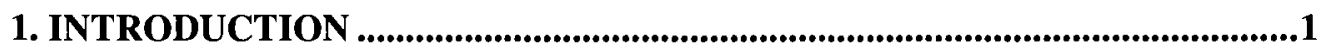

1.1 Theory of Disinfection.......................................................................... 1

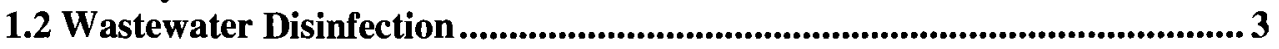

1.3 Ultraviolet Radiation Disinfection ..................................................................... 5

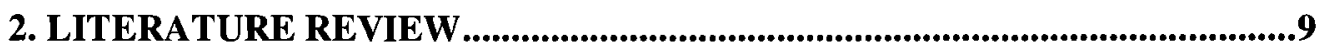

2.1 A Synthetic Surrogate for Wastewater Flocs.............................................9

2.2 Microbial Enumeration ............................................................................. 12

2.3 Scattering and Absorbance of UV Light .................................................... 14

2.5 Effect of Particles on UV Disinfection.............................................................. 17

2.6 Effect of Particle-Microbe Association on UV Disinfection ........................ 21

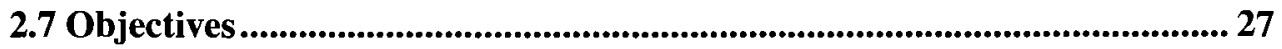

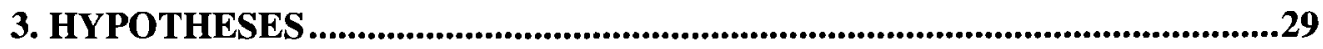


4.1 Preliminary Experiments........................................................................ 30

4.1.1 Determination of Ingredients for Synthetic Media ............................... 30

4.1.2 Flocculation Observations .............................................................. 33

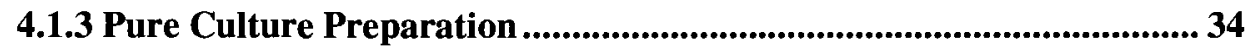

4.1.4 Survival of Bacteria in PBS and Water ................................................ 35

4.2 General Experimental Procedures ....................................................................... 36

4.2.1 Sterilization of Glassware and Equipment Used.................................... 37

4.2.2 Preparation of Stock Solutions and Growth Media ............................... 37

4.2.3 Preparation of Synthetic Solution............................................................ 39

4.2.4 UV Collimated Beam Setup ..................................................................... 41

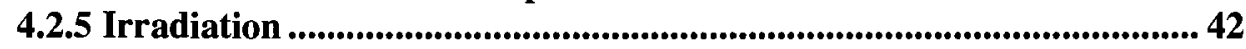

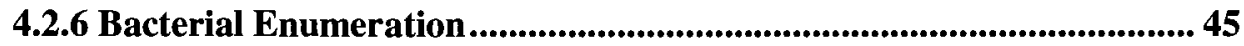

4.2.7 Particle Size Count Tests ........................................................................ 47

4.3 Phase Specific Experimental Design........................................................... 48

4.3.1 Phase I - Particle Only Solution (Effect of Particles) Experiments .... 49

4.3.2 Phase II - Effect of Calcium Concentration Experiments..................... 49

4.3.3 Phase III - Effect of Alginate Concentration Experiments .................. 51

4.3.3.1 Particle Free Inactivation Tests .................................................... 52

4.4 Miscellaneous Analytical Measurements .................................................... 52

4.5 Data Presentation.................................................................................. 52

5. RESULTS AND DISCUSSION

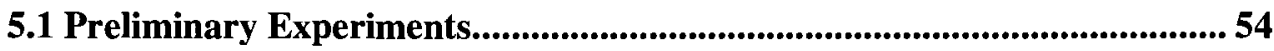

5.2 Phase I: Effect of Particles on UV Inactivation ......................................... 57

5.3 Water Quality Parameters Analyzed ........................................................... 66

5.4 Phase II: Effect of Calcium Dose on Flocculation and UV Inactivation .... 69

5.4.1 1- $\mu \mathrm{m}$ Experiments .............................................................................. 72

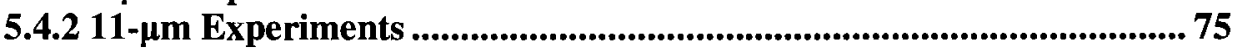

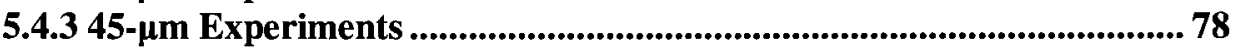

5.4.4 Phase II Comparison of 1-, 11-, and 45- $\mu \mathrm{m}$ Experiments..................... 80

5.5 Phase III: Effect of Alginate Dose on Flocculation and UV Inactivation .. 83

5.5.1 Particle Free-Varying Alginate Experiments .........................................83

5.5.2 UV Inactivation Experiments in Presence of particles ......................... 86

5.5.3 Phase III Comparison of 1-, 11-, and 45- $\mu \mathrm{m}$ Experiments .................. 94

5.6 Various Factors That May Have Affected the Inactivation Rates .............. 98

5.7 Concluding Remarks .............................................................................. 100

6. CONCLUSIONS AND RECOMMENDATIONS FOR FUTURE RESEARCH104

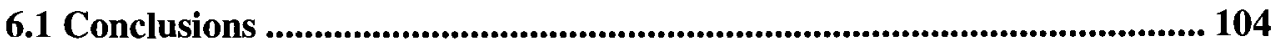

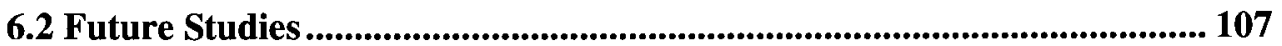




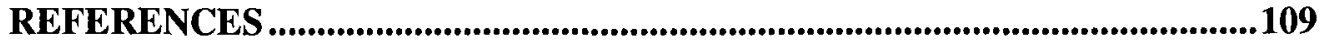

APPENDIX A: RAW DATA ........................................................................................118

APPENDIX B: LINEARIZED DOSE-RESPONSE CURVES AND

INACTIVATION RATE CONSTANTS...........................................................154 


\section{LIST OF TABLES}

Table 4.1: Latex particle characteristics........................................32

Table 4.2: Experimental design used for different phase............................48 


\section{LIST OF FIGURES}

Figure 1.1: UV induced damage to the DNA: after UV exposure adjacent thymine bases bond with each other, instead of across the ladder. . .6

Figure 1.2: A typical dose-response curve where lag and tailing are observed. ....7

Figure 2.1: Divalent cation bridging within a floc. . .011

Figure 2.2: Three idealized cases of EPS distribution within a floc. .24

Figure 4.1: General experimental scheme. .37

Figure 4.2: UV collimated beam setup. .041

Figure 4.3: Phase II experimental scheme. .50

Figure 4.4: Phase III experimental scheme. .51

Figure 5.1: Bacterial growth curve plotted by measuring the suspension's absorbance at $500 \mathrm{~nm}$ over 18 hours.

Figure 5.2: 1- $\mu \mathrm{m}$ Latex Particle Solution; Range $(\mu \mathrm{m})$ : 1.00-25.25, Mean $(\mu \mathrm{m})$ : 1.78, Mode $(\mu \mathrm{m}): 1.00-2.25$, Standard Deviation $(\mu \mathrm{m}): 0.86$, Total Concentration of Particles (\#/mL): 6613, Concentration of Particles in 1.00-2.25 Range $(\# / \mathrm{mL})$ : 6015. .58

Figure 5.3: 11- $\mu \mathrm{m}$ Latex Particle Solution; Range $(\mu \mathrm{m})$ : 1.00-21.25, Mean $(\mu \mathrm{m})$ : 10.81, Mode $(\mu \mathrm{m}): 10.25-11.25$, Standard Deviation $(\mu \mathrm{m}): 1.18$, Total Concentration of Particles (\#/mL): 6632, Concentration of Particles in 8.25-15.25 Range (\#/mL): 6523.

Figure 5.4: 45- $\mu \mathrm{m}$ Latex Particle Solution; Range $(\mu \mathrm{m})$ : 1.00-124.25, Mean $(\mu \mathrm{m})$ : 34.89, Mode $(\mu \mathrm{m}): 2.25-3.25$, Standard Deviation $(\mu \mathrm{m}): 18.32$, Total Concentration of Particles (\#/mL): 7917, Concentration of Particles in 30.2590.25 Range (\#/mL): 6044.

Figure 5.5: Phase-I UV inactivation experiments of three different solutions containing equal number concentrations of $1-, 11-$, or $45-\mu \mathrm{m}$ latex particles and

E. coli.

Figure 5.6: Absorbance and turbidity measurements of Phase I experiments. ...66

Figure 5.7: The image on the left shows the original floc as it appears on the screen and the image on the right shows how it is perceived by the instrument for counting. .68

Figure 5.8: Particle number concentrations measured (particles $>5 \mu \mathrm{m}$ ) for the conditions studied in Phase II. 
Figure 5.9: Particle mean size values measured (particles $>5 \mu \mathrm{m}$ ) for the conditions studied in Phase II.

Figure 5.10: Absorbance values measured at $254 \mathrm{~nm}$ for conditions studied in Phase II.

Figure 5.11: Phase-II UV inactivation experiments with $1-\mu \mathrm{m}$ particles, $10 \mathrm{mg} / \mathrm{L}$ alginate and varying concentrations of calcium ions.

Figure 5.12: Figure 5.12: Flocs formed in 1- $\mu \mathrm{m}$ experiments of Phase II, flocculation conditions: $10 \mathrm{mg} / \mathrm{L}$ alginate and calcium doses as indicated on the figure.

Figure 5.13: Phase-II UV inactivation experiments with $11-\mu \mathrm{m}$ particles, $10 \mathrm{mg} / \mathrm{L}$ alginate and varying concentrations of calcium ions.

Figure 5.14: Flocs formed in 11- $\mu \mathrm{m}$ experiments of Phase II, flocculation conditions: $10 \mathrm{mg} / \mathrm{L}$ alginate and calcium doses as indicated on the figure. ........76

Figure 5.15: Phase-II UV inactivation experiments with $45-\mu \mathrm{m}$ particles, $10 \mathrm{mg} / \mathrm{L}$ alginate and varying concentrations of calcium ions.

Figure 5.16: Flocs formed in 45- $\mu \mathrm{m}$ experiments of Phase II, flocculation conditions: $10 \mathrm{mg} / \mathrm{L}$ alginate and calcium doses as indicated on the figure. .79

Figure 5.17: Phase II dose-response curves in the absence of calcium and at 10 $\mathrm{mg} / \mathrm{L}$ alginate.

Figure 5.18: Phase II dose-response curves at a calcium concentration of $5 \mathrm{mM}$ and an alginate concentration of $10 \mathrm{mg} / \mathrm{L}$.

Figure 5.19: Phase II dose-response curves at a calcium concentration of $10 \mathrm{mM}$ and an alginate concentration of $10 \mathrm{mg} / \mathrm{L}$.

Figure 5.20: Phase II dose-response curves at a calcium concentration of $15 \mathrm{mM}$ and an alginate concentration of $10 \mathrm{mg} / \mathrm{L}$.

Figure 5.21: Absorbance of the samples measured at $254 \mathrm{~nm}$ when different concentrations of alginate were added to particle-free suspensions of bacteria. .84

Figure 5.22: Phase III dose-response curves of particle $\&$ calcium free solutions containing varying concentrations of alginate $(0$ to $40 \mathrm{mg} / \mathrm{L})$.

Figure 5.23: Particle number concentrations measured (particles $>5 \mu \mathrm{m}$ ) for the conditions studied in Phase III.

Figure 5.24: Particle mean size values measured (particles $>5 \mu \mathrm{m}$ ) for the conditions studied in Phase III. 
Figure 5.25: Absorbance values measured at $254 \mathrm{~nm}$ for conditions studied in Phase III.

Figure 5.26: Phase III dose-response curves of 1- $\mu \mathrm{m}$ experiments at a calcium concentration of $10 \mathrm{mM}$ and varying concentrations of alginate (0 to $40 \mathrm{mg} / \mathrm{L}$ ).

Figure 5.27: Phase III dose-response curves of 11- $\mu \mathrm{m}$ experiments at a calcium concentration of $10 \mathrm{mM}$ and varying concentrations of alginate $(0$ to $40 \mathrm{mg} / \mathrm{L})$.

Figure 5.28: Figure 5.28: Phase III dose-response curves of 45- $\mu \mathrm{m}$ experiments at a calcium concentration of $10 \mathrm{mM}$ and varying concentrations of alginate ( 0 to $40 \mathrm{mg} / \mathrm{L})$.

Figure 5.29: Flocs formed in 1- $\mu \mathrm{m}$ experiments of Phase III, flocculation conditions: $10 \mathrm{mM}$ calcium and alginate concentration as indicated on the figure.

Figure 5.30: Flocs formed in 11- $\mu \mathrm{m}$ experiments of Phase III, flocculation conditions: $10 \mathrm{mM}$ calcium and alginate concentration as indicated on the figure.

Figure 5.31: Flocs formed in 45- $\mu \mathrm{m}$ experiments of Phase III, flocculation conditions: $10 \mathrm{mM}$ calcium and alginate concentration as indicated on the figure.

Figure 5.32: Phase III dose-response curves of particle-experiments at a calcium concentration of $10 \mathrm{mM}$ and in the absence of alginate.

Figure 5.33: Phase III dose-response curves of particle-experiments at a calcium concentration of $10 \mathrm{mM}$ and an alginate concentration of $10 \mathrm{mg} / \mathrm{L}$.

Figure 5.34: Phase III dose-response curves of particle-experiments at a calcium concentration of $10 \mathrm{mM}$ and an alginate concentration of $20 \mathrm{mg} / \mathrm{L}$.

Figure 5.35: Phase III dose-response curves of particle-experiments at a calcium concentration of $10 \mathrm{mM}$ and an alginate concentration of $40 \mathrm{mg} / \mathrm{L}$. .96

Figure 5.36: Comparison of dose-response curves of Phase III particle-free 0 $\mathrm{mg} / \mathrm{L}$ alginate experiment with Phase I experiments. 


\section{LIST OF APPENDICES}

APPENDIX A: RAW DATA ............................................118 APPENDIX B: LINEARIZED DOSE-RESPONSE CURVES AND INACTIVATION CONSTANTS.............................................154 


\section{LIST OF ACRONYMS AND NOMENCLATURE}

\begin{tabular}{|c|c|}
\hline ATCC & American Type Culture Collection \\
\hline CFU & Colony Forming Units \\
\hline CT & Chlorine dose: chlorine concentration times contact time \\
\hline C.V. & Coefficient of Variation \\
\hline DCB & Divalent Cation Bridging \\
\hline DNA & Deoxyribonucleic Acid \\
\hline ECD & Equivalent Circular Diameter \\
\hline E. coli & Escherichia coli \\
\hline EPS & Extracellular Polymeric Substances \\
\hline IS & Integrating Sphere \\
\hline $\mathbf{k}$ & Inactivation Rate Constant (Log-Inactivation / UV Dose) \\
\hline MF & Membrane Filtration \\
\hline MTF & Multiple Tube Fermentation \\
\hline NTU & Nephelometric Turbidity Units \\
\hline PBS & Phosphate-Buffered Solution \\
\hline RNA & Ribonucleic Acid \\
\hline TYG & Tryptone-Glucose-Yeast Broth \\
\hline US EPA & United States Environmental Protection Agency \\
\hline UV & Ultraviolet \\
\hline WERF & Water Environment Federation \\
\hline
\end{tabular}




\section{CHAPTER 1}

\section{INTRODUCTION}

This chapter aims to give a general background on wastewater disinfection and issues related to disinfection efficiency. As ultraviolet (UV) disinfection is the focus of this research, other disinfection methods that are currently used at wastewater treatment plants are briefly explained and issues that are related to UV disinfection and that are of importance for this study are discussed more in detail.

\subsection{Theory of Disinfection}

Disinfection refers to the inactivation and/or destruction of microorganisms capable of causing diseases; however, it is not a selective process and does not distinguish between harmless and harmful organisms. Unlike sterilization which is the destruction of all microorganisms present, disinfection results in only a partial destruction. Disinfection processes during treatment of water or wastewater form an essential and final barrier against human exposure to pathogenic microorganisms which can be categorized under four main groups: bacteria; viruses, amoebic cysts, and protozoan cysts.

An ideal disinfectant would have to possess a wide range of characteristics including: high availability, low interaction with extraneous material, no corrosiveness, no staining properties, no toxicity to higher life forms; high penetration, solubility and stability; and high toxicity to microorganisms. The most common ways of achieving disinfection are by use of chemical agents, physical agents, mechanical means, and radiation (Metcalfe and Eddy Inc., 2003). 
Chemical agents used in disinfection processes consist of chlorine and its compounds, bromine, iodine, ozone, phenol and phenolic compounds, alcohols, heavy metals and related compounds, dyes, soaps and synthetic detergents, quaternary ammonium compounds, hydrogen peroxide, peracetic acid, various alkalies, and various acids. Oxidizing chemicals, chlorine being the most frequently used one, are the most common means of chemical disinfection universally. Physical agents used in disinfection processes include heat, light, and sound waves. Additionally, certain processes during wastewater treatment, such as filtration and sedimentation, also result in removal of bacteria and other disease-causing organisms. This is referred to as mechanical means of disinfection. Disinfection by radiation, on the other hand, is achieved via electromagnetic, acoustic, and particle radiation techniques.

The principal mechanisms that have been proposed to explain the action of disinfectants include: damage to the cell wall, alteration of cell permeability, alteration of the colloidal nature of the protoplasm, enzyme inhibition, and damage to the cell deoxyribonucleic acid (DNA) and ribonucleic acid (RNA). Damage or destruction of the cell wall causes cell lysis and eventually death of the cell. Alteration of cell permeability results in allowance of vital nutrients, such as nitrogen and phosphorus, to leak out through the cytoplasmic membrane. Changing the nature of cell proteins is a typical example of cell destruction by alteration of the colloidal nature of cell protoplasm. Enzyme inhibition is another way of inactivation that can be achieved through oxidizing agents capable of altering the chemical composition of enzymes [Water Environment Research Foundation (WERF), 1995]. Finally, inactivation of microorganisms via damage to the cell DNA (or RNA) involves absorption of ultraviolet light by DNA or RNA pyrimidine bases followed by the 
formation of a covalent dimer between the two bases inhibiting cell replication (Bolton and Linden, 2003).

Factors influencing disinfection can be listed as follows: type of disinfectant, type of target microorganism, disinfectant concentration and contact time, $\mathrm{pH}$ of the medium, temperature of the medium, chemical and physical interference with disinfection (characteristics of suspending liquid), protective effect of macroinvertebrates, and some other factors such as whether the indicator organisms are laboratory-grown or indigenous and whether previous exposure to disinfectants has occurred or not (Bitton, 2005). Some of these factors are an integral part of this research as will be explained in more detail in the following chapters.

\subsection{Wastewater Disinfection}

Water reuse applications such as agricultural irrigation, landscape irrigation, industrial recycling and reuse, groundwater recharge, recreational/environmental uses, nonpotable urban uses, and potable uses have been a driving force for better disinfection of wastewater as stricter regulations regarding pathogenic content have been put into effect to better protect public health.

In recent years improvement of the quality of wastewater effluents prior to their discharge into receiving water bodies have become necessary also due to factors such as increased population, increased mobility of population, increased recreation, increased sewage discharge, and increased water use; all of which weaken the effectiveness of natural barriers (dilution and residence time) protecting potable water intakes from possible contamination by discharged wastewaters. Disinfection, as it 
forms the last barrier against transmission of waterborne diseases, remains as the most viable protection available (White, 1978). Emerging health and environmental concerns, stricter regulations, and development of new technologies are affecting the design of disinfection systems and changing the extent of disinfection required for wastewater prior to its discharge. Historically, chlorine has been the most widely used disinfectant for wastewater. However, recently due to the discoveries related to the harmful effects of chlorination by-products and disinfectant residuals, treatment facilities have had to put dechlorination systems in operation or replace chlorination systems by other means of disinfection, preferably with no known hazardous byproduct formation at doses that would typically be encountered, such as the UV radiation systems (Malley et al., 1995). Moreover, other studies indicating UV light's effectiveness against chlorine resistant pathogens: Cryptosporidium parvum and Giardia lamblia (Linden et al., 2002; Shin et al., 2001; Clancy et al., 2000), along with improvements in the UV lamp and ballast design technologies have accelerated the widespread application of UV radiation in wastewater treatment. As of today, wastewater disinfection by UV radiation can be considered as a competitive alternative to chlorination in terms of cost and effectiveness against pathogens (Metcalfe and Eddy Inc., 2003).

In Canada, water quality standards are regulated by provincial authorities. Although UV disinfection is not addressed explicitly by most provinces, in Ontario and Quebec the regulations are such that "UV disinfection is recognized as an alternate disinfection technology" and it is noted that "particle removal can be waived if proved not necessary" [American Water Works Association (AWWA), American Society of Civil Engineers, 2005]. 


\subsection{Ultraviolet Radiation Disinfection}

UV radiation occurs in the portion of the electromagnetic spectrum from 100 to 400 $\mathrm{nm}$, yet germicidal activity is limited to radiation mainly in the UV-C range: at wavelengths between 245 and 285 nm (US EPA, 1999). The most common type of lamps employed for producing UV radiation are mercury lamps, however, other lamp technologies are also being developed including xenon and excimer lamps. Furthermore, there exist three different lamp arrangements, namely: low-pressure low-intensity, low-pressure high-intensity, and medium-pressure high-intensity systems. In most laboratory scale experiments, including this project, low-pressure low-intensity UV lamps, which generate essentially monochromatic radiation at a wavelength of $254 \mathrm{~nm}$, are used. This wavelength is considered highly germicidal due to its proximity to the $260 \mathrm{~nm}$ wavelength at which point DNA's absorbance reaches a peak. In treatment plant applications, the lamps are enclosed in quartz tubes, which isolate the lamps from direct water contact and keep the lamp wall temperature under control. The reason for employing quartz as the encapsulation material is to allow the passage of germicidal light (Metcalfe and Eddy Inc., 2003; Bitton, 2005).

UV light is considered a physical rather than a chemical disinfecting agent, as nothing is being added to the water except for energy in the form of radiation. Therefore, under most circumstances no chemical change is observed and only the temperature of the medium increases as heat is produced by the energy input (White, 1978; Metcalfe and Eddy Inc., 2003).

As mentioned previously, the inactivation of microorganisms by UV light is achieved by absorption of radiation by the nucleic acids. Once a sufficient amount of radiation 
is absorbed, thymine and cytosine dimerization takes place, which in turn inhibits replication or causes death of the cell (Figure 1.1).
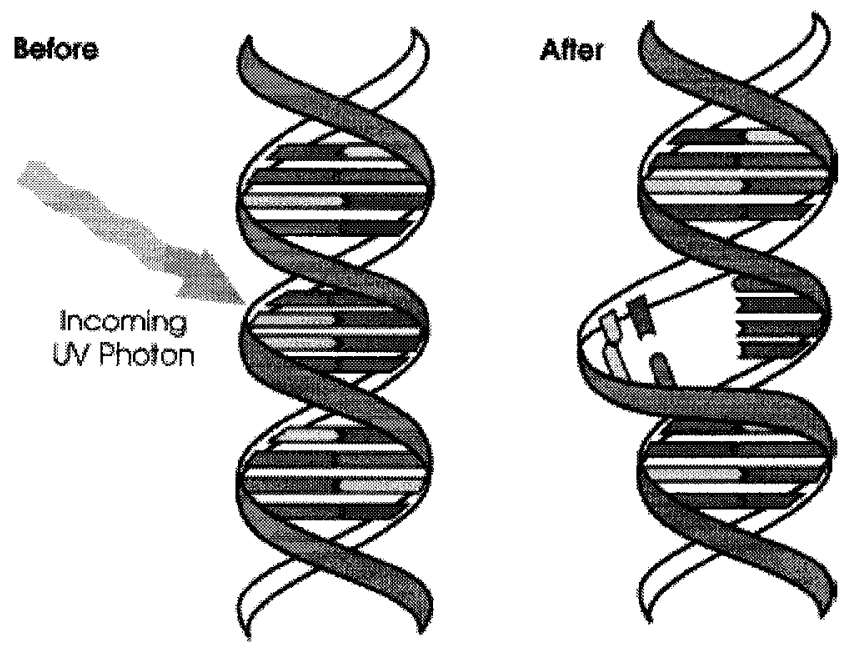

Figure 1.1: UV induced damage to the DNA: after UV exposure adjacent thymine bases bond with each other, instead of across the ladder (Source: Allen, J., 2001).

With regard to the mechanism of inactivation by UV light, several characteristics of the suspending liquid (i.e., wastewater) play a crucial role in the effectiveness of UV disinfection processes. However, by far the most important parameter that controls the extent of UV disinfection is the UV dose itself. Similar to the case of chlorination where efficiency is based on contact time and concentration, the effectiveness of UV disinfection is based on radiation intensity and exposure time, the product of which gives the UV dose. The intensity is usually reported in units of milliwatts per square centimeter $\left(\mathrm{mW} / \mathrm{cm}^{2}\right)$ and the exposure time in units of seconds (s). Therefore, the UV dose is reported in units of millijoules per square centimeter $\left(\mathrm{mJ} / \mathrm{cm}^{2}\right)$. Throughout this research, intensity, exposure time and dose values were always measured and reported in units mentioned above. 
Typically, the rate and extent of inactivation achieved after UV exposure is analyzed by plotting a dose-response curve, which is a plot of the logarithm of the ratio of number of surviving bacteria to the initial number of bacteria versus the UV dose applied. In cases where inactivation of a sample containing only dispersed bacteria is of concern the dose-response curve is expected to follow first-order kinetics (Farnood, 2004). On the other hand, in most cases a lag or shoulder effect at low doses due to self-aggregation of microbes (Severin et al, 1983) or cellular repair mechanisms (Jagger, 1967), and a tailing effect at high doses due to shielding of bacteria by particles (Qualls et al, 1983) are observed. These phenomena are demonstrated also in Figure 1.2.

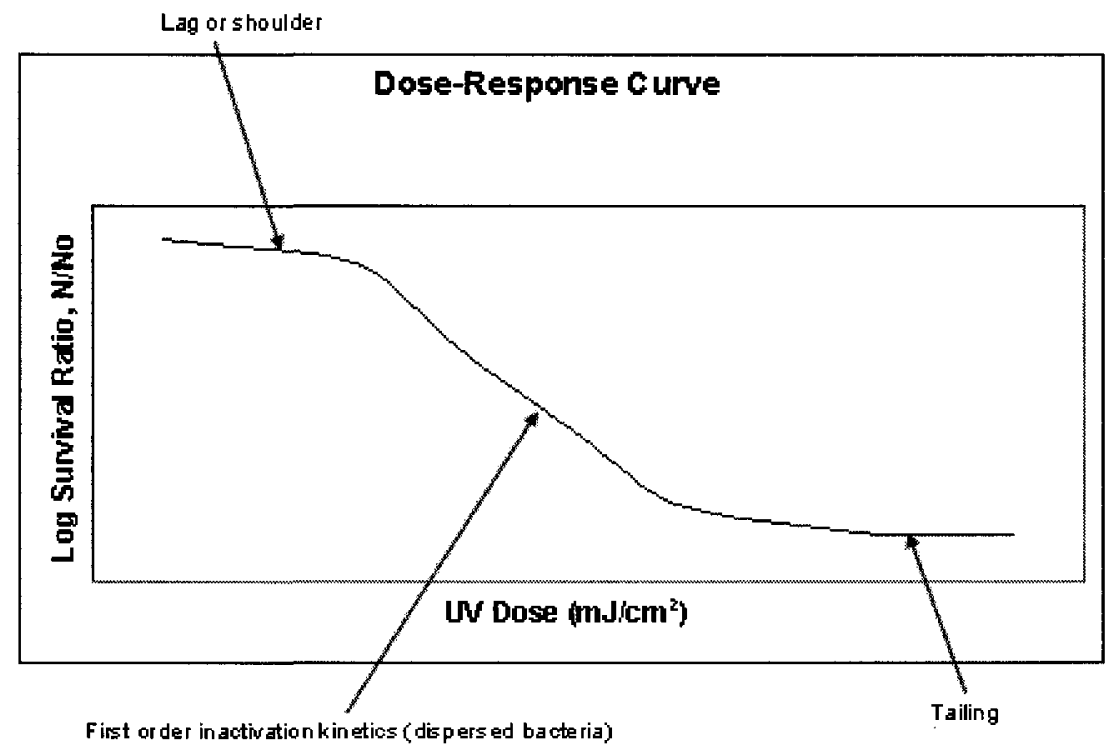

Figure 1.2: A typical dose-response curve where lag and tailing are observed. (Source: Metcalfe and Eddy Inc., 2003, Modified).

One of the problems related to the application of UV systems in treatment facilities arise from the lack of information on UV intensity and the actual time of exposure for all the target organisms going through the UV reactor. (Metcalfe \& Eddy Inc., 2003). However, such problems are not expected to be encountered in experiments 
conducted with bench scale UV collimated beam apparatus since the UV irradiance measurements are accurate and the samples are well-mixed.

Theoretically wastewater can be disinfected to any degree desired provided that adequate amounts of UV energy reach the target organisms (White, 1978). Therefore, the main concern in wastewater disinfection by UV radiation has always been to ensure delivery of UV light to the target organisms without any loss of energy to the other constituents present in the system or to the water itself. With that regard, the transmittance of UV light throughout the system becomes the determining factor as to how much of the dose produced by the lamps is actually delivered to the target organisms. In other words any interference in the form of absorption or scattering of the UV light resulting from the liquid medium itself (colour, dissolved substances) or the other materials present (suspended solids) will have a defining effect on the outcomes of UV disinfection. As these issues are the subject of recent and ongoing studies, including this project, a more detailed review of the theory and findings are presented in the literature review chapter. 


\section{CHAPTER 2}

\section{LITERATURE REVIEW}

In order to understand the problems related to the limitations of UV disinfection of wastewaters, one needs to look at: 1. the characteristics of particles and flocs found in wastewaters, 2. the interactions between particles and target organisms and among target organisms themselves (flocculation, aggregation), and 3. the interactions between the aforementioned factors and the UV light as well as the microbial enumeration practices followed.

\subsection{A Synthetic Surrogate for Wastewater Flocs}

The very first step of this project was to create a synthetic system that enables one to study the effects of particles and bioflocculation on UV disinfection in a controlled and reproducible way. In order to achieve this goal a better understanding of the mechanisms involved in bioflocculation is necessary and needs to be established.

Bioflocculation is defined as the natural process of microorganisms aggregating into flocs (Sobeck and Higgins, 2002). Different organisms present in the wastewater (bacteria, fungi, viruses and protozoa) together with the other organic and inorganic constituents of wastewater form flocs in a polymeric network holding them together. This polymeric network is referred to as the extracellular polymeric substances (EPS) and mainly originates from the microorganisms and/or the wastewater itself (Friedman et al., 1969; Pavoni et al., 1972; Horan and Eccles, 1986; Urbain et al., 1993). It has been shown that EPS play a key role in bioflocculation and the total mass of EPS can be as high as $80 \%$ of the total mass of the floc (Frolund et al., 1996). 
It has also been reported that due to the presence of negatively charged functional groups (such as carboxyl groups) within the EPS, the net charge of flocs tends to be negative (Horan and Eccles, 1986; Frolund et al., 1996). Therefore, the flocs formed by bioflocculation (bioflocs) are considerably different in their physical and chemical nature than chemical flocs achieved through flocculation induced via inorganic chemical addition, such as alum or ferric chloride.

In addition to EPS, cations have also been shown to play an important role in bioflocculation primarily due to the net negative charge of bioflocs. The divalent cation bridging (DCB) theory suggests that divalent cations [specifically calcium $\left(\mathrm{Ca}^{2+}\right)$ and magnesium $\left(\mathrm{Mg}^{2+}\right)$ ions due to their abundance in natural aquatic systems] have an overall promoting effect on floc formation as they enhance bridging between negatively charged functional groups within the EPS (Tezuka, 1969). According to this theory, it is this bridging mechanism that facilitates aggregation and stabilization of biopolymers and microorganisms. Monovalent cations $\left(\mathrm{Na}^{+}, \mathrm{NH}_{4}^{+}\right.$, and $\left.\mathrm{K}^{+}\right)$, on the other hand, have been shown to have a deteriorating effect on biofloc formation as they displace divalent cations (Higgins and Novak, 1997). Bruus et al. (1992) found that when calcium ions are present, alginate which is a polysaccharide formed by two monosaccharide units starts forming alginate gels. The fact that extracellular polymers extracted from activated sludge have a greater affinity toward calcium ions than magnesium ions led to the conclusion that alginate is an important component of EPS (Bruus et al., 1992). The role of divalent cations within a floc is demonstrated in Figure 2.1. 


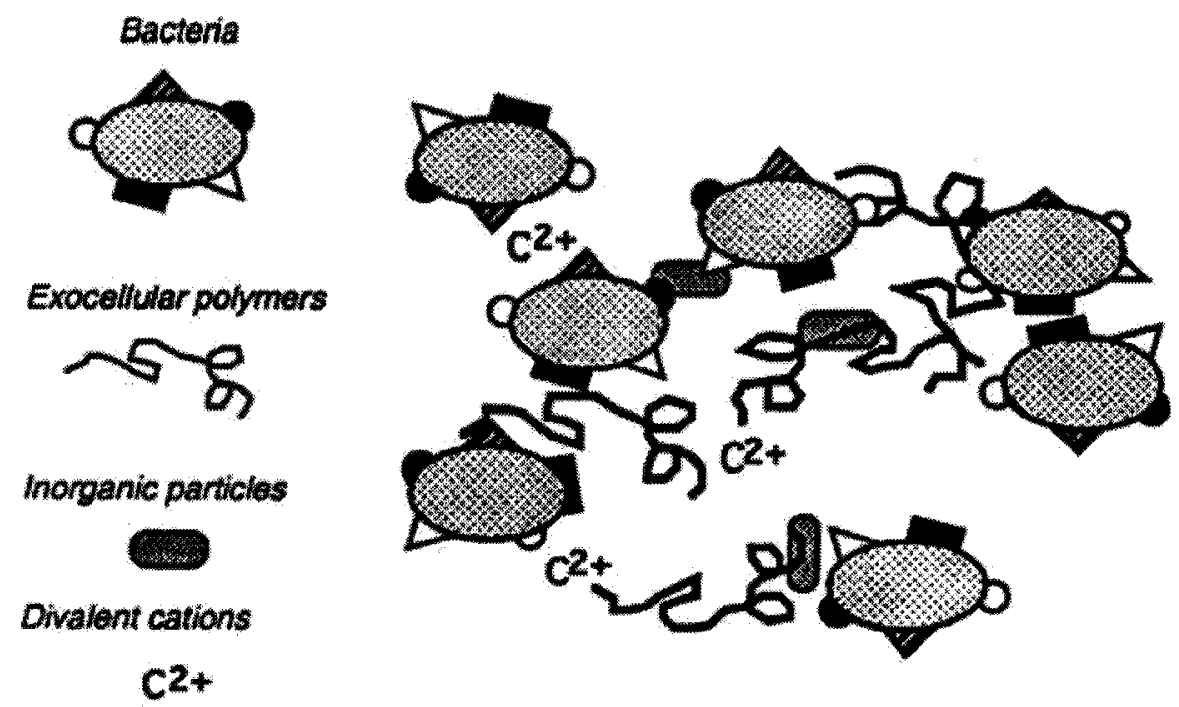

Figure 2.1: Divalent cation bridging within a floc (Source: Urbain et al., 1993, Modified).

Due to its time-dependent highly variable nature and lack of control over its composition, it is very difficult to work with bioflocs in natural systems. For example, samples taken from a wastewater treatment plant on the same day may exhibit completely different characteristics. Samples may also develop significantly different properties over a shorter period of time compared to the duration of the analyses making the laboratory data very difficult if not impossible to reproduce (Sanin and Vesilind, 1999). Therefore, for studying the effect of particles and bioflocculation on UV disinfection, it is crucial to use a stable, well-defined and well-controlled surrogate that can simulate the particle characteristics, and coagulation and flocculation properties of water and wastewater samples.

A stable chemical surrogate for activated sludge was created by using polystyrene latex particles, alginate and calcium ions (Sanin and Vesilind, 1996). In that system, alginate simulated the extracellular material and calcium ions facilitated the bridging 
between the negatively charged functional groups as discussed previously. Sanin and Vesilind (1996) reported formation of visible flocs physically very similar to activated sludge flocs immediately following calcium addition. The synthetic matrix, called synthetic sludge, was prepared by addition of latex particles first, followed by alginate addition and mixing to provide adsorption of alginate onto particle surfaces. Within time periods as short as $\mathbf{5}$ seconds after calcium addition visible floc formation was observed to take place at calcium concentrations of 10 and $15 \mathrm{mM}$. As well, no visible floc formation was observed when initial calcium concentration was set at $5 \mathrm{mM}$ and a faster visible floc formation was seen at higher calcium concentrations ( 20 and 25 $\mathrm{mM}$ ). This observation verified the importance of calcium in bridging and kinetics of bioflocculation.

A further study of Sanin and Vesilind (1999) investigated the suitability of synthetic sludge in terms of its physical properties as a surrogate for wastewater sludge. The study concluded that synthetic sludge may serve as a good surrogate material in experiments dealing with physical properties of sludge especially when reproducibility is of concern.

\subsection{Microbial Enumeration}

The two most commonly used methods for enumeration of fecal coliforms in wastewater analyses are the membrane filtration (MF) and the multiple tube fermentation (MTF) techniques as described in Standard Methods: [American Public Health Association (APHA), American Water Works Association and Water Pollution Control Federation, 2005]. Both of these methods work best for analyzing suspensions of dispersed bacteria (also called free-swimming bacteria) that are not 
associated with particles or self-aggregated (clumped). However, coliform bacteria have been found to be frequently particle-associated in wastewater. Since particleassociated and clumped bacteria are counted as single colonies when these techniques of enumeration are directly used, usually the organism concentrations are underestimated (Parker and Darby, 1995).

Several methods of treatment prior to enumeration have been suggested to overcome this problem. Various physical and chemical techniques to extract (free) organisms from particles, flocs and other organisms were shown to be effective at varying degrees (Örmeci and Linden, 2005). Mamane and Linden (2006a) employed vortex mixing to release spores from spore-spore and spore-particle aggregates and concluded that sufficient extraction was achieved. Borst and Selvakumar (2003) investigated the effect of 1 - and 2-minute blending on microbial enumeration with standard MF method. It was reported that increasing the blending time from 1 to 2 minutes caused an increase in the detected concentration of fecal coliform, whereas, no significant change occurred in the case of $E$. coli and total coliform enumerations.

The extent of underestimation of the measured microbial concentration was reported to reach such levels that enumeration following elution resulted in concentrations up to 340 times greater than enumeration without any elution. This was shown to be more significant for samples irradiated at higher UV doses as the ratio of particleassociated organisms to total organisms is expected to increase with increasing applied UV dose (Parker and Darby, 1995). Therefore, microbial analysis techniques that do not include an extraction step prior to enumeration might lead to flawed conclusions by underestimating the microbial concentration. 


\subsection{Scattering and Absorbance of UV Light}

It is necessary to look at some of the important concepts that govern the transmittance of UV light within a suspension volume in order to better understand how they might affect the inactivation of target organisms.

Research by Huber and Frost (1998) pointed out that in a medium with obstacles light will be deflected from its original path. This deflection is referred to as scattering and the degree of it depends on the nature of the particles. When many particles in a solution scatter light collectively the overall effect is called turbidity. The intensity of scattered light (turbidity) in a solution depends on the concentration and size of particles, and the refractive index difference between the particles and the medium. Turbidity is proportional to the concentration of a suspension and it was shown that for an equal mass concentration forward scattering dominated when particles were large $(5 \mu \mathrm{m})$, whereas equally distributed scattering took place when particles were small $(0.05 \mu \mathrm{m})$. The refractive index of a particle depends on its composition and as a natural consequence the difference between the indices of water and a particle is less when the particles are watery materials (such as biological cells), and more for inorganic particles (such as metal oxides). The larger this difference is the more scattering occurs (Huber and Frost, 1998).

When UV light is scattered by particles, although its energy is reduced, it is still capable of inactivating microbes. UV light that is absorbed by particles on the other hand, is no longer available for inactivation (Huber and Frost, 1998; Mamane and Linden, 2006b). However, the effect of absorbance can be properly factored into the delivered UV dose calculations such that no significant reduction in disinfection 
efficiency takes place for a specific UV dose (Christensen and Linden, 2003). The UV absorbance of a suspension can be accounted for in the dose calculation by the integration of Beer-Lambert law over the sample depth (Morowitz, 1950). It was observed by Christensen and Linden (2003) that solutions with turbidity values less than 3 NTU could be disinfected by UV irradiation with no loss of efficiency when UV absorbance of the sample was measured directly. However, it became evident that this way of absorbance measurements did not take into account the effect of light scattering and led to an overestimation of UV dose when higher turbidities were encountered. A significant portion of the scattered light, especially the fraction which was backscattered, was found not to have been detected properly by direct absorbance measurement techniques, thereby falsely increasing the absorbance measured.

Further research conducted by Christensen and Linden (2003), and Mamane and Linden (2006b) suggested that use of integrating sphere (IS) spectroscopy, which allows for the collection of reflected and transmitted radiation simultaneously, would be able to account for the effects of light scattering and measure the true absorbance of the sample solution. The results of Christensen and Linden's study (2003) indicated that the increased UV demand due to the presence of particles could be properly factored into the UV dose calculation such that for the same UV dose no significant difference in inactivation would be observed among solutions having turbidities ranging from 0 to $10 \mathrm{NTU}$, as long as the absorbance was measured using IS spectrophotometry. The study conducted by Mamane and Linden (2006b) reported that the overdosing due to scattering might have led to less significant inactivation differences than expected in studies investigating the effects of particle-microbe association. 


\subsection{Corrections Necessary for Determination of Average UV Dose Delivered}

In order to produce reliable and reproducible data which are comparable to the works of other researchers, it is essential to follow standardized procedures for the determination of UV dose. Bolton and Linden (2003) have identified such a protocol for bench scale UV apparatuses, which includes several practical corrections for accurate detection of the average irradiance (intensity of UV light) in the water and therefore determination of delivered dose. Although this protocol contains specifications for both monochromatic (254 nm) and polychromatic (200-400 nm) UV systems, procedures provided for monochromatic UV lamps only are summarized in this chapter since the project was based on such systems.

Four correction factors were suggested for low pressure (monochromatic) UV lamps: the reflection factor, the petri factor, the water factor, and the divergence factor. The reflection factor constitutes for the amount of light that is reflected off the surface of the samples. The petri factor is a correction for the uneven distribution of the light across the surface of the sample. The water factor is necessary as it accounts for the decrease in irradiance due to the absorption of light by water along its way through the sample depth. And finally, the divergence factor is needed to account for the amount of light that diverges out of the sample volume before crossing the entire sample depth. These factors are to be used for the adjustment of the incident irradiance (UV intensity) such that the average irradiance within the sample volume is calculated as the product of the factors and the incident irradiance. The incident irradiance must be measured in the centre of the exposure field at the same distance from the UV lamp as the samples to be irradiated are. Once the average irradiance (the true irradiance) is determined, required exposure times are calculated simply by 
dividing the desired UV doses to the average irradiance provided by the UV lamps (Bolton and Linden, 2003).

\subsection{Effect of Particles on UV Disinfection}

The presence of suspended solids in wastewater plays an important role in UV disinfection kinetics. For an efficient disinfection, it is essential that sufficient amounts of UV light penetrates the water volume and is delivered to the target organisms. Particles impact UV disinfection performance by interfering with the penetration and transmittance of UV light within the system. The interference usually occurs by different mechanisms: scattering, absorption, reflection and diffusion of incident UV light (Batch et al., 2004). Through these mechanisms particles can lead to a decrease in inactivation of target organisms by decreasing the transmission of UV energy through the water column such that the delivered dose is reduced (shading), or by shielding of the organisms as a consequence of particle-microbe association (Passantino et al., 2004; Christensen and Linden, 2003). How these mechanisms work and to what extent they affect the disinfection performance are relatively complicated; hence, it is necessary that they are discussed in detail by evaluating previous research.

For the inquiry of effects of particles on UV disinfection the main study parameter has been turbidity in most of the previous research work. The reasons for this choice are the widespread use of turbidity in regulations as a water quality parameter and because turbidity is a simple way of measuring particles content of a sample by detecting the intensity of light scattered (AWWA, 1999). However, although turbidity measurements are usually directly proportional to mass concentration of particles, 
they are poor indicators of number concentration [i.e., equal numbers of different sized particles do not result in equal turbidities as light scattering depends on the particle size (Huber and Frost, 1998)].

Passantino et al. (2004) investigated the effects of turbidity and algae on UV inactivation of MS2 bacteriophage with medium-pressure UV lamps. Turbidity levels up to 12 NTU and algal concentrations up to $42 \mu \mathrm{g} / \mathrm{L}$ were examined by using suspensions of montmorillonite clay particles and Chlorella vulgaris cells. The study was conducted by spiking turbidity and the MS2 into a sample water and no steps were taken to facilitate particle-association. The results of this study indicated that there was no significant difference in inactivation at doses of 40 and $80 \mathrm{~mJ} / \mathrm{cm}^{2}$ with changing turbidity or chlorophyll concentration in synthetic samples. This was attributed to minor interference of particles with the UV light and to the lack of association of MS2 with the particles.

Batch et al. (2004) conducted a similar study as Passantino et al. (2004) examining the effect of turbidity, and additionally the particle count and size on UV disinfection of MS2 bacteriophage. This study focused on natural turbidities found in filtered waters from different water treatment plants, hence the range of turbidities investigated were relatively low $(<0.3 \mathrm{NTU})$. The results showed no significant decrease in inactivation of MS2 with increasing turbidity over the range of UV doses employed (10, 30, 60, and $100 \mathrm{~mJ} / \mathrm{cm}^{2}$ ) when both low-pressure and medium-pressure UV lamps were used.

The main similarities between the studies conducted by Passantino et al. (2004) and Batch et al. (2004) are that both studies worked on solutions that essentially 
represented surface waters, and did not involve a coagulation/flocculation step enhancing association of the spiked organisms with the particles. Thus, both studies were essentially focused on the effects of increased UV absorbance of the bulk solution (shading) on inactivation performance rather than impacts of particle shielding. In addition, since in both studies the absorbance values of the solutions examined and the other corrections suggested in Bolton and Linden (2003) were properly factored into the calculation of delivered UV dose, which possibly accounted for the effects of shading, the impacts were found to be minor.

Emerick et al. (2000), on the other hand, studied the effect of particle size on UV disinfection with a wastewater treatment plant sample by employing a serial filtration method to achieve size segregation. It was found that at a UV dose of $100 \mathrm{~mJ} / \mathrm{cm}^{2}$, inactivation of coliform bacteria was not significantly affected by particle size when the particle sizes compared were larger than a minimum critical size $(10 \mu \mathrm{m})$. In other words, survival of bacteria was not significantly different in the presence of particles having a diameter larger than $40 \mu \mathrm{m}$, than in the presence of particles in the $11-40 \mu \mathrm{m}$ range. Therefore, it was concluded that a critical size (in the $10 \mu \mathrm{m}$ size range) controls the shielding ability of particles such that particles smaller than that size do not effectively shield bacteria, whereas, for particles larger than that size the extent of shielding provided does not depend on particle size. The study by Emerick et al. (2000) also implied that the minimum size governing particle shielding was dependent on the size of the target organism (in their study around $10 \mu \mathrm{m}$ for coliform bacteria which have a size range of 1-3 $\mu \mathrm{m})$.

Batch et al. (2004), on the other hand, reported that the effect of particle size and count on UV disinfection of MS2 was not statistically significant, even though the 
particle size effect experiments were based on the findings of Emerick et al. (2000) and thus the experiments were performed by dividing the particles into two groups as smaller and larger than $10 \mu \mathrm{m}$ in size. However, the target organisms studied in the work of Batch et al. (2004), MS2 Bacteriophage, were several orders of magnitude smaller, ranging in between $25-27 \mathrm{~nm}$ in size, than coliform bacteria which are 1-3 $\mu \mathrm{m}$ in size; thus it would be expected that the critical size of interest for size effect in this study may have been smaller than $10 \mu \mathrm{m}$. The observed differences between the two studies were also attributed to the absence of particle-association, and the differences in the nature of particles present in water and wastewater.

Wu et al. (2005) studied the impacts of goethite particles on UV disinfection of $E$. coli. The experiments were conducted in synthetic systems composed of only goethite particles $(0.2$ by $2 \mu \mathrm{m}$ in size) and $E$. coli, and separate suspensions were prepared and allowed to mix for different lengths of time $(0.5 \mathrm{~h}$ to $24 \mathrm{~h})$ in order to vary the rates of particle-microbe association reached. The study reported significant particlemicrobe association after 24 hours of mixing, which resulted in a significant reduction in inactivation. These findings clearly imply that microbes may be protected from UV irradiation even in the presence of small particles (the same size range as the organisms) provided that some degree of association between particles and microbes was achieved, and that particle-microbe association might be achieved without any chemical addition.

The previous work summarized above indicates that the ultimate concern for UV disinfection efficiency is the particle-association of target organisms. The following 
section presents a summary of the recent studies which investigate the effects of particle-association of microorganisms on UV disinfection more in detail.

\subsection{Effect of Particle-Microbe Association on UV Disinfection}

As mentioned previously, in addition to the effects of particles on the transmission of UV energy through the water volume, another major factor controlling the efficiency of UV disinfection introduced by particles is the particle-microbe association phenomenon (Christensen and Linden, 2003). In fact, coliform bacteria have been shown to be commonly particle-associated in wastewater (Parker and Darby, 1995). Therefore, most of the previous research work examined specifically the effects of particle-association of target organisms and focused on samples such as secondary wastewater effluents, which already have a large ratio of particle-associated organisms embedded in large networks of flocs. Nonetheless, other studies were conducted on synthetic solutions simulating source water characteristics in which case flocculation and thus, particle association was induced via inorganic chemical coagulants common to drinking water industry.

Parker and Darby (1995) investigated the correlations between shielding of particleassociated coliform bacteria from UV light and water quality parameters (suspended solids, turbidity, and UV transmittance). The experiments were performed on secondary effluents taken from secondary sedimentation basins of a wastewater treatment plant before chlorine disinfection. Bacteria enumeration was carried out through multiple tube fermentation (MTF) method and taking the limitations of the technique into account, an extraction step was introduced prior to microbial enumeration. The extent of shielding particle-associated coliform acquired was 
measured by employing sequences of 'blend-irradiate' and 'irradiate-blend' experiments. The 'blend-irradiate' experiments were designed to extract organisms from particles prior to irradiation in order that these organisms were exposed to the UV light in a dispersed state. The 'irradiate-blend' experiments were designed to free organisms from particles after irradiation in order that the enumeration represented the bacterial concentration accurately. The comparison of the results from 'blendirradiate' experiments with 'irradiate-blend' experiments indicated the extent of shielding provided to coliform bacteria. The overall results of the study showed that secondary effluents contained significant concentrations of particle-associated coliforms, and that these organisms were shielded at a substantial degree; however, no correlations between water quality parameters and the degree of particle-association, and the degree of shielding from UV light were found to be statistically significant.

Following studies further investigated the subject of particle-association and shielding from UV light, by looking into particle characteristics and their relation to light penetration (Loge et al., 1999), self-aggregation of organisms (Mamane and Linden, 2006a), and floc characteristics and size (Farnood, 2005). Templeton et al. (2005) and Mamane and Linden (2006a) also conducted their studies with different pathogenic organisms than coliform bacteria: MS2 coliphage and bacteriophage T4, and bacillus subtilis spores, respectively.

In their study of light penetration to wastewater particles, Loge et al. (1999) found that absorbance can occur to such a degree that the transmission of UV light is completely blocked if the entire incident light was to hit the solid material. Therefore, it was concluded that the observed penetration of UV light, as indicated by persistent 
inactivation of organisms located within particles at higher UV doses, is due to the porous structure of wastewater particles. The main implications of this finding are that it is not only the size of a floc or a particle that controls or limits the inactivation of target organisms but also the structure, and that the spatial distribution of microbes within a floc or a particle determines to what degree they will be protected from UV irradiation. In accordance with these implications, it was also hypothesized by Loge et al. (1999) that a highly porous particle with pathways for light penetration would not necessarily provide more protection to an organism embedded deep within the particle than a smaller particle would provide to an organism located closer to the particle surface but lacking a light pathway.

Farnood (2005) addressed the same issue of light penetration by examining it on a floc based rather than a particle based manner. In the first part of the study, actual wastewater samples were used to investigate the effect of floc size on UV disinfection performance. Three size fractions with nominal ranges of $150 / 125,90 / 75$, and $53 / 45$ $\mu \mathrm{m}$ were prepared by filtration of the wastewater samples followed by a distilled water rinsing step. The results indicated a noticeable decrease in inactivation with increasing floc size. Moreover, the dose-response curves showed a more prominent tailing effect for larger flocs implying a higher ratio of completely protected microbes to the total concentration of microbes. When the inactivation rates of floc samples were compared to that of free fecal coliform, it was observed that even at very low UV doses a large difference in concentration of surviving organisms existed. This observation strongly suggests that most of the coliform bacteria present in the samples were associated with particles. The second part of the study concentrated on the role of floc composition. As in the case of Loge et al. (1999) it was hypothesized that the 
intensity of UV light within a floc depends not only on the size of the flocs but also on their composition. With that regard, particular attention was given to the EPS content of the flocs and how their spatial distribution affects the UV penetration. Absorbance measurements on EPS extracted from pure cultures of Klebsiella sp. Were used to model three idealized cases of EPS distribution within flocs. It was hypothesized that depending on whether the EPS was concentrated in the centre of a floc (Figure 2.2a), uniformly distributed within a floc (Figure 2.2b), or around the floc forming a coating layer (Figure 2.2c); the reduction in the intensity of UV light could vary from less than 1 up to $55 \%$.

(a)

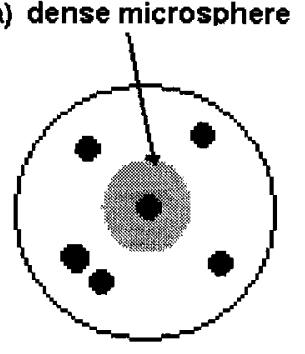

(b)

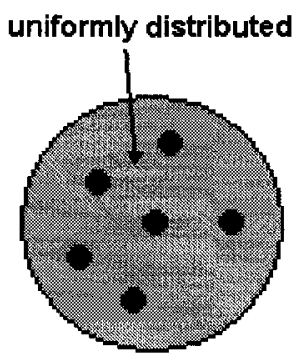

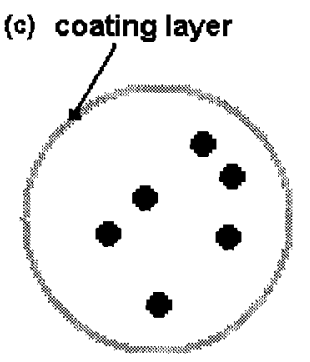

Figure 2.2: Three idealized cases of EPS distribution within a floc (Source: Farnood, 2005).

Templeton et al. (2005) and Mamane and Linden (2006a), both strongly arguing for the necessity of a step to facilitate particle-microbe association, conducted their studies on systems where particle-association of microbes was achieved by coagulating the added particles and microbes with chemical coagulants. These two studies were very similar in terms of the methodology followed. Both studies had a high degree of control over the parameters examined as the samples were welldefined synthetic solutions of particles. Other similarities worthy of note between the 
two studies were: taking the average UV irradiance calculation corrections suggested by Bolton and Linden (2003) into account and including an elution/extraction step prior to microbial enumeration.

Templeton et al. (2005) concentrated more on the size effect and investigated the issue by using viruses, which are one to two orders of magnitude smaller than bacteria. Therefore, unlike coliform bacteria which were shown to be protected from UV light by particles larger than $10 \mu \mathrm{m}$ by Emerick et al. (2000), it was postulated that viruses might be protected by much smaller particles. In order to examine this hypothesis, the effects of particles smaller and larger than $0.45 \mu \mathrm{m}$ were compared, and results supporting the hypothesis were found. In addition to the effect of particle size, particles with different characteristics (inorganic clay particles, and organic humic acid and activated sludge particles) were used to provide an insight to the effect of particle composition. The study found strong evidence for the importance of floc and particle composition on UV inactivation: the highest degree of shielding was observed with organic humic acid particles rather than same size inorganic clay particles or larger sized activated sludge particles. This was attributed to the high UV absorbing characteristics of humic acid particles. Another important indication of the study's results was, contrary to the main theory of particle-association mentioned above, that induced flocculation through the addition of alum or ferric chloride coagulants did not lead to a statistically significant reduction of virus inactivation. This led to the hypothesis that viruses might have attached to the particles primarily through electrostatic attraction (self-attachment), and only to a lesser extent by the aid of coagulants. Finally, it was also suggested that the degree of association, that is whether the microbes were only surface-attached, or partially or completely enmeshed 
within particles, may have played an important role on inactivation efficiency. The evidence for this suggestion originated from the experiments with activated sludge particles. In these experiments, the reduction in inactivation as a result of particleassociation was more distinct at higher UV doses implying that surface-attached microbes were likely to be inactivated at lower doses, whereas, the completely enmeshed ones were unlikely to be inactivated even at higher doses, thereby limiting the overall level of inactivation.

Mamane and Linden (2006a), on the other hand, focused more on self-aggregation of microbes as well as the particle-microbe association, by studying Bacillus subtilis spores suspended in simulated drinking water. Four different suspensions were prepared for the UV irradiance experiments consisting of: suspended spores, aggregated spores, spores cosuspended with clay particles, and spores aggregated with clay particles. The findings of the study showed that solutions of both spore-spore aggregates and spore-clay aggregates resulted in less UV inactivation of spores compared to the solutions of suspended spores as well as the solutions of spores cosuspended with clay particles, which clearly emphasized the significance of particle-microbe association. However, contrary to the findings of Templeton et al. (2005) the percent of protected microbes within an aggregate decreased as the UV dose increased. One explanation to this situation might be the different doses of UV applied in each study.

One of the biggest advantages of the studies conducted by Templeton et al. (2005) and Mamane and Linden (2006a), when compared to the studies conducted with actual wastewater samples, is that both studies were performed in well-defined and 
controlled systems. This enabled the researchers to examine the effect of parameters of concern one at a time by keeping the other parameters constant. However, since the employed mechanism of achieving particle-microbe association was induced flocculation via inorganic chemicals, it should be expected that the structure, composition, and size of the flocs produced, as well as the extent of particle-microbe association reached would be different than wastewater flocs (bioflocs).

\subsection{Objectives}

The main goal of this research was to study the effects of particles and bioflocculation on UV disinfection in a completely controlled and reproducible system where particles tested were of uniform size, a clear distinction between particles and flocs was made and analyses of particle characteristics of the solutions were based on number concentrations rather than turbidity. It is also the first study of its kind in terms of the way particle-microbe association was facilitated. The following are the specific objectives for the research:

- To test the possible use of a synthetic surrogate for studying bioflocs and their effects on UV disinfection

- To determine the effect of particle size on UV disinfection in a fully controlled environment

- To investigate the impacts of floc size, structure, and composition on UV disinfection 
- To examine the degree of association between organisms and particles within a floc structure and its effects on UV disinfection

- To investigate the role of extracellular polymeric substances on UV disinfection 


\section{CHAPTER 3}

\section{HYPOTHESES}

In Section 2.7, the objectives of the research were laid out. In this chapter, a list of the hypotheses that will be examined is presented. The next chapter will outline the experimental designs for the tests done in order to examine these hypotheses.

- Investigation of the effects of bioflocculation on UV disinfection can be conducted in a synthetic medium where system parameters are kept under control and particle-microbe association is facilitated by introducing alginate (EPS) and calcium ions to the system.

- Effect of particle size on UV disinfection may be better evaluated by comparative studies of solutions containing different sized particles in equal numbers.

- An increase in particle size may not result in a higher rate of shielding.

- Flocs of same size may not necessarily provide the same rate of protection to the embedded bacteria, as degree of shielding depends on other factors such as porosity of the floc, what size particles the floc is composed of, and the spatial distribution of EPS within the floc.

- In the presence of excessive amounts of EPS mechanisms other than particleassociation or self-clumping of bacteria might be effective in shielding of microbes from UV irradiation, such as coating of bacteria with EPS. 


\section{CHAPTER 4}

\section{MATERIALS AND METHODS}

In order to study the effect of bioflocculation on UV disinfection, it is important to use a stable, well-defined and well-controlled surrogate that can simulate the particle characteristics, and coagulation and flocculation properties of water and wastewater samples. Therefore, the project was started with a preliminary phase focused on determining the optimum conditions to run UV radiation disinfection tests under different particle size, particle concentration, floc size and floc structure conditions. Following the preliminary work, three main experimental phases were designed. Phase I focused solely on the effect of particles on inactivation kinetics of bacteria by UV light, whereas in Phase II and Phase III, the effects of bioflocculation at varying degrees were examined by changing divalent cation (calcium $-\mathrm{Ca}^{2+}$ ) concentration at a fixed extracellular polymer (alginate) concentration (Phase II), and by changing alginate concentration at a fixed calcium concentration (Phase III).

\subsection{Preliminary Experiments}

The preliminary work included determination of ingredients for the preparation of synthetic media, flocculation kinetics observations, pure culture bacteria preparation, and survival tests of bacteria in distilled water and phosphate buffered solution (PBS).

\subsubsection{Determination of Ingredients for Synthetic Media}

The aim of the synthetic wastewater was not to simulate an actual wastewater sample with chemical and biological constituents, but rather to create a simple flocculation matrix with the essential constituents that could be used to evaluate one parameter at a 
time. Since the main objective of this study was to evaluate the effects of particles and flocs on UV disinfection of bacteria, the essential constituents included in the matrix were particles, flocculating agents and the bacteria themselves. As well, additions of flocculating agents were limited to cations and extracellular polymers with the intention of maintaining the synthetic system uncomplicated and keeping key parameters such as UV absorbance of the solution under control.

This study was highly sensitive to the particle concentration and size distribution properties of the makeup water. For that reason the source distilled water was analyzed with the particle counter prior to use and significantly high concentrations of particles were detected. In order to reduce the background particle concentration in the solution to a minimum, thus enabling a higher degree of control over particle size distribution and number concentration parameters, the distilled water was filtered through $0.45 \mu \mathrm{m}$ filter paper at all times throughout the project. Another concern about the distilled water was its suitability for use as the main medium. Due to issues related to osmotic pressure and survival of bacteria in the synthetic solution, supplementing certain ions to the medium might be necessary. This concern led to the testing of bacterial survival in water medium as discussed in Section 4.1.4.

There were two promising particle alternatives that were considered for the experiments: clay particles and latex particles. However, the clay option was abandoned as polystyrene latex spheres presented a better alternative due to their size specific availability and relatively higher uniformity. 
Three different sizes of latex particles having the same physical and chemical properties were selected: $1 \mu \mathrm{m}, 11 \mu \mathrm{m}$, and $45 \mu \mathrm{m}$. The particles were obtained from Duke Scientific Corporation (CA, USA) and their characteristics are given in Table 4.1. The $1 \mu \mathrm{m}$ particles were used to represent small particles being close to the size of bacteria (approximately $1 \mu \mathrm{m}$ ) and corresponding to the minimum detection limit of the particle counter employed. The $11 \mu \mathrm{m}$ particles resembled the hypothesized minimum particle size (on the order of $10 \mu \mathrm{m}$ for wastewater) controlling the capability to shield bacteria from UV light (Emerick et al., 2000). Whereas, the $45 \mu \mathrm{m}$ particles served the purpose of testing with larger size particles that may be present in wastewater and provide excessive protection from disinfectants.

Table 4.1: Latex particle characteristics

\begin{tabular}{l|lll}
\hline $\begin{array}{l}\text { Physical/Chemical } \\
\text { Properties }\end{array}$ & $1 \mu \mathrm{m}$ & $11 \mu \mathrm{m}$ & $\mathbf{4 5 \mu m}$ \\
\hline & & & \\
Particle Composition & Polystyrene & Polystyrene & Polystyrene \\
Particle Density & $1.05 \mathrm{~g} / \mathrm{cm}^{3}$ & $1.05 \mathrm{~g} / \mathrm{cm}^{3}$ & $1.05 \mathrm{~g} / \mathrm{cm}^{3}$ \\
Solubility in Water & Insoluble & Insoluble & Insoluble \\
Size Uniformity (C.V.) & $\leq 3 \%$ & $\leq 20 \%$ & $\leq 15 \%$ \\
\hline
\end{tabular}

Based on previous studies on synthetic wastewater sludge (Sanin and Vesilind, 1996; Örmeci and Vesilind, 2000) flocculating agents were chosen without any comparative testing. It was decided that alginate would be used as the extracellular polymer and calcium (II) as the divalent cation (or bridging agent). The concentrations of alginate and calcium (II) to be applied were also determined based on those studies. Other 
matters regarding flocculation such as; time dependency and the extent of flocculation, are discussed in Section 4.1.2.

For the bacterial seeding, Escherichia coli $\left(\mathrm{ATCC}^{\circledR} 23631^{\mathrm{TM}}\right)$ from the fecal coliform family was chosen, as it is one of the most commonly used indicator organisms of fecal contamination in waters.

\subsubsection{Flocculation Observations}

Throughout this project flocculation was achieved following the same order: by addition of alginate first and then calcium ions (flocculating agents) to a solution already containing bacteria and particles. It should be noted that flocculation is a time dependent process (i.e., the floc size increases with time) therefore each sample had to be flocculated for the same period of time prior to UV exposure for an accurate comparison of flocculation effects on inactivation of bacteria. In the samples tested during preliminary experiments, flocculation to a certain degree (not visible to the naked eye but detectable by the particle counter) started occurring directly following the addition of alginate; however, what effectively initiated flocculation to a much higher extent (observable by the naked eye) was the addition of calcium (II) into a solution which already contained alginate. Therefore, it was decided that the calcium addition was to be undertaken separately for each sample to be irradiated in order that the flocculation time could be kept constant (the steps involved are described in more detail in the following sections). The preliminary experiments indicated that visible flocs started forming within 5 minutes at the lowest concentrations of calcium and alginate tested $(5 \mathrm{mM}$ and $10 \mathrm{mg} / \mathrm{L}$, respectively). Based on the tests with higher doses of flocculating agents, concentrations of 5,10 and $15 \mathrm{mM}$ for calcium ion 
addition and 10,20 and $40 \mathrm{mg} / \mathrm{L}$ for alginate addition were chosen to be used in this project since these concentrations provided a wide range of floc sizes that could be studied.

\subsubsection{Pure Culture Preparation}

A single strain of $E$. coli $\left(\mathrm{ATCC}^{\circledR} 23631^{\mathrm{TM}}\right.$ ) was obtained from Cedarlane Laboratories (Hornby, ON). The bacteria came in the form of a pellet and were revived following the procedures suggested by the main supplier (ATCC). In brief, the procedures involved rehydrating the pellet in $0.5 \mathrm{~mL}$ of TYG broth (ATCC Medium \#603) and transferring this aliquot into a tube (primary tube) containing $6 \mathrm{~mL}$ of TYG medium to be incubated at $37^{\circ} \mathrm{C}$ for 24 hours. The suspension in the primary tube was dispensed, in volumes of $1 \mathrm{~mL}$, into five micro-tubes directly after incubation and stored in the deep-freezer at a temperature of $-20^{\circ} \mathrm{C}$ or below as the backup stock of bacteria. Another batch of bacteria was grown from the remaining $1 \mathrm{~mL}$ in the primary tube by transferring the suspension into a flask containing $100 \mathrm{~mL}$ of TYG medium and incubating at $37^{\circ} \mathrm{C}$ until somewhere between late exponential and early stationary growth phases was reached. This was determined by measuring the absorbance of the suspension at $500 \mathrm{~nm}$ in a UV-visible spectrophotometer (Varian Cary 100BIO, Victoria, Australia). Once the bacteria reached the desired growth phase, where the increase in absorbance slowed down considerably, the solution was taken out of the incubator and was dispensed, in volumes of $1 \mathrm{~mL}$, into micro-tubes and stored in the deep-freezer at a temperature of $-20^{\circ} \mathrm{C}$ or below as the primary stock. A fresh suspension of bacteria was prepared for each trial from the primary stock in the freezer by reviving the frozen culture (volume of $1 \mathrm{~mL}$ ) in a $100 \mathrm{~mL}$ Tryptic Soy Broth, which is another suitable growth medium for $E$. coli. Whenever the fresh 
culture preparation procedure was performed, care was taken to keep the incubation time of the suspension between late exponential and early stationary growth phases. The prepared suspensions for weekly use were kept in the refrigerator (at $4^{\circ} \mathrm{C}$ ) at all times except when bacteria were to be injected into the synthetic matrix.

\subsubsection{Survival of Bacteria in PBS and Water}

As discussed in earlier sections, distilled water as it is (without any ion addition) may not be suitable for the project. The proposed alternative to distilled water was phosphate buffered solution (PBS) as it is the recommended solution as dilution water in Standard Methods (APHA, 2005).

Although for the purposes of this study utilizing distilled water as the working solution would be preferred over a solution containing ions (PBS) due to possible interference of the ions added with the flocculation kinetics, during preliminary experiments it was observed that the bacterial concentration in pure distilled water was not stable and there was a rapid decrease in number of bacteria likely due to osmotic pressure. Considering the fact that inactivation experiments can take up to 8 hours, the difference in bacterial concentration at the beginning and the end of a trial might be significant. This would affect the results of this study by interfering with the survival rate (survival rate is calculated by dividing the number of surviving bacteria by the number of initially present bacteria). Thus if the initial concentration does not remain relatively constant throughout the course of each trial, a significant error factor would be introduced into the survival calculations. What is more, the negative impacts of working with a PBS solution can be overlooked considering the fact that magnesium ions (the divalent cationic component of PBS) have a relatively lower 
affinity for the extracellular polymer structure compared to calcium ions (Bruus et al., 1992). Due to the reasons explained above, PBS was decided to be used in the experiments, and it was prepared following the recipe given in Standard Methods (APHA, 2005) and the procedure given in Section 4.2.2.

\subsection{General Experimental Procedures}

This section intends to provide information on the general experimental procedures followed in the experiments. Information on the design of the experiments and each experimental phase is provided in Section 4.3.

The experiments in each phase typically followed this sequence: sterilization of glassware and equipment, preparation of stock solutions and growth media, preparation of the synthetic solution, measurement of the UV irradiance and arrangement of the collimated beam, inactivation, bacterial enumeration, and particle counts. Each phase essentially consisted of 3 sets of experiments (due to 3 different sizes of particles). A set of experiments therefore means testing different conditions of flocculation with the same particle size. A general experimental scheme is provided in Figure 4.1. 


\section{Experimental Scheme}

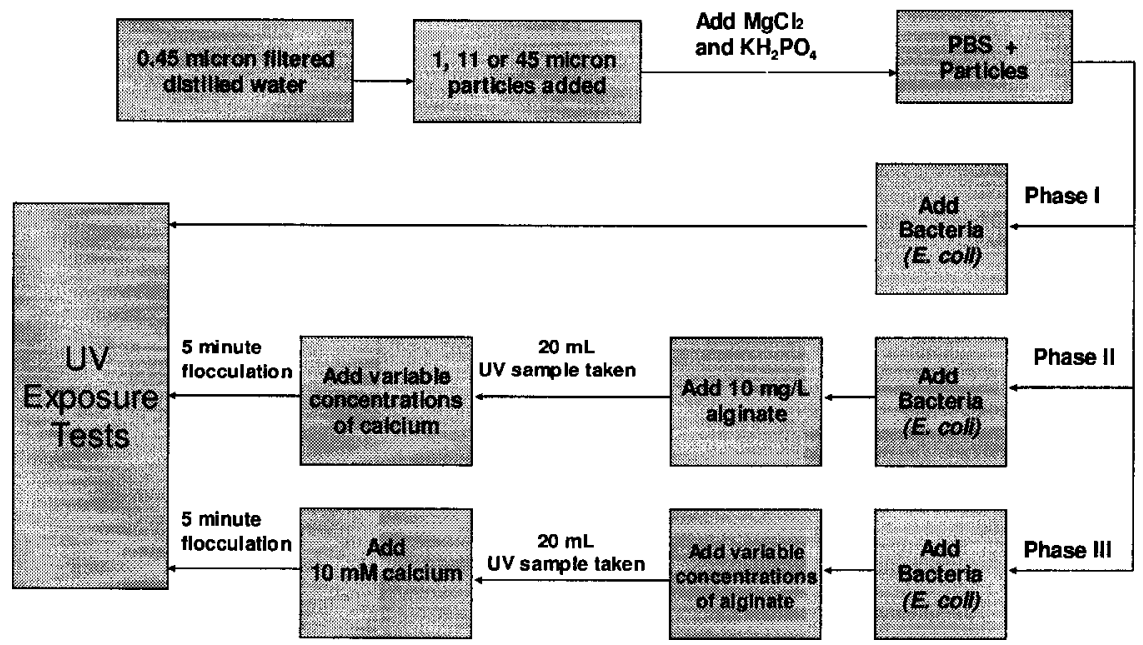

Figure 4.1: General experimental scheme.

\subsubsection{Sterilization of Glassware and Equipment Used}

All the beakers, flasks, vials, tubes, graduated cylinders, and filtration units were always washed with tap water first, rinsed with distilled water afterwards and finally sterilized in the UV reactor by keeping under irradiation for at least 5 minutes, prior to any use. The pipettes were cleaned with pure ethyl alcohol and the tips were autoclaved for 15 minutes at $121^{\circ} \mathrm{C}$ before use.

\subsubsection{Preparation of Stock Solutions and Growth Media}

The stock solutions consistently used throughout the project included: the magnesium chloride solution, the phosphate buffer solution, the calcium chloride solution and the alginic acid solution. In addition to these stock solutions, Difco ${ }^{\mathrm{TM}}$ M-Endo Agar LES (Becton, Dickinson \& Company, MD, USA) and Bacto ${ }^{\mathrm{TM}}$ Tryptic Soy Broth (Becton, 
Dickinson \& Company, MD, USA) were continually used as the growth media for membrane filtration (MF) tests and E. coli stock preparation, respectively.

The PBS is recommended as a solution to be used for dilutions during MF analyses in Standard Methods. For this project it was used also as the main solvent in order to enhance bacterial survival as discussed in Section 4.1.4. Magnesium chloride and phosphate buffer solutions together form the contents of PBS. For the preparation of phosphate buffer, $34 \mathrm{~g}$ of potassium dihydrogen phosphate $\left(\mathrm{KH}_{2} \mathrm{PO}_{4}\right)$ was dissolved in $500 \mathrm{~mL}$ distilled water, and then the $\mathrm{pH}$ of the solution was adjusted to $7.2 \pm 0.5$ by titrating with $1 \mathrm{~N}$ sodium hydroxide $(\mathrm{NaOH})$ and finally the volume was brought up to $1 \mathrm{~L}$ with distilled water. Magnesium chloride solution on the other hand was simply prepared by dissolving $81.1 \mathrm{~g}$ of magnesium chloride hexahydrate $\left(\mathrm{MgCl}_{2} \cdot 6 \mathrm{H}_{2} \mathrm{O}\right)$ in 1 $\mathrm{L}$ distilled water. Finally, a litre of PBS consists of $1.25 \mathrm{~mL}$ stock phosphate buffer solution and $5 \mathrm{~mL}$ magnesium chloride solution. The stock solutions of magnesium chloride and phosphate buffer were sterilized by autoclaving at $121^{\circ} \mathrm{C}$ for 15 minutes at least once every week and in case of floc formation or turbidity occurrences the stocks were discarded and fresh ones were prepared.

Anhydrous calcium chloride salt $\left(\mathrm{CaCl}_{2}\right)$ was used for the preparation of calcium (II) stock solution. In order to yield a stock with a concentration of $0.5 \mathrm{M} \mathrm{Ca}^{2+}, 11.1 \mathrm{~g}$ of anhydrous salt was added into $200 \mathrm{~mL}$ of distilled water and completely dissolved by mixing. This stock solution was the primary source of calcium applied to initiate flocculation at different rates throughout the project. 
Alginate solution was prepared by mixing alginic acid (in the form of alginic acid sodium salt derived from brown algae, obtained from Sigma Chemical Company, MO, USA) in water at a concentration of $5 \mathrm{~g} / \mathrm{L}$. In order to ensure that alginate is completely dissolved in water, a hand blender was first used and the solution was mixed on a magnetic stirrer overnight. Both M-Endo Agar LES and Tryptic Soy Broth were prepared following the directions provided by the suppliers on the product containers. M-Endo Agar LES was prepared in batches that would be used within less than 2 weeks and Tryptic Soy Broth was prepared in required amounts and used directly after preparation for revival of frozen bacterial stock.

\subsubsection{Preparation of Synthetic Solution}

The first material to be prepared for the synthetic system was the water itself. As this research is essentially about effects of particles, extreme care was taken to have practically particle free solutions prior to the addition of specific size particles at desired number concentrations. All three phases included the three different sizes of particles $(1,11$, and $45 \mu \mathrm{m})$ to be tested. To increase the consistency of particle number concentration and size distribution within a set of experiments, stock particle solutions were prepared in large volumes at the beginning of an experiment set and preserved by keeping the containers tightly sealed, therefore allowing for the same particle-stock solution to be used throughout a set of experiments. Prior to initiation of each UV exposure trial (specific particle size, alginate concentration and calcium concentration) a $200 \mathrm{~mL}$ sample was taken from the previously prepared particlestock solution and dispensed into a $1 \mathrm{~L}$ beaker which had been rinsed with particlefree filtered water. After that point the beaker was continuously mixed with magnetic 
stirring rods and always kept covered unless a sample was to be withdrawn from the beaker or a material was to be added into the beaker.

The initial particle number concentrations were selected as 6,000 particles $/ \mathrm{mL}$ for all three sizes of particles, and in all three phases. However, due to the impracticality of achieving the exact same number concentration at all times there was a slight variation in particle concentration in different experiment sets (within $\pm 10 \%$ of the target). The particle stock solutions were prepared by injecting small amounts of concentrated polystyrene latex particle suspensions (10\% solids content) into a continuously mixed beaker containing filtered distilled water and simultaneously checking the concentration of particles in the beaker with the particle counter, until the desired level was achieved.

The subsequent ingredients added into the beaker (containing $200 \mathrm{~mL}$ of particledistilled water suspension) were magnesium chloride and phosphate buffer as the solution needs to be turned into a PBS, a stable environment for the bacteria. Following this, the bacteria were added in amounts leading to an initial bacterial concentration of between $1 \times 10^{6}$ and $3 \times 10^{6}$ colony forming units per $100 \mathrm{~mL}$ (CFU/100 mL).

Due to the different procedures followed for different phases after the addition of bacteria, the details for the addition of other materials are given under sections allocated to each phase $(4.3 .1,4.3 .2,4.3 .3)$. 


\subsubsection{UV Collimated Beam Setup}

The UV setup consisted of a set of low-pressure mercury lamps (Phillips UV-C germicidal lamps) emitting nearly monochromatic ultraviolet light at $253.7 \mathrm{~nm}$. Furthermore, through successive baffles the system was brought to perform as a collimated beam apparatus. Stirring is crucial for assuring equal UV dose delivery to all microorganisms in the solution during inactivation (Bolton and Linden, 2003), therefore a stirring mechanism was placed at the bottom of the UV reactor and the samples were continuously mixed, at low speeds with micro stirring rods to avoid vortex formation. The UV apparatus is depicted also in Figure 4.2.

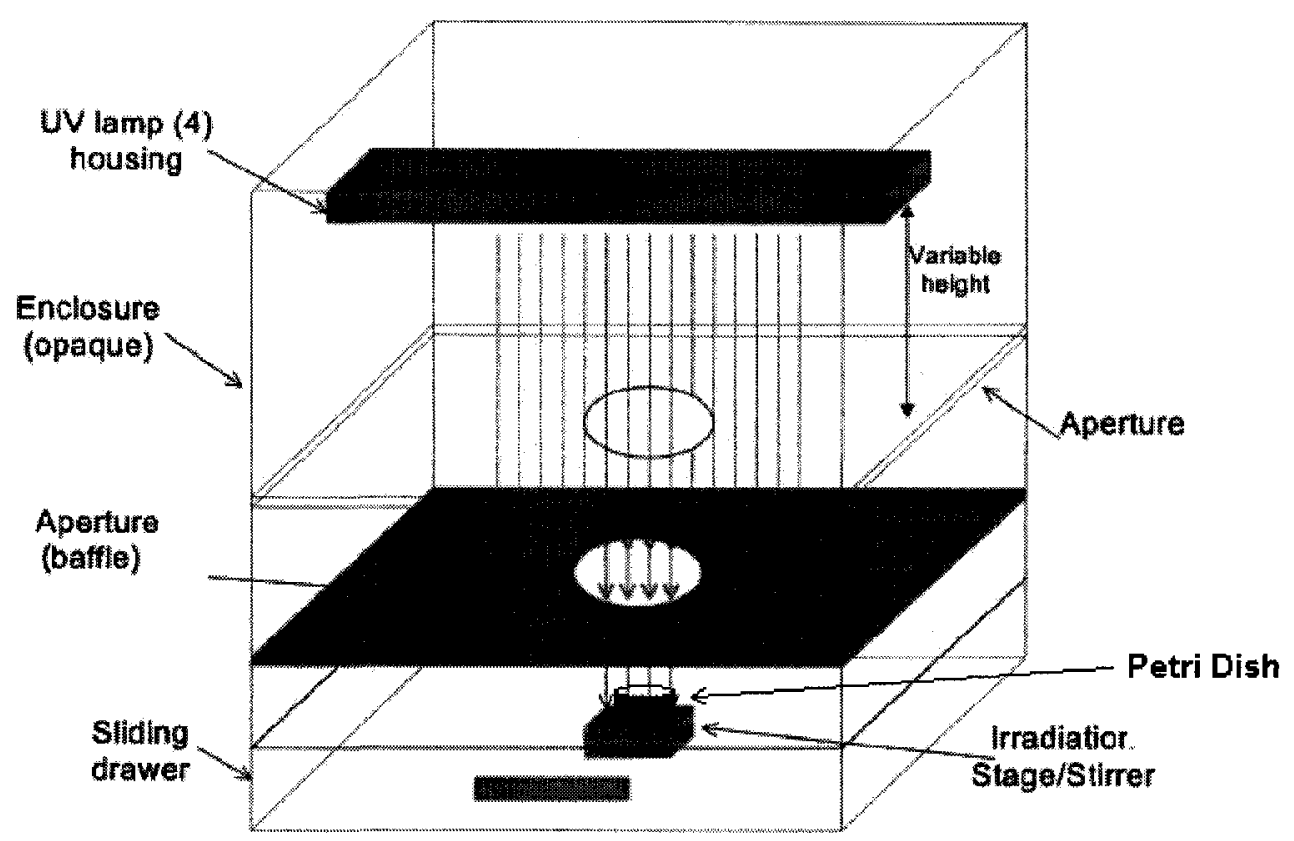

Figure 4.2: UV collimated beam setup (Source: Bolton and Linden, 2003, Modified). 


\subsubsection{Irradiation}

The irradiation tests were performed in the UV apparatus described in the previous section. Throughout this project 6 UV doses were tested $(0,30,60,90,120,150$ $\mathrm{mJ} / \mathrm{cm}^{2}$ ). In order to calculate the required exposure times to reach these UV doses procedures outlined by Bolton and Linden (2003) were followed. As briefly discussed in Chapter 2, for a system employed with a low pressure UV lamp these procedures include the following four necessary corrections to be included in the calculation of the actual germicidal irradiance throughout the sample volume;

1) Reflection Factor

2) Petri Factor

3) Water Factor

4) Divergence Factor

In addition to being a low pressure system the depth of the sample to be irradiated is also an important factor in the calculation of true irradiance. In order to keep corrections as simple as possible the sample volume was kept at $20 \mathrm{~mL}$ yielding a sample depth of less than $2 \mathrm{~cm}$. When a sample's depth is less than $2 \mathrm{~cm}$ that sample is referred to as a shallow sample and the exposure times are calculated accordingly (Bolton and Linden, 2003).

The most important inputs for the calculation of exposure times were the incident irradiance values $\left(\mathrm{mW} / \mathrm{cm}^{2}\right)$ measured with a radiometer (International Light, MA, USA) at the surface of the sample to be irradiated. Since the intensity of light emitted by the UV lamps was fluctuating, extreme care was taken to obtain a representative intensity for each sample to be tested; therefore, before each UV exposure the 
intensity was measured and exposure times were calculated accordingly. Other inputs required for the calculation of exposure times included: the distance between the UV lamps and the top of the sample surface, the Petri dish diameter and the sample volume, and the absorption coefficient of the sample. The distance between the UV lamps and the top of the sample surface is related to the divergence factor and was always fixed at $48.5 \mathrm{~cm}$ for all the experiments involved. The Petri dishes used for the entire set of experiments had a diameter of $6.5 \mathrm{~cm}$ and the sample volume was fixed at $20 \mathrm{~mL}$, leading to a sample depth of $6.03 \mathrm{~mm}$, these two values (Petri dish diameter and sample volume) were required for the calculation of Petri factor, divergence factor and water factor. As well, the absorption coefficient (absorbance for a $1 \mathrm{~cm}$ path length) is related to the water factor and for each different set of conditions it was measured at $254 \mathrm{~nm}$ in a UV-visible spectrophotometer (Varian Model Cary 100BIO, Victoria, Australia), which had previously been balanced by distilled water in the same cuvette as the one used for the samples. The exposure times required to deliver the desired UV doses were calculated based on the data given above. An explanation of the calculations involved follows.

The reflection factor is calculated by subtracting the fraction of light that is reflected upon entry to water medium from air medium. As the fraction reflected I is a constant between these two media such that $R=0.025$, the reflection factor is also equal to a constant value of $0.975(1-R)$.

The Petri factor accounts for the non-uniformity of the irradiance field over the sample and is calculated by averaging the intensity measured at different points within 
the irradiance field. However, the UV apparatus employed in this project provided a uniform irradiance field and thus, Petri factor was taken as unity (1).

The water factor is defined as:

$$
\text { Water Factor }=\frac{1-10^{-a \ell}}{a \ell \ln (10)}
$$

where $a=$ absorbance for a $1 \mathrm{~cm}$ path length $\left(\mathrm{cm}^{-1}\right)$ and $\ell=$ vertical path length $(\mathrm{cm})$ of the water in the Petri dish. Since water factor is a function of the absorbance it was assigned a different value for every different condition tested.

The divergence factor is defined as:

$$
\text { Divergence Factor }=\frac{L}{(L+\ell)}
$$

where $\mathrm{L}=$ the distance between the UV lamps and the top of the sample surface $(\mathrm{cm})$ and as in the water factor $\ell=$ vertical path length $(\mathrm{cm})$ of the water in the Petri dish. Since both $L$ and $\ell$ had fixed values throughout the project, the divergence factor was also fixed at 0.9877 . 
Thus, the average irradiance $\left(E_{\text {avg }}^{\prime}, \mathrm{mW} / \mathrm{cm}^{2}\right)$ in the water is defined by:

$$
E_{\text {avg }}^{\prime}=E_{0} \times \text { Reflection Factor } \times \text { Petri Factor } \times \text { Water Factor } \times \text { Divergence Factor }
$$

where $E_{0}=$ radiometer reading (intensity, $\mathrm{mW} / \mathrm{cm}^{2}$ ) at the centre of the sample's surface.

Finally, dose is defined as:

$$
\text { Dose }=E_{\text {avg }}^{\prime} \times \text { Exposure Time }
$$

Therefore, once the average irradiance was calculated the exposure times were achieved simply by dividing the desired doses by the average irradiance values.

\subsubsection{Bacterial Enumeration}

The UV exposed samples were first deflocculated in centrifuge tubes on a vortex mixer (Baxter Diagnostics Inc., IL, USA) for 2 minutes in order to break apart particle-associated and clumped bacteria and phase out the effects of such formations on the bacterial counts. Since the time elapsed both after the UV exposure and the deflocculation is crucial, each sample was taken immediately to the vortex mixer directly following UV irradiation and membrane filtration was carried out immediately after deflocculation. 
Bacterial enumeration was carried out by following Standard Total Coliform Membrane Filter Procedure (Protocol 9222 B) given in Standard Methods (APHA, 2005). M-Endo Agar LES medium was used as a selective growth medium and three replicates were made at each dilution. The filtration was carried out using glass filtration units by applying suction through $0.45-\mu \mathrm{m}$ Millipore (MA, USA) filter paper and pouring in approximately $20 \mathrm{~mL}$ of diluted samples. The volumes filtered were recorded and all the bacterial concentration values were adjusted accordingly to report the units as CFU/100mL.

Dilutions were performed in $100 \mathrm{~mL}$ graduated cylinders filled with required amounts of PBS and the time spent by bacteria in the dilution water was minimized in order to prevent death or growth of bacteria during dilution. To make sure that the bacterial concentration in any dilution cylinder was kept homogeneous, the cylinders were sealed with parafilm and shaken at least 5 times prior to the next step dilution or filtration.

Additionally, control samples were prepared and filtered in between the actual sample filtrations against the possible causes of error from contamination of stock solutions or the distilled water. These control samples included the distilled water itself, PBS, magnesium chloride stock solution, phosphate buffer stock solution, calcium (II) stock solution and alginate stock solution.

Once the samples of a certain set were all filtered and the filter papers were placed appropriately on the growth media, they were put in the incubator (HACH BOD Incubator, CO, USA) and incubated for $24( \pm 3$ hours $)$ at $37^{\circ} \mathrm{C}$. The bacterial counts 
were repeated at least three times, more in cases where the number counted varied between different counts.

\subsubsection{Particle Size Count Tests}

Particle size counts were performed with the help of DPA4100 Particle Analysis System (BrightWell Technologies, Ottawa, ON). Since the concentrations worked with fell within the range of allowable concentrations during the course of the experiments, dilution was not deemed necessary in order to carry out particle counts for any sample. This provided a major advantage since dilution may impact the size and distribution of particles/flocs. Depending on the availability of the solution to be tested 5 to $10 \mathrm{~mL}$ samples were injected into the sampling syringe of the instrument and sufficient mixing was provided through a stirring rod. Due to the sensitivity of the measurements, care was taken to keep the instrument and the environment clean any time a sample was being run. The analyses were undertaken in a volume based analysis mode and each test was finalized when $1 \mathrm{~mL}$ of the suspension in the sampling syringe was analyzed. This took about 5 to 6 minutes of analysis time depending on the efficiency of the instrument with the specific solution to be tested. Several trials were conducted for the stock-particle solution preparations to come up with the desired particle number concentrations. For the analysis of flocculated samples, flocculation was initiated inside the sampling syringe (calcium ions were injected into the syringe) to minimize any error that might result from the disruption of flocs during their transfer from one container to another and also to keep the flocculation time constant for each sample. As with the inactivation experiments flocculation was allowed for 5 minutes once all the ingredients were added without any disturbance and only then the analysis was started. 
Particle count tests explained above analyzed particle number concentration, and particle size distribution characteristics of the samples. In addition, for qualitative analysis of flocculation and flocs the image capturing tool of the software was utilized. This tool is capable of taking pictures of particles/flocs satisfying a chosen criterion (such as size) during the analysis of the sample.

\subsection{Phase Specific Experimental Design}

The differences in experimental setup for each phase are described more in detail in the following three sections. The experimental matrices used for the 3 phases are given in Table 4.2

Table 4.2: Experimental design used for different phases

\begin{tabular}{l|ccc}
\hline & $\begin{array}{c}\text { Particle Size } \\
\boldsymbol{\mu m}\end{array}$ & $\begin{array}{c}\text { Alginate Concentration } \\
\boldsymbol{m g} / \boldsymbol{L}\end{array}$ & $\begin{array}{c}\text { Calcium } \\
\text { Concentration } \\
\boldsymbol{m M}\end{array}$ \\
\hline \multirow{3}{*}{ Phase I } & 1 & 0 & 0 \\
& 11 & 0 & 0 \\
& 45 & 0 & 0 \\
\hline \multirow{3}{*}{ Phase II } & 1 & 10 & $0,5,10,15$ \\
& 11 & 10 & $0,5,10,15$ \\
& 45 & 10 & $0,5,10,15$ \\
\hline & 1 & $0,10,20,40$ & 10 \\
& 11 & $0,10,20,40$ & 10 \\
\hline
\end{tabular}




\subsubsection{Phase I - Particle Only Solution (Effect of Particles) Experiments}

The purpose of the particle only solution tests was to see the effect of particle size on UV disinfection when particles of different sizes were present in same number concentrations in the solutions. Therefore, no flocculating agents were added to the solutions in this phase and the synthetic solution was composed of only particles and bacteria in PBS. The preparation was conducted exactly in the same order as explained in Section 4.2.3.

In order to carry out UV irradiation experiments, for each dose a $20 \mathrm{~mL}$ sample was withdrawn with $10 \mathrm{~mL}$ sterile wide-bore pipettes (Fisher 2-10 mL pipettes) and injected into a Petri dish; Petri dishes of $6.5 \mathrm{~cm}$ diameter were used for the UV irradiance part of the experiments. The Petri dishes were mixed using micro stir bars continuously starting a few seconds before the UV exposure of the samples and throughout the irradiance. The samples were exposed to UV doses of $0,30,60,90$, 120 , and $150 \mathrm{~mJ} / \mathrm{cm}^{2}$. After UV exposures, the suspensions were subjected to vortex mixing for 2 minutes in order to break apart bacteria-bacteria or bacteria-particle aggregates. The final step involved the bacterial enumeration which was conducted by membrane filtration technique as discussed in Section 4.2.6.

\subsubsection{Phase II - Effect of Calcium Concentration Experiments}

The purpose of Phase II was to look at the effect of floc size with each of the three different size particles by keeping the alginate concentration fixed at $10 \mathrm{mg} / \mathrm{L}$ and varying the calcium concentration from 0 to $15 \mathrm{mM}$ by intervals of $5 \mathrm{mM}$. An experimental scheme for Phase II is given in Figure 4.3. 


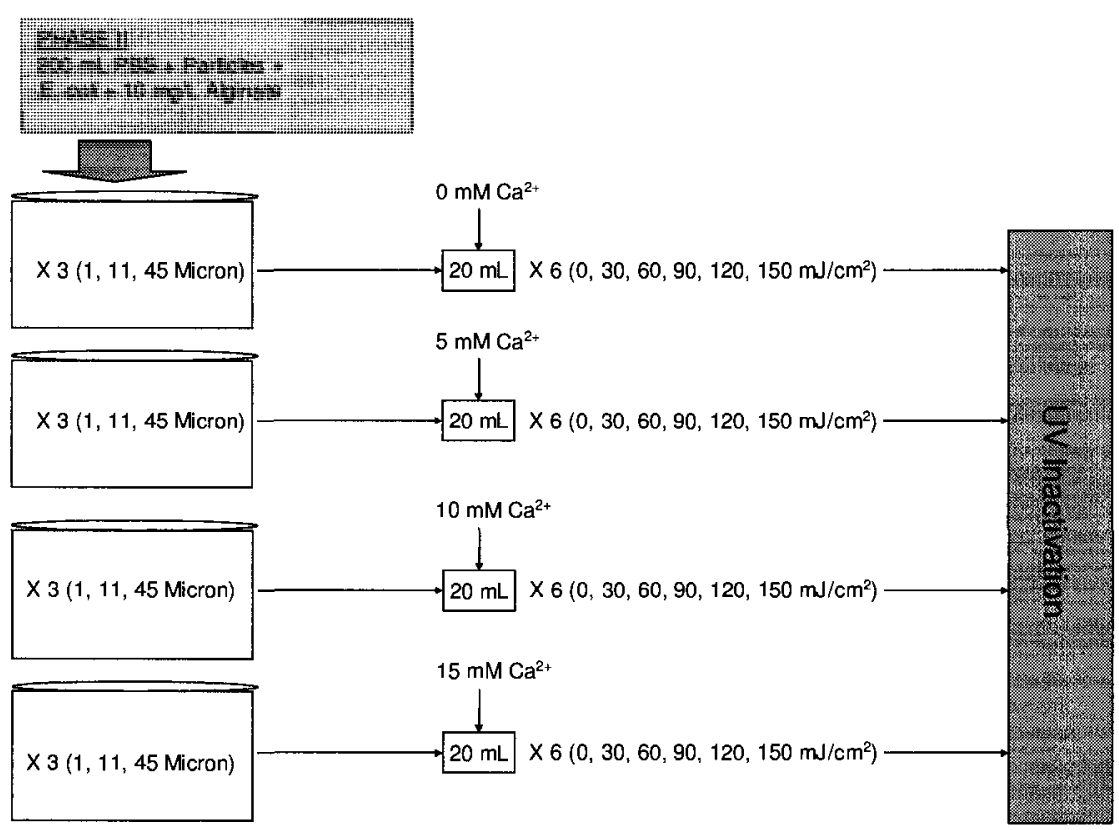

Figure 4.3: Phase II experimental scheme.

In Phase II, an alginate concentration of $10 \mathrm{mg} / \mathrm{L}$ was achieved through injection of $400 \mu \mathrm{L}$ alginic acid stock solution $(5 \mathrm{~g} / \mathrm{L})$ into a beaker containing $200 \mathrm{~mL}$ of particles and bacteria in PBS. After the addition of alginate, the solution was left for mixing for at least an hour to allow for alginate to be adsorbed on particles and bacteria (solid surfaces). Once sufficient mixing was achieved, $20 \mathrm{~mL}$ samples were prepared for each UV dose to be applied as described in Section 4.3.1 (Phase I). However, this time prior to UV exposure the $20 \mathrm{~mL}$ samples were flocculated by adding varying amounts of calcium $\left(0,5,10\right.$, and $\left.15 \mathrm{mM} \mathrm{Ca}^{2+}\right)$. A 5-minute flocculation time was allowed before exposure to UV light as determined during the preliminary experiments (during which no mixing was provided except for the first few seconds where they were hand rotated). The steps following flocculation were the same as in Phase I. 


\subsubsection{Phase III - Effect of Alginate Concentration Experiments}

Phase III focused on the effect of alginate (EPS) on UV inactivation of bacteria by varying the alginate concentration at a fixed calcium ion concentration $(10 \mathrm{mM})$. Four different alginate concentrations $(0,10,20$, and $40 \mathrm{mg} / \mathrm{L})$ were tested. An experimental scheme for Phase III is given in Figure 4.4.

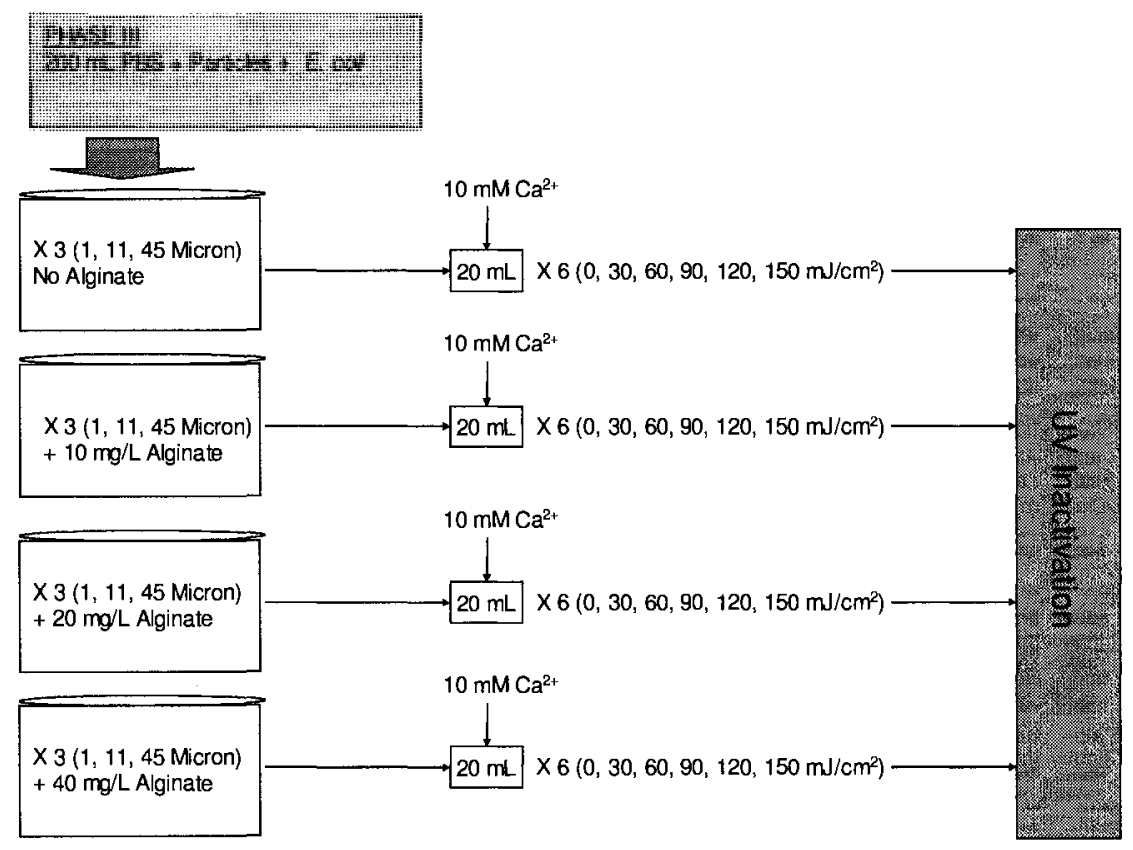

Figure 4.4: Phase III experimental scheme.

In Phase III the same order of steps as Phase II were followed by only changing the initial alginate concentration in the beaker as mentioned and flocculating by addition of $10 \mathrm{mM}$ calcium (II) at all times. 


\subsubsection{Particle Free Inactivation Tests}

In order to determine inactivation rates and the effects of EPS on inactivation in a particle free environment, a set of experiments were added to Phase III of the project. These experiments were run in the absence of particles and calcium ions and with varying concentrations of alginate $(0,10,20$, and $40 \mathrm{mg} / \mathrm{L})$.

Particle free inactivation trials were undertaken in a very similar fashion as Phase II and Phase III except that no particles were present and no calcium addition took place. Therefore, only bacteria were added into the PBS medium and alginate addition was varied as $0,10,20$ and $40 \mathrm{mg} / \mathrm{L}$. The same procedures were followed as in Phase I, II and III for the inactivation and bacterial enumeration.

\subsection{Miscellaneous Analytical Measurements}

Although the main water quality parameters of interest for the project were particle/floc number concentration, particle/floc size distribution, and UV absorbance of the solutions; turbidities of the base solutions (i.e. solutions containing 1-, 11-, and 45- $\mu \mathrm{m}$ particles only) were also measured for comparison purposes. Turbidity measurements were performed using a turbidimeter (Scientific Inc., FL, USA) and were reported in nephelometric turbidity units (NTU).

\subsection{Data Presentation}

The inactivation data are presented in the form of dose-response curves which were plotted using the following method of calculation. Mean concentration (CFU/100 mL) of $E$. coli spiked in solutions before UV irradiation was taken as the initial bacterial 
concentration, $\mathrm{N}_{0}$. For each UV dose the arithmetic mean of three replicates of $E$. coli concentration was calculated, and taken as the surviving bacterial concentration, $\mathrm{N}$. The $\log _{10}$ transformation of $\mathrm{N} / \mathrm{N}_{0}$ (LOG Survival) was plotted against the UV dose generating a dose-response curve.

The suitable portions of the dose-response curves were linearized and analyzed for first-order inactivation kinetics. Figures showing the linearizations, and the inactivation rate constant $(\mathrm{k})$ values obtained are provided in Appendix B.

The raw data used for the generation of the figures provided in Chapter 5 are given in Appendix A. 


\section{CHAPTER 5}

\section{RESULTS AND DISCUSSION}

The results and discussion will be split into several sections discussing preliminary experiments and the three phases studied in this project. The purpose of the preliminary experiments was to identify the general frame for the experimental setup, and most importantly determine the components of the synthetic matrix that were to be used in the experiments. In the first phase, the effect of particle size on UV disinfection was investigated by running trials with three different sizes of latex particles which were introduced to the samples in equal number concentrations. The second and third phases both looked into the effect of bioflocculation, floc size, structure and composition on UV disinfection with the second phase focusing on the effect of floc size and structure, and the third phase on the effect of extracellular polymeric substances.

\subsection{Preliminary Experiments}

Preliminary experiments, as were explained in Chapter 4 in detail, were composed of determination of ingredients for the preparation of synthetic media, flocculation kinetics observations, pure culture bacteria preparation, and survival tests of bacteria in distilled water and PBS.

The materials to be used in the synthetic matrix preparation were determined based on previous work of Sanin and Vesilind (1996). However, selection of particles to be used was based primarily on size uniformity, in order to achieve a size distribution curve centred as narrowly as possible around the chosen size of particles (i.e., a high 
kurtosis). Therefore, instead of clay particles polystyrene latex particles of three different sizes $(1,11$, and $45 \mu \mathrm{m})$ were chosen.

The initial flocculation observations were made visually and consisted of mainly previously tested concentrations of calcium and alginate in works of Sanin and Vesilind (1996) and Örmeci and Vesilind (1999). As explained in Chapter 4, a combination of four doses of calcium $(0,5,10$, and $15 \mathrm{mM})$ and four doses of alginate $(0,10,20$, and $40 \mathrm{mg} / \mathrm{L})$ were tested to examine whether flocs formed were similar in size and structure to those found in water and wastewater samples, and whether their formation was completed within a reasonable amount of time (approximately 5 minutes). The results achieved with these concentrations were found to be satisfactory.

The E. coli culture was prepared at least once a week to provide fresh suspensions of bacteria for the inactivation tests. The bacteria were grown until they reached a phase of late $\log$ to early stationary as suggested by the supplier. This assured that the change in bacterial concentrations in the test suspensions due to growth or death of bacteria would be minimized. The time required to reach the desired growth phase was determined by measuring the absorbance of the suspension at $500 \mathrm{~nm}$. A typical absorbance curve is provided in Figure 5.1, as can be seen in the figure the early stationary phase was reached after 12 to 14 hours of incubation at $37^{\circ} \mathrm{C}$. 


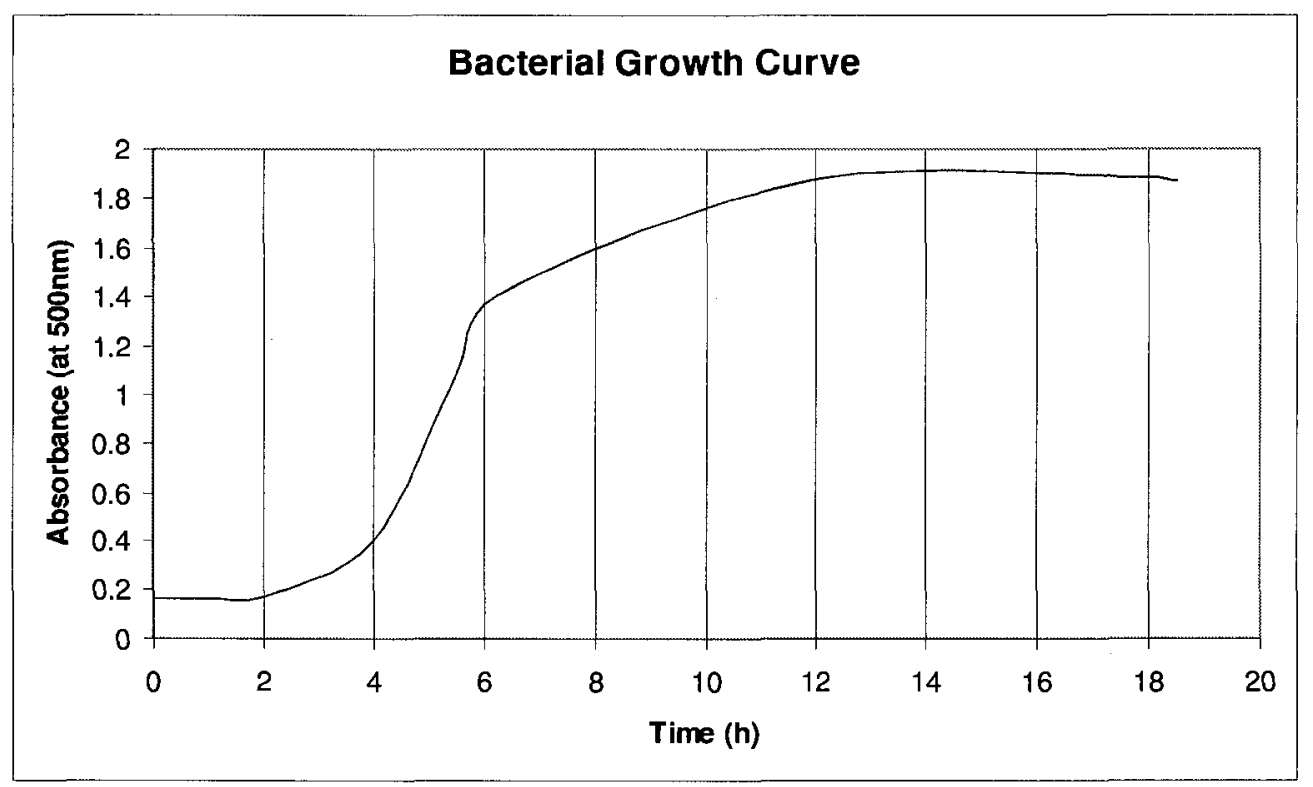

Figure 5.1: Bacterial growth curve plotted by measuring the suspension's absorbance at $500 \mathrm{~nm}$ over 18 hours.

In order to ensure the accuracy and reproducibility of results, it is important to have a stable bacterial count in the synthetic matrix during UV inactivation tests. Both distilled water and PBS could be used as the main medium for the synthetic system; distilled water having the advantage of containing no ions that could impact the flocculation rate and background UV absorbance. The survival of bacteria was monitored in two beakers: one containing PBS and the other distilled water as the suspension medium. The trials were carried out at room temperature and the change in CFU within 24 hours after injection of bacteria into solutions was measured by the MF technique. The results indicated a considerably stable bacterial concentration in PBS (only $6.9 \%$ reduction in total concentration in 24 hours), and a complete loss of bacteria population in distilled water in a few hours. Therefore, it was decided that PBS would be used as the base solution for the synthetic system, regardless of any minor interference that might result from the ingredients of PBS such as the magnesium ions. 


\subsection{Phase I: Effect of Particles on UV Inactivation}

Phase I of the project consisted of three sets of experiments in which three different particle sizes $(1,11$, and $45 \mu \mathrm{m})$ were tested for their potential of protecting $E$. coli from UV light inactivation.

The very fist step of Phase I (and of Phase II and III, as well) was to run particle count tests to check the initial number concentration of particles in the synthetic solutions to be used. These measurements represent the basis of the study where particle number concentrations of any size of interest was set to a target particle concentration of $6,000 \pm 600$ particles/mL before addition of any of the other constituents (i.e., the solution contained only particles and filtered distilled water at this point). Previous studies reported particle number concentrations in secondary wastewater effluents as 1,000 to 2,000 particles/mL for particles larger than $10 \mu \mathrm{m}$ (Emerick et al., 2000; Örmeci and Linden, 2002), and as 13,000 to 18,000 particles/mL for particles larger than $2 \mu \mathrm{m}$ (Örmeci and Linden, 2002). When particles less than $2 \mu \mathrm{m}$ in size are considered the number concentration reaches $10^{6}$ to $10^{7}$ particles $/ \mathrm{mL}$ (Parker et al., 1971). Therefore, the target particle concentration chosen $(6,000 \pm 600$ particles $/ \mathrm{mL})$ was in a range that could represent wastewater effluent samples. Another reason for keeping the target particle concentration in this range was to provide particle suspensions that could be analyzed with the particle size counter without dilution. Dilution might cause significant deviations from the original composition of a sample by changing the solution's ionic strength and composition (Örmeci and Linden, 2002), and this is particularly critical for flocs which are fragile and can break apart easily (Mamane and Linden, 2006a). 
Figures 5.2 through 5.4 show the initial particle number concentrations and size distributions of solutions containing 1-, 11-, and 45- $\mu \mathrm{m}$ latex particles, respectively. The same base solutions were used for the experiments in Phase II and Phase III as well, in order to be able to make comparisons among the three phases of the project.

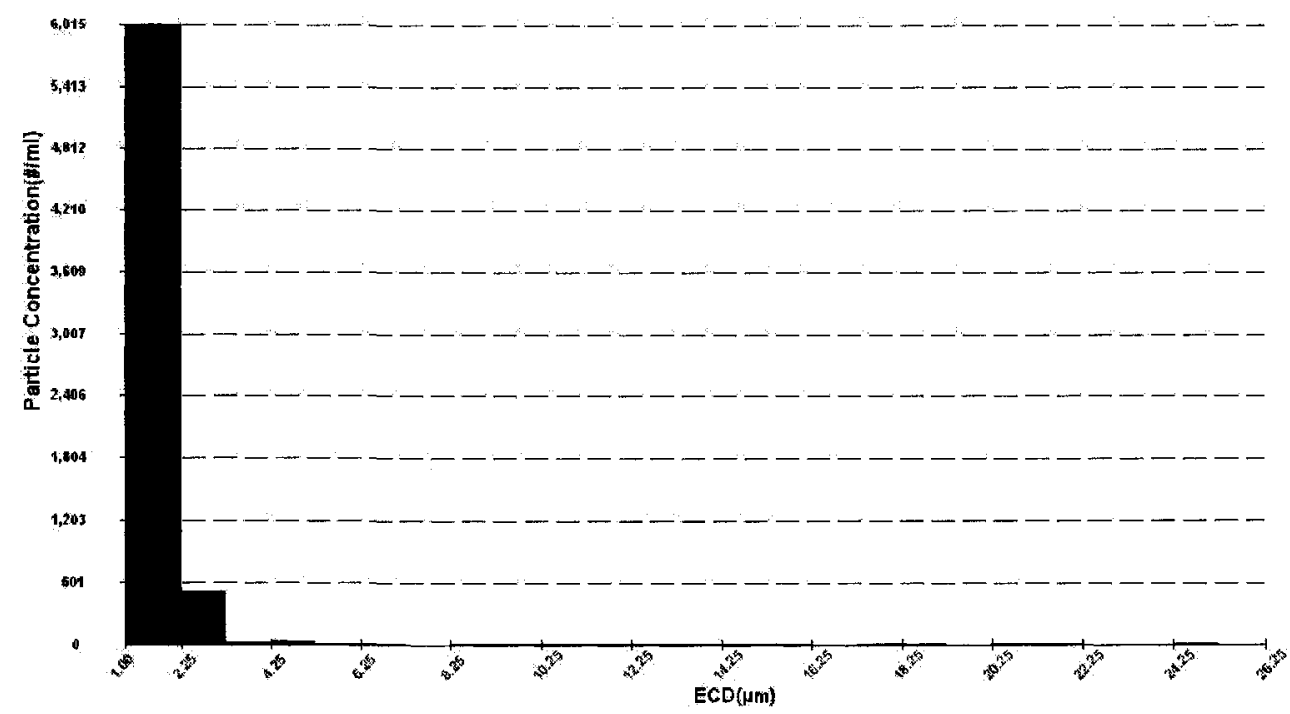

Figure 5.2: 1- $\mu \mathrm{m}$ Latex Particle Solution; Range $(\mu \mathrm{m})$ : 1.00-25.25, Mean $(\mu \mathrm{m}): 1.78$, Mode $(\mu \mathrm{m}): 1.00-2.25$, Standard Deviation $(\mu \mathrm{m}): 0.86$, Total Concentration of Particles (\#/mL): 6613, Concentration of Particles in 1.00-2.25 Range (\#/mL): 6015. 


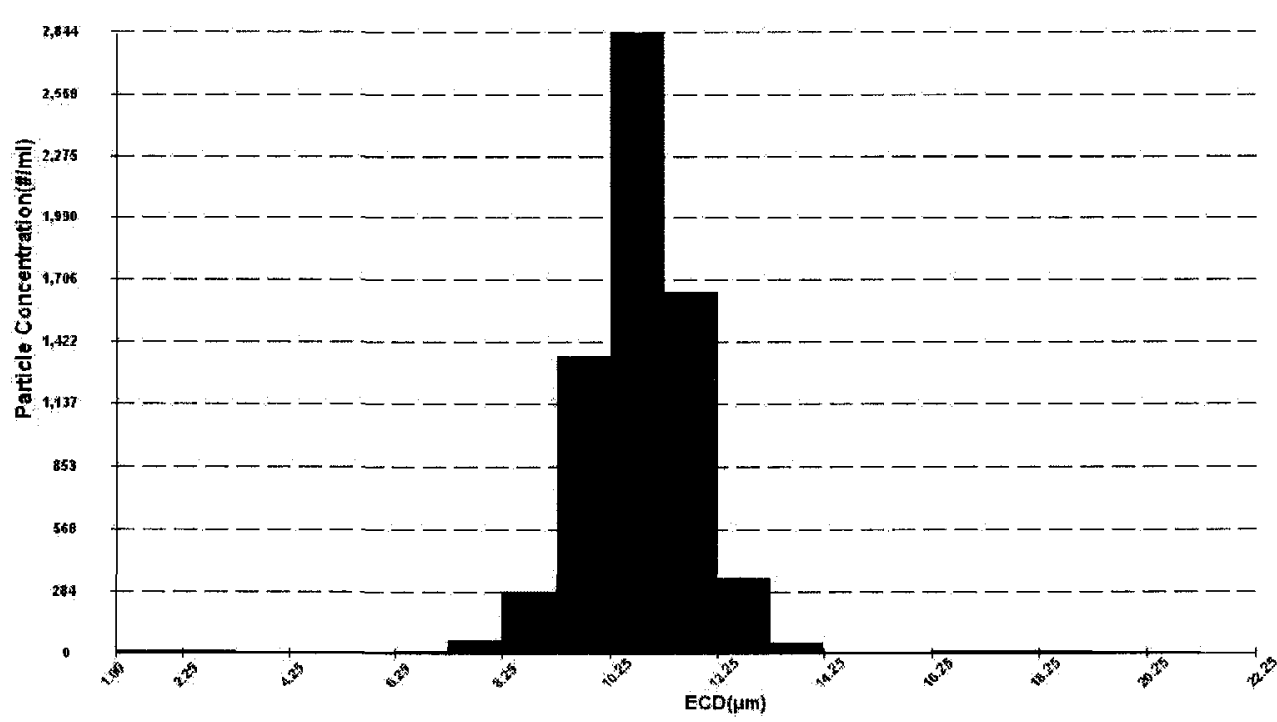

Figure 5.3: 11- $\mu \mathrm{m}$ Latex Particle Solution; Range $(\mu \mathrm{m})$ : 1.00-21.25, Mean $(\mu \mathrm{m})$ : 10.81, Mode $(\mu \mathrm{m}): 10.25-11.25$, Standard Deviation $(\mu \mathrm{m}): 1.18$, Total Concentration of Particles (\#/mL): 6632, Concentration of Particles in 8.25-15.25 Range (\#/mL): 6523.

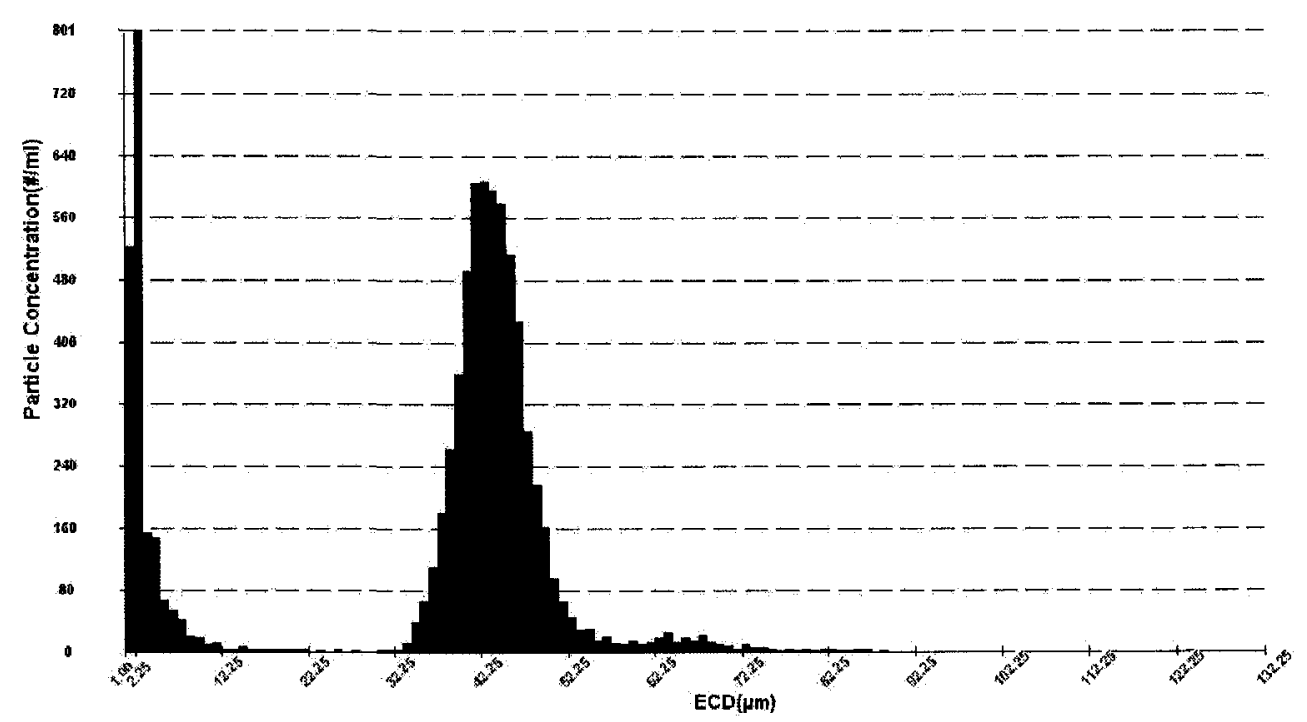

Figure 5.4: $45-\mu \mathrm{m}$ Latex Particle Solution; Range $(\mu \mathrm{m})$ : 1.00-124.25, Mean $(\mu \mathrm{m})$ : 34.89, Mode $(\mu \mathrm{m}): 2.25-3.25$, Standard Deviation $(\mu \mathrm{m}): 18.32$, Total Concentration of Particles (\#/mL): 7917, Concentration of Particles in 30.25-90.25 Range (\#/mL): 6044.

One of the problems that arose during the preparation of solutions of different sized particles with an equal number concentration stemmed from the presence of 
impurities (mainly in the form of smaller particles: size less than $3.25 \mu \mathrm{m}$ ) in the distilled water used as well as in the original latex particle suspensions as obtained from the manufacturer. The effect of impurities originating from the supplied stock of latex suspensions was relatively high for the $45-\mu \mathrm{m}$ suspensions, and almost nonexistent for the 1- and 11- $\mu \mathrm{m}$ suspensions. This turned out to be an issue only for the $45-\mu \mathrm{m}$ solutions, since the background particle concentration in the distilled water was kept at negligible levels (less than 200 particles $/ \mathrm{mL}$ ) through effective filtration before use. In the case of $45-\mu \mathrm{m}$ solutions, it became virtually impractical to prepare a solution having the target number concentration of $45-\mu \mathrm{m}$ particles without having a significant concentration of particles of other sizes (Figure 5.4). To account for the effect of impurities, the decision of whether or not the target number concentrations were achieved, was based on only particles falling within a certain size range, that is 1 to $2.25 \mu \mathrm{m}, 8.25$ to $15.25 \mu \mathrm{m}$, and 30.25 to $90.25 \mu \mathrm{m}$; for $1-, 11-$, and $45-\mu \mathrm{m}$ solutions, respectively. These ranges were chosen based on the uniformity characteristics of the particles employed and the sensitivity of the particle counter with regards to the size being studied.

Once solutions satisfying the target particle number concentrations were achieved, other constituents of the synthetic medium (alginate and $\mathrm{Ca}^{2+}$ ions) were added, and samples were exposed to UV irradiation as described in Chapter 4. The dose-response curves for all three experiments are provided in Figure 5.5. Each data point on the figure represents the average of three replicates and error bars indicate the standard deviation. Error bars which are not visible are smaller than the data point markers. 


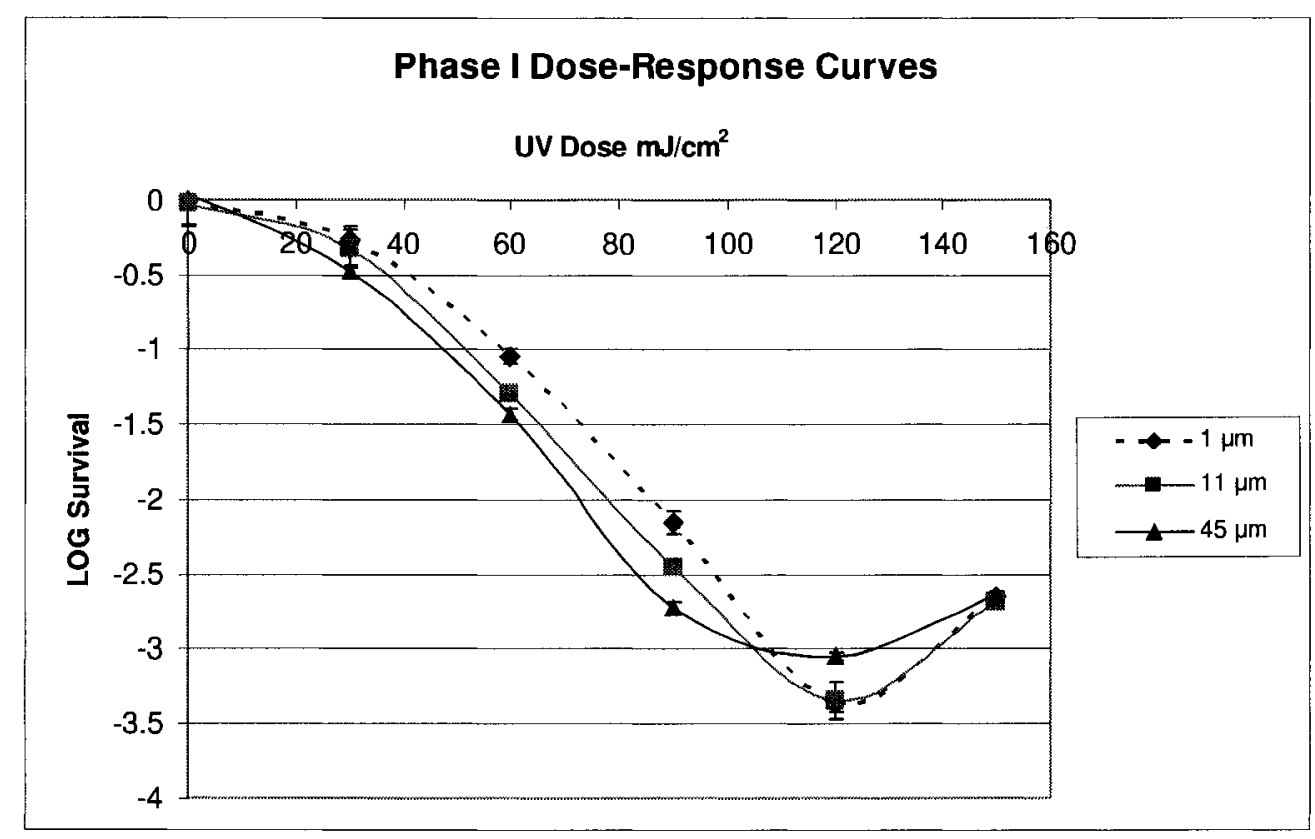

Figure 5.5: Phase-I UV inactivation experiments of three different solutions containing equal number concentrations of 1-, 11-, or $45-\mu \mathrm{m}$ latex particles and $E$. coli.

The first implication of the dose-response curves shown in Figure 5.5 was that shoulder and tailing effects were observed for all three particle sizes tested. The shoulder effect might have originated from the clumping effect (Severin et al., 1983). If the suspended bacteria in a solution undergo a process of self-aggregation, then a certain dose of UV will be necessary for effective inactivation to occur. Furthermore, the possible repair mechanisms, that the bacteria are capable of, are more significant at lower doses (Lindenauer and Darby, 1994) and likely to cause a reduction in the rate of inactivation achieved (Jagger, 1967). The inactivation curves followed firstorder inactivation kinetics between UV doses of 30 to $120 \mathrm{~mJ} / \mathrm{cm}^{2}$, and a tailing effect was observed at UV doses over $120 \mathrm{~mJ} / \mathrm{cm}^{2}$ with the exception of $45-\mu \mathrm{m}$ particle solution where tailing was observed to start at $90 \mathrm{~mJ} / \mathrm{cm}^{2}$. The tailing effect is usually a result of the presence of particles and more importantly particle-microbe association and it indicates that some of the target organisms are completely protected from the 
UV light irradiation (Qualls et al., 1983; Mamane-Gravetz and Linden, 2004). Tailing might also be observed due to self-aggregation of microbes (Craik et al., 2001; Mamane-Gravetz and Linden 2004).

Since Phase I experiments were conducted in the absence of flocculating agents (calcium and alginate) significant particle-microbe association was not expected at this stage. However, the observed shoulder and tailing effects indicated that selfaggregation of bacteria might have occurred in the samples. Blatchley et al. (2001) reported that self-aggregation of bacteria might be sufficient to provide complete protection from UV light. In fact, in certain cases self-aggregation process was reported to be more effective in protecting microbes from UV irradiation than particle-microbe association (Mamane and Linden, 2006a). In addition, non-induced particle-microbe association might have also played a role. It was reported that mechanisms such as electrostatic attraction and adsorption (due to hydrophobicity) might provide a suitable environment for the microbes to attach onto particles on their own, and such mechanism of attachment might even be more prevailing than attachment achieved through induced flocculation (Templeton et al., 2005). Further supporting the importance of self attachment processes, Wu et al. (2005) reported that attachment of microbes onto particles to a degree significantly affecting the efficiency of UV disinfection was achieved simply by allowing the samples to be mixed for sufficient amounts of time.

A comparison of dose-response curves from Phase I with dose-response curves from Phase II and Phase III can provide the basis for understanding whether or not self- 
aggregation can be more effective than induced aggregation. This will be discussed further in Phase II and Phase III.

One of the unexpected features of the dose-response curves was the decrease seen in the degree of inactivation between doses of 120 and $150 \mathrm{~mJ} / \mathrm{cm}^{2}$. The experiments were repeated several times to make sure that the decrease observed in inactivation was not due to an experimental error. This decrease was not reported in the literature before, but by examining the data published in other papers it is clear that a similar decrease was also observed, but not recognized, in other studies (Loge et al., 1996; Emerick et al., 1999; Emerick et al., 2000; Blatchley et al., 2001; Dietrich et al., 2002). It should also be noted that relatively few UV disinfection studies have applied UV doses higher than $100 \mathrm{~mJ} / \mathrm{cm}^{2}$. The inactivation decrease beyond $120 \mathrm{~mJ} / \mathrm{cm}^{2}$ may be explained by the formation of bacterial aggregates upon UV exposure (Blatchley et al., 2001). It was reported that bacterial aggregates reaching sizes as large as $10 \mu \mathrm{m}$ might form which could provide additional protection to the microorganisms under prolonged UV exposure. Another reason for the observed trend might be a higher rate of recovery of bacterial cells due to longer exposure times at higher UV doses as bacteria are known to be capable of repairing UV induced damage. However, it would be expected that the effect of repair mechanisms would be minor as the difference between UV exposure times for different doses was small and the irradiation experiments were run in the dark where bacterial repair is slow. More research is required to better understand the reasons behind the observed decrease in UV inactivation, which was not part of the scope of this work. 
Contrary to the general understanding of larger particles protecting bacteria better from the UV light, the results of Phase I indicated that less protection was achieved as the size of particles became larger. One explanation to this situation might be different aggregation characteristics of different sized particles with E coli. For instance, in a 1$\mu \mathrm{m}$ particle and bacteria system, bacteria might be located in a cloud of particles of about the same size as the bacteria. Whereas, as the particles get larger the allocation of bacteria and particles might be such that particles are surrounded by bacteria attached onto their surfaces. The latter case is likely to provide less protection to target organisms as they might still be fully exposed to UV light, with no effective shielding being provided. In particular, when the transmittance of UV light in the bulk solution is taken properly into account for UV dose determination, no significant inactivation deficiency would be expected under such circumstances (i.e., due to shading). However, when the bacteria get actually enmeshed within a particle-floc structure, then a higher degree of protection from UV light is to be expected due to shielding. Another difference in the characteristics of aggregation achieved with particles of different size may be due to the differences in total particle surface area available. As all the samples were prepared to contain equal numbers of particles, the larger the particle size the higher the total surface area will be. Therefore, it can be hypothesized that more bacteria-bacteria aggregates would be formed when less particle surface is available for bacteria to attach onto. Noting that under certain circumstances self aggregates of bacteria have a higher survival rate than particleassociated bacteria (Mamane and Linden, 2006a), lower levels of inactivation can be expected for smaller particle samples as observed in Phase I. A further discussion on this topic is presented in Phase II and Phase III where the effect of different rates of 
flocculation on UV disinfection was studied by applying varying doses of calcium and alginate to the system.

Another factor that might have played a significant role in the observed trend of 'inactivation rate increases with increasing particle size' may have been the overestimation of samples' UV absorbance. The UV absorbance measurements of the samples are used in the calculations of UV dose as a correcting factor, and when a bulk solution's absorbance is measured, an overestimation of the absorbance values might be of concern due to the effects of scattering (mainly backscattering). Spectrophotometers are not capable of differentiating between light that is scattered and light that is absorbed. Therefore, the scattered light is falsely measured as absorbed light unless an integrated sphere (IS) sensor is used to correct for that. Scattered light has the capacity to inactivate microbes, whereas absorbed light does not (Mamane and Linden, 2006b), and thus an overestimation of absorbance might lead to overdosing of samples. The extent of this overestimation is expected to be greater for solutions having higher turbidities (Christensen and Linden, 2003). As well, the extent of scattering was reported to depend on geometrical factors and larger particles were found to cause a more fluctuating scattering pattern (Mamane and Linden, 2006b). Thus, the error factor introduced to the absorbance measurements would be greater with solutions containing larger particles.

Figure 5.6 shows the absorbance and turbidity of solutions containing 1-, 11-, and 45$\mu \mathrm{m}$ particles. The results showed that the absorbance and turbidity of the 1- and 11$\mu \mathrm{m}$ solutions were very low, and thus scattering would not be expected to have had a significant effect on these samples. The $45-\mu \mathrm{m}$ solution, on the other hand, had five- 
fold higher absorbance and forty-fold higher turbidity compared to the other samples; hence, scattering effects might have played a role in the inactivation of the $E$. coli in this sample. It is not known, however, if this effect would be significant or not.

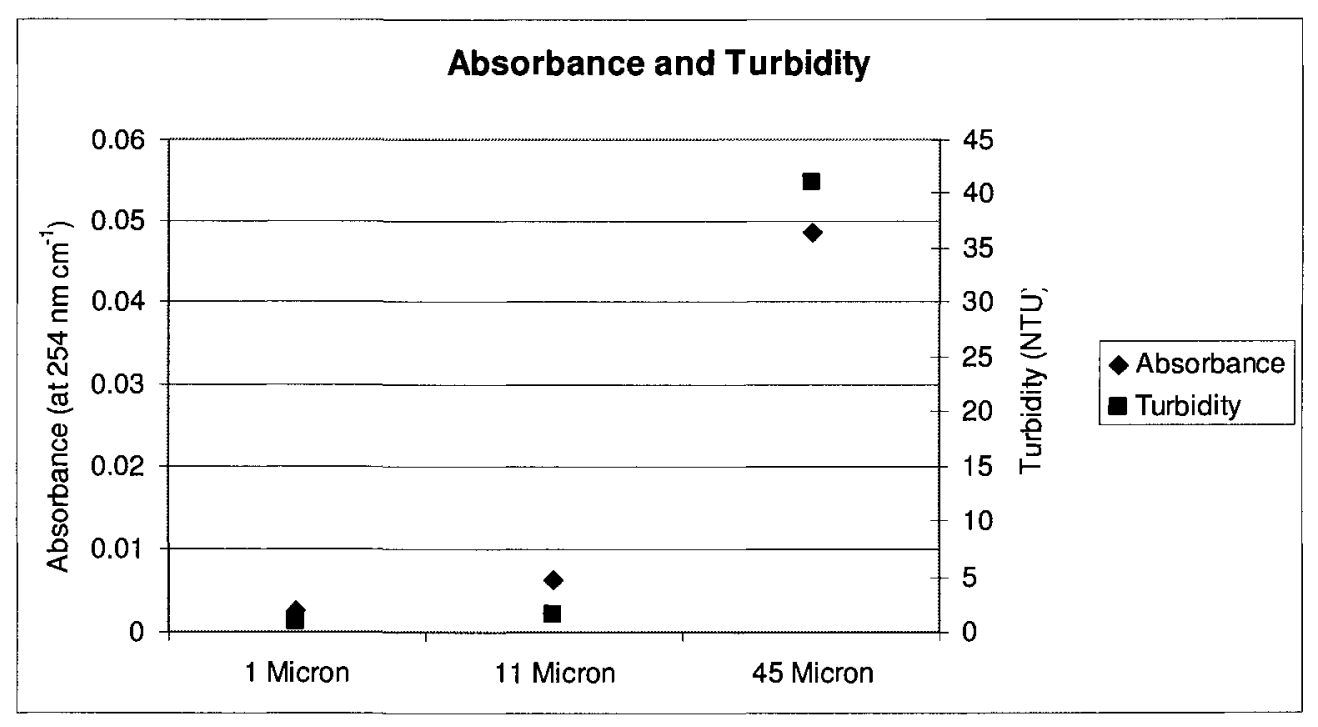

Figure 5.6: Absorbance and turbidity measurements of Phase I experiments.

\subsection{Water Quality Parameters Analyzed}

The main parameters that were examined in order to correlate with the inactivation data in this project were: particle number concentration, particle size distribution, and floc structure and size. These parameters were measured using the DPA4100 Particle Analysis System (BrightWell Technologies Inc., Ottawa, ON), which is a new generation particle counter that uses flow microscopy technology to analyze particle populations and has significant advantages over the conventional particle counters. The size distribution and number concentration of particles and flocs were obtained through analyses of the samples representing all the different conditions of bioflocculation studied throughout the project. As well, images captured during the 
count tests are also included in this chapter for qualitative analysis of floc structure and size.

Particle counts in water samples quickly change due to continuous coagulation and break up of flocs. In addition, particle counters have certain limitations in detecting the size of aggregates that might be loosely held together. The following issues should be considered when evaluating the particle count data. First, the software of the instrument calculates mean size based on number concentration analysis; therefore, contrary to a case where the mean size is calculated based on mass concentration, the increase in mean size following flocculation will not be as significant as the degree of flocculation. This means, although flocs contain many particles, they will be counted as individual entities and their influence on the average size calculation will be less due to lower number concentrations. Second, particles and bacteria having sizes around or lower than the minimum detection limit of the instrument $(1 \mu \mathrm{m})$ may not always be detected. However, as soon as a flocculating agent is added to the suspension, these particles and bacteria will likely be coated with the polymer and start flocculating becoming more detectable. A sudden increase in the number of smaller sized entities that were not previously detected may lead to a shift towards a smaller mean size when in fact the size of all the individual entities in the suspension is increasing. Third, the particle size analyzer may not be very sensitive to floc size measurement due to the following reasons: (1) Flocs come in various shapes and often are far from being spherical. (2) Some flocs might be counted as more than one entity due to the presence of relatively low-density regions (which are perceived as empty space rather than part of the floc by the instrument, see Figure 5.7). (3) The adhesive properties of flocs coated with the polymer may cause clogging in the flowcell (the 
part of the instrument in which the actual analysis of the sample is being made) particularly when the flocs formed are very large.

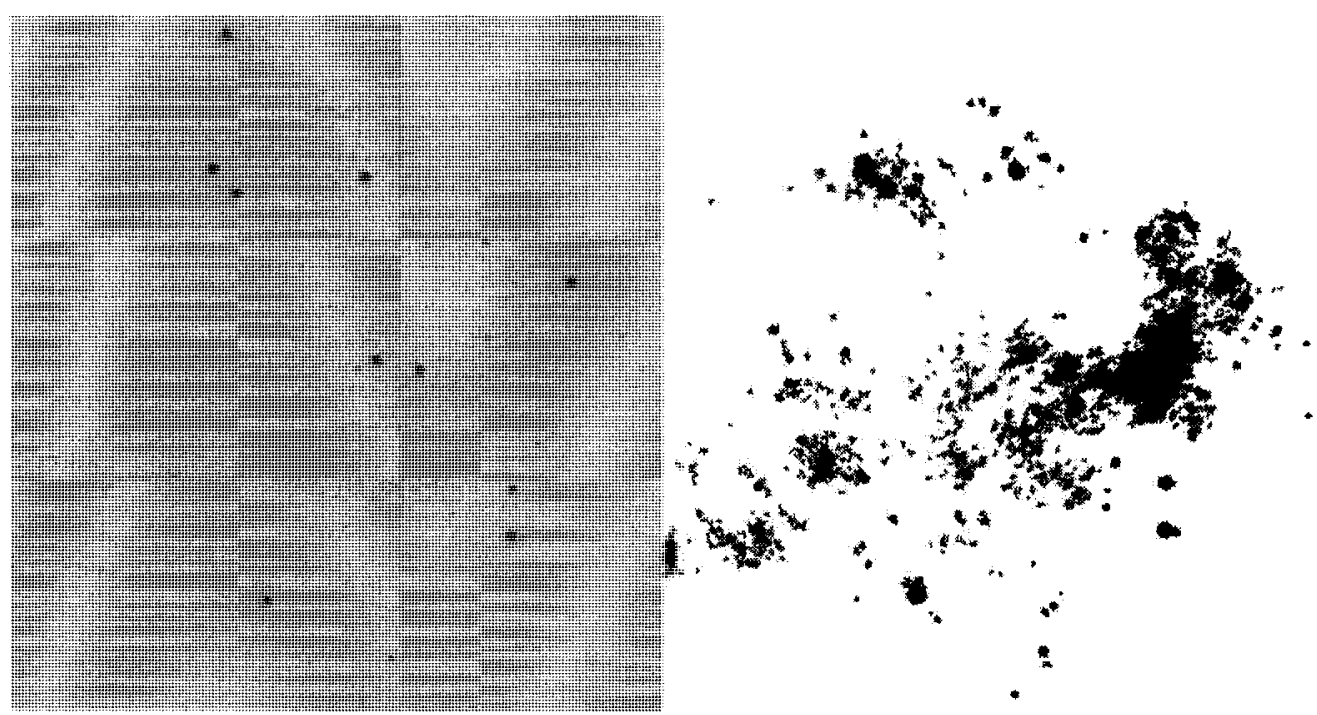

Figure 5.7: The image on the left shows the original floc as it appears on the screen and the image on the right shows how it is perceived by the instrument for counting.

Due to the reasons mentioned above the particle distribution analysis plots were prepared in a way that particles/flocs of size smaller than $5 \mu \mathrm{m}$ were excluded. This would allow for a relatively more precise correlation to be made between inactivation and particle count data by focusing on effects of flocculation on size distribution. The figures showing the particle count data are given under relevant sections.

In addition to the particle counts, bulk absorbance values of the samples were also measured for better interpretation of inactivation data. Figures showing absorbance data are provided under relevant sections. 


\subsection{Phase II: Effect of Calcium Dose on Flocculation and UV Inactivation}

Phase II of the project consisted of three sets of experiments focusing on the effect of floc size, structure, and composition on UV disinfection. In this phase bacteria and the particles were aggregated by adding alginate and calcium. The irradiation experiments were carried out on samples containing three different sized particles (1-, 11- and 45$\mu \mathrm{m})$, a fixed amount of alginate $(10 \mathrm{mg} / \mathrm{L})$, and four different concentrations of calcium $(0,5,10$, and $15 \mathrm{mM})$. The only variable within each set of experiment was the calcium concentration, and the floc size and characteristics were controlled by varying it.

Particle analysis results of the conditions studied in Phase II are presented in Figures 5.8 and 5.9. These figures show the change in number concentration and mean size, respectively.

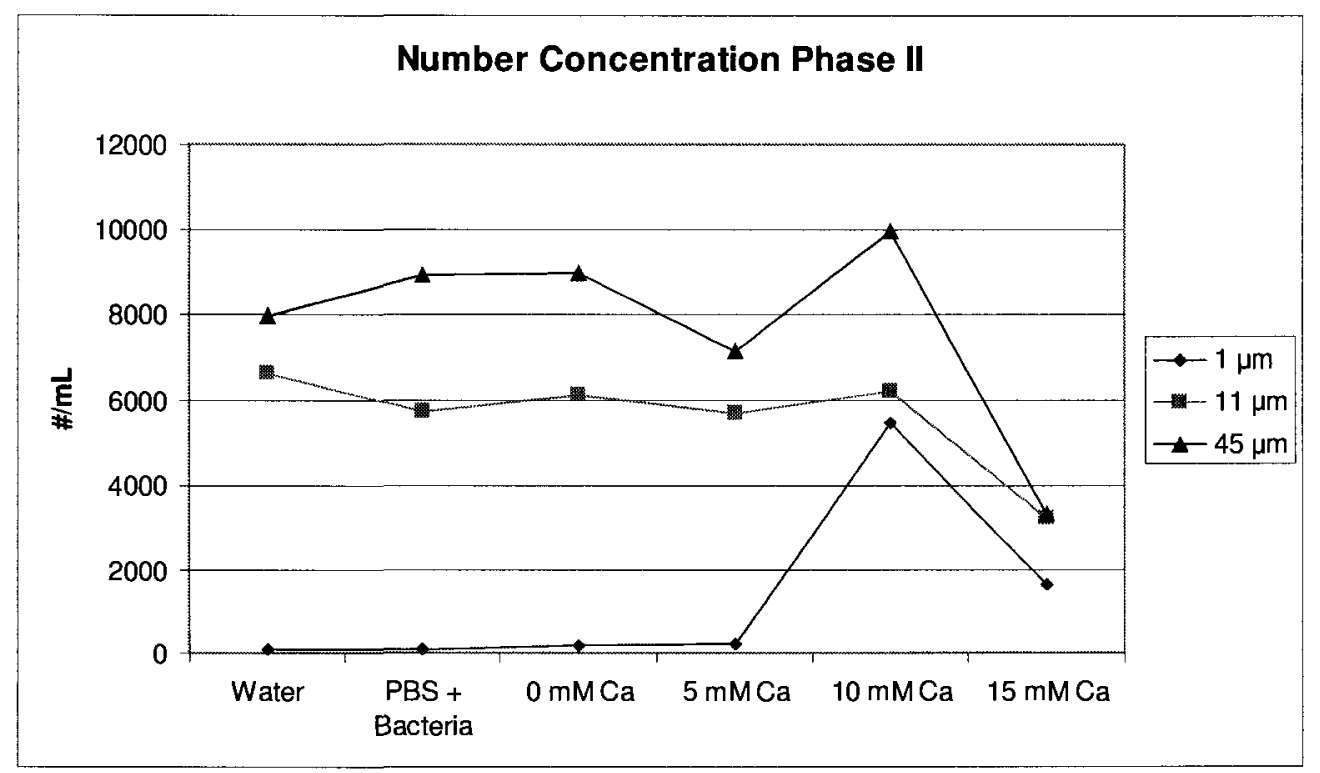

Figure 5.8: Particle number concentrations measured (particles $>5 \mu \mathrm{m}$ ) for the conditions studied in Phase II. 


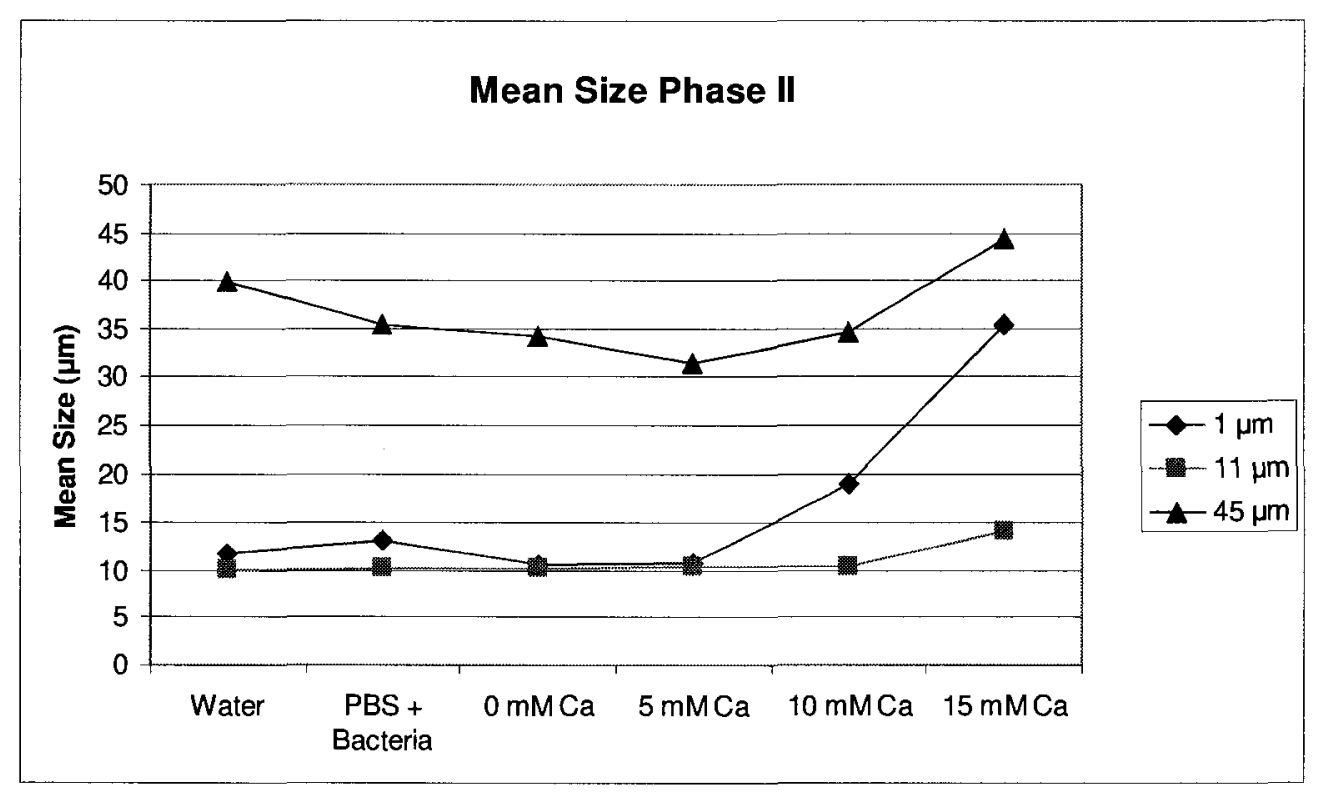

Figure 5.9: Particle mean size values measured (particles $>5 \mu \mathrm{m}$ ) for the conditions studied in Phase II.

The general trend observed in the particle count data was that up until $10 \mathrm{mM}$ calcium addition there was a slight decrease in number concentration which indicated minor flocculation as small particles and bacteria aggregated to form flocs larger than $5 \mu \mathrm{m}$ in size. The considerable increase observed in $1-\mu \mathrm{m}$ series at $10 \mathrm{mM}$ was due to the exclusion of particles smaller than $5 \mu \mathrm{m}$ in the plots (the original suspension contained $1-\mu \mathrm{m}$ particles which were not counted until significant flocculation occurred). Yet, the sharp decrease seen at $15 \mathrm{mM}$ for all three cases, was an indication of a more significant flocculation as at this point most flocs were large enough to be counted as one entity. The mean size graph shows a parallel trend to the particle count data as the large decrease seen in the particle counts was matched by a large increase in the mean size of particles further supporting the existence of significant flocculation. Finally, the graphs also show that, $1-\mu \mathrm{m}$ suspension generated larger flocs compared to the $11-\mu \mathrm{m}$ suspension, and the largest flocs were observed in the 45- $\mu \mathrm{m}$ suspension. 
The results of absorbance measurements are given in Figure 5.10. Since absorbance measurements corresponded to those of the bulk solutions, the plots shown in the figure may not directly be comparable to the rate of flocculation. As UV absorbing material can be concentrated within the flocs, a high concentration of highly UV absorbing flocs may not necessarily lead to an equally highly UV absorbing solution. The main implication of absorbance data was that a significant difference exists between $45-\mu \mathrm{m}$ suspensions, and $1-$ and $11-\mu \mathrm{m}$ suspensions. This might partly be caused by the higher levels of light scattering (especially backscattering) in the $45-\mu \mathrm{m}$ sample.

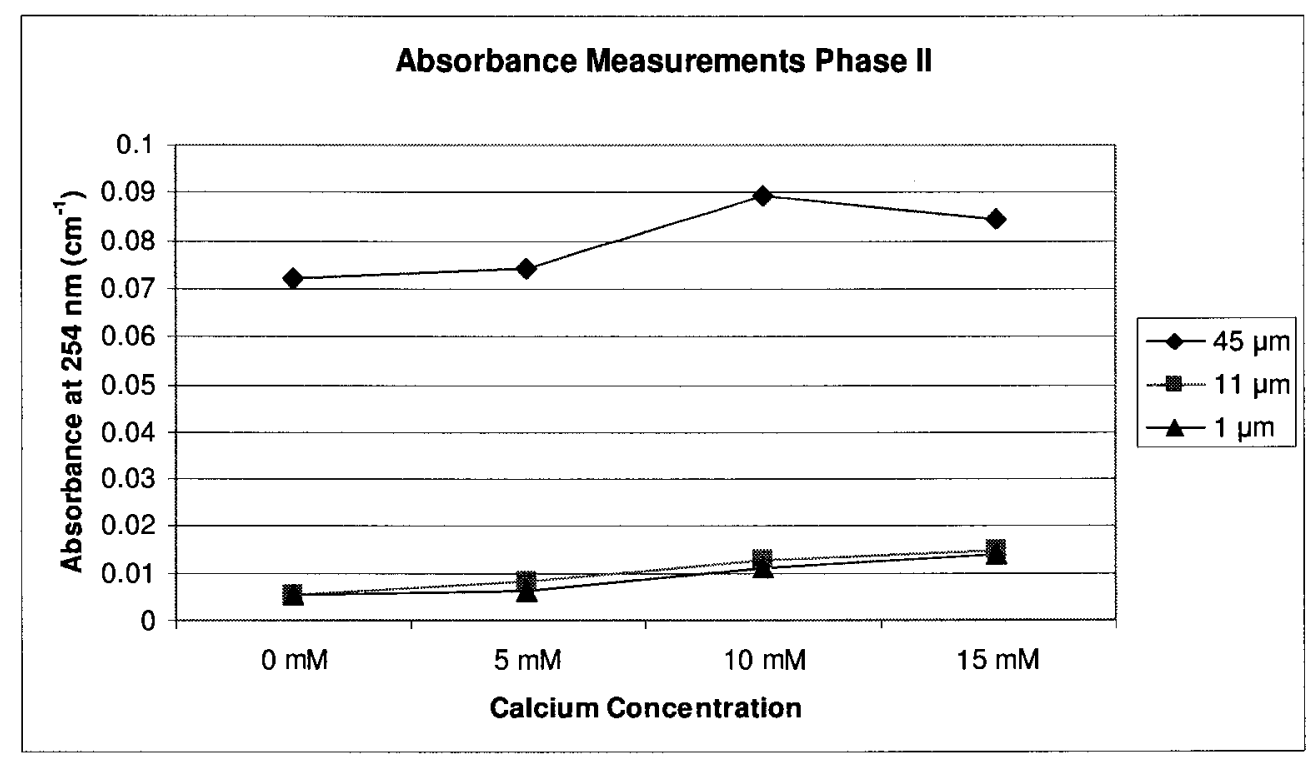

Figure 5.10: Absorbance values measured at $254 \mathrm{~nm}$ for conditions studied in Phase II.

Results of Phase II inactivation experiments are split into four sections, three of which explain the results of experiments run with 1-, 11 - and $45-\mu \mathrm{m}$ particles, and the last section discusses the results in a comparative manner. 


\subsubsection{1- $\mu \mathrm{m}$ Experiments}

The inactivation results of $1-\mu \mathrm{m}$ experiments of Phase II are shown in Figure 5.11. The data points on the figure represent the average of three replicates and the error bars indicate standard deviation. Error bars which are not visible are smaller than the data point markers. In addition, images showing flocs formed under different conditions tested are given in Figure 5.12. These images were captured by the particle counter during size analyses.

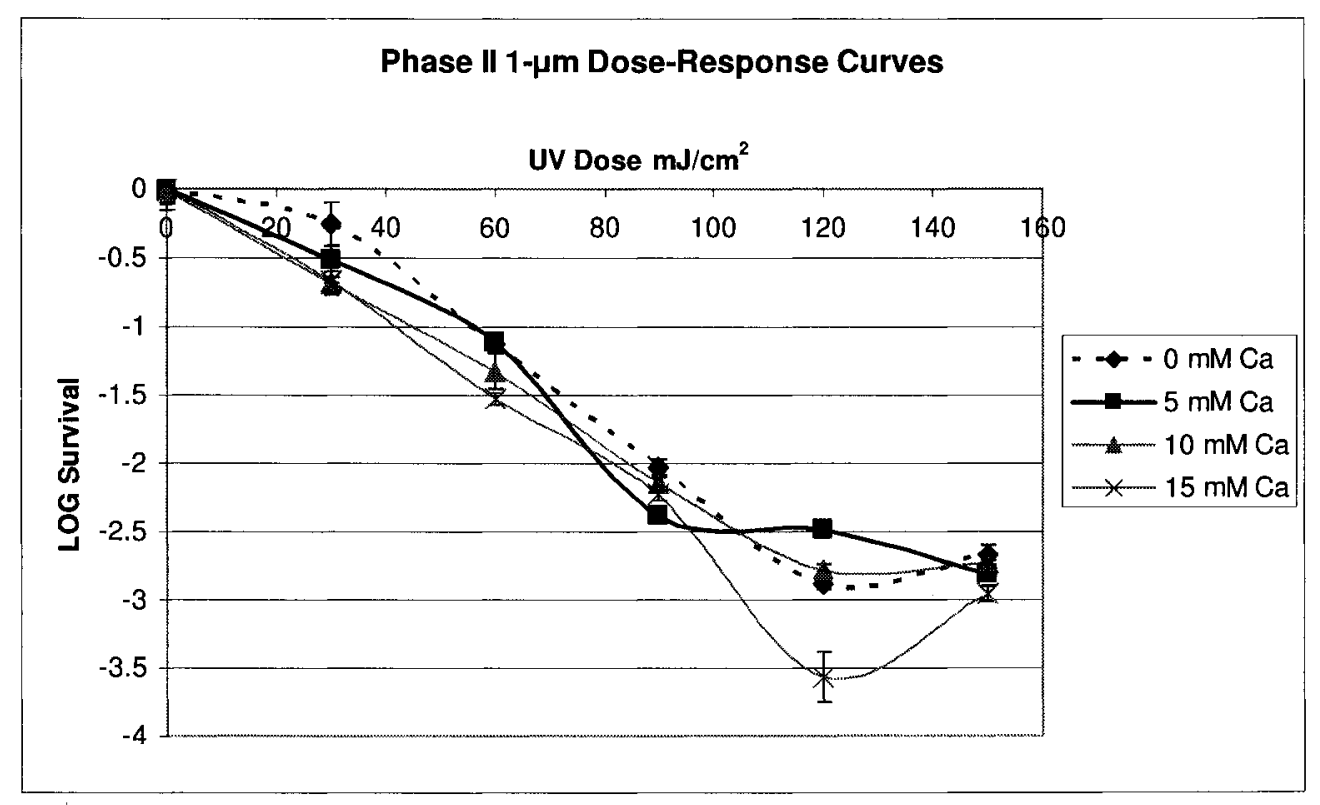

Figure 5.11: Phase-II UV inactivation experiments with $1-\mu \mathrm{m}$ particles, $10 \mathrm{mg} / \mathrm{L}$ alginate and varying concentrations of calcium ions. 

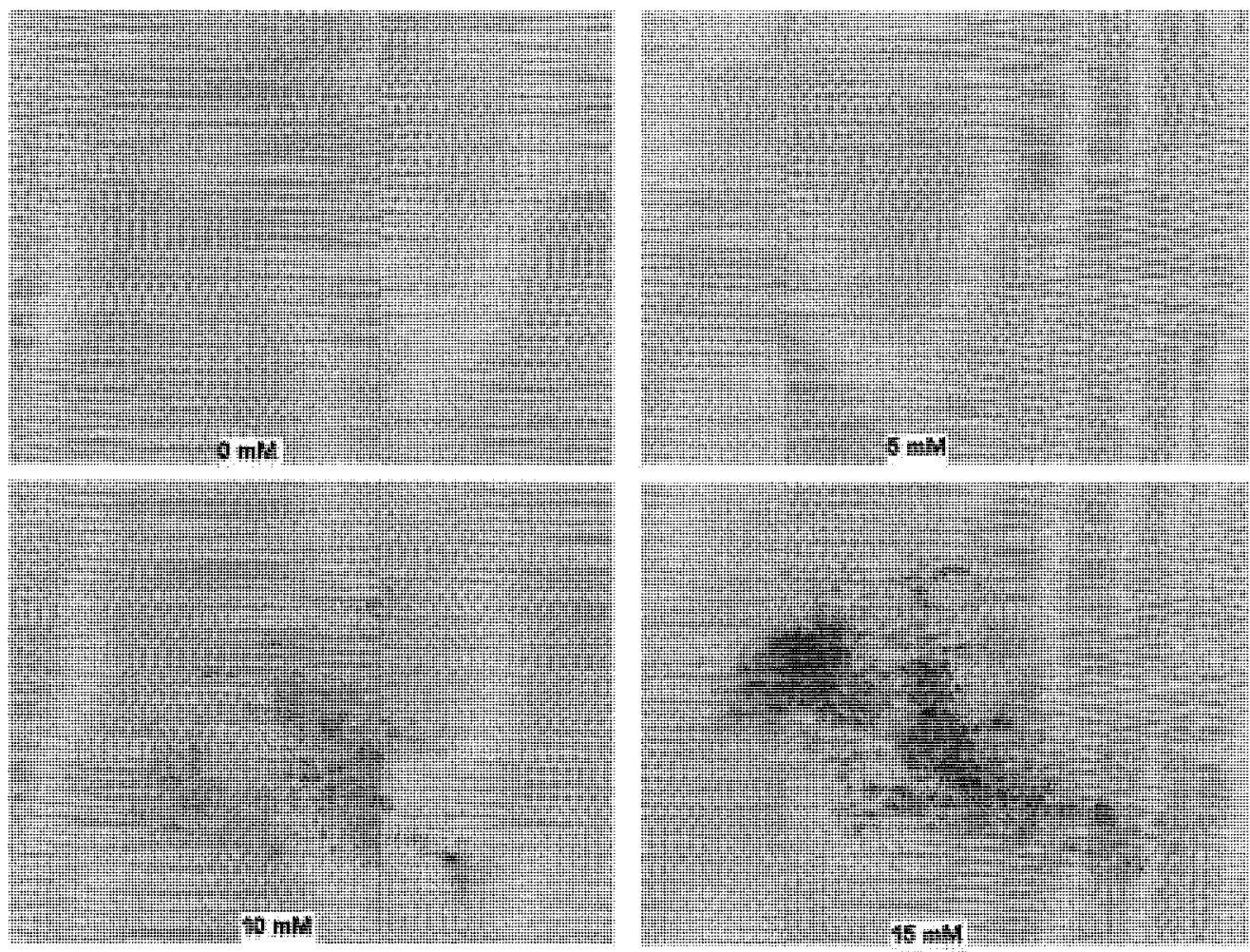

Figure 5.12: Flocs formed in $1-\mu \mathrm{m}$ experiments of Phase II, flocculation conditions: $10 \mathrm{mg} / \mathrm{L}$ alginate and calcium doses as indicated on the figure.

When the dose-response curves given in Figure 5.11 and floc images given in Figure 5.12 are evaluated together a few conclusions can be drawn. Firstly, as can be seen in Figure 5.12, effective flocculation appears to have begun at a calcium concentration of $10 \mathrm{mM}$, which was followed by a denser floc formation when calcium concentration reached $15 \mathrm{mM}$. Based on only this information, a significant decrease in inactivation would be expected for 10 and $15 \mathrm{mM}$ samples. However, the $1-\mu \mathrm{m}$ experiment results showed no trend of reduction in UV irradiation efficiency with increasing calcium dose. One explanation to this situation could be that the particlemicrobe association was governed by attachment of microbes to particles on their own; however, this hypothesis contradicts the images in Figure 5.12 as they clearly indicate significant particle-association being reached after $10 \mathrm{mM}$ calcium 
concentration addition. Therefore, the most likely explanation for the observed trends in inactivation data would be the organic coating hypothesis: coating of bacterial cells with organic molecules (alginate in this case). Templeton et al. (2005) reported that when the inactivation levels of samples containing activated sludge flocs (largest in size) were compared with those of samples containing humic acid floc particles (highest absorbance), the humic acid floc particles were found to provide a higher rate of shielding to the target organisms (viruses). This was attributed to some form of coating that might have occurred such that the microbes were covered with humic acid particles. Due to the very high UV absorbance capacity of the humic acid, the organisms would be protected to a very high extent, if not completely, from UV light. Considering that all 1- $\mu \mathrm{m}$ Phase II experiments were conducted in the presence of 10 $\mathrm{mg} / \mathrm{L}$ alginate, it can be hypothesized that an organic coating of the bacterial cells by alginate may have governed the inactivation process. In such a case, regardless of the floc size or density achieved a significant difference in inactivation levels might not be seen over the range of UV doses tested.

Secondly, unlike Phase I where all curves had a shoulder segment, the shoulder effect was observed only for $0 \mathrm{mM}$ calcium experiment in Phase II; however, tailing was seen in all curves. This implies that readily destructible free swimming bacteria were likely present in 5,10 , and $15 \mathrm{mM}$ calcium samples. The reason why $0 \mathrm{mM}$ calcium experiment showed no shoulder effect while other experiments of Phase II did is unknown. The tails observed indicate a high possibility of the presence of completely protected microbes. 
Thirdly, the fluctuations in inactivation levels over $120 \mathrm{~mJ} / \mathrm{cm}^{2} \mathrm{UV}$ dose were observed for three experiments out of four with the highest difference occurring in the $15 \mathrm{mM}$ case. If as claimed by Blatchley et al. (2001) irradiation causes bacteria to form aggregates, then these aggregates might well be stronger when more favourable conditions are available for aggregation (such as a higher concentration of flocculating agents). Therefore, stronger aggregates formed this way would be, firstly more difficult to inactivate and secondly harder to break apart during vortex mixing.

\subsubsection{1- $\mu \mathrm{m}$ Experiments}

The inactivation results of $11-\mu \mathrm{m}$ experiments of Phase II are shown in Figure 5.13. The data points on the figure represent the average of three replicates and the error bars indicate standard deviation. Error bars which are not visible are smaller than the data point markers. In addition, images showing flocs formed under different conditions tested are given in Figure 5.14. These images were captured by the particle counter during size analyses. 


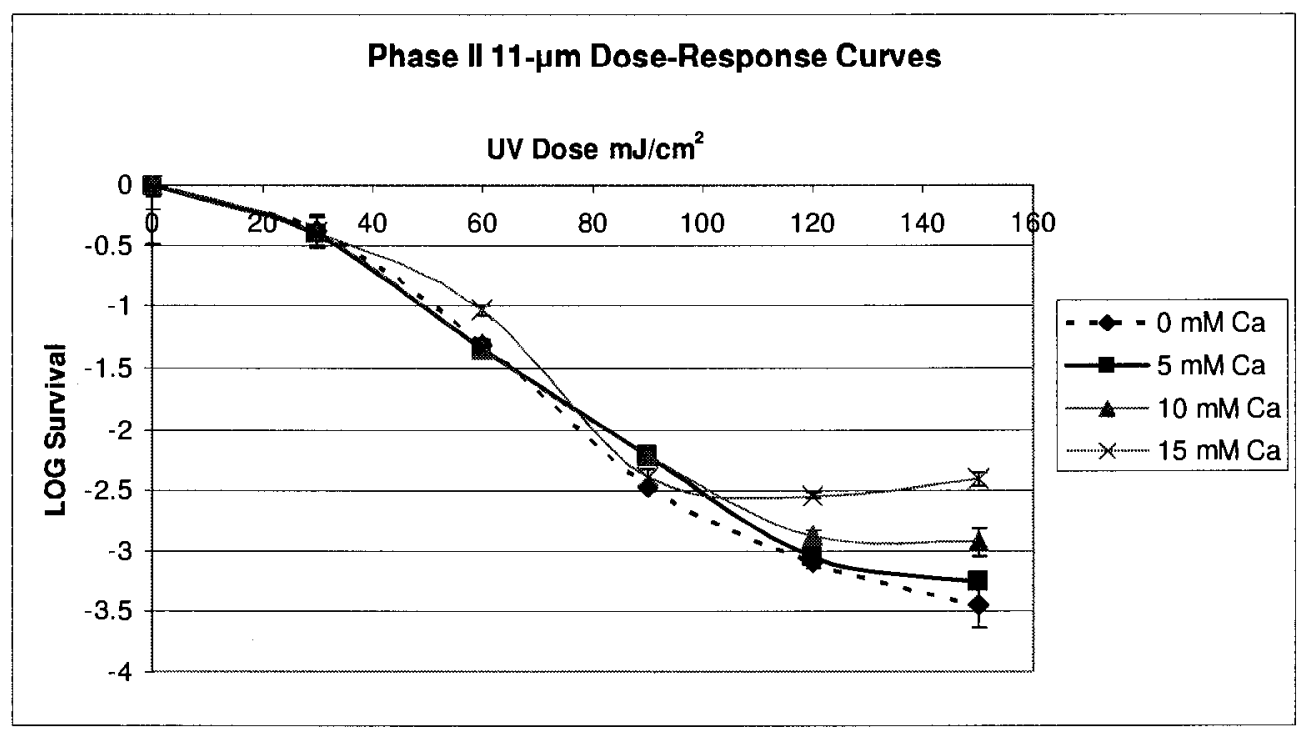

Figure 5.13: Phase-II UV inactivation experiments with $11-\mu \mathrm{m}$ particles, $10 \mathrm{mg} / \mathrm{L}$ alginate and varying concentrations of calcium ions.
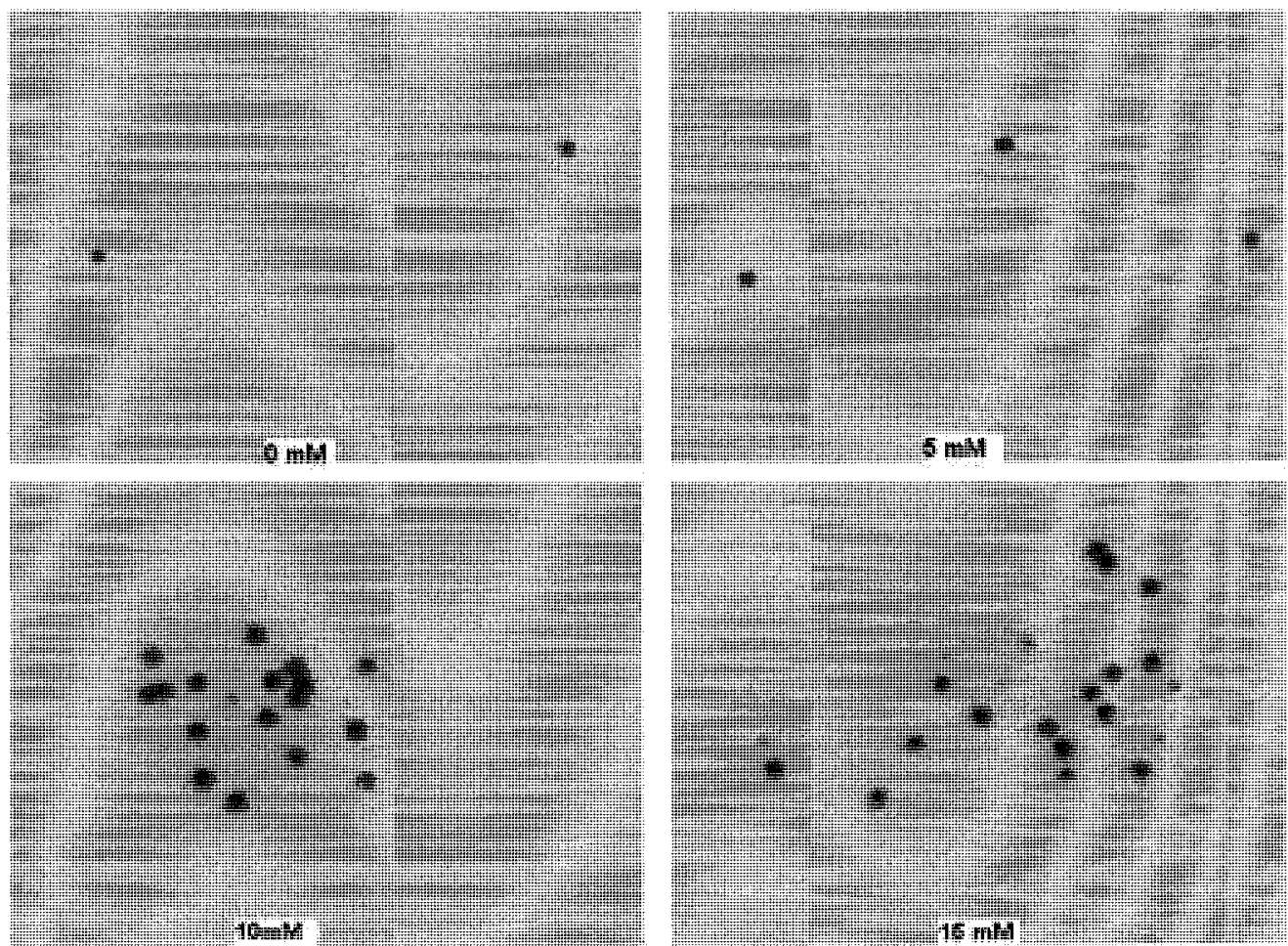

Figure 5.14 Flocs formed in 11- $\mu \mathrm{m}$ experiments of Phase II, flocculation conditions: $10 \mathrm{mg} / \mathrm{L}$ alginate and calcium doses as indicated on the figure. 
As can be seen in Figure 5.14, effective flocculation was observed to start at a calcium concentration of $10 \mathrm{mM}$ for $11-\mu \mathrm{m}$ experiments, as well. This observation is also in agreement with particle count and mean size data shown in Figures 5.8 and 5.9. Although variations to a certain extent can be seen, in general the dose-response curves provided in Figure 5.13 coincide with the floc/particle observations and suggest that higher particle-microbe association achieved when calcium concentration was increased resulted in higher survival rates. Furthermore, the difference in the rate of inactivation became more evident at higher UV doses; particularly at 120 and 150 $\mathrm{mJ} / \mathrm{cm}^{2}$ where the difference in inactivation between the most flocculated sample (15 $\left.\mathrm{mM} \mathrm{Ca}{ }^{2+}\right)$ and the least flocculated sample $\left(0 \mathrm{mM} \mathrm{Ca}^{2+}\right)$ reached a maximum of 1.04 log. This suggests that the majority of the bacteria may have not been attached or partially attached to the particles, and that only at higher doses fully embedded microbes began to limit the overall level of inactivation (Templeton et al., 2005).

Shoulder and tailing effects were observed for all curves presented in Figure 5.13. The shoulder segments (until $30 \mathrm{~mJ} / \mathrm{cm}^{2}$ ) of the curves followed the exact same trend which implies that the bacteria being inactivated up until a dose of $30 \mathrm{~mJ} / \mathrm{cm}^{2}$ may have mostly been self-aggregated and dispersed bacteria, and essentially not the ones deeply associated with particles. Another implication of the inactivation data is that all the curves followed similar first-order inactivation kinetics up until UV doses of $120 \mathrm{~mJ} / \mathrm{cm}^{2}$, except for the $15 \mathrm{mM} \mathrm{Ca}^{2+}$ curve which started tailing at $90 \mathrm{~mJ} / \mathrm{cm}^{2}$. This observation can be attributed to the presence of microbes that were attached on the particle surfaces, in which case a significant degree of shielding would not be expected. At very high doses of UV, on the other hand, the surviving bacteria are predicted to be those that were completely protected from UV light by being 
embedded in the flocs. Therefore, it can be concluded that for 11- $\mu \mathrm{m}$ particles complete shielding effect was observed only with flocs achieved at calcium doses of 10 and $15 \mathrm{mM}$, as indicated by the strong tailing effects, and the ratio of completely shielded bacteria is likely to increase with increased flocculation.

\subsubsection{5- $\mu \mathrm{m}$ Experiments}

The inactivation results of $45-\mu \mathrm{m}$ experiments of Phase II are shown in Figure 5.15. The data points on the figure represent the average of three replicates and the error bars indicate standard deviations. Error bars which are not visible are smaller than the data point markers. In addition, images showing flocs formed under different conditions tested are given in Figure 5.16. These images were captured by the particle counter during size analyses.

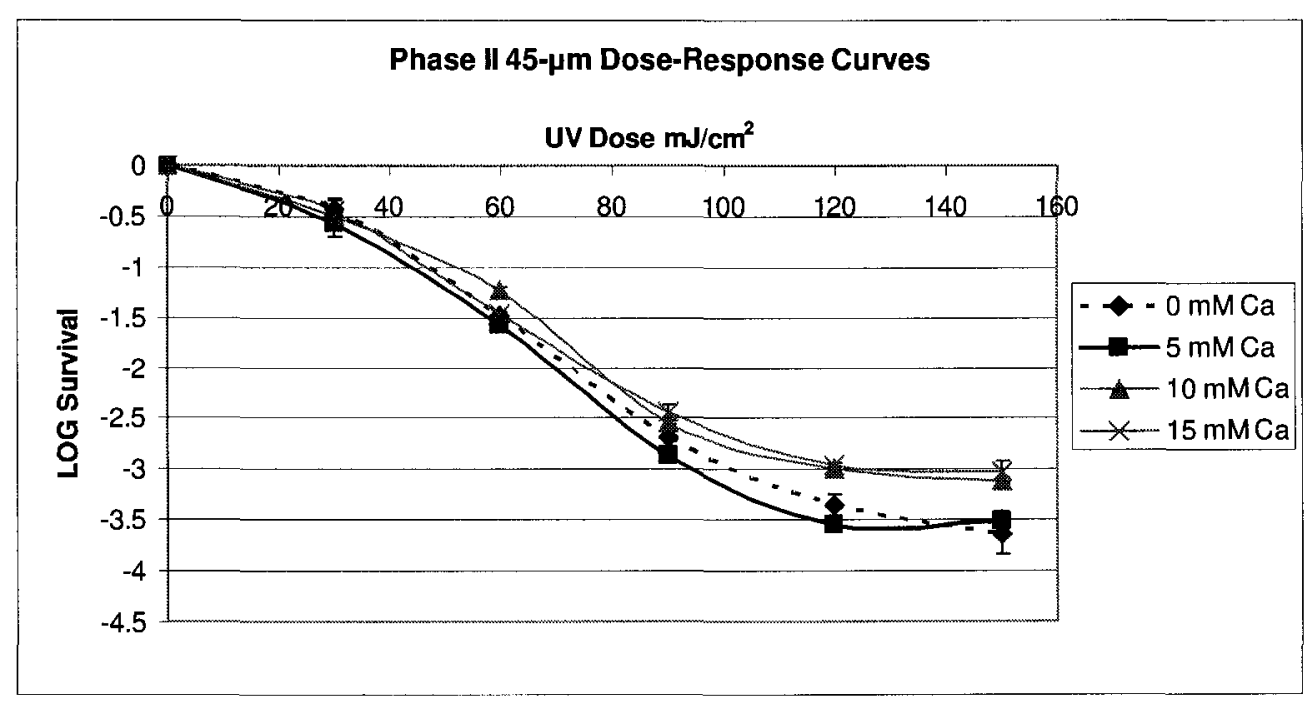

Figure 5.15: Phase-II UV inactivation experiments with $45-\mu \mathrm{m}$ particles, $10 \mathrm{mg} / \mathrm{L}$ alginate and varying concentrations of calcium ions. 



Figure 5.16: Flocs formed in 45- $\mu \mathrm{m}$ experiments of Phase II, flocculation conditions: $10 \mathrm{mg} / \mathrm{L}$ alginate and calcium doses as indicated on the figure.

The $45-\mu \mathrm{m}$ experiments of Phase II provided results very similar to those of $11-\mu \mathrm{m}$ experiments. As can be seen in Figure 5.15, the log survival curves of the four different experiments showed similar patterns of inactivation rate up until a dose of 90 $\mathrm{mJ} / \mathrm{cm}^{2}$ from this point on 10 and $15 \mathrm{mM} \mathrm{Ca}^{2+}$ curves depicted complete shielding assets as implied by the strong tailing effect. The 0 and $5 \mathrm{mM} \mathrm{Ca}^{2+}$ curves also demonstrated tailing effects; however, at a relatively lower extent. In addition, these $\log$ survival rates provided evidence for the hypothesis that the ratio of completely shielded microbes would be higher for the more flocculated samples (10 and $15 \mathrm{mM}$ $\left.\mathrm{Ca}^{2+}\right)$ as compared to less flocculated samples $\left(0\right.$ and $\left.5 \mathrm{mM} \mathrm{Ca}^{2+}\right)$. These observations are in agreement with the floc/particle analyses shown in Figures 5.8, 5.9, and 5.16. 


\subsubsection{Phase II Comparison of 1-, 11-, and 45- $\mu \mathrm{m}$ Experiments}

The following figures (Figure 5.17 through 5.20) are provided for the comparison of Phase II experiments. The figures are arranged in a way so that under same conditions of flocculation (same amount of alginate and calcium) the inactivation trends of different sized particles can be compared.

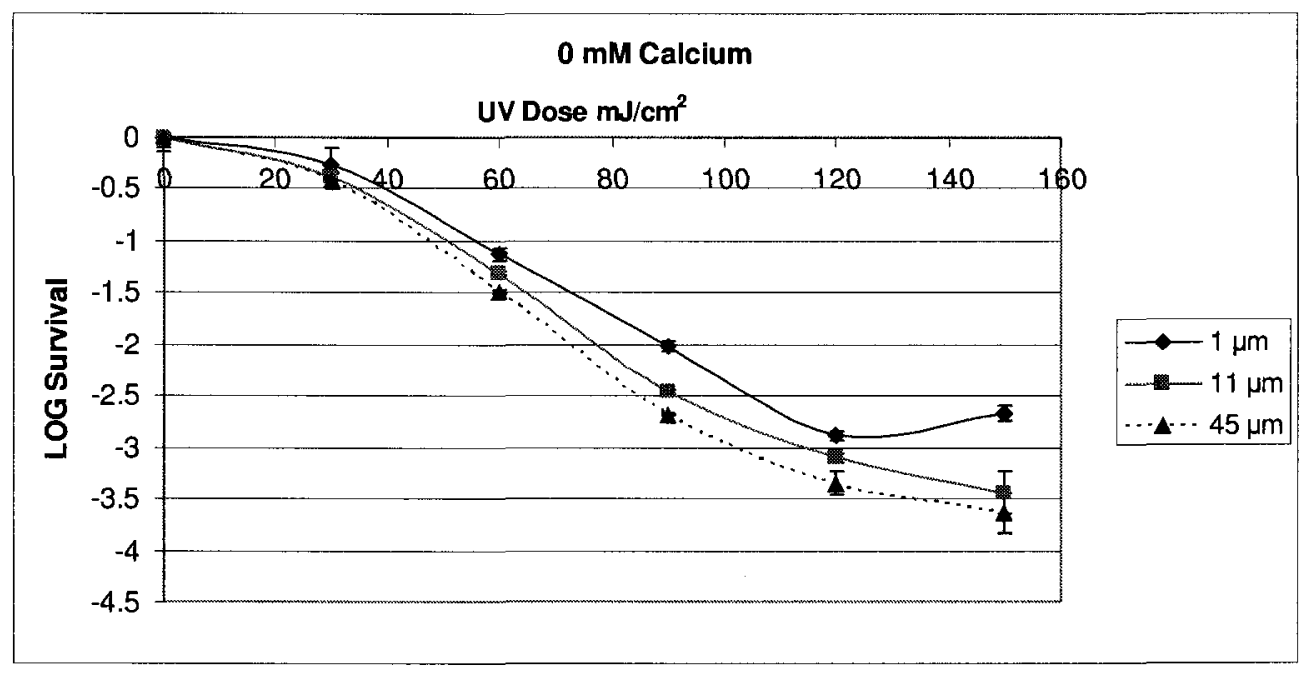

Figure 5.17: Phase II dose-response curves in the absence of calcium and at $10 \mathrm{mg} / \mathrm{L}$ alginate. 


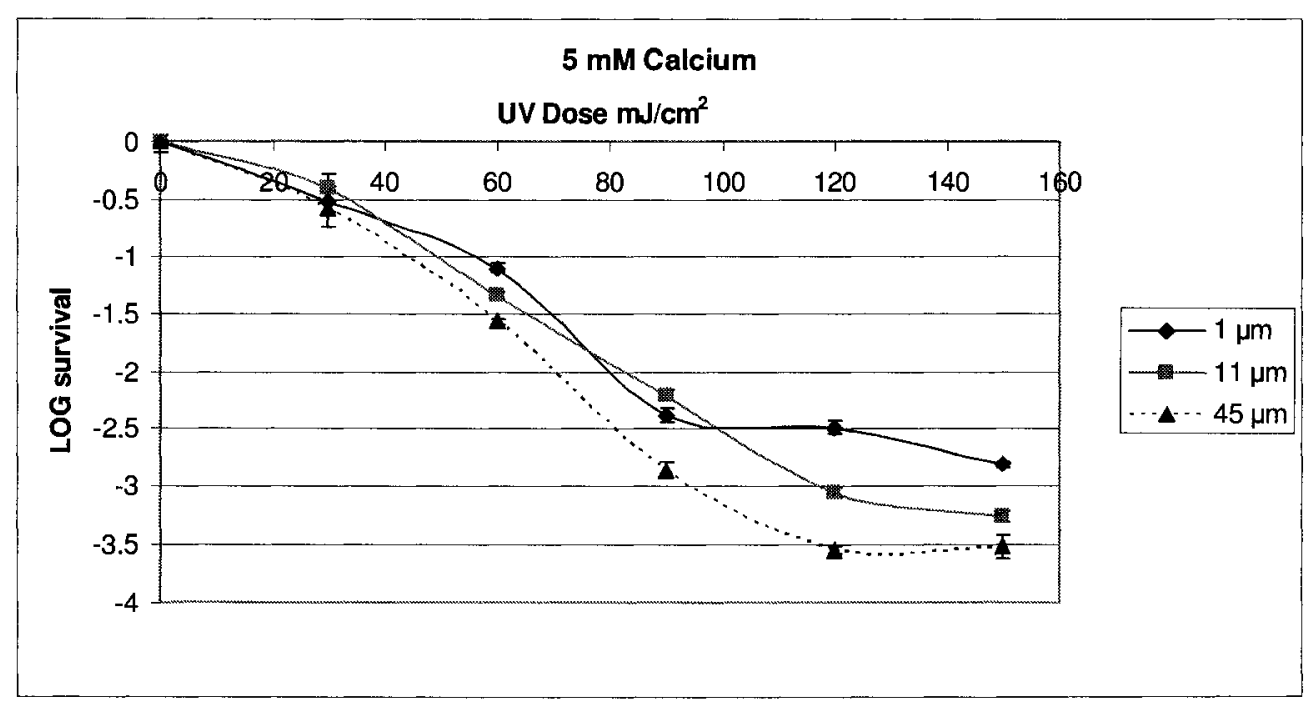

Figure 5.18: Phase II dose-response curves at a calcium concentration of $5 \mathrm{mM}$ and an alginate concentration of $10 \mathrm{mg} / \mathrm{L}$.

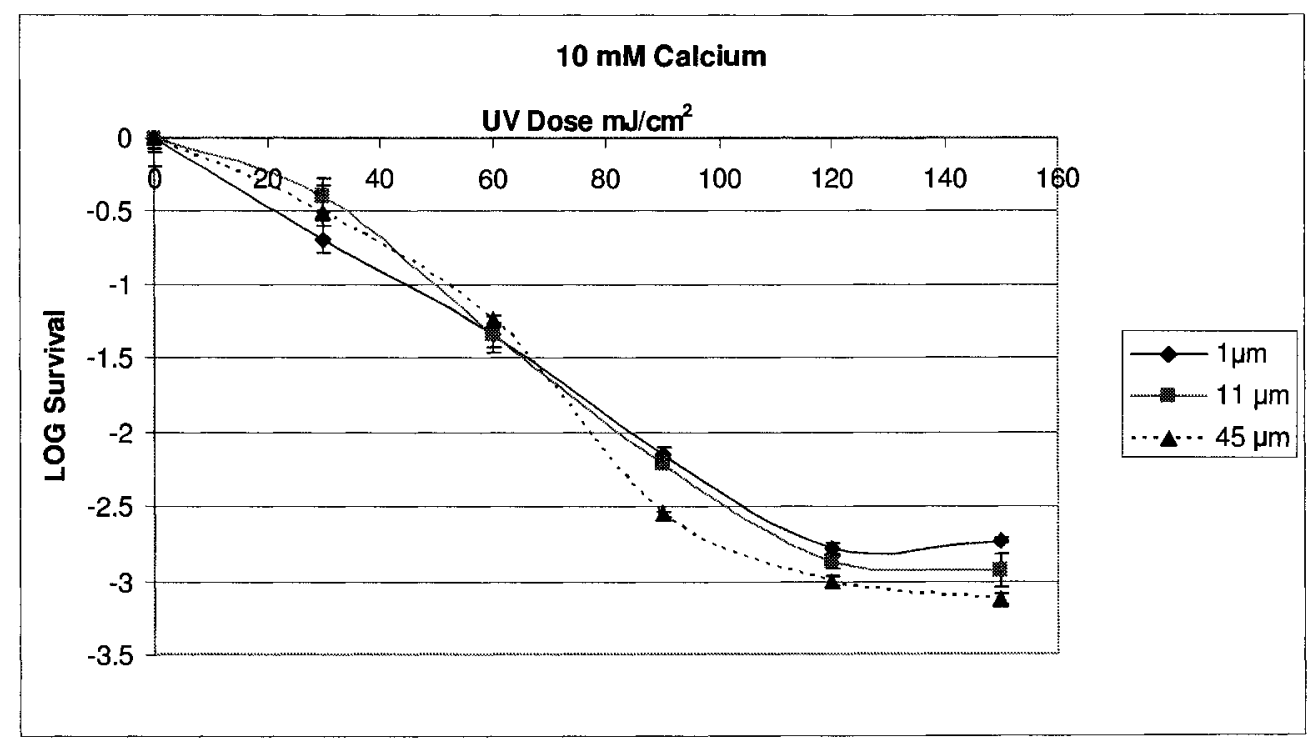

Figure 5.19: Phase II dose-response curves at a calcium concentration of $10 \mathrm{mM}$ and an alginate concentration of $10 \mathrm{mg} / \mathrm{L}$. 


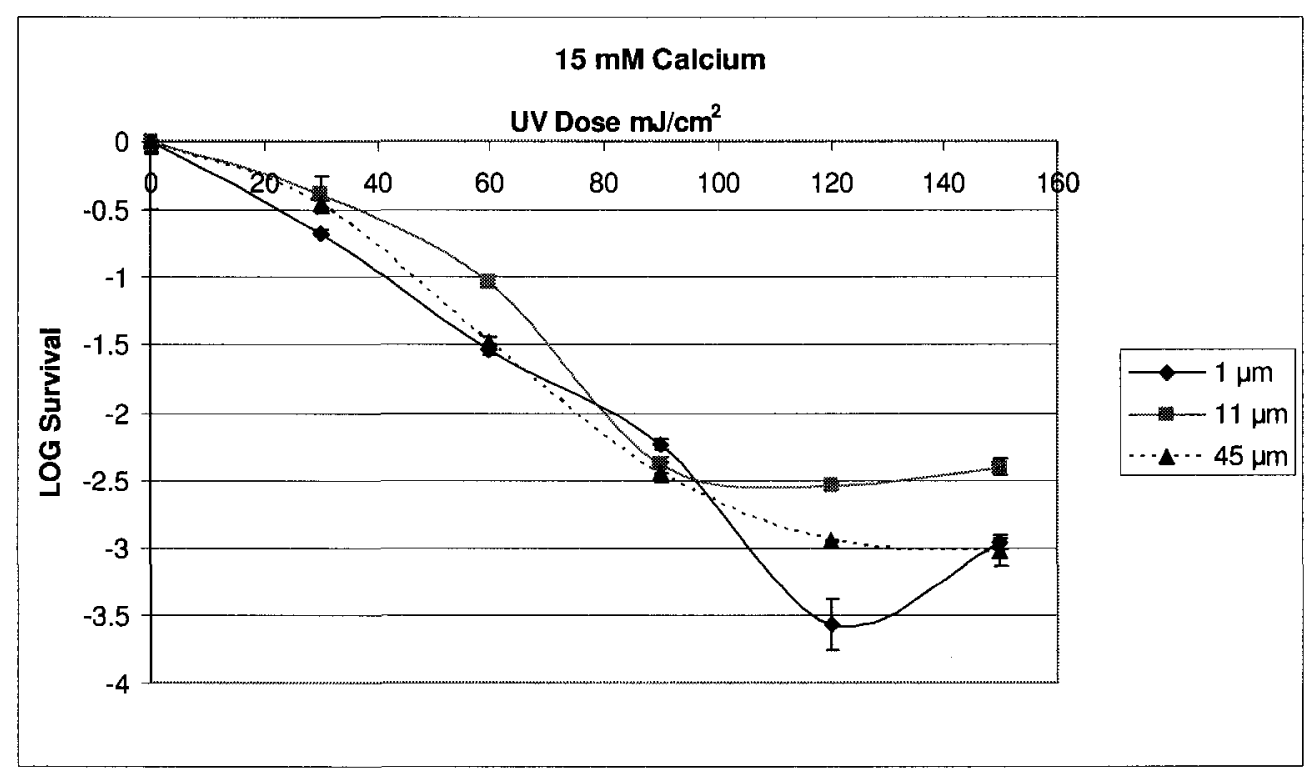

Figure 5.20: Phase II dose-response curves at a calcium concentration of $15 \mathrm{mM}$ and an alginate concentration of $10 \mathrm{mg} / \mathrm{L}$.

As shown in Figures 5.17 through 5.20 the general trend observed in Phase I (i.e., less inactivation with smaller particles) was also persistent when flocculation was induced. Except for the case of 15-mM-calcium-experiments all dose-response curves indicated a trend of decreasing inactivation with decreasing particle size. The variation in the results of the 15 -mM-calcium-experiments might have been due to the larger degree of flocculation achieved. As explained in the previous sections, the trends observed in $1-\mu \mathrm{m}$ experiments of Phase II were significantly different than those observed in 11 - and $45-\mu \mathrm{m}$ experiments. This suggests that particle-association through flocculation may have become more effective in shielding bacteria at this level of flocculation ( $15 \mathrm{mM}$ calcium) than other mechanisms of shielding that were effective in 1- $\mu \mathrm{m}$ samples such as organic coating. This is further supported by the fact that the differences in the levels of inactivation achieved in the $10 \mathrm{mM}$ calcium case (Figure 5.19) were less significant than 0 and $5 \mathrm{mM}$ calcium cases (Figures 5.17 and 5.18). 


\subsection{Phase III: Effect of Alginate Dose on Flocculation and UV Inactivation}

Phase III of the project consisted of four sets of experiments focusing on the effect of extracellular polymers (alginate), floc size, structure, and composition on UV disinfection. The first set of experiments was performed in the absence of both particles and calcium in order to evaluate the impact of alginate alone on UV inactivation of E. coli. In the remaining sets of experiments of Phase III, bacteria and the particles were aggregated by adding a fixed amount of calcium (10mM), and four different concentrations of alginate $(0,10,20$, and $40 \mathrm{mg} / \mathrm{L})$, so that the variation in the bioflocculation process and the floc characteristics were achieved by changing the alginate concentration this time. In Phase II, the alginate concentration was kept fixed $(10 \mathrm{mg} / \mathrm{L})$ and the calcium concentrations were varied $(0,5,10$, and $15 \mathrm{mM})$. It was expected that the floc structures formed in Phase II and Phase III would be different even when the floc sizes were similar.

Phase III results will be discussed in three sections focusing on particle-free experiments, particle experiments, and comparative analysis of particle experiments.

\subsubsection{Particle Free-Varying Alginate Experiments}

The very first experiments of Phase III concentrated on the effects of alginate on UV inactivation by conducting irradiation experiments on particle free solutions of bacteria and alginate. The alginate (EPS) may affect the achievable level and rate of UV disinfection in a medium by promoting self-aggregation and organic coating of bacterial cells. In addition, as shown in Figure 5.21 alginate addition increases the UV 
absorbance of the bulk solution and may reduce the UV dose delivered to the target microorganisms.

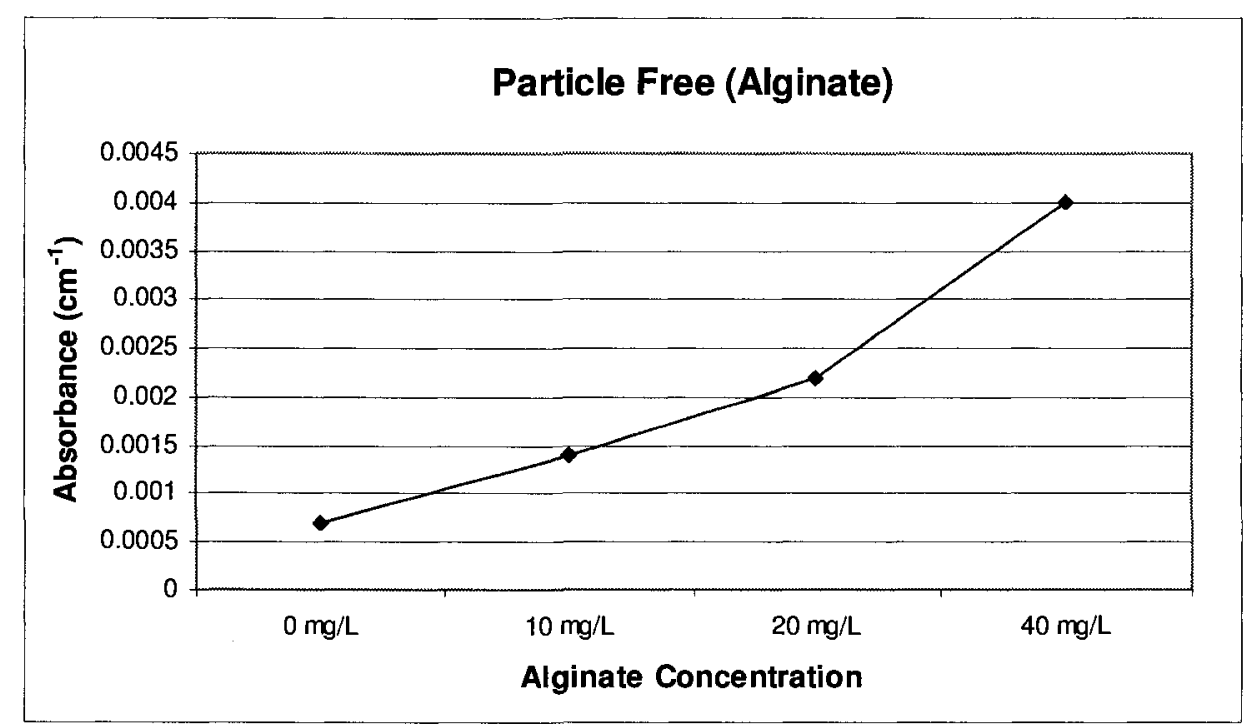

Figure 5.21: Absorbance of the samples measured at $254 \mathrm{~nm}$ when different concentrations of alginate were added to particle-free suspensions of bacteria.

The dose-response curves of particle-free-varying-alginate-concentration experiments are provided in Figure 5.22. Each data point on the figure indicates the mean of three replicates and the error bars stand for standard deviation. Error bars which are not visible are smaller than the data point markers. These samples contained alginate and E. coli only, and no particles. 


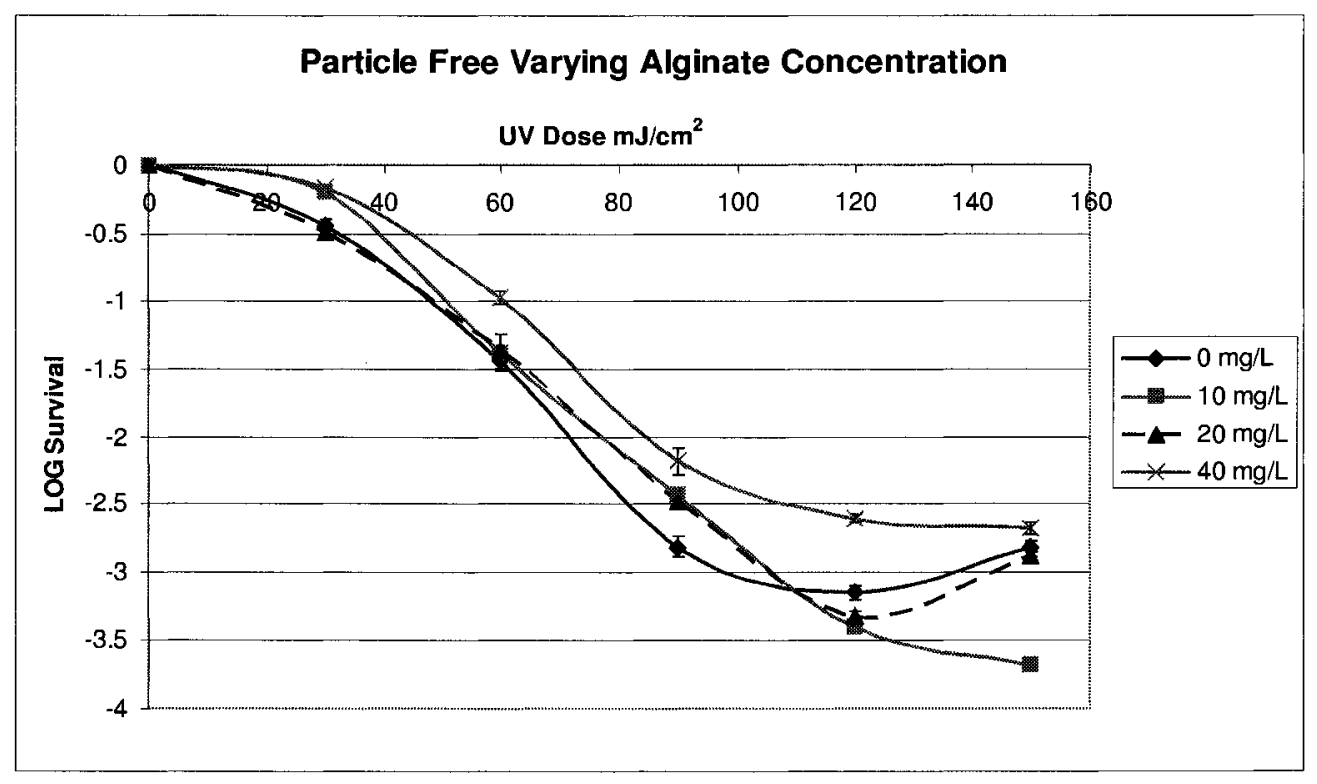

Figure 5.22: Phase III dose-response curves of particle \& calcium free solutions containing varying concentrations of alginate $(0$ to $40 \mathrm{mg} / \mathrm{L})$.

As can be seen in Figure 5.22, the shoulder and tailing effects were observed in all curves at varying degrees, which is a strong indication of shielding of microbes from UV irradiation in the form of organic coating and/or a promoted bacterial aggregation. Furthermore, the fact that strong tailing was observed (for instance, $40 \mathrm{mg} / \mathrm{L}$ alginate experiment) even when the medium was particle-free, supports the hypothesis that clumping of bacteria and organic coating can provide sufficient shielding protecting bacteria even from very high doses of UV light.

Another main implication of the dose-response curves given in Figure 5.22 is that higher alginate concentrations led to higher survival rates although this trend appeared to show some variation at higher doses of UV, where tailing began. Nonetheless, the variations observed at higher doses of UV could be due to the counteracting effects of alginate on inactivation and possibly on enumeration as well. It can be hypothesized that as alginate concentration is increased more aggregation and coating of bacteria 
would be achieved which in turn would result in lower levels of inactivation. Also, if as reported by Blatchley et al. (2001) irradiation promotes formation of bacterial aggregates, it is likely that more aggregates would be formed in presence of EPS. On the other hand, a higher level of bacterial aggregation may theoretically lead to an underestimation of bacterial counts; however because vortex mixing was used to break up these aggregates before enumeration, this is not expected to have a significant effect on results.

\subsubsection{UV Inactivation Experiments in Presence of particles}

The results of 1-, 11-, and 45- $\mu \mathrm{m}$ experiments of Phase III will be discussed together as the observed trends are in agreement with each other among all three sets. Particle count, mean size, and absorbance analyses are shown in Figure 5.23 through 5.25.

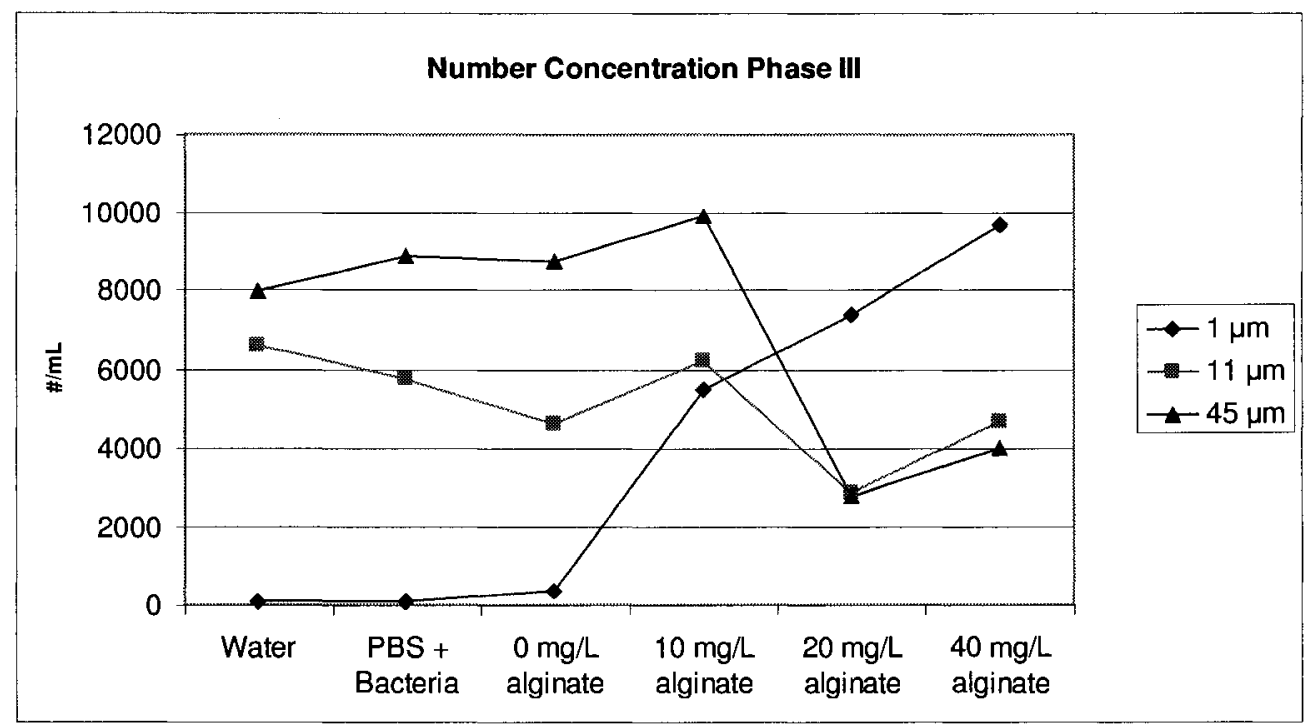

Figure 5.23: Particle number concentrations measured (particles $>5 \mu \mathrm{m}$ ) for the conditions studied in Phase III. 


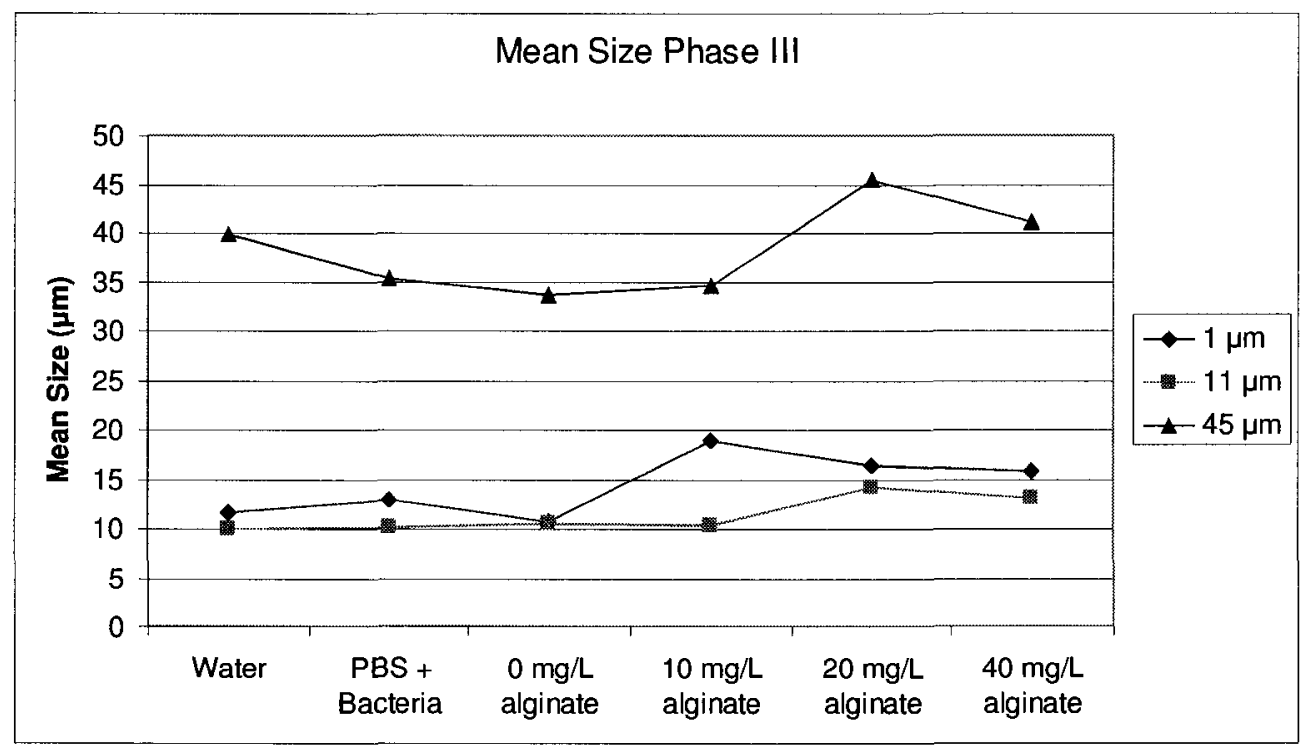

Figure 5.24: Particle mean size values measured (particles $>5 \mu \mathrm{m}$ ) for the conditions studied in Phase III.

The particle number concentration data showed parallel patterns for the 11- and 45$\mu \mathrm{m}$ samples, and an increasing trend for the 1- $\mu \mathrm{m}$ samples. As explained in Section 5.4, the difference observed for the $1-\mu \mathrm{m}$ samples originated from the fact that these plots were made excluding particles less than $5 \mu \mathrm{m}$ in size, therefore a constant increase in number of particles larger than $5 \mu \mathrm{m}$ was merely an indication of flocculation and organic coating of $1-\mu \mathrm{m}$ particles. The decreases observed in 11 - and $45-\mu \mathrm{m}$ samples were matched by increases in mean size as a direct outcome of flocculation, and the sharp decrease observed at the $20 \mathrm{mg} / \mathrm{L}$ alginate indicated a radical increase in the flocculation rate. Similar to the data obtained in Phase II, Figures 5.23 and 5.24 imply that once a significant degree of flocculation was achieved, the size and number concentration characteristics of the samples also changed significantly. Furthermore, the extent of change was different for different particle sizes such that the mean size of a suspension containing 1- $\mu \mathrm{m}$ particles was observed to be larger than that of a suspension containing $11-\mu \mathrm{m}$ particles when high 
concentrations of alginate were present. The fact that the number of entities counted having sizes larger than $5 \mu \mathrm{m}$ was also higher in $1-\mu \mathrm{m}$ samples compared to $11-\mu \mathrm{m}$ samples at high concentrations of alginate ( 20 and $40 \mathrm{mg} / \mathrm{L}$ ) provides further evidence as to how much variability there may have been in floc structure, size, and composition among the samples.

Figure 5.25 shows the absorbance values measured for each particle suspension. As the alginate concentration of the samples increased, their UV absorbance increased as well. Similar to the observations in Phase II, the UV absorbance of the samples containing the $45-\mu \mathrm{m}$ particles were higher compared to the 1 - and $11-\mu \mathrm{m}$ particle samples. This might partly be due to the higher backscattering of light in presence of larger particles that could be measured as absorbance.

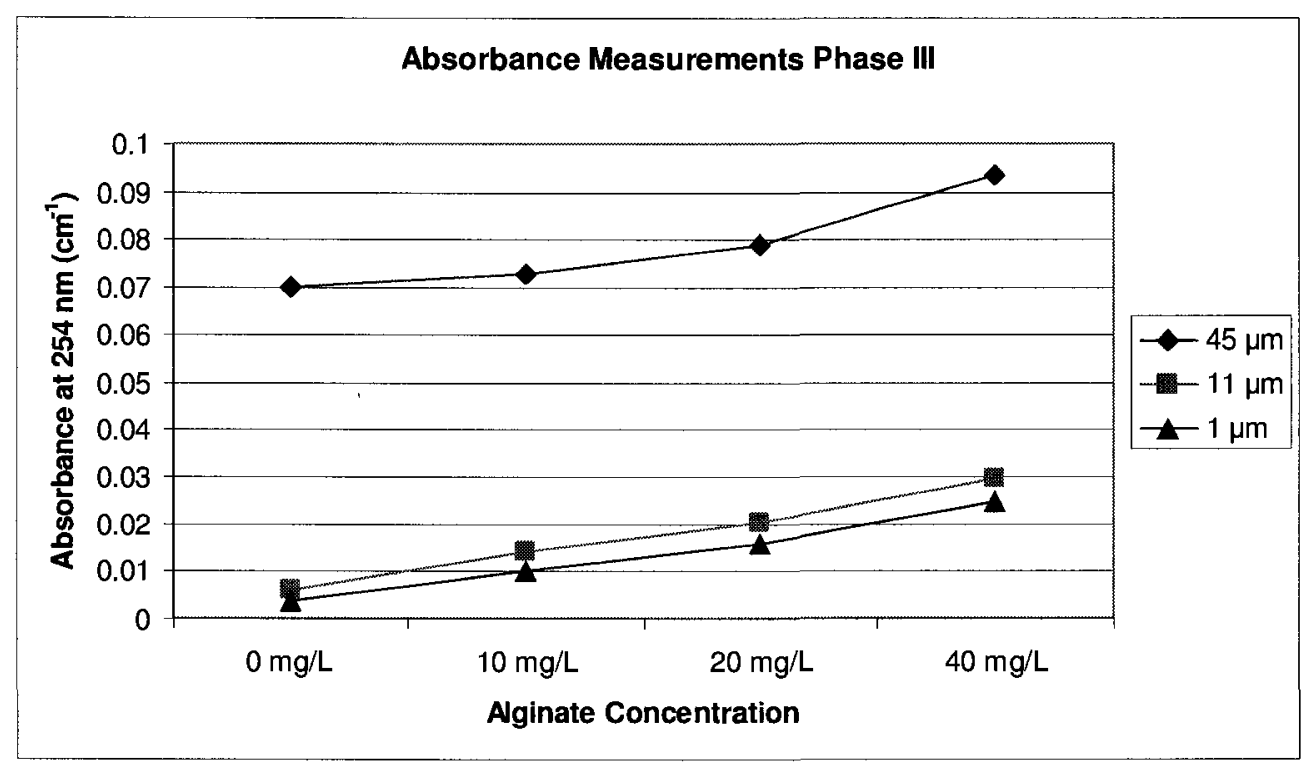

Figure 5.25: Absorbance values measured at $254 \mathrm{~nm}$ for conditions studied in Phase III. 
The dose-response curves of Phase III are given in Figures 5.26 through 5.28, each data point on the dose-response figures represents the average of three replicates and the error bars show the standard deviation. Error bars which are not visible are smaller than the data point markers. In addition, images showing flocs formed under different conditions tested are given in Figures 5.29 through 5.31. These images were captured by the particle counter during size analyses.

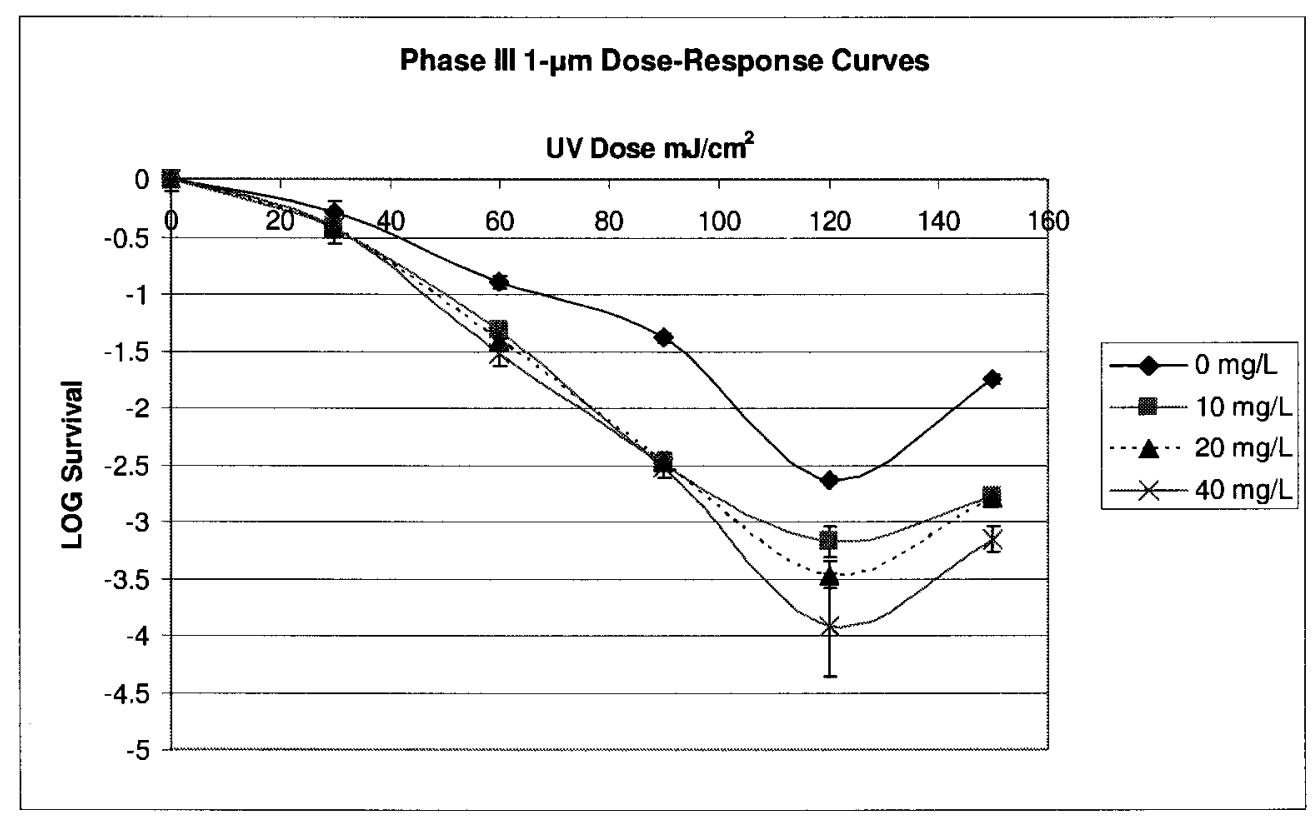

Figure 5.26: Phase III dose-response curves of 1- $\mu \mathrm{m}$ experiments at a calcium concentration of $10 \mathrm{mM}$ and varying concentrations of alginate ( 0 to $40 \mathrm{mg} / \mathrm{L}$ ). 


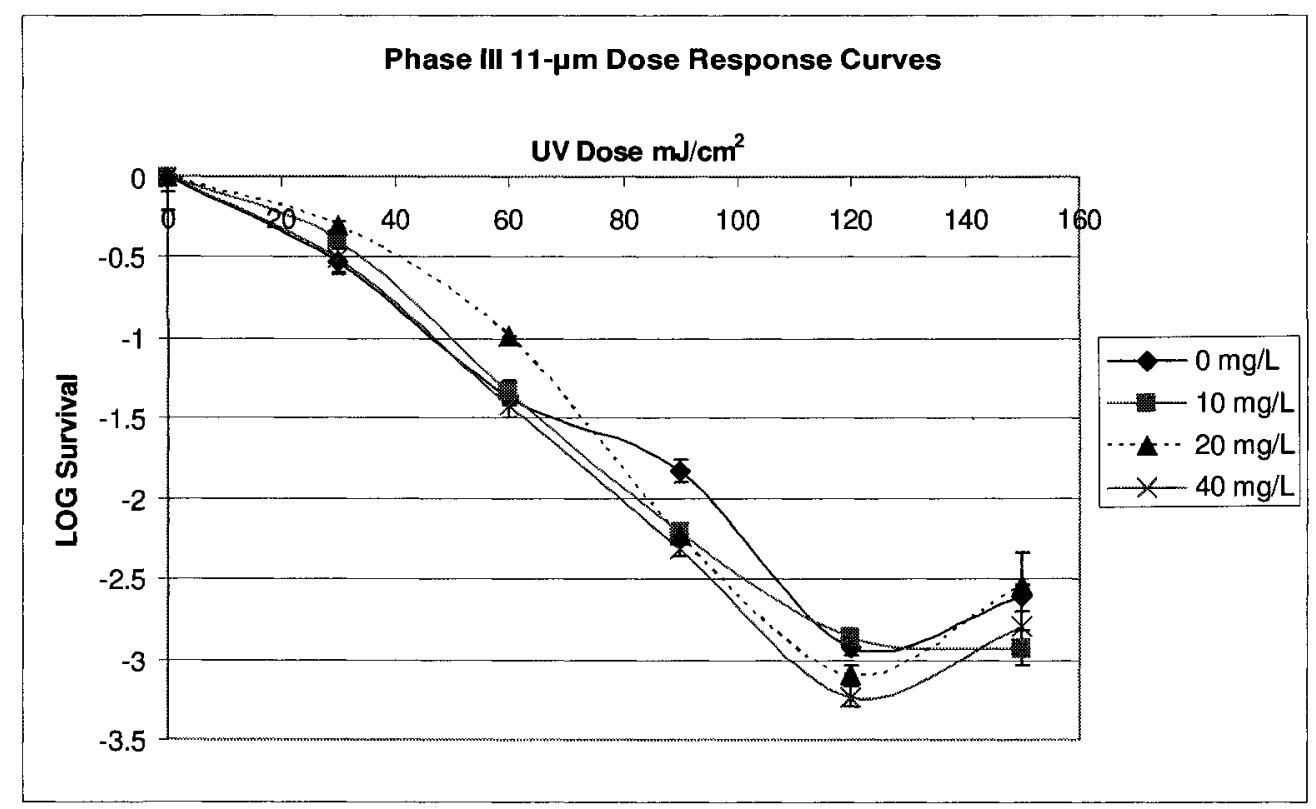

Figure 5.27: Phase III dose-response curves of $11-\mu \mathrm{m}$ experiments at a calcium concentration of $10 \mathrm{mM}$ and varying concentrations of alginate ( 0 to $40 \mathrm{mg} / \mathrm{L}$ ).

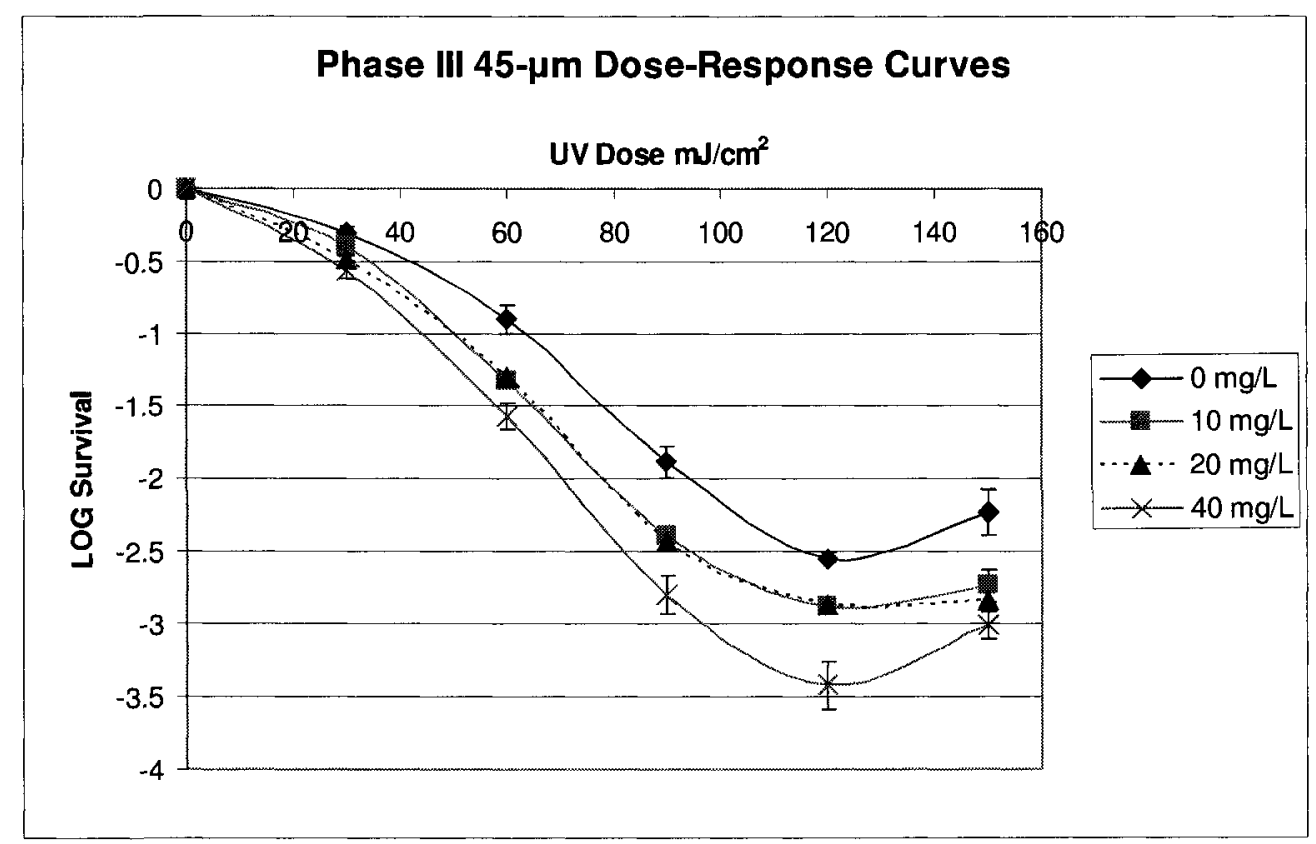

Figure 5.28: Phase III dose-response curves of $45-\mu \mathrm{m}$ experiments at a calcium concentration of $10 \mathrm{mM}$ and varying concentrations of alginate ( 0 to $40 \mathrm{mg} / \mathrm{L}$ ). 

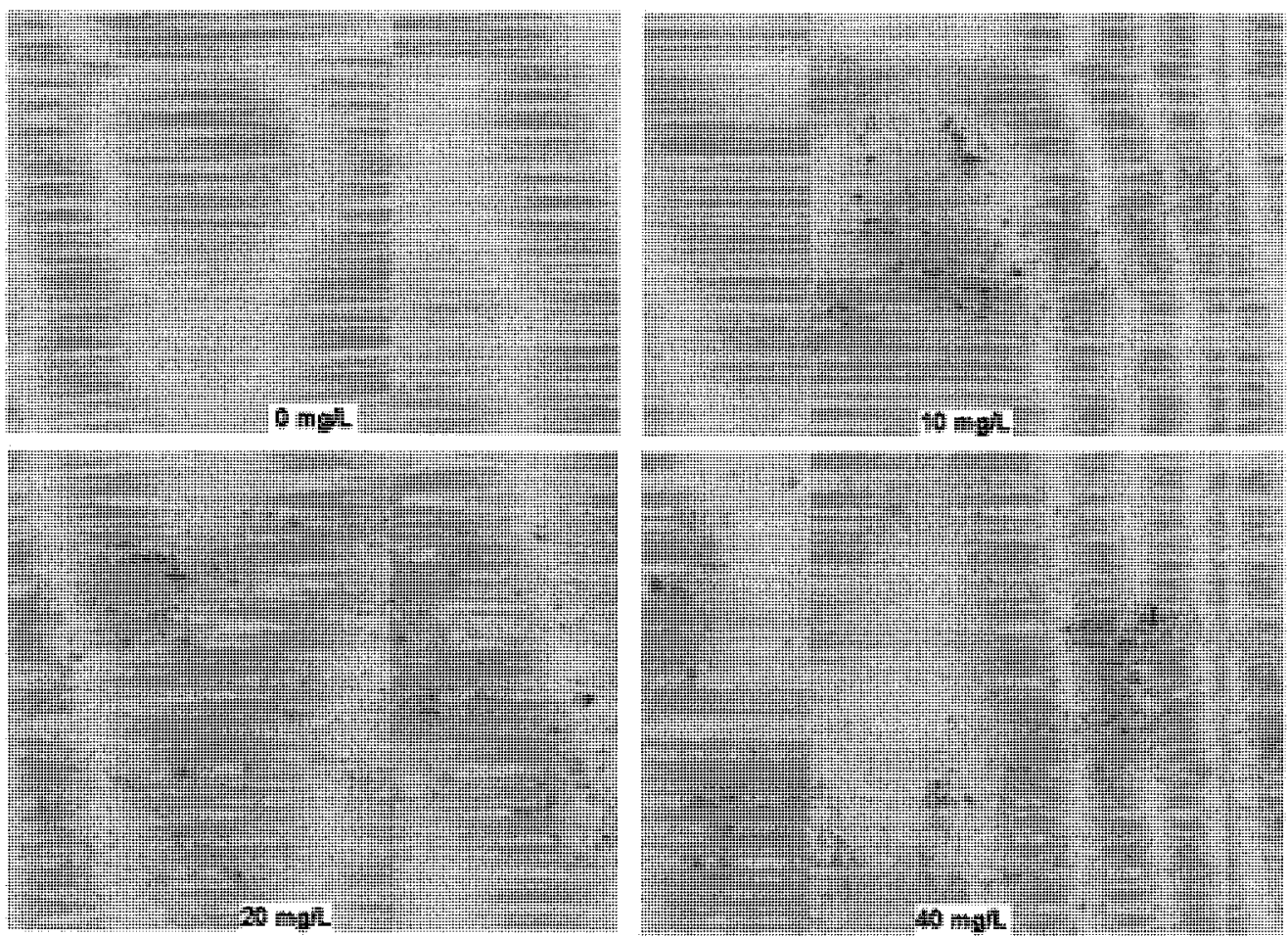

Figure 5.29: Flocs formed in 1- $\mu \mathrm{m}$ experiments of Phase III, flocculation conditions: $10 \mathrm{mM}$ calcium and alginate concentration as indicated on the figure. 

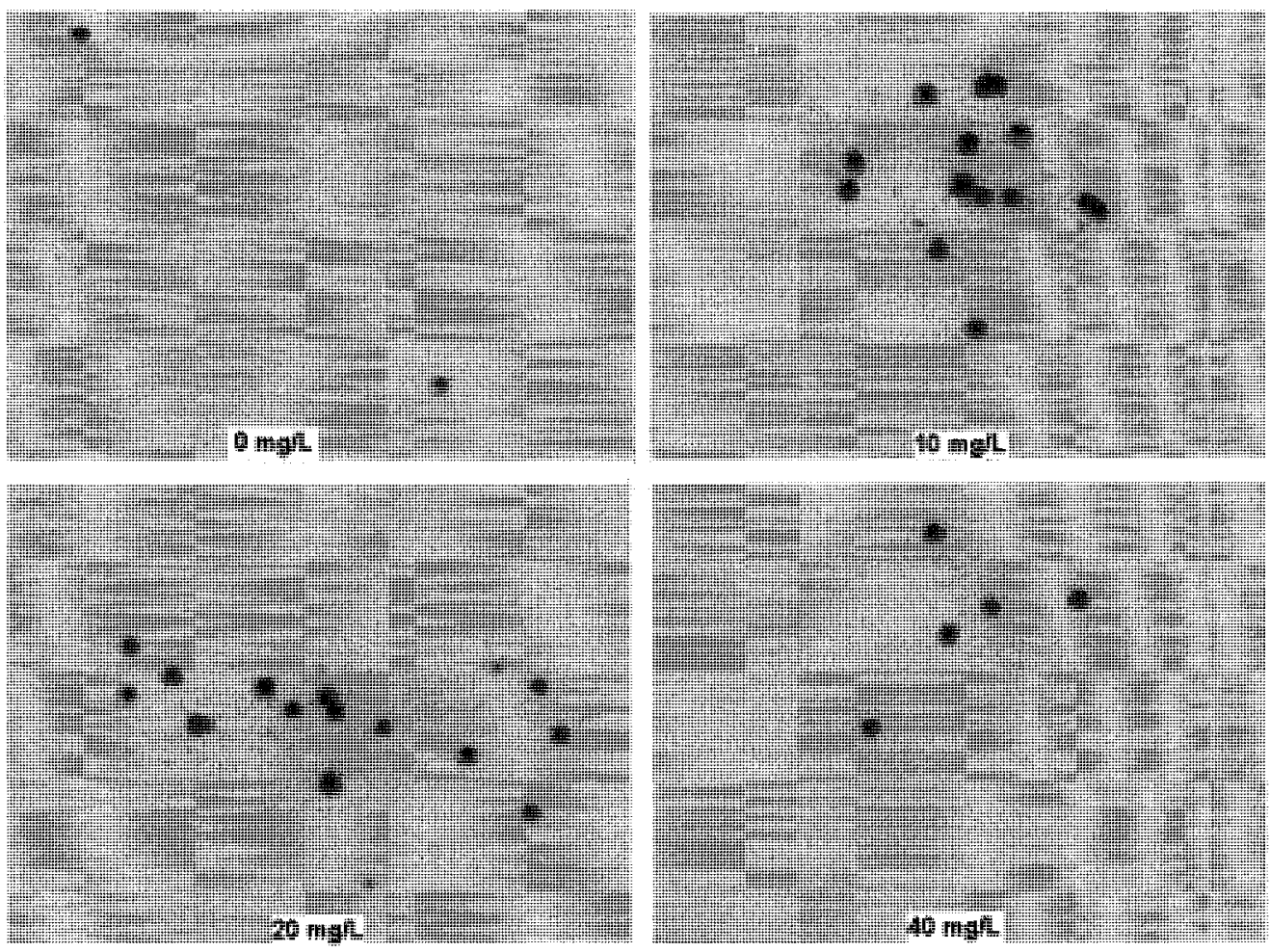

Figure 5.30: Flocs formed in $11-\mu \mathrm{m}$ experiments of Phase III, flocculation conditions: $10 \mathrm{mM}$ calcium and alginate concentration as indicated on the figure. 

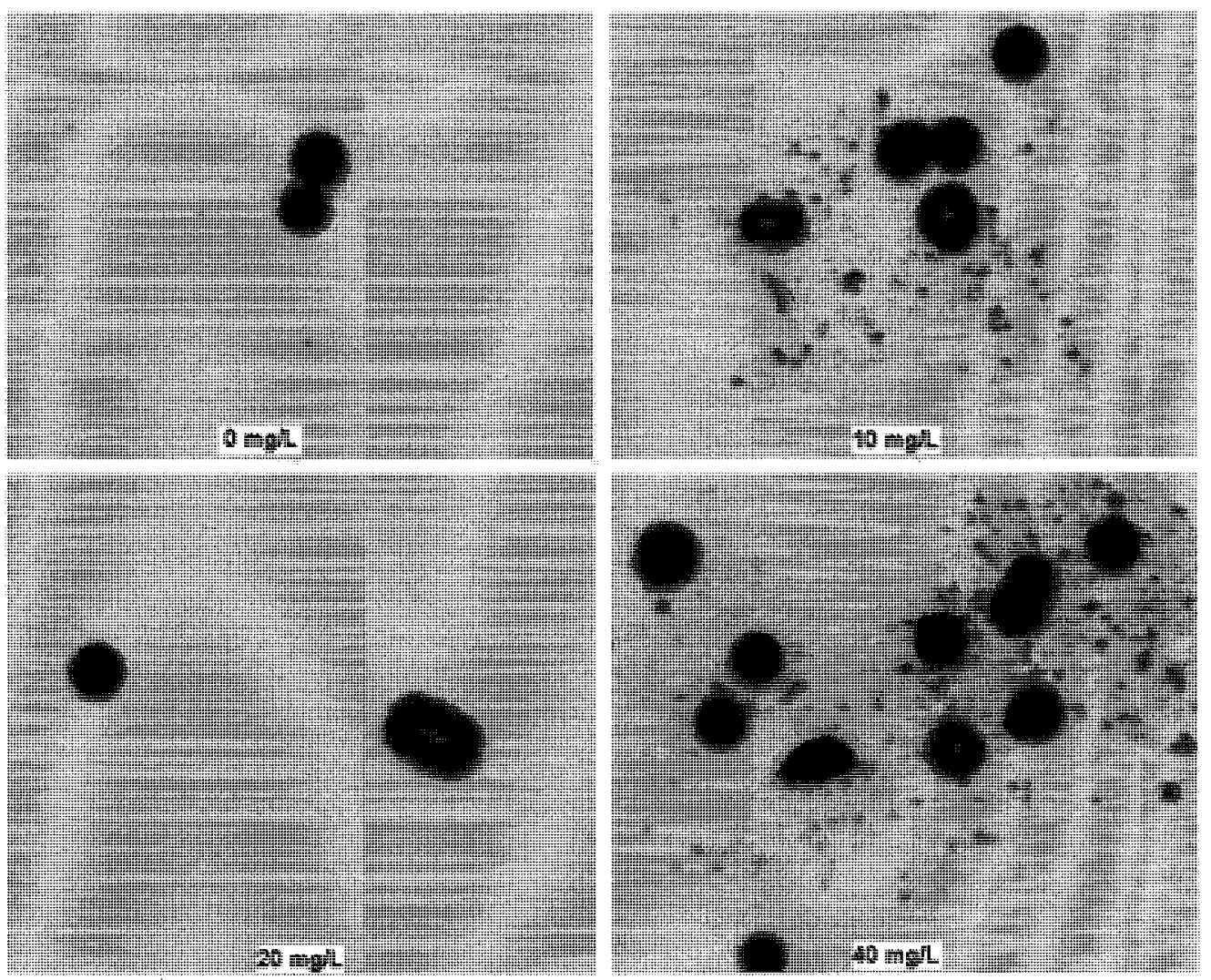

Figure 5.31: Flocs formed in $45-\mu \mathrm{m}$ experiments of Phase III, flocculation conditions: $10 \mathrm{mM}$ calcium and alginate concentration as indicated on the figure.

When floc images (Figures 5.29 through 5.31) are evaluated together with particle number concentration and mean size data (Figures 5.23 and 5.24) it can be concluded that $10 \mathrm{mg} / \mathrm{L}$ alginate concentration was sufficient for considerably large and dense floc formation. The image results also confirm that strong aggregation of bacteria and particles did not exist initially and started forming after alginate addition to the samples.

In contrary to the results of particle-free experiments with alginate (Figure 5.22), presence of particles in samples resulted in an increase in inactivation rates with increasing alginate concentration (Figures 5.26 through 5.28). The opposite trend 
observed between these experiments suggests that presence of particles changed the inactivation conditions completely. It is possible, for example, that particles and bacteria might have been competing for alginate such that in presence of particles there was less alginate available for coating of bacterial cells which would lead to higher inactivation rates. As particle size increases, when there are equal numbers of particles in samples, total particle surface area that can adsorb alginate would also increase. Finally, at high concentrations of alginate, it might also be more difficult to break up the aggregates during the deflocculation of samples.

\subsubsection{Phase III Comparison of 1-, 11-, and 45- $\mu \mathrm{m}$ Experiments}

For easier comparison purposes, the dose-response curves of particle experiments of Phase III are also plotted in a manner that the data corresponding to the same conditions of flocculation (same amount of alginate and calcium) are provided together. The plots are shown in Figures 5.32 through 5.35. 


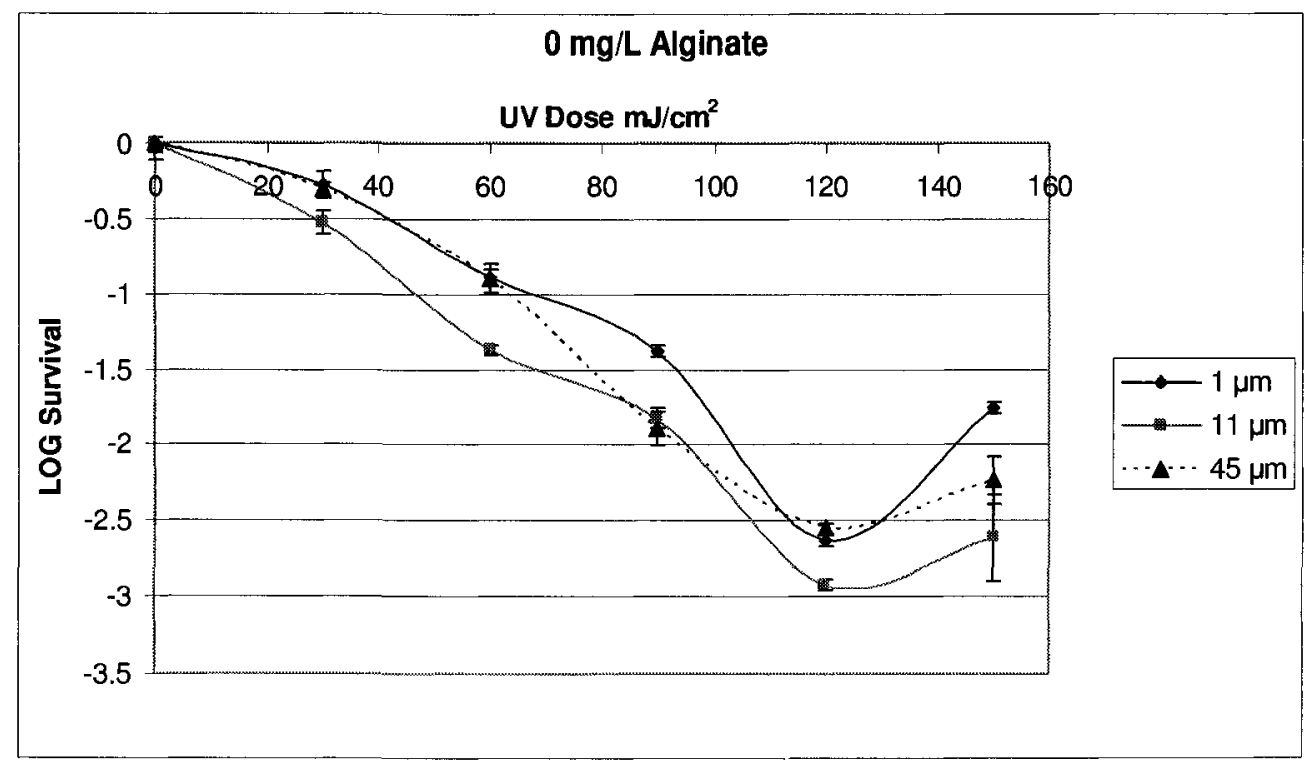

Figure 5.32: Phase III dose-response curves of particle-experiments at a calcium concentration of $10 \mathrm{mM}$ and in the absence of alginate.

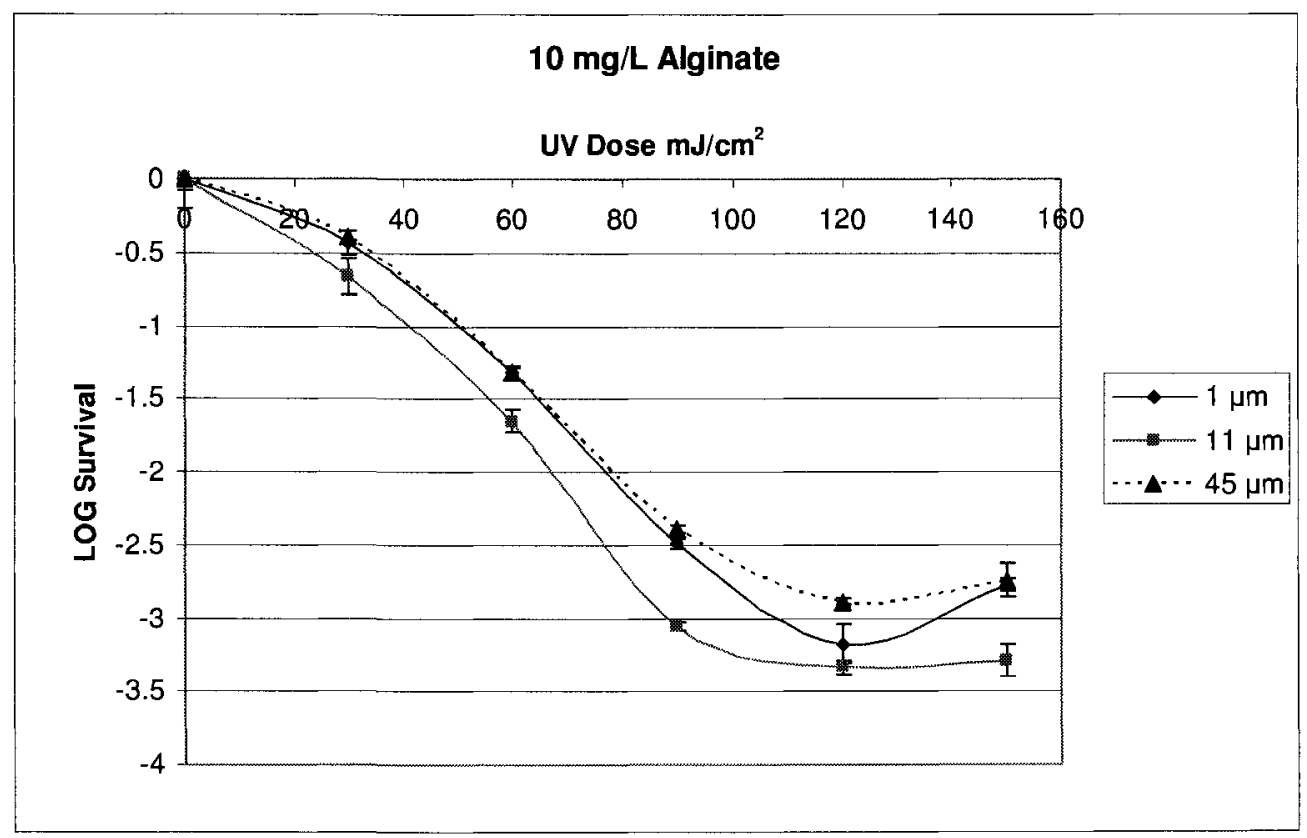

Figure 5.33: Phase III dose-response curves of particle-experiments at a calcium concentration of $10 \mathrm{mM}$ and an alginate concentration of $10 \mathrm{mg} / \mathrm{L}$. 


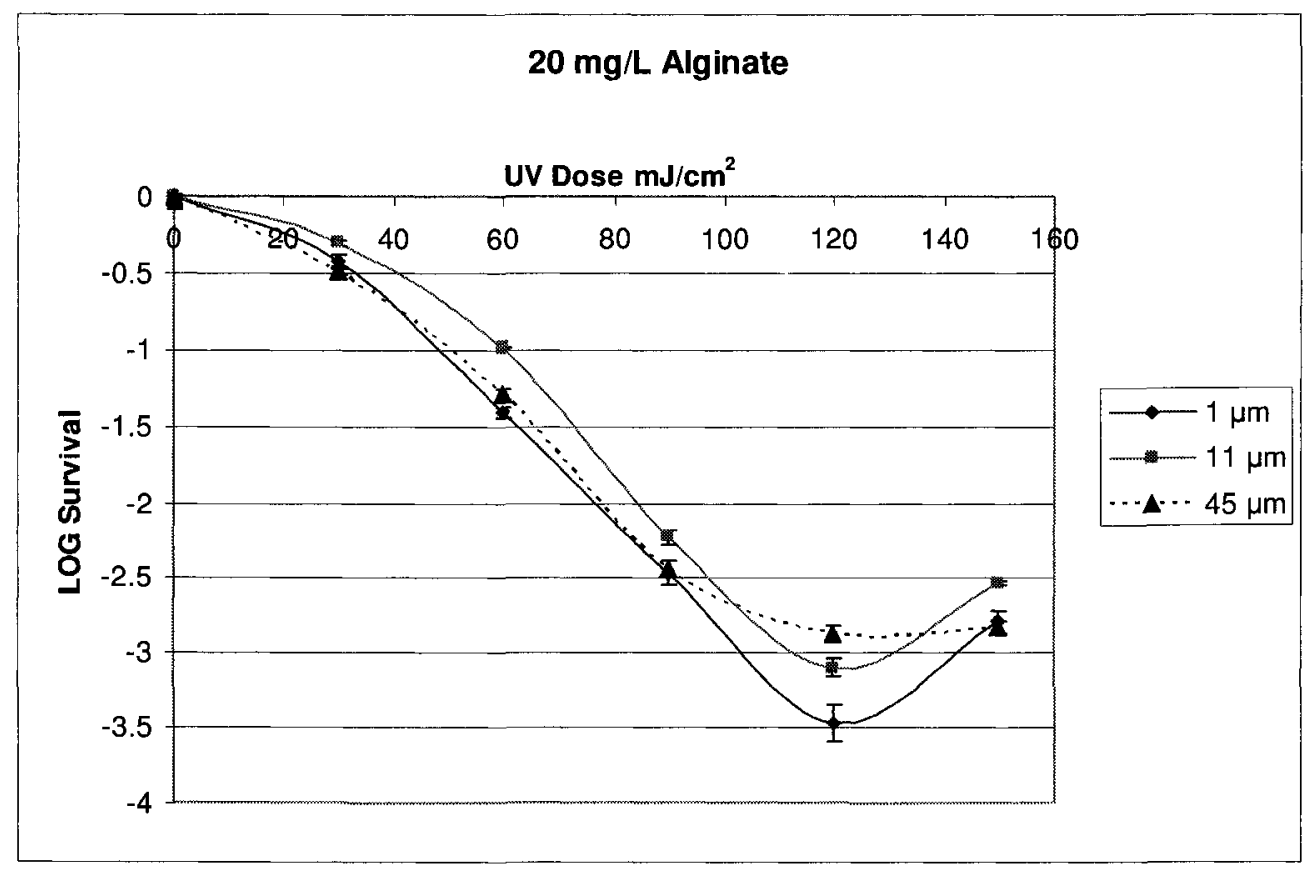

Figure 5.34: Phase III dose-response curves of particle-experiments at a calcium concentration of $10 \mathrm{mM}$ and an alginate concentration of $20 \mathrm{mg} / \mathrm{L}$.

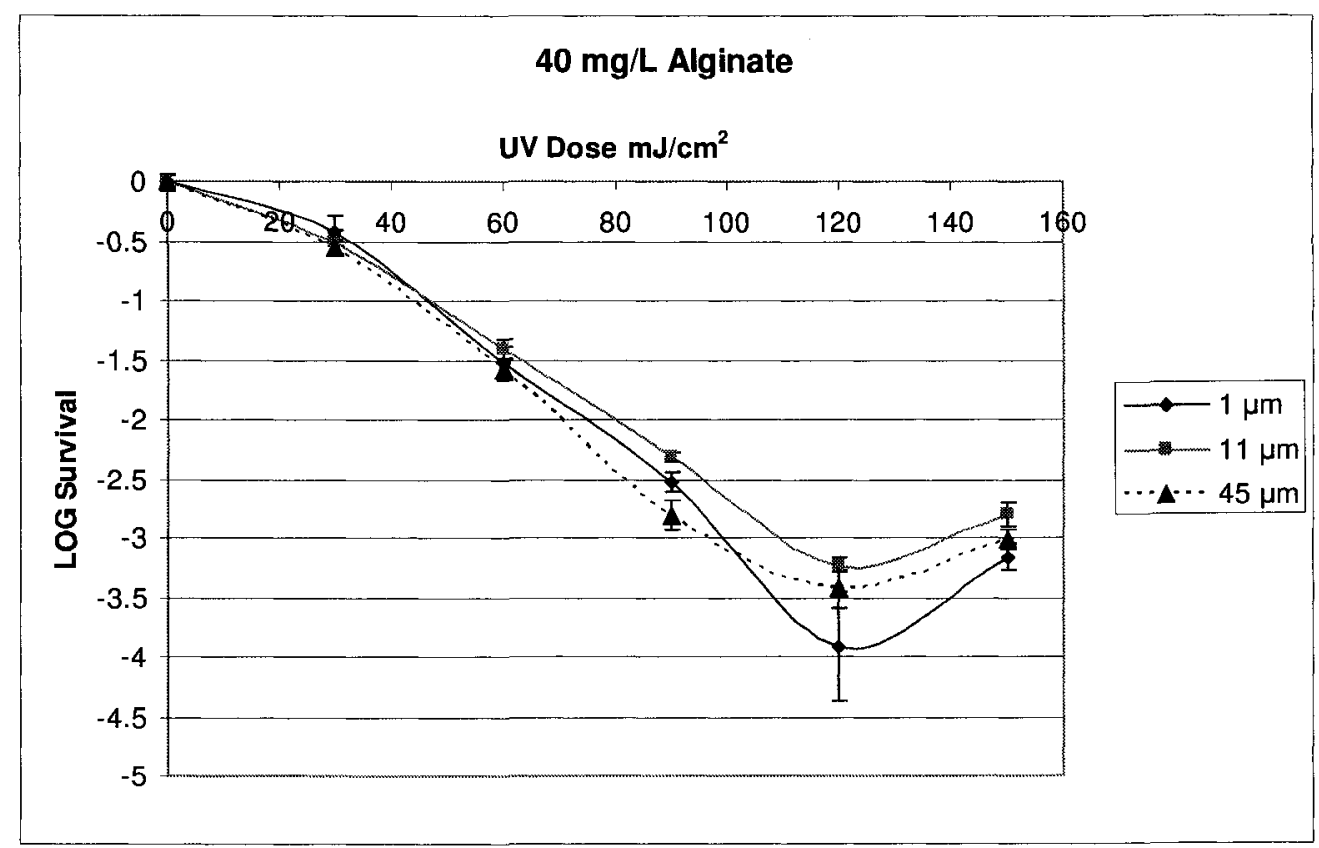

Figure 5.35: Phase III dose-response curves of particle-experiments at a calcium concentration of $10 \mathrm{mM}$ and an alginate concentration of $40 \mathrm{mg} / \mathrm{L}$. 
In general, no significant trend was observed in the comparative dose-response curves of Phase III. A few interesting points that can be noted in Figures 5.32 and 5.33 are discussed below.

As presented in Figure 5.32, $0 \mathrm{mg} / \mathrm{L}$ alginate-experiments did not show the same trend of 'a decrease in particle size leads to a decrease in inactivation' as in Phase I (Figure 5.5). This observation suggests that even in the absence of alginate, bacteria were still prone to self-aggregation and associated with particles when calcium ions were present in the medium as compared to cases where calcium was absent. This is further supported by the fact that bacteria are capable of producing EPS, thus possibly allowing them to benefit from calcium ions to aggregate even without any addition of alginate to the system.

Another interesting observation was that although the $10 \mathrm{mg} / \mathrm{L}$ alginate-experiments of Phase III were identical to the $10 \mathrm{mM}$ calcium-experiments of Phase II in terms of the flocculation conditions studied, the depicted trends are relatively different (Figure 5.19 and 5.33). This can be attributed to the fact that variations of $0.1-$ to $0.2-\log$ inactivation are typical even between replicate UV irradiation experiments (Templeton et al., 2005), and factors other than the flocculation conditions, as discussed in Section 5.6, may have caused higher degrees of variation in the outcomes of the experiments as these experiments were not exact replicates of each other.

It can be observed that the comparative graphs of Phase III support the hypothesis that in the presence of low concentrations of alginate $(10 \mathrm{mg} / \mathrm{L})$, as examined in Phase II, the observed differences in inactivation levels can be attributed to a competition for 
alginate between bacteria and particles as this hypothesized 'competition' appears not to have existed in the absence of alginate, or when there was sufficient amounts of alginate available (i.e., alginate concentrations of 20 and $40 \mathrm{mg} / \mathrm{L}$ ).

Furthermore, alginate experiments also indicated that concentration of alginate may have played a more important role than the size characteristics of particles, as the level of protection achieved was observed to vary with the change in alginate concentration rather than the type of particles involved.

\subsection{Various Factors That May Have Affected the Inactivation Rates}

Based on the information available in the literature, the following factors might have slightly influenced the observed inactivation rates of microorganisms. A short summary is included herein to enhance the discussion of results.

Firstly, the age of bacteria might play a role in the inactivation process. Depending on the incubation time, the cultures might progress into different phases of physiological development along the stationary phase section of the bacterial growth curve (Blatchley et al., 2001). It was reported that older bacterial cultures tend to show a higher resistance to disinfection possibly due to a more developed polysaccharide sheath (Metcalfe and Eddy Inc., 2003). The E. coli culture grown and used throughout this project was incubated for similar time periods $(12-15 \mathrm{~h})$ therefore, no significant effect of bacteria age is expected on the inactivation results.

Secondly, equal UV doses might not necessarily be equally effective. UV dose is a function of two parameters: UV intensity and exposure time. Since the same UV dose 
can be achieved by different combinations of exposure time and UV intensity, for the same UV doses employed throughout the project the relative ratio of these two factors were different in all sets of experiments. In the case of chlorine disinfection, where the combined effect of contact time and chlorine concentration are referred to as chlorine dose or CT value, the rate of disinfection has been shown to be different when different combinations of these two parameters were used to reach the same chlorine dosage (Örmeci and Linden, 2005). In the case of UV disinfection too, there might theoretically be a difference in inactivation kinetics when the same dose is reached via different combinations of intensity and exposure time. However, no significant difference in inactivation rates of particle associated bacteria was observed when intensity was increased ten times while keeping the delivered dose equal (Metcalfe and Eddy Inc., 2003). Furthermore, an increase in disinfection efficiency with a higher UV intensity should not be expected since the UV absorbance of particles is much higher than the bulk solution itself (Emerick et al., 1999). This shows the importance of particle/floc structure during UV inactivation as the composition and structure (porosity) of particles can determine to what extent microbes associated with these particles would be inactivated.

Finally, since a particle associated with multiple bacteria may still lead to one colony forming unit regardless of how many bacteria it actually harbours (Qualls et al., 1983), a treatment step for breaking up the aggregates and detaching the bacteria from particles is necessary before the enumeration step. Örmeci and Linden (2005) tested several extraction techniques for the detachment of bacteria from particles and reported that the physical techniques, such as blending and homogenization, perform better than the chemical techniques. Vortex mixing was used in this study to break up 
the bacterial aggregates and flocs before the enumeration step and to minimize the effects of such aggregates on the enumeration, and thereby the inactivation results. At high concentrations of alginate and calcium, however, some aggregates might have remained in the samples.

\subsection{Concluding Remarks}

It was decided that some of the discussion points would be better discussed in a separate section where all the phases can be evaluated together.

As previously discussed in Section 5.2 of this chapter, due to their high turbidity and UV absorbance characteristics, $45-\mu \mathrm{m}$ samples could have been overdosed leading to higher than expected inactivation. In order to further analyze whether this situation actually was the case or not, a comparative plot was prepared (Figure 5.36). This plot includes all the dose-response curves of Phase I as they were provided before (Figure 5.5 ) and in addition, the dose-response curve of $0 \mathrm{mg} / \mathrm{L}$ alginate case of the particlefree experiments of Phase III (from Figure 5.22). The aim of this graph is to provide a particle-free basis to better evaluate the effect of particles on UV disinfection. 


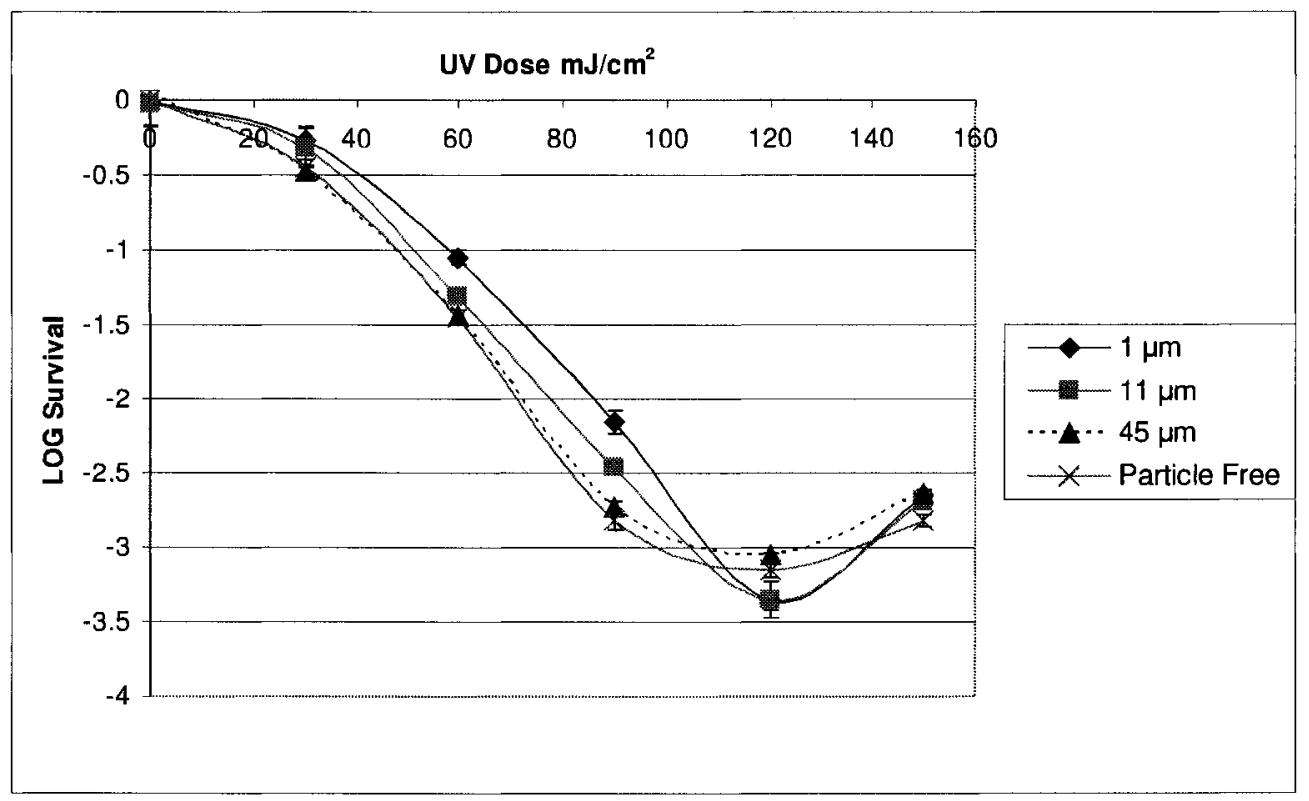

Figure 5.36: Comparison of dose-response curves of Phase III particle-free $0 \mathrm{mg} / \mathrm{L}$ alginate experiment with Phase I experiments.

As can be seen in Figure 5.36, the particle-free curve showed the highest level of inactivation which indicates that even without any flocculation being induced from outside a system a reduction in inactivation might be observed when particles are present in this system (as in Phase I experiments). Therefore, it can be concluded that the different levels of inactivation observed were likely due to different self-induced particle-microbe association characteristics as explained in Section 5.2. It should also be noted that the particle-free curve was followed most closely by the $45-\mu \mathrm{m}$ curve. This suggests that if there had been an overestimation of UV absorbance in $45-\mu \mathrm{m}$ samples (as explained in Section 5.2), the overdosing of the samples might have overcome the effects of mechanisms hindering inactivation.

The particle composition plays a major role as to what extent particles can provide shielding or shading to microbes. Inorganic particles such as clay tend to scatter light rather than absorb it (Bitton et al., 1972), whereas organic particles such as humic 
acid tend to absorb more (Qualls et al., 1983). When particles are of highly absorbing nature their porosity becomes crucial to the effectiveness of UV inactivation as how much of the light hitting the particle is being let into the particle is governed by the particle's porosity (Loge et al., 1999). Furthermore, in the case of flocs as hypothesized by Farnood (2005), spatial distribution of EPS would be one of the main factors determining the penetration of UV light into the floc. The hydrophobicity of particles, on the other hand, will determine the extent of attachment between the particles and the bacteria, this type of attachment would become very important especially when the flocculating agents are absent in the medium in which case the particle-microbe association would completely be governed by self-attachment mechanisms. As particles having the same chemical composition (polystyrene latex) and surface characteristics were used in this project, the differences observed in inactivation rates for a given particle size were largely based on the size and structure of the flocs formed.

Factors such as location of microbes to particles within a floc, the spatial distribution of EPS within a floc, and type of microbial attachment to particles (i.e. surface attachment, or partial or complete embedding) are crucial for the level of inactivation that can be achieved. Therefore, to better assess those factors a detailed analysis of the floc structure, and the mechanism and degree of particle-microbe association needs to be performed. Such an analysis can be made via transmission electron microscopy imaging (Templeton et al., 2005).

Finally, it should be noted that this is the first study of its kind that used a completely controlled and reproducible system to study the effect of particles and flocs on UV 
disinfection. The majority of previous work was carried out with actual water or wastewater samples where it was not possible to conduct controlled experiments due to the changing characteristics of the samples. Furthermore, a clear distinction between the terms 'floc' and 'particle' was made in this project whereas these terms are misused interchangeably in the literature and flocs are frequently cited as particles. It is crucial to make the distinction between particles and flocs in order to accurately evaluate the effects of presence of particles on UV disinfection. 


\section{CHAPTER 6}

\section{CONCLUSIONS AND RECOMMENDATIONS FOR FUTURE RESEARCH}

The results of this research indicate several important limitations of currently available theories regarding the effects of particles, flocs, particle-microbe association, self-aggregation of microbes, and UV absorbing substances on UV disinfection efficiency. As the conclusions derived from different phases of the project are closely related, they are provided altogether in point form. A future studies section follows the conclusions.

\subsection{Conclusions}

Based on the results presented in the previous chapter the following conclusions were derived.

- Unless UV irradiation experiments are run in a completely controlled system, the inactivation results can be misinterpreted due to the competing effects from different parameters such as particle size, floc size, floc composition and structure. In that regard, synthetic systems utilizing induced bioflocculation offer several advantages and enable completely controlled and reproducible experiments which would not be possible with natural water and wastewater samples. The synthetic system used in this study is a very promising tool and will help to better understand the limitations of UV disinfection in presence of particles and flocs.

- When particles of different sizes were present in equal number concentrations in test samples, inactivation efficiency decreased with decreasing particle size. The 
dose-response curve of the sample containing $45-\mu \mathrm{m}$ particles did not show much deviation from that of a particle-free solution; whereas, 11- and 1- $\mu \mathrm{m}$ particle solutions resulted in less inactivation.

- A distinction between the concepts of 'floc' and 'particle' is necessary to properly evaluate effects of particle size and particle-microbe association on disinfection. The presence of larger sized particles does not directly imply a higher degree of particle-microbe association as shown by Phase I results. Whereas, the presence of larger flocs implies that particle-microbe association possibly exists at a higher extent.

- A higher degree of particle-microbe association achieved through bioflocculation at a fixed concentration of alginate and increasing concentration of calcium ions, resulted in a lower rate of inactivation of $E$. coli with UV irradiation in samples containing 11- and $45-\mu \mathrm{m}$ particles. Samples containing 1- $\mu \mathrm{m}$ particles did not show the same trend even though similar floc sizes were reached. This indicates that same size flocs do not necessarily provide the same degree of shielding and floc structure also plays an important role in determining the level of shielding.

- Deviations from simple first-order inactivation kinetics were observed in doseresponse curves of all cases in the form of shoulder, tailing, or both. The tails observed in the UV dose-response curves imply that a remaining population of microbes was present even at very high UV doses, which could cause a public health threat. 
- When highly UV absorbing substances (alginate) are present in sufficient amounts, the dominant mechanism limiting the level of inactivation appears to be the coating of bacterial cells with alginate.

- Self-aggregation of bacteria is a significant mechanism limiting the level of UV disinfection and in certain cases may even be more effective than particleassociation in the shielding of bacteria from UV irradiation.

- An increase in alginate concentration decreased the inactivation rate in the absence of particles. However, the experiments did not show the same trend when particles were present in the medium. This indicates that inactivation characteristics can completely change in presence of particles.

- UV absorbance of the bulk solution is not a reliable indicator of the absorbance within flocs. Each floc might demonstrate a unique nature of absorbing UV depending on the spatial distribution of EPS. The spatial distribution of EPS within flocs may significantly affect the level of shielding microbes can acquire by determining the extent of reduction in the UV light intensity before reaching the microbes.

- Particle size distribution analyses need to be accompanied by other means of analysis techniques such as image capturing to better evaluate the rate of particlemicrobe association, the rate of self-clumping of microbes, floc size, and floc structure. 


\subsection{Future Studies}

Based on the results and conclusions presented previously, the following recommendations for future research are made.

- Similar experiments evaluating the effect of particles and flocs on disinfection rates should be conducted with other disinfectants such as chlorine and monochloramine to see whether the same trends and level of shielding exist under same conditions. This would be very useful in comparing the performance of traditional and alternative disinfectants.

- Future research may also perform similar tests using isolated or mixed cultures of different target organisms such as viruses or other types of bacteria.

- In order to better understand the level of shielding acquired by coating of bacteria with organic compounds in presence of particles, particles of different chemical compositions should be tested. In particular, the impacts of inorganic and hydrophilic particles should be compared with organic and hydrophobic particles.

- Advanced techniques of microscopy should be utilized to better evaluate the effects of floc structure, floc composition, and spatial distribution of EPS, microbes and particles within a floc; on UV inactivation.

- A comprehensive investigation of different elution and/or extraction methods should be conducted for different UV doses and different rates of bacteria- 
particle and bacteria-bacteria association in order to ensure the accuracy of the enumeration tests.

- Evaluation of particle size distribution and UV absorbance data before and after UV irradiation may help better understand the concept of tailing and the reasons for the fluctuations observed in inactivation levels at higher doses of UV. 


\section{REFERENCES}

Allen, J. (September 6, 2001). Ultraviolet radiation: how it affects life on earth. Retrieved from http://earthobservatory.nasa.gov/Library/UVB/printall.php

American Public Health Association (APHA), American Water Works Association and Water pollution Control Federation, 2005. Standard Methods for the Examination of Water and Wastewater. APHA/AWWA, Washington DC.

American Water Works Association (AWWA), 1999. Water Quality and Treatment: A Handbook of Community Water Supplies. McGraw-Hill, New York, N.Y.

American Water Works Association (AWWA), American Society of Civil Engineers, 2005. Water Treatment Plant Design. McGraw-Hill, New York, N.Y.

Batch, L. F., Schulz, R. C., and Linden, K. G. (2004). Evaluating water quality effects on UV disinfection of MS2 coliphage. Journal of American Water Works Association, 96(7), 75-87

Bitton, G., Henis, Y., and Lahav N. (1972). Effect of several clay minerals and humic acid on the survival of Klebsiella aerogenes exposed to ultraviolet irradiation. Applied Microbiology, 23, 870-874

Bitton, G., 2005. Wastewater Microbiology. Wiley-Liss, John Wiley \& Sons, Hoboken, N.J. 
Blatchley, E. R., Dumontier, N., Halaby, T. N., Levi, Y., and Laine, J. M. (2001). Bacterial responses to ultraviolet irradiation. Water Science and Technology, 43(10), $179-186$

Bolton, J. R., and Linden, K. G. (2003). Standardization of methods for fluence (UV dose) determination in bench-scale UV experiments. Journal of Environmental Engineering, 129(3), 209-215

Borst, M., and Selvakumar, A. (2003). Particle-associated microorganisms in stormwater runoff. Water Research, 37(1), 215-223

Bruus, J. H., Nielsen, P. H., and Keiding, K. (1992). On the stability of activated sludge flocs with implications to dewatering. Water Research, 26(12), 1597-1604

Christensen, J., and Linden, K. G. (2003). How particles affect UV light in the UV disinfection of unfiltered drinking water. Journal of American Water Works Association, 95(4), 179-189

Clancy, J. L., Bukhari, Z., Hargy, T. M., Bolton, J. R., Dussert, B. W., and Marshall, M. M. (2000). Using UV to inactivate Cryptosporidium. Journal of American Water Works Association, 92(9), 97-104 
Craik, S. A., Weldon, D., Finch, G. R., Bolton, J. R., and Belosevic, M. (2001). Inactivation of Cryptosporidium parvum oocysts using medium- and low-pressure ultraviolet radiation. Water Research, 35(6), 1387-1398

Dietrich, J. P., Basagaoglu, H., Loge, F. G., and Ginn, T. R. (2003). Preliminary assessment of transport processes influencing the penetration of chlorine into wastewater particles and the subsequent inactivation of particle-associated organisms. Water Research, 37, 139-149

Emerick, R. W., Loge, F. J., Thompson, D., and Darby, J. L. (1999). Factors influencing ultraviolet disinfection performance part II: association of coliform bacteria with wastewater particles. Water Environment Research, 71(6), 1178-1187

Emerick, W. R., Loge, F. J., Ginn, T., and Darby, J. L. (2000). Modeling the inactivation of particle-associated coliform bacteria. Water Environment Research, $72(4), 432-438$

Farnood, R. (2004). Investigation of factors affecting the ultraviolet disinfection of biological aggregates. PARTEC 2004, Nuremberg, Germany.

Farnood, R. (2005). Flocs and ultraviolet disinfection. In I. G. Droppo, G. G. Leppard, S. N. Liss \& T. G. Milligan (Eds.), Flocculation in Natural and Engineered Environmental Systems (385-395). CRC Press, Boca Raton, FL. 
Friedman, B. A., Dugan, P. R., Pfister, R. M., and Remsen, C. C. (1969). Structure of exocellular polymers and their relationship to bacterial flocculation. Journal of Bacteriology, 98(3), 1328-1334

Frolund, B., Palmgren, R., Keiding, K., and Nielsen, P. H. (1996). Extraction of extracellular polymers from activated sludge using a cation exchange resin. Water Research, 30(8), 1749-1758

Higgins, M. J., and Novak, J. T. (1997). The effect of cations on the settling and dewatering of activated sludges: laboratory experience. Water Environment Research, $69,215-224$

Horan, N. J., and Eccles, C. R. (1986). Purification and characterization of extracellular polysaccharide from activated sludges. Water Research, 20(11), 14271432

Huber, E., and Frost, M. (1998). Light scattering by small particles. Aqua, 47(2), 8794

Jagger, J., 1967. Introduction to research in ultraviolet photobiology. Prentice-Hall, Eaglewood Cliffs, N.J.

Linden, K. G., Shin, GA.,Faubert, G., Cairns, W., and Sobsey, M. D. (2002). UV disinfection of Giardia lamblia cysts in water. Environmental Science and Technology, 36(11), 2519-2522 
Lindenauer, K. G., and Darby, J. L. (1994). Ultraviolet disinfection of wastewater: effect of dose on subsequent photoreactivation. Water Research, 28(4), 805-817

Loge, F. J., Darby, J. L., and Tchobanoglous, G. (1996). UV disinfection of wastewater: a probabilistic approach to design. Journal of Environmental Engineering, 122(12), 1078-1084

Loge, F. J., Emerick, R. W., Thompson, E. D., Nelson, D. C., and Darby, J. L. (1999). Factors influencing ultraviolet disinfection performance part I: light penetration to wastewater particles. Water Environment Research, 71(3), 377-381

Malley, J. P., Shaw, J. P., and Ropp, J. R., 1995. Evaluation of By-products Produced by Treatment of Groundwaters with Ultraviolet Irradiation. The Foundation and American Water Works Association, Denver, CO.

Mamane-Gravetz, H., and Linden, K. G. (2004). UV disinfection of indigenous aerobic spores: implications for UV reactor validation in unfiltered waters. Water Research, 38(12), 2898-2906

Mamane, H., and Linden, K. G. (2006a). Impact of particle aggregated microbes on UV disinfection. I: Evaluation of spore-clay aggregates and suspended spores. Journal of Environmental Engineering, 132(6), 596-606 
Mamane, H., and Linden, K. G. (2006b). Impact of particle aggregated microbes on UV disinfection. II: proper absorbance measurement for UV fluence. Journal of Environmental Engineering, 132(6), 607-615

Metcalf and Eddy Inc., 2003. Wastewater Engineering: Treatment and Reuse. McGraw- Hill, Boston, MA.

Morowitz, H. J. (1950). Absorption effects in volume irradiation of microorganisms. Science, $111,229-230$

Örmeci, B., and Linden, K. G. (2002). Comparison of UV and Chlorine Inactivation of Particle and Non-Particle-Associated Coliform. Water Supply, 2(5-6), 403-410

Örmeci, B., and Linden, K. G. (2005). Comparison of physical and chemical methods for extraction of coliform from wastewater particles and flocs. Environmental Engineering Science, 22(4), 459-471

Örmeci. B., and Vesilind, A. P. (2000). Development of an improved synthetic sludge: a possible surrogate for studying activated sludge dewatering characteristics. Water Research, 34(4), 1069-1078

Parker, D. S., Jenkins, D., and Kaufman, W. J. (1971). Physical conditioning of the activated sludge floc. Journal of Water Pollution Control Federation, 43, 1897 
Parker, J. A., and Darby, J. L. (1995). Particle-associated coliform in secondary effluents: shielding from ultraviolet light disinfection. Water Environment Research, $67(7), 1065-1075$

Passantino, L., Malley, J. Jr., Knudson, M., Ward, R., and Kim, J. (2004).Effect of low turbidity and algae on UV disinfection performance. Journal of American Water Works Association, 96(6), 128-137

Pavoni, J. L., Tenney, M. W., and Echelberger, W. F. Jr. (1972). Bacterial exocellular polymers and biological flocculation. Journal of Water Pollution Control Federation, $44(3), 414-429$

Qualls, R. G., Flynn, M. P., and Johnson, J. D. (1983). The role of suspended particles in ultraviolet disinfection. Journal of Water pollution Control federation, 55(10), $1280-1285$

Sanin, D. F., and Vesilind, A. P. (1996). Synthetic sludge: a physical/chemical model in understanding bioflocculation. Water Environment Research, 68(5), 927-933

Sanin, D. F., and Vesilind, A. P. (1999). A comparison of physical properties of synthetic sludge with activated sludge. Water Environment Research, 71(2), 191-196

Severin, B. F., Suidan, M. T., and Engelbrecht, R. S. (1983).Kinetic modeling of UV disinfection of water. Water Research, 17(11), 1669-1678 
Shin, GA., Linden, K. G., Arrowood, M. J., and Sobsey, M. D. (2001). Low-pressure UV inactivation and DNA repair potential of Cryptosporidium parvum oocysts. Applied Environmental Microbiology, 67(7), 3029-3032

Sobeck, D. C., and Higgins, M. J. (2002). Examination of three theories for mechanisms of cation-induced bioflocculation. Water Research, 36(3), 527-538

Templeton, M. R., Andrews, R. C., and Hofmann R. (2005).Inactivation of particleassociated viral surrogates by ultraviolet light. Water Research, 39(15), 3487-3500

Tezuka, Y. (1969). Cation-dependent flocculation in a Flavobacterium species predominant in activated sludge. Applied Microbiology, 17(2), 222-226

US EPA. 1999. Alternative Disinfectants and Oxidants Guidance Manual, Report \# 815-R-99-014, US EPA, Office of Water, Washington, DC.

Urbain, V., Block, J. C., and Manem, J. (1993).Bioflocculation in activated sludge: an analytic approach. Water Research, 27(5), 829-838

Water Environment Research Foundation (WERF), 1995. Comparison of UV Irradiation to Chlorination: Guidance for Achieving Optimal UV Performance: Project 91-WWD-1, Alexandria, VA.

White, C. G., 1978. Disinfection of Wastewater and Water for Reuse. Van Nostrand Reinhold, New York, N.Y. 
Wu, Y., Clevenger, T., and Deng B. (2005).Impacts of goethite particles on UV disinfection of drinking water. Applied and Environmental Microbiology, 71(7), $4140-4143$ 


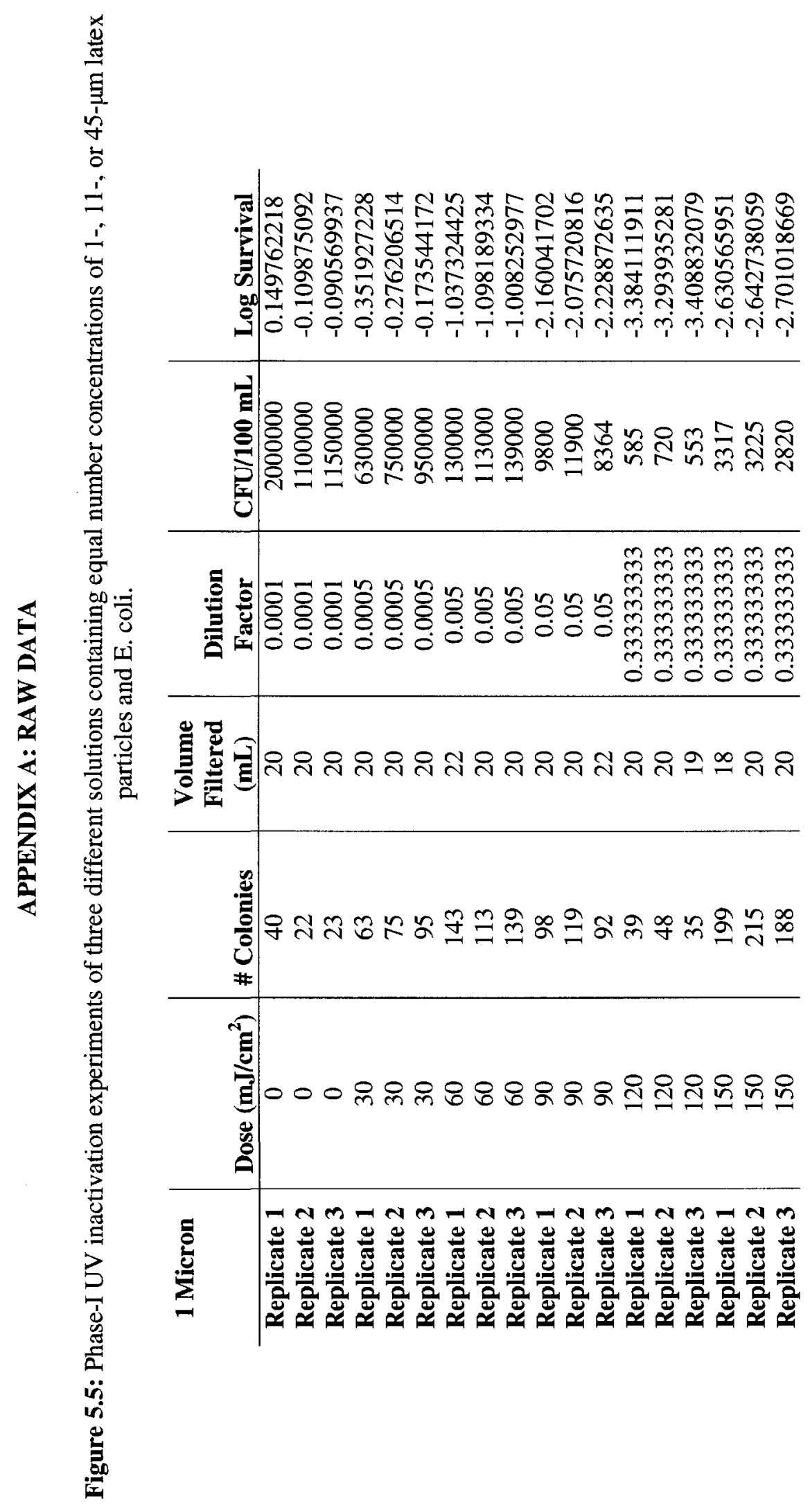




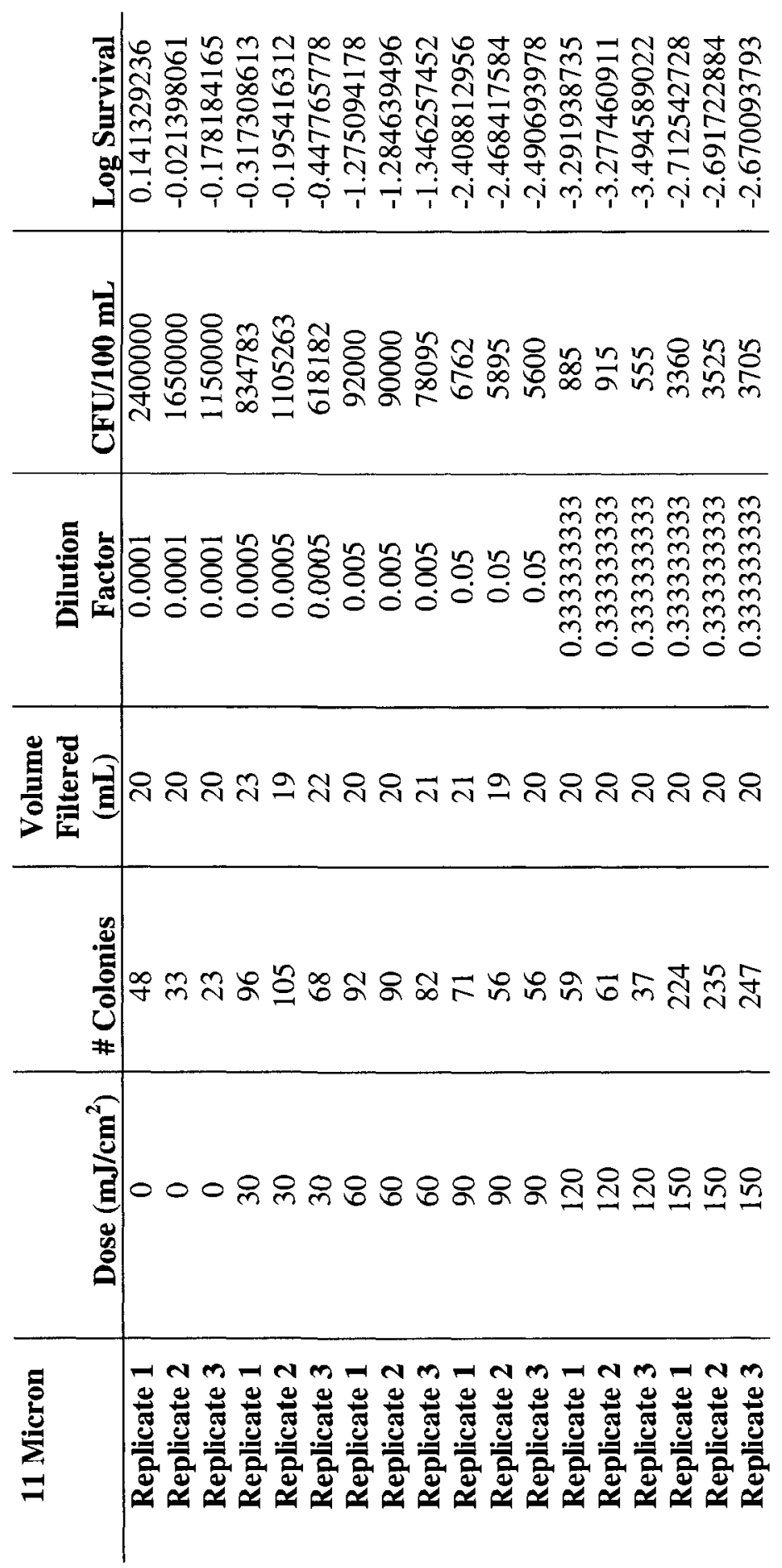




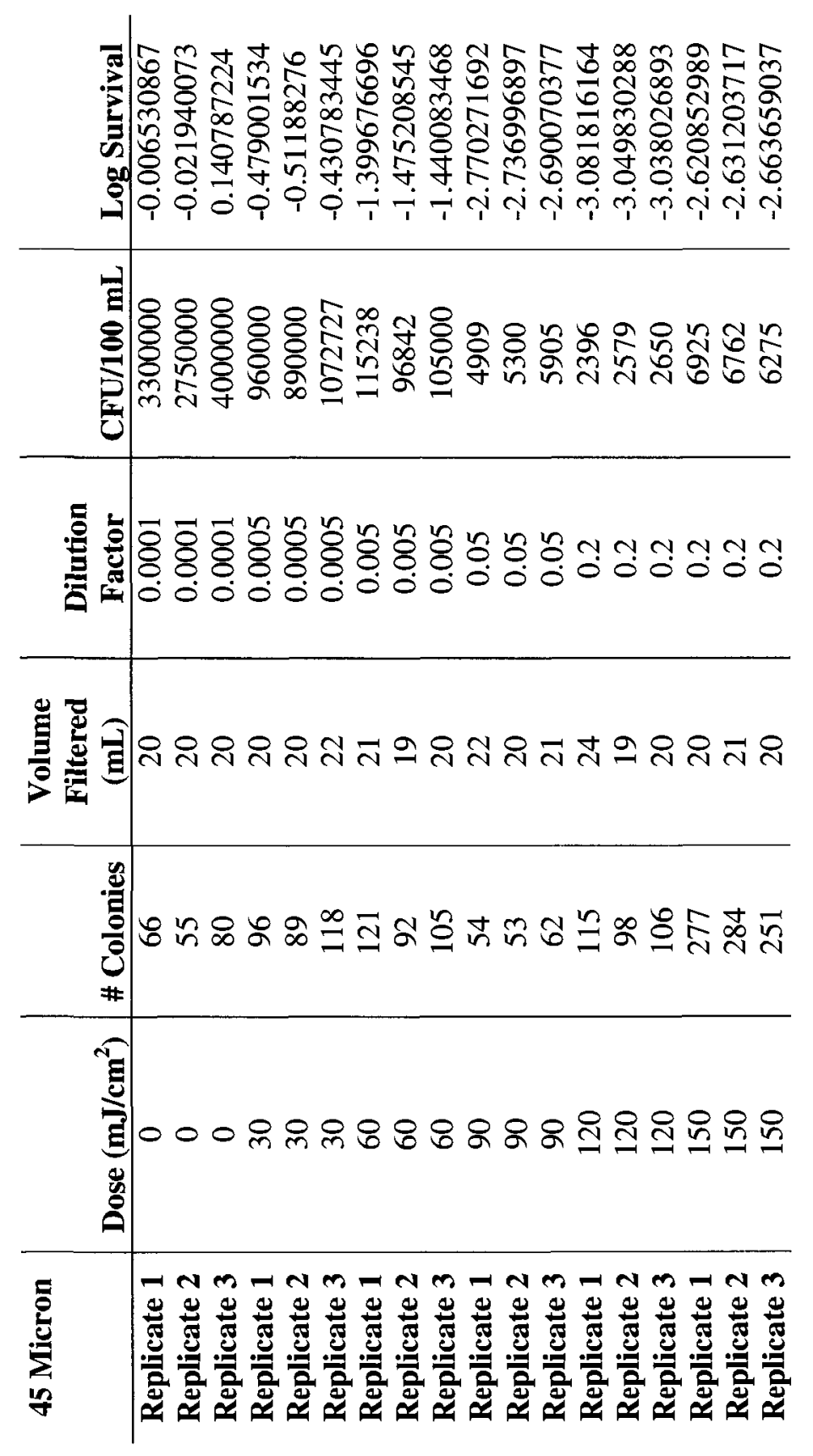




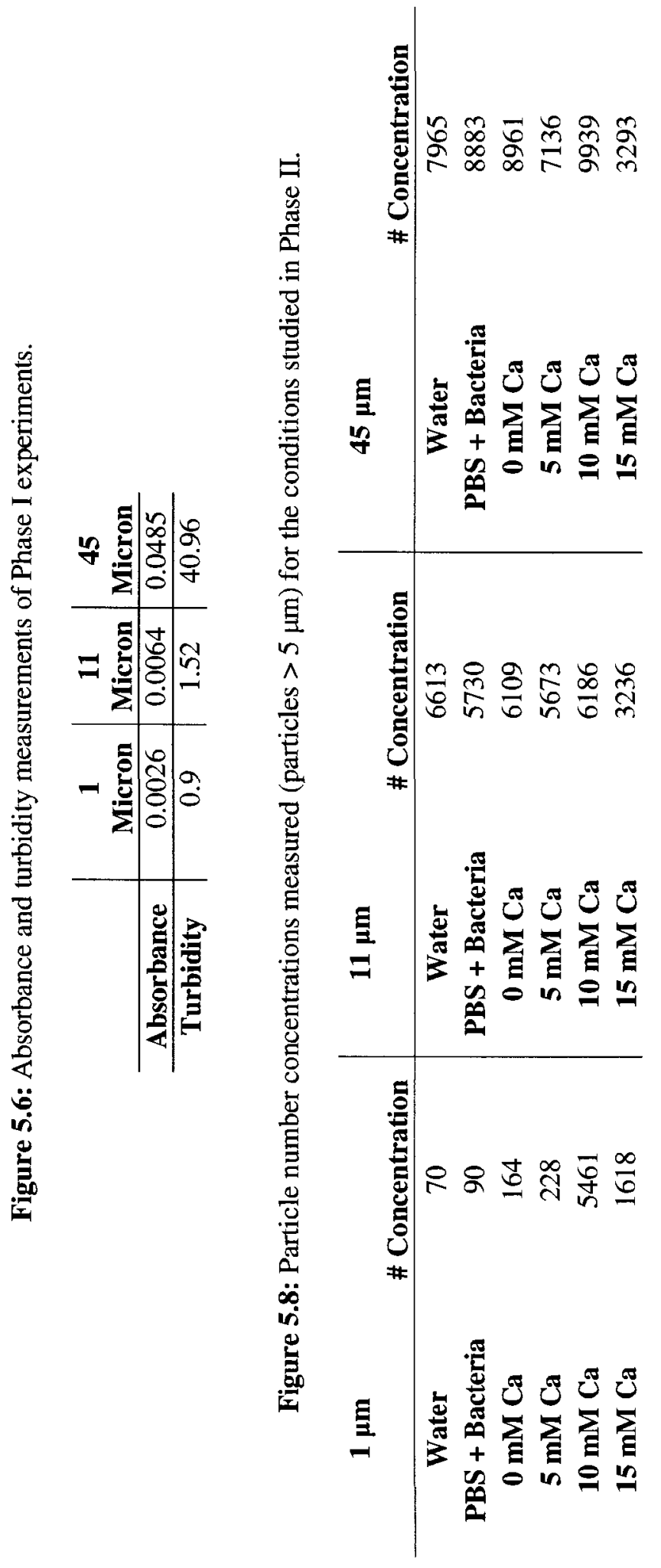




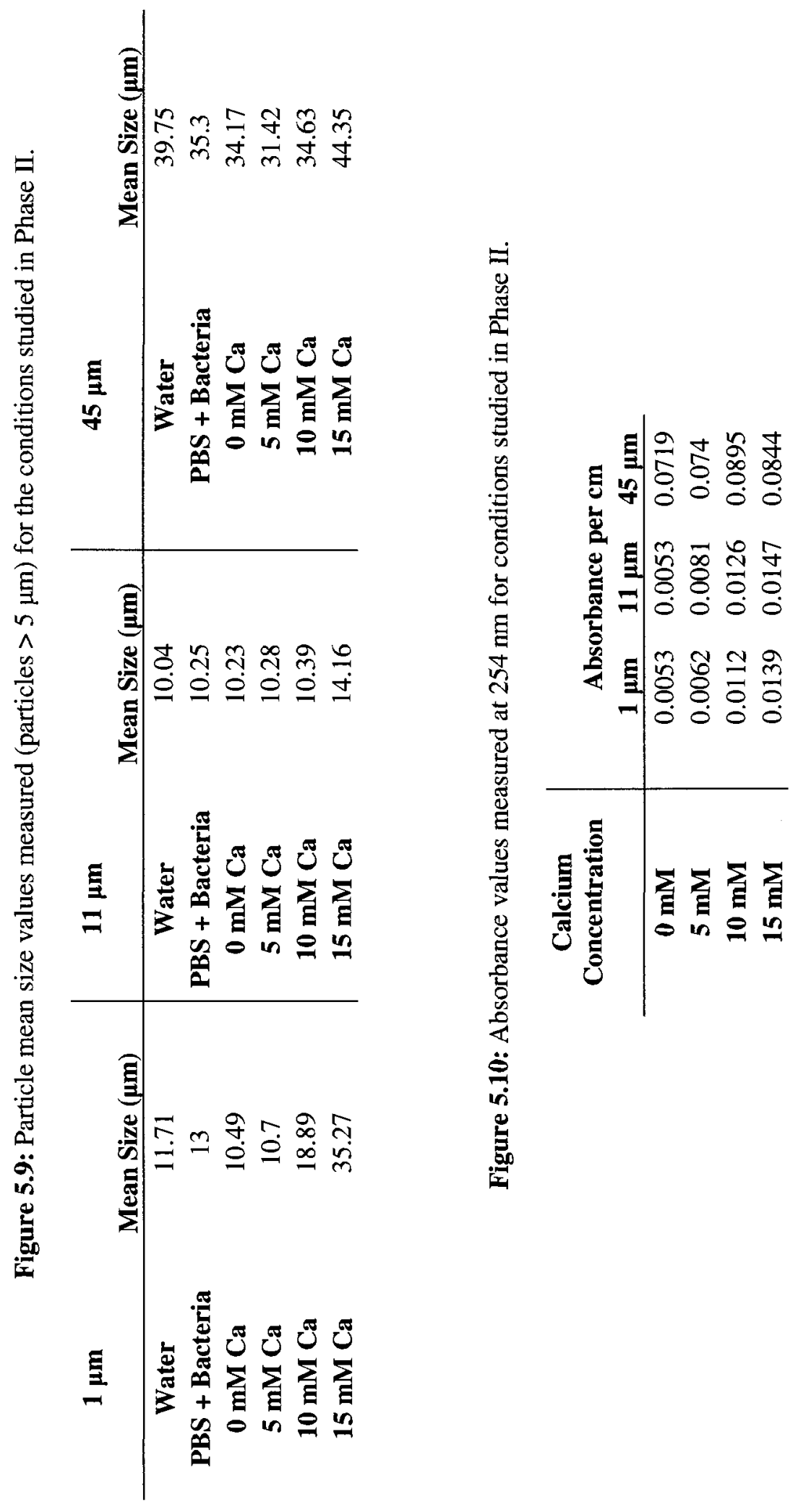




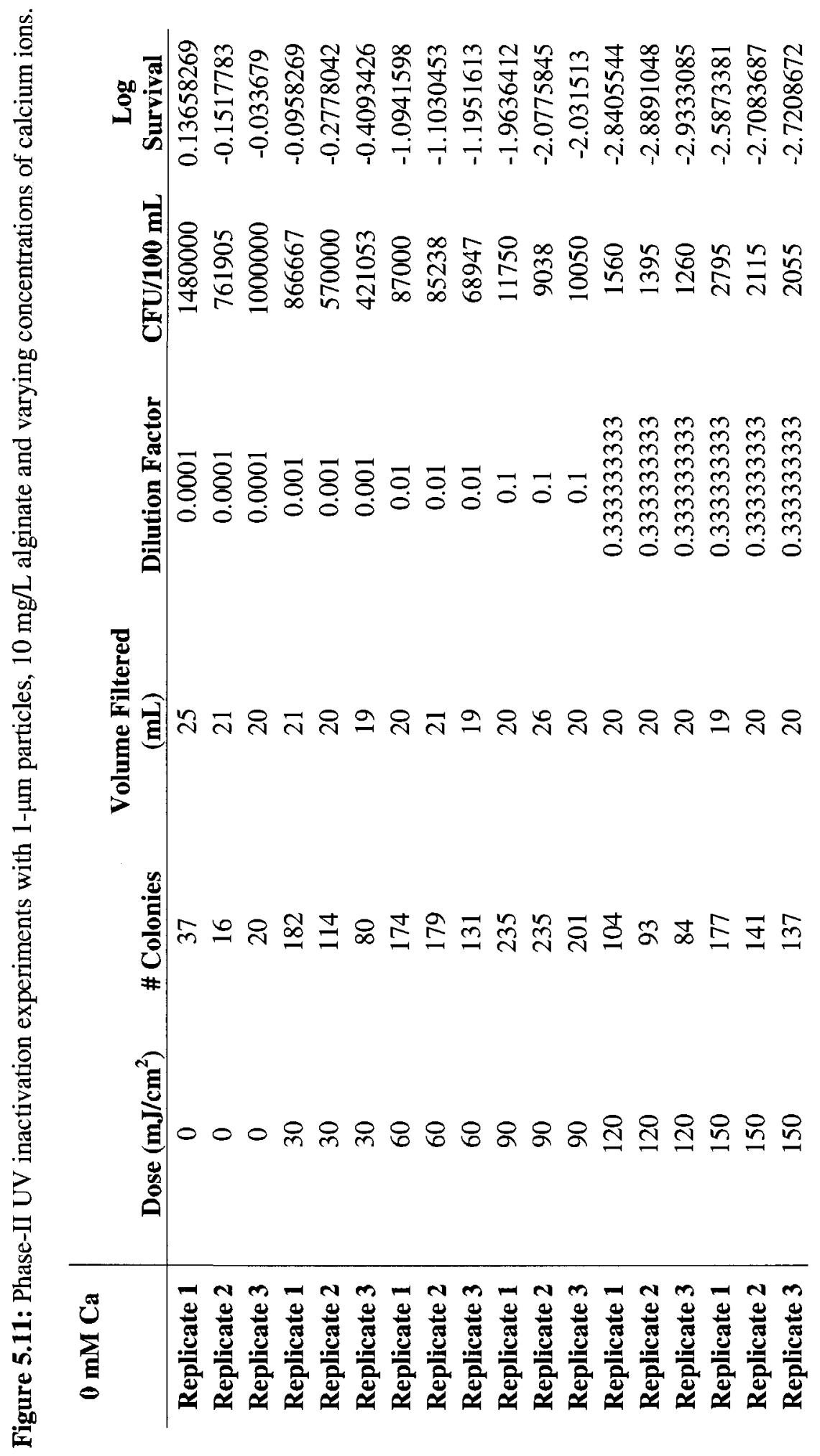




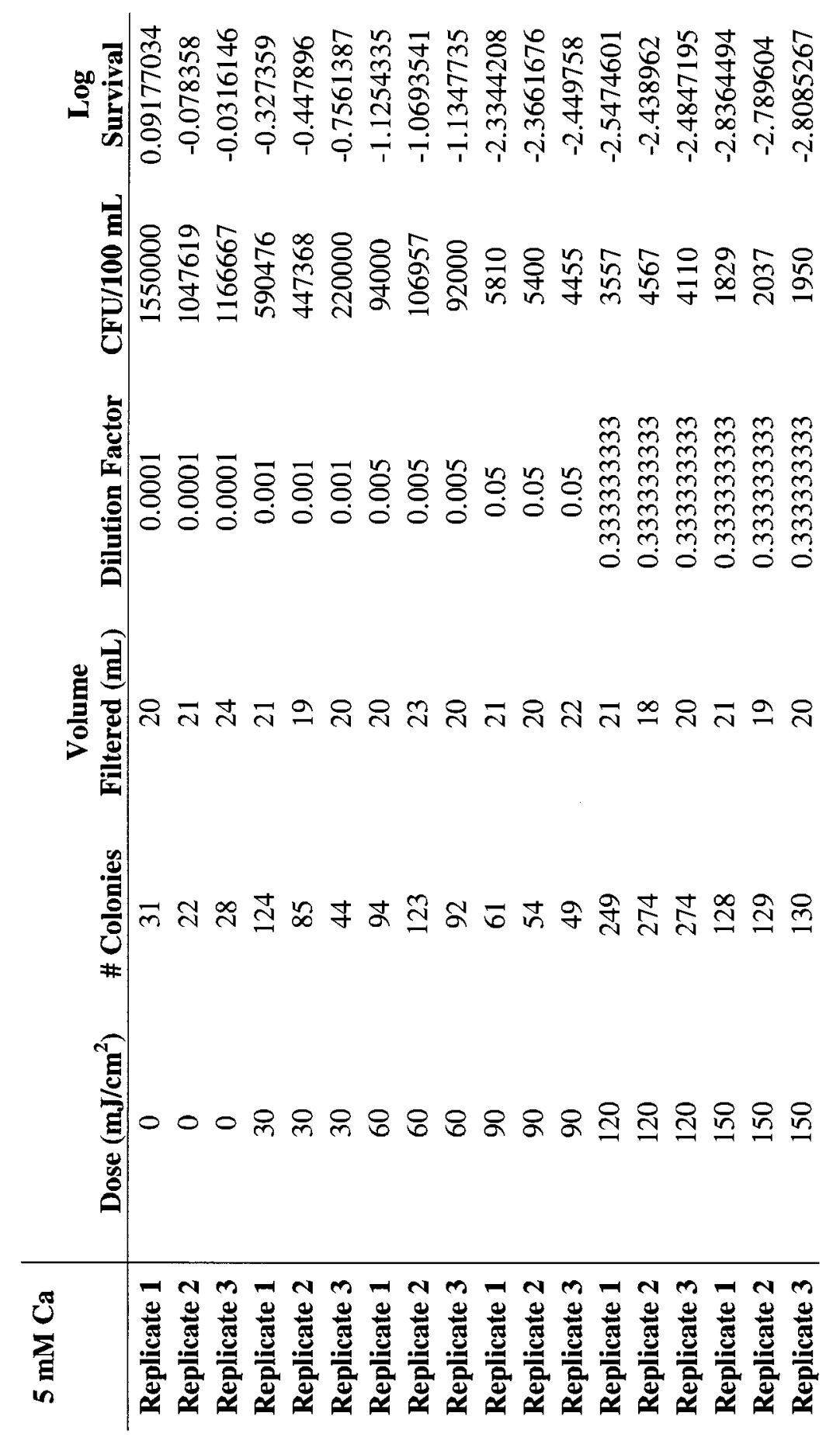




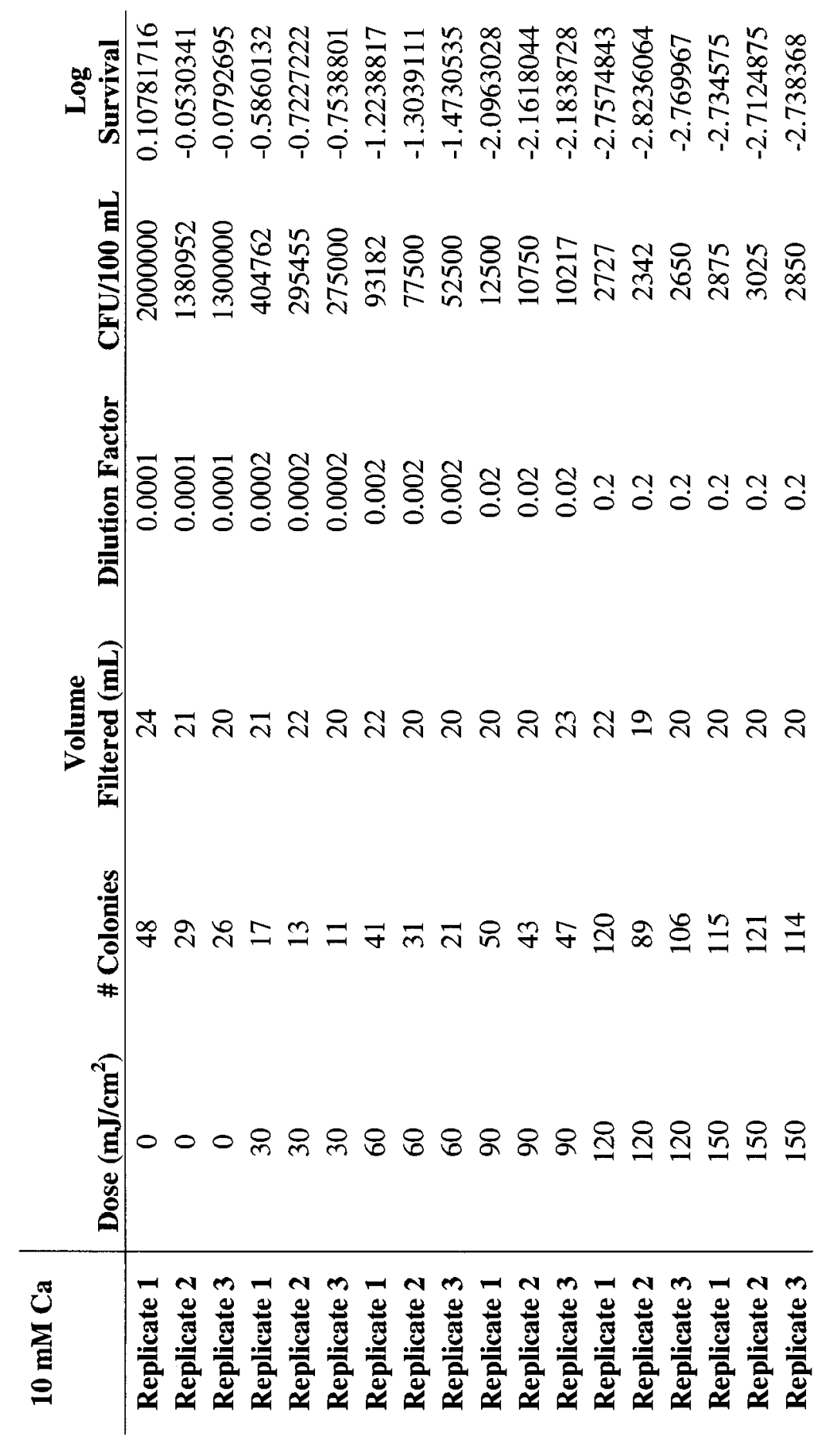




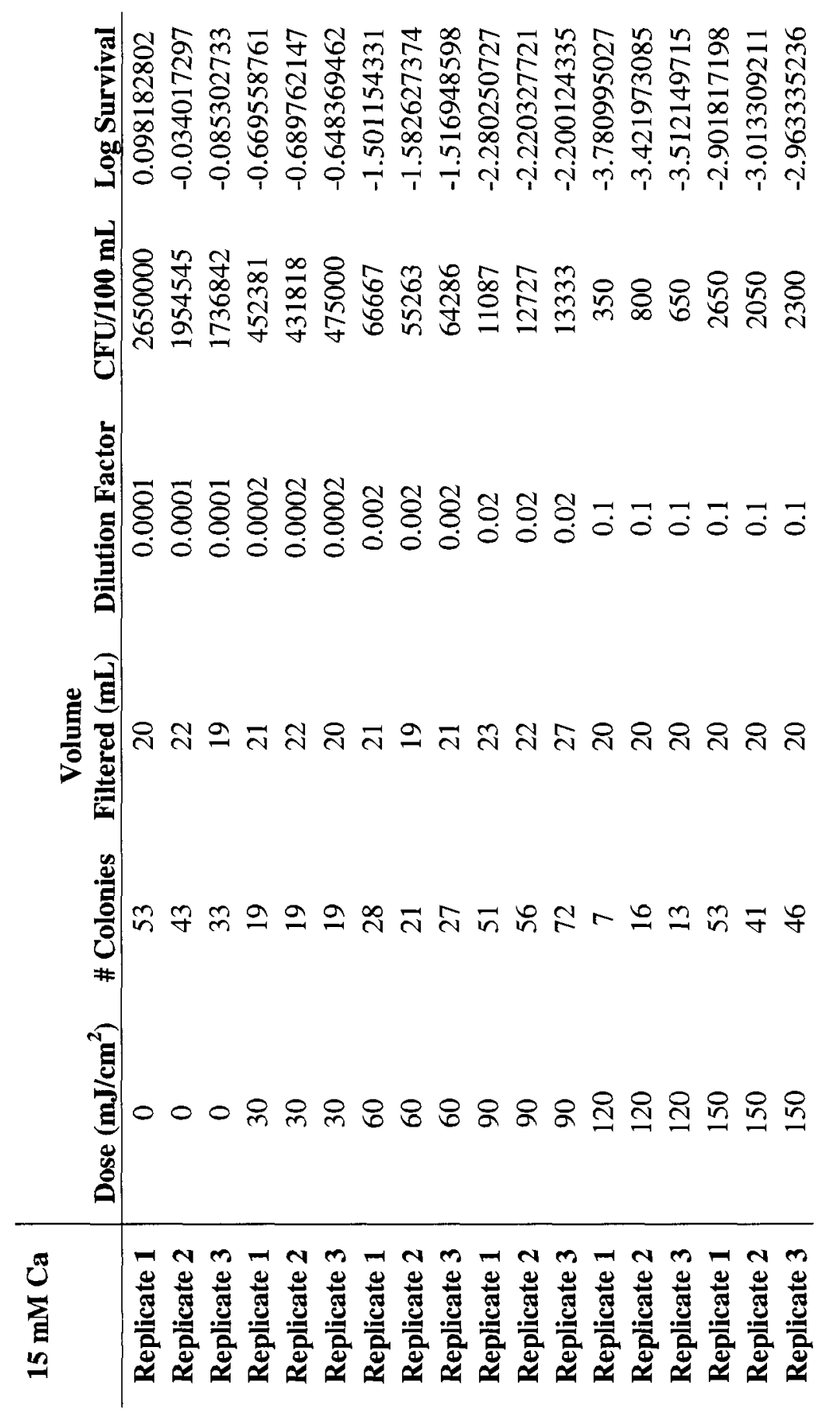




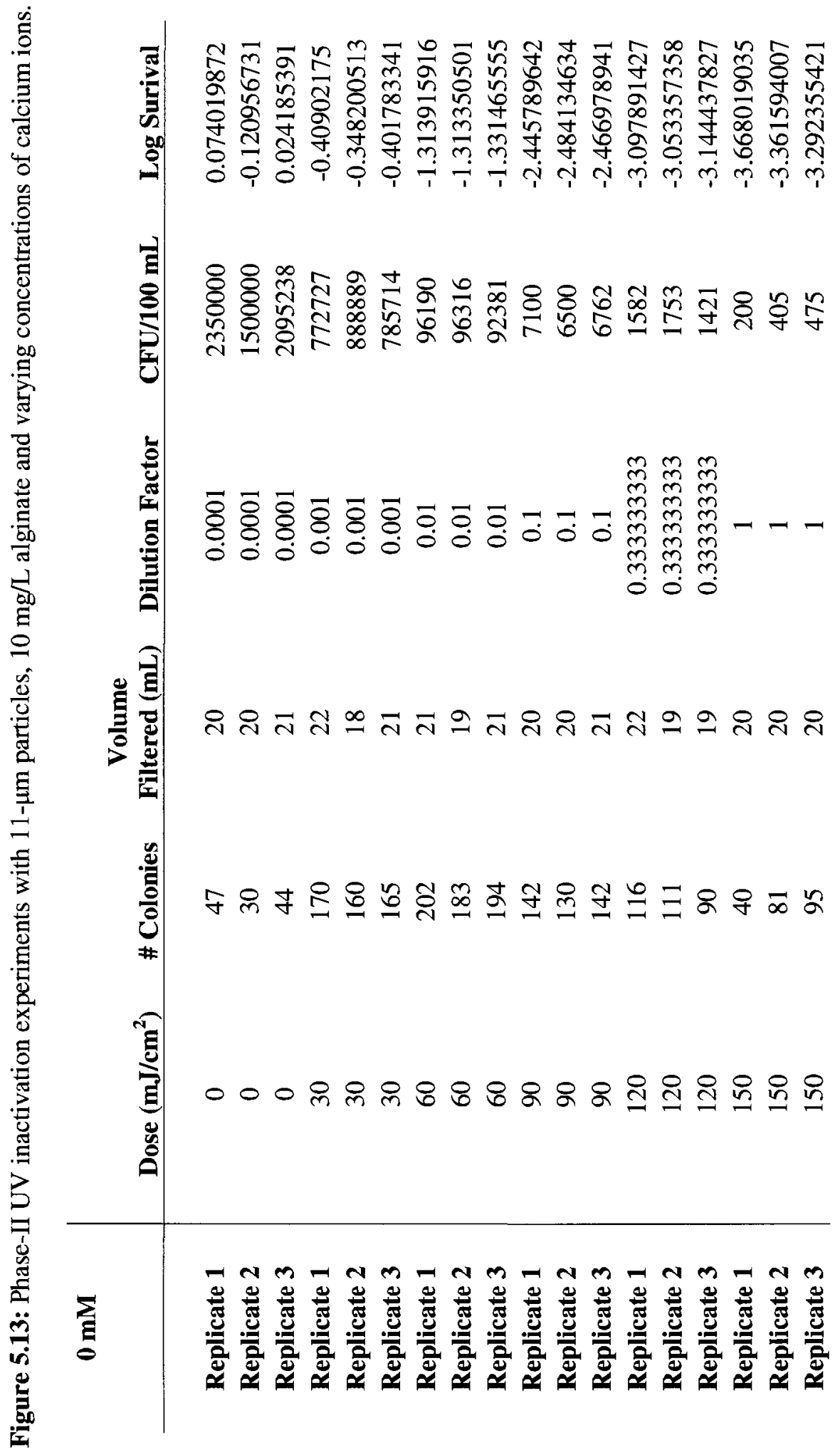




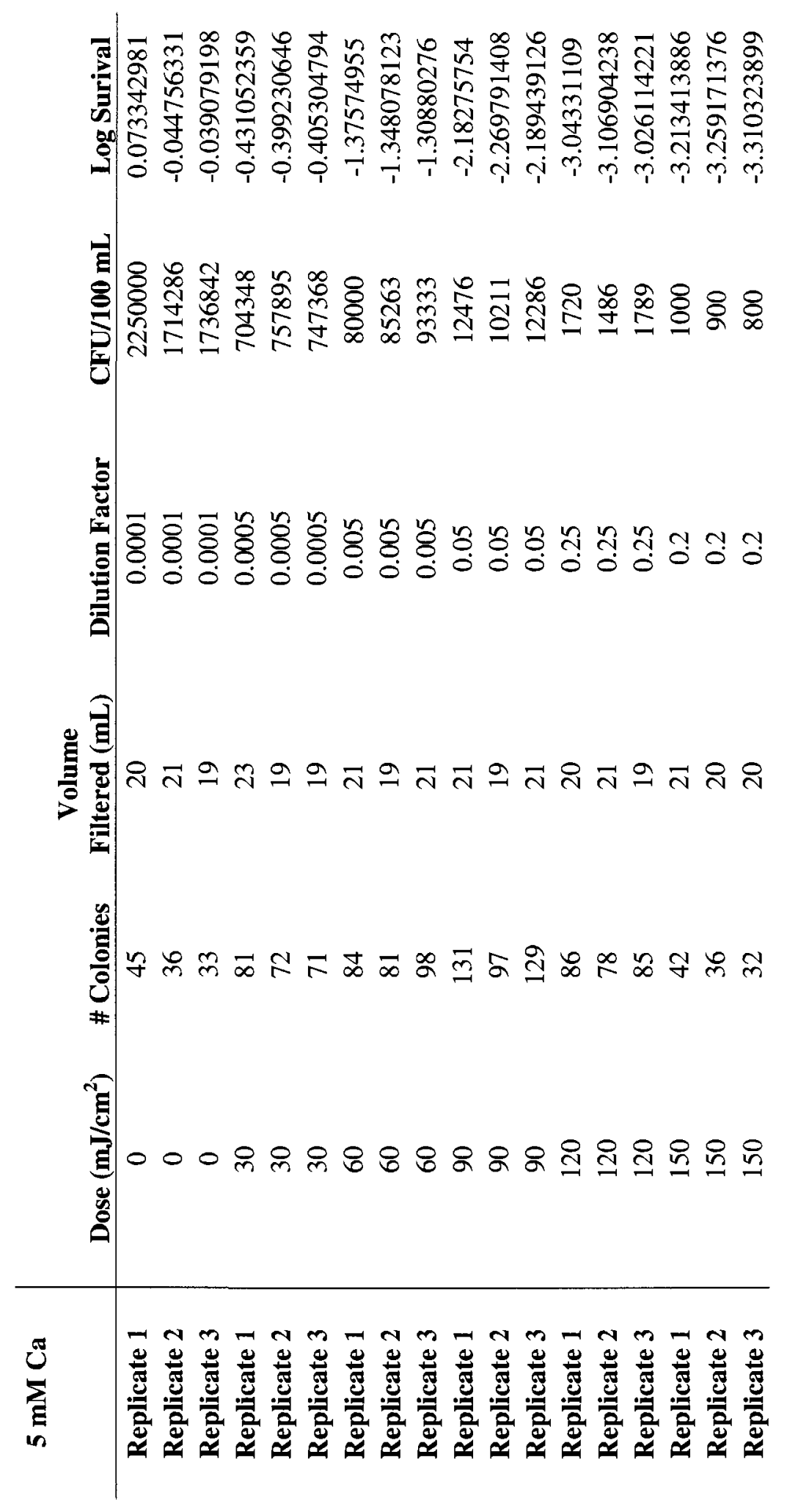




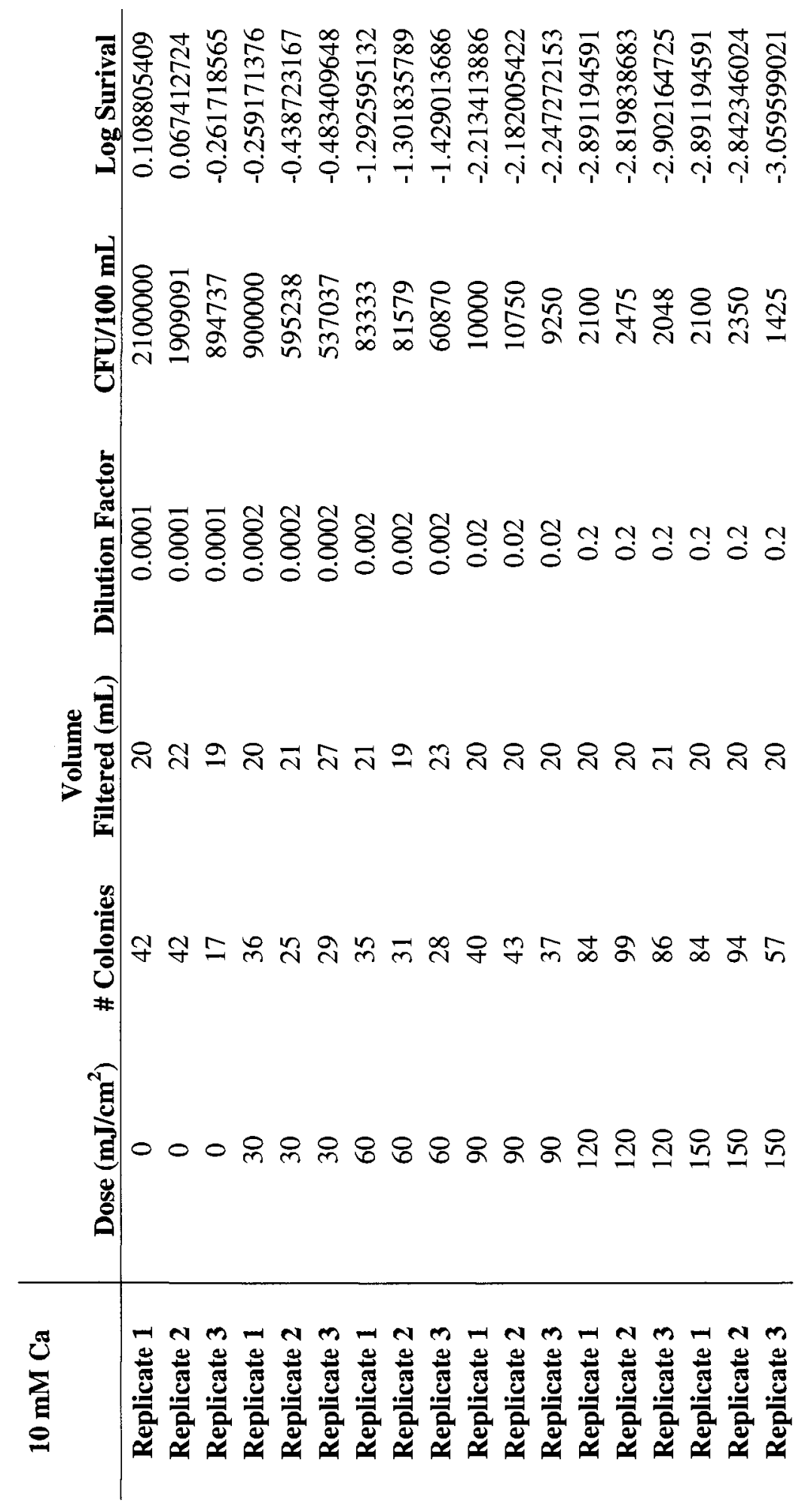




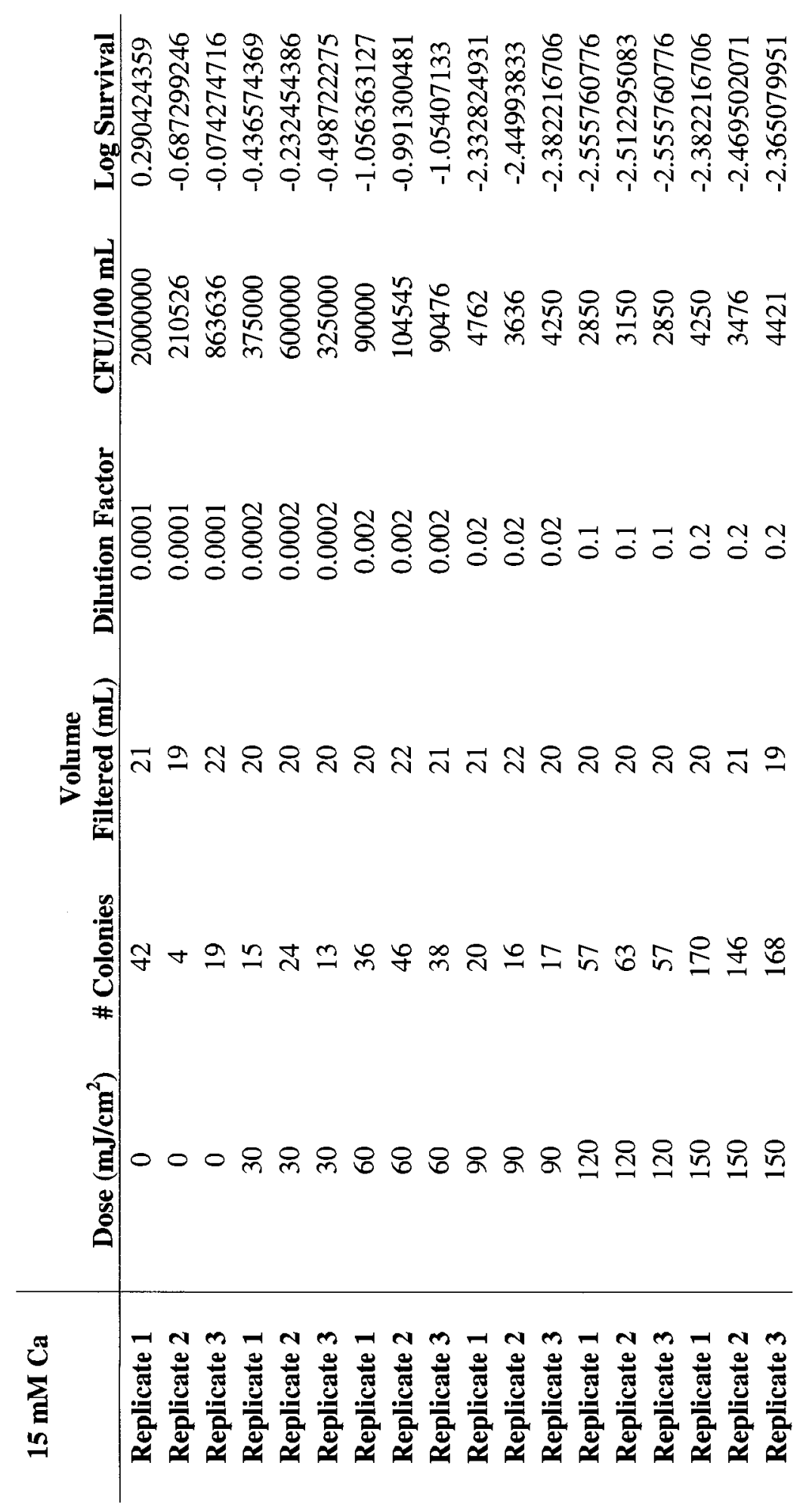




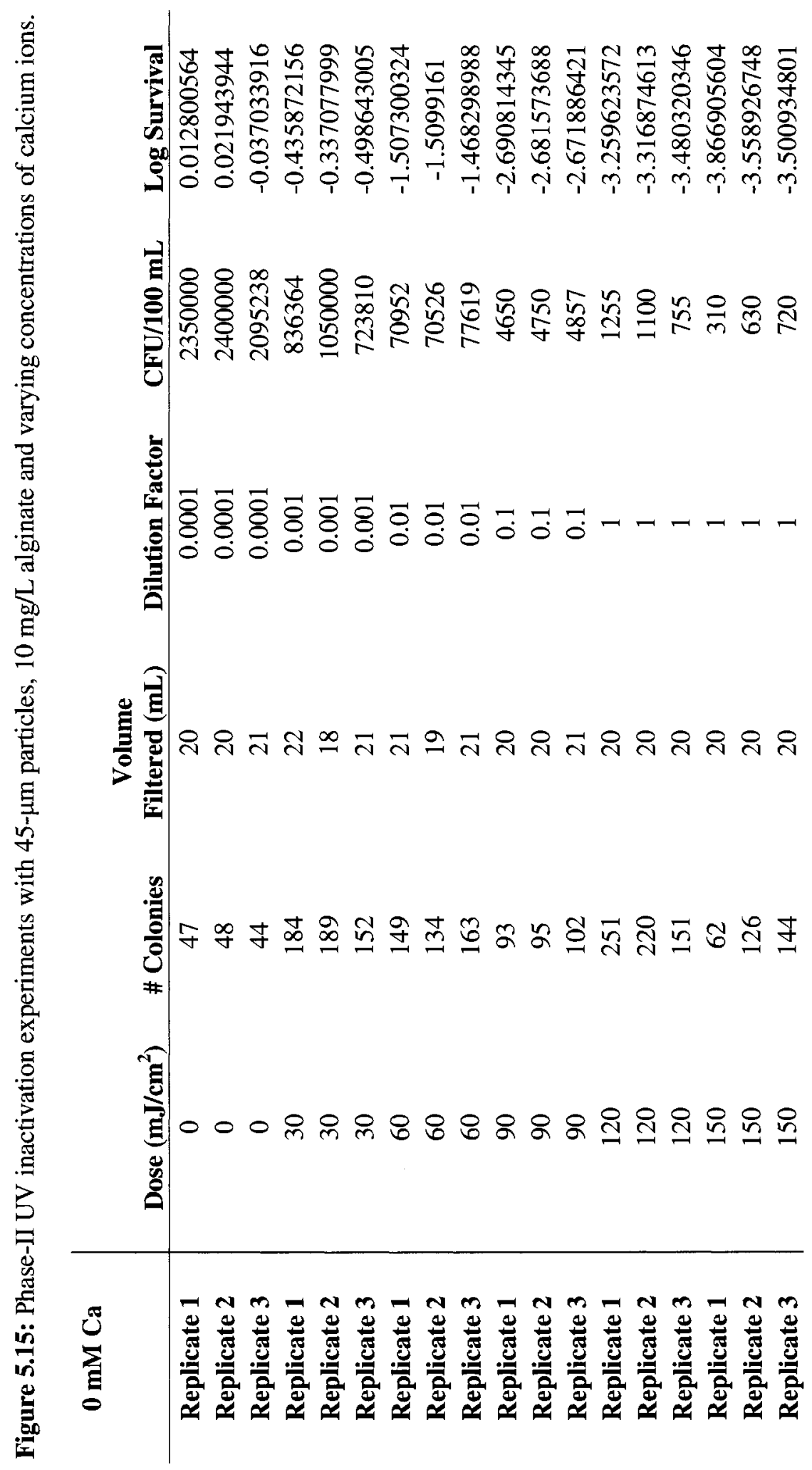




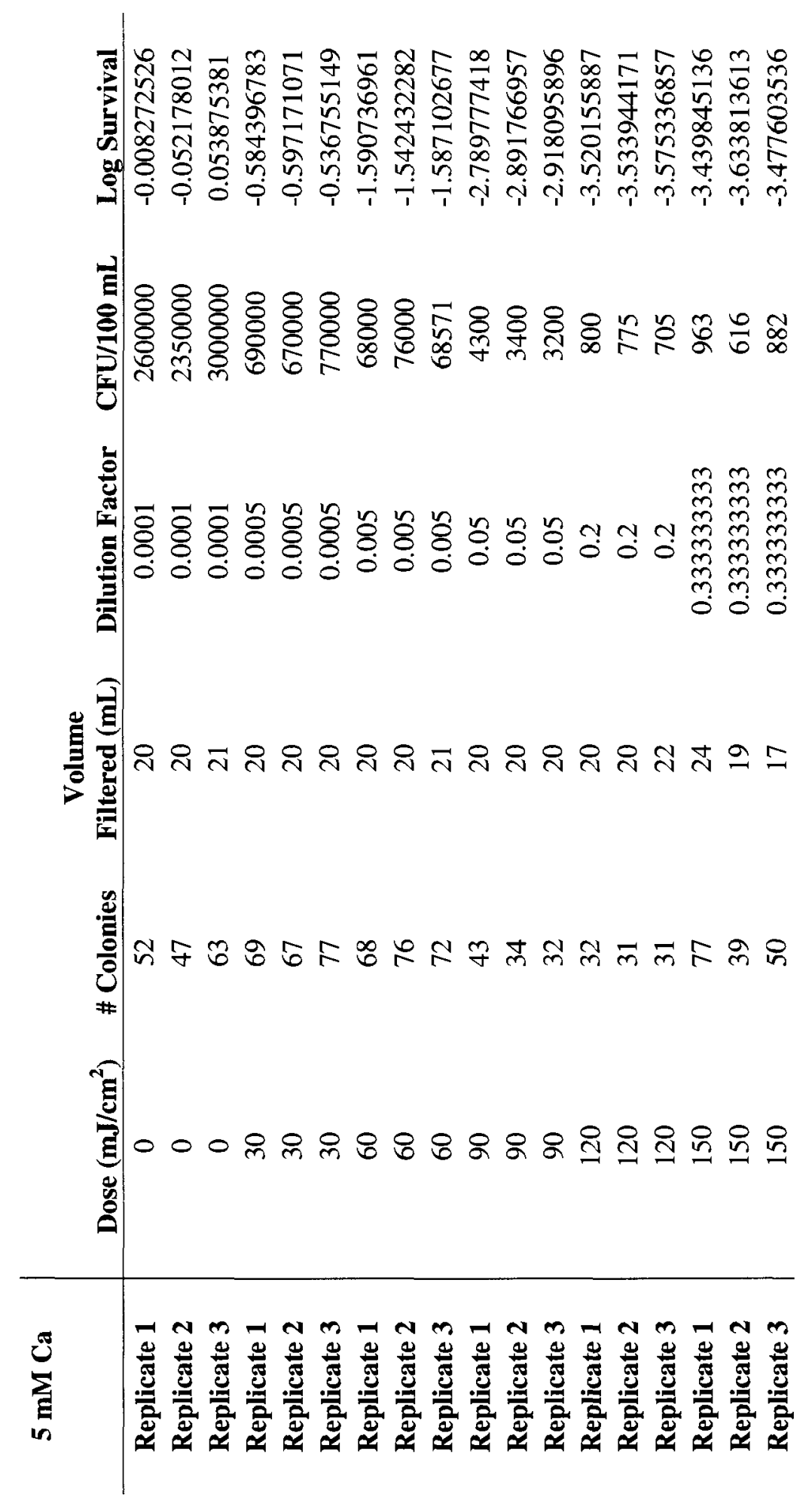




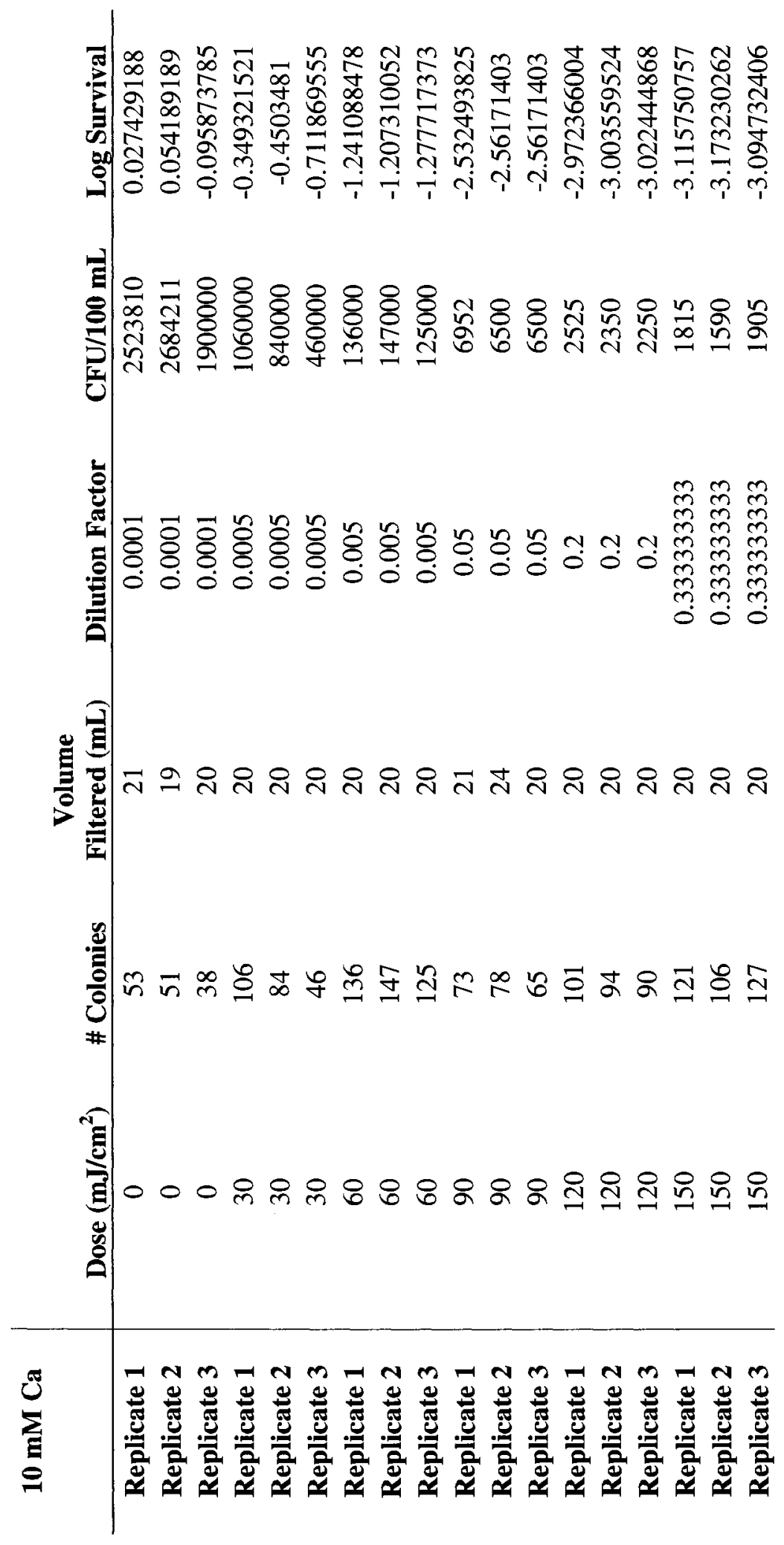




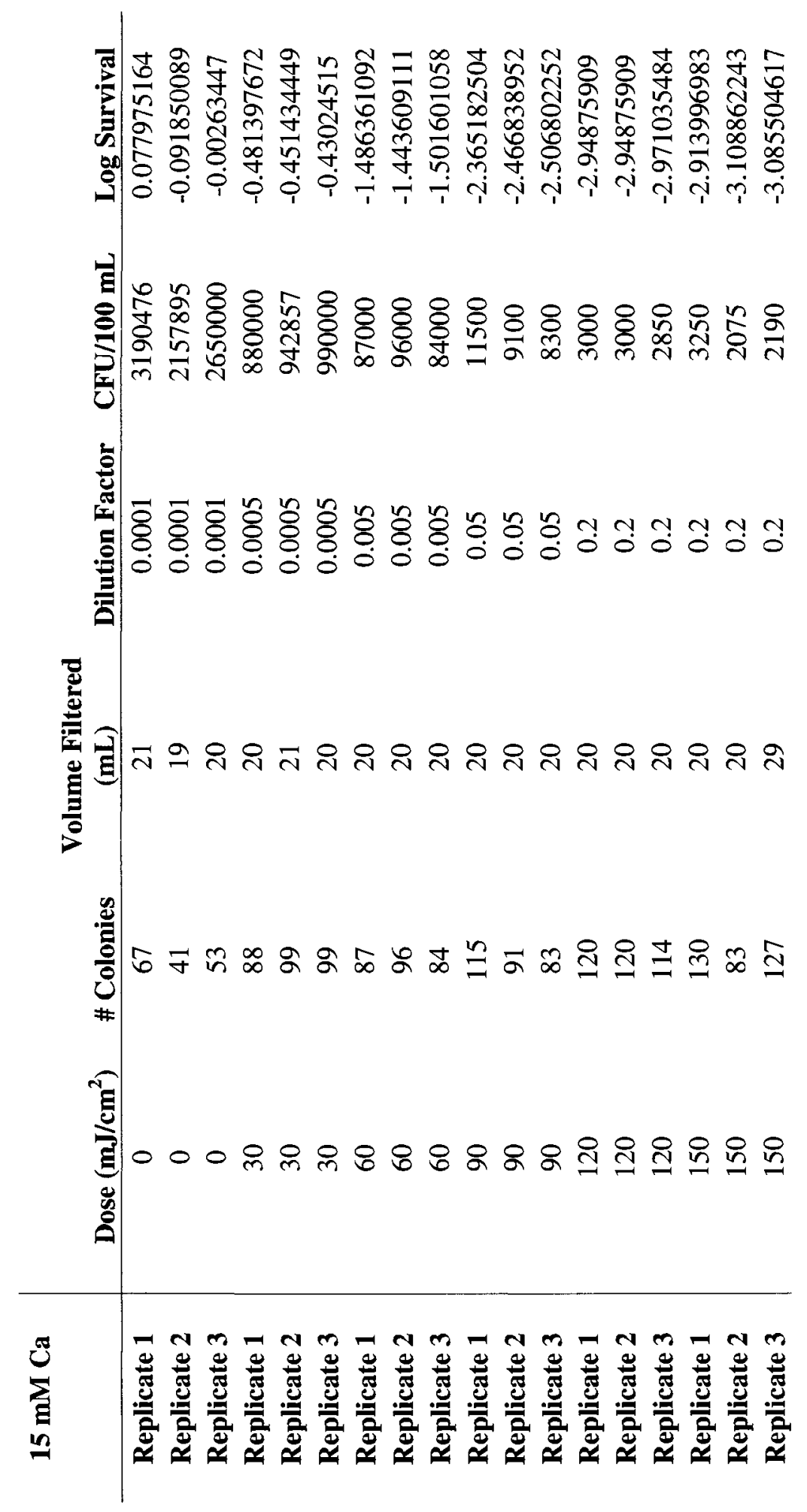




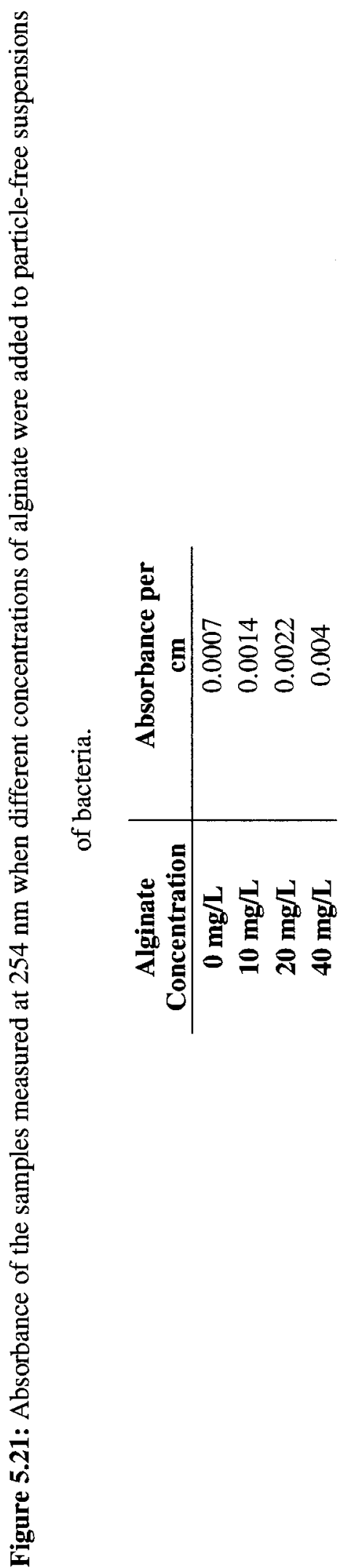




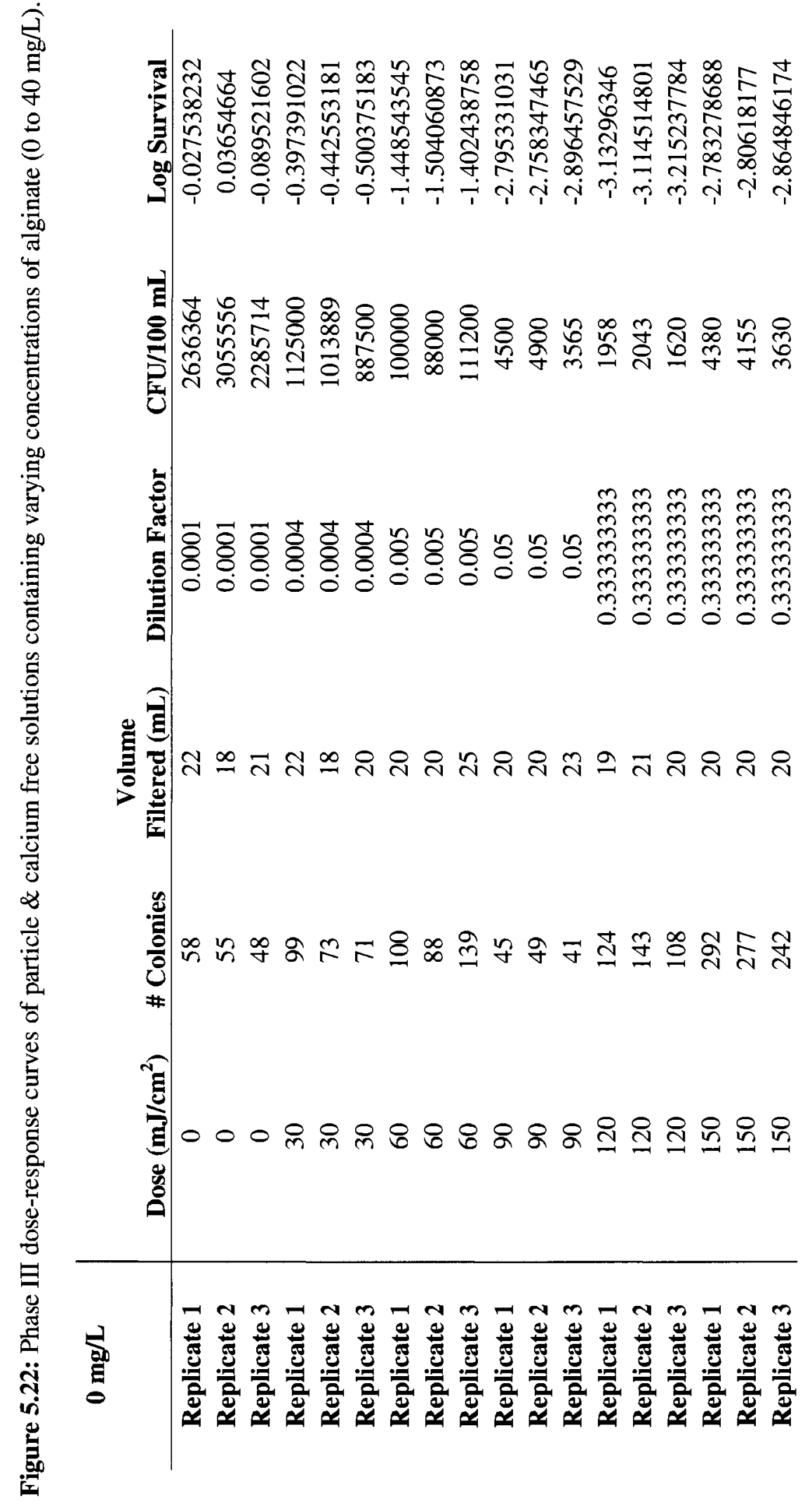




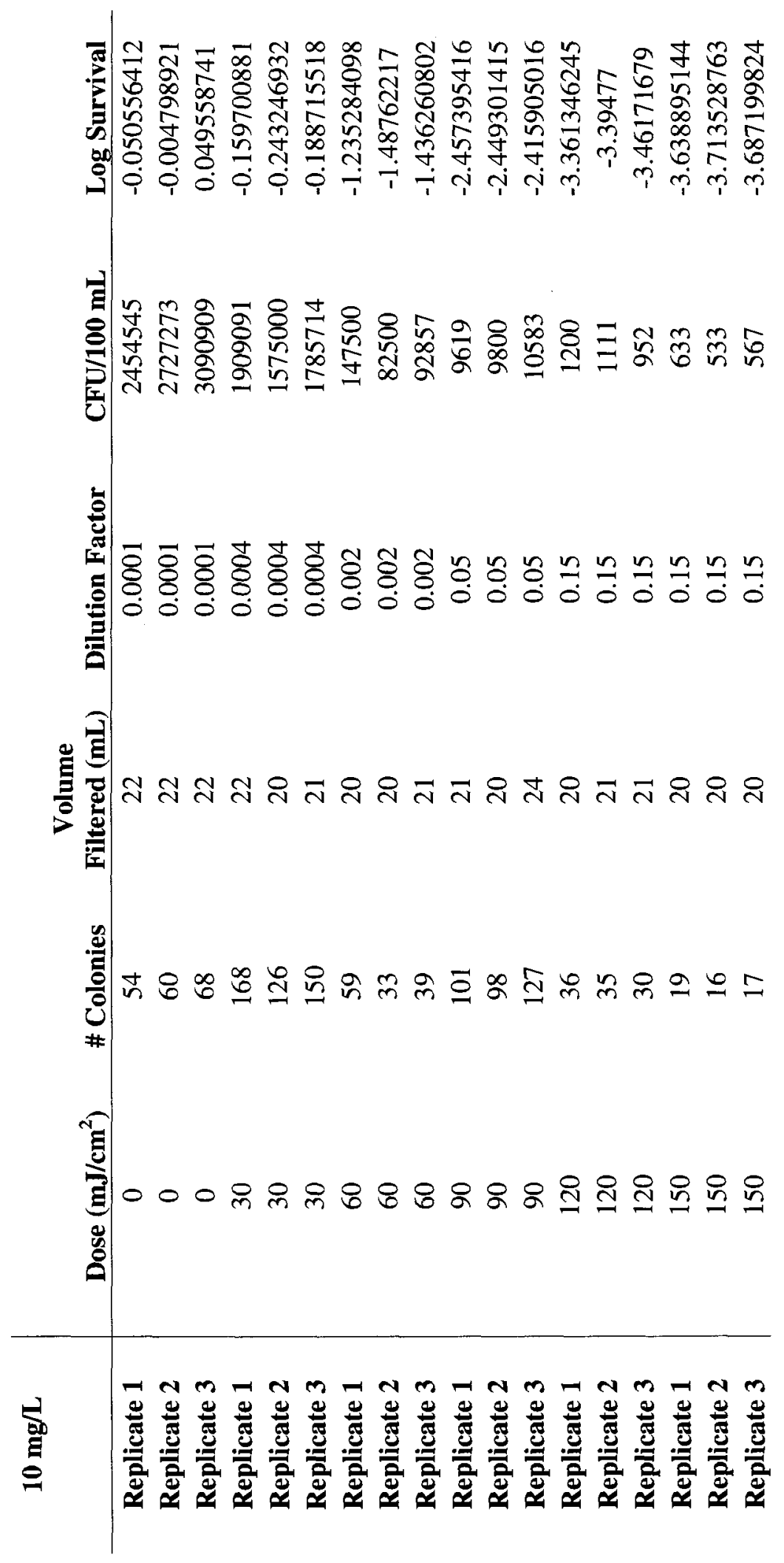




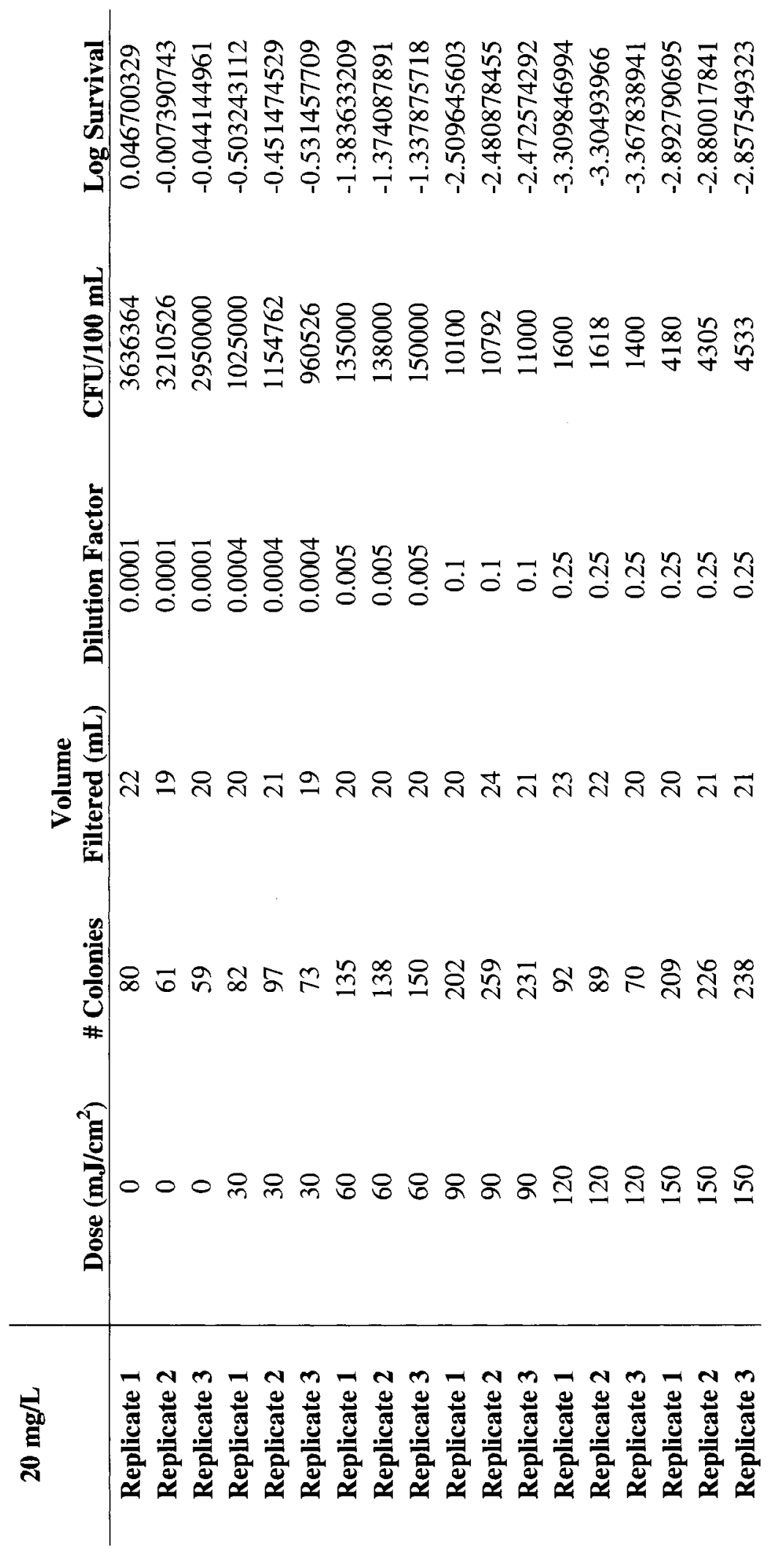




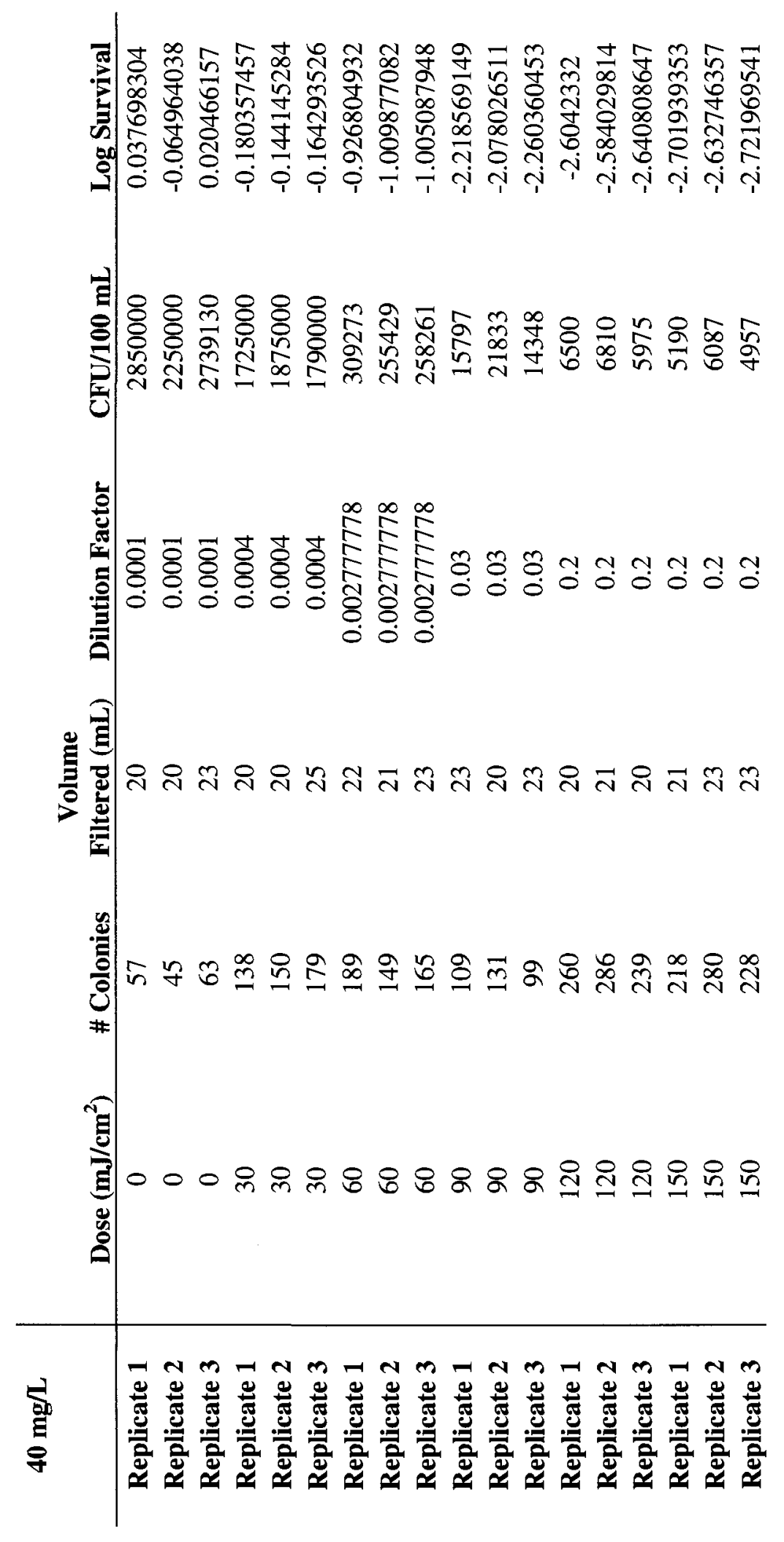



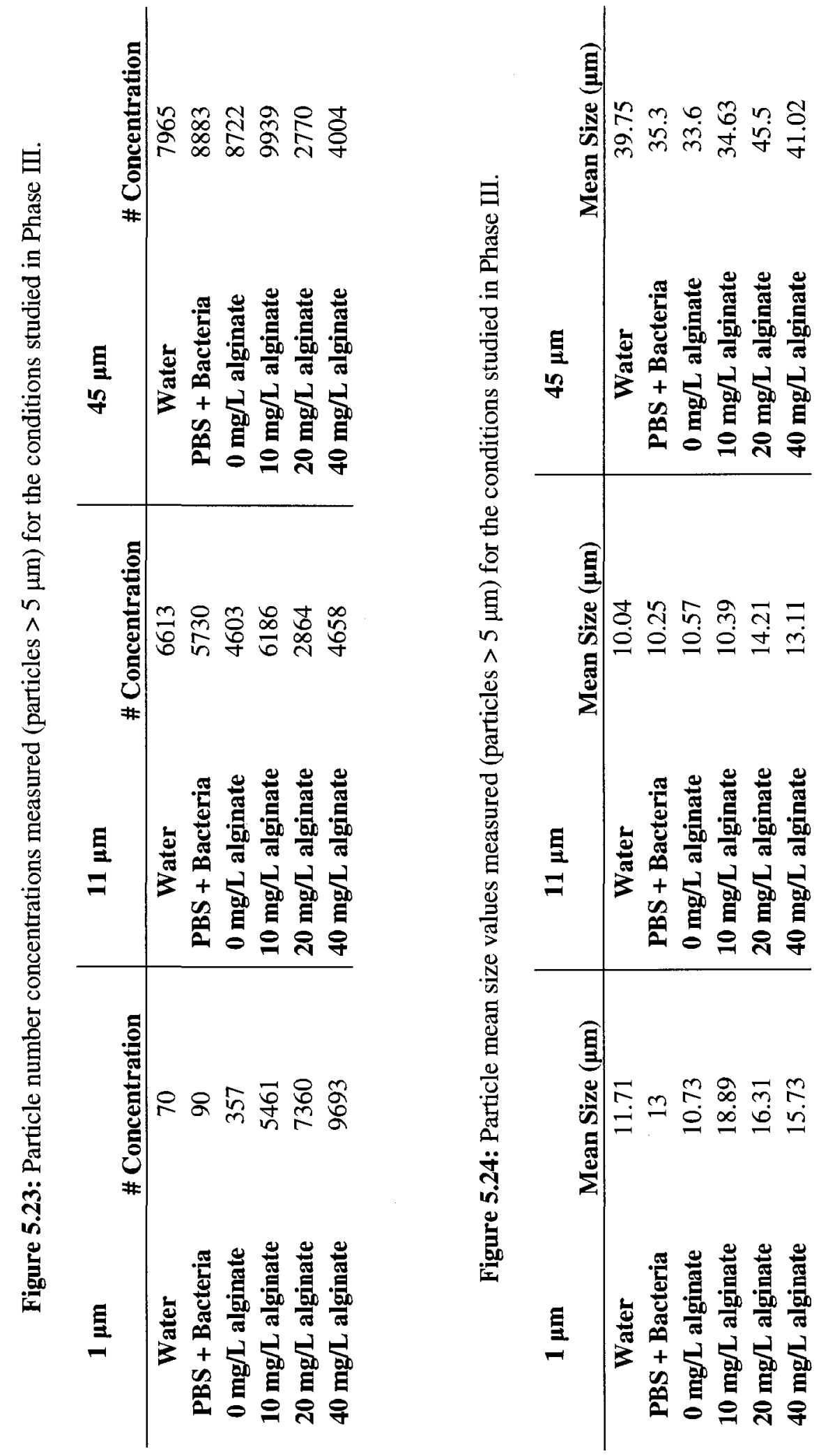


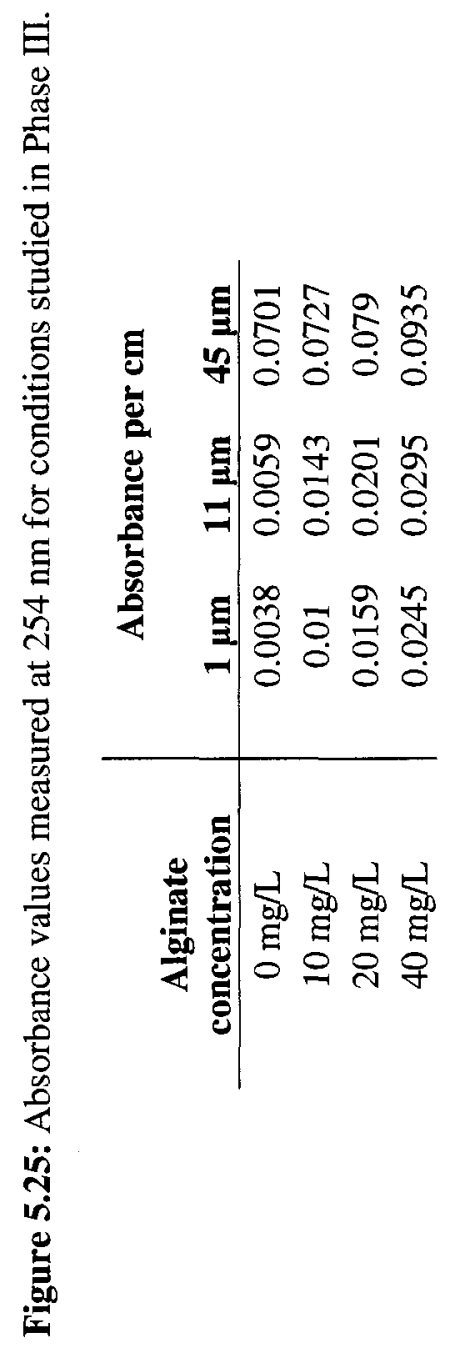




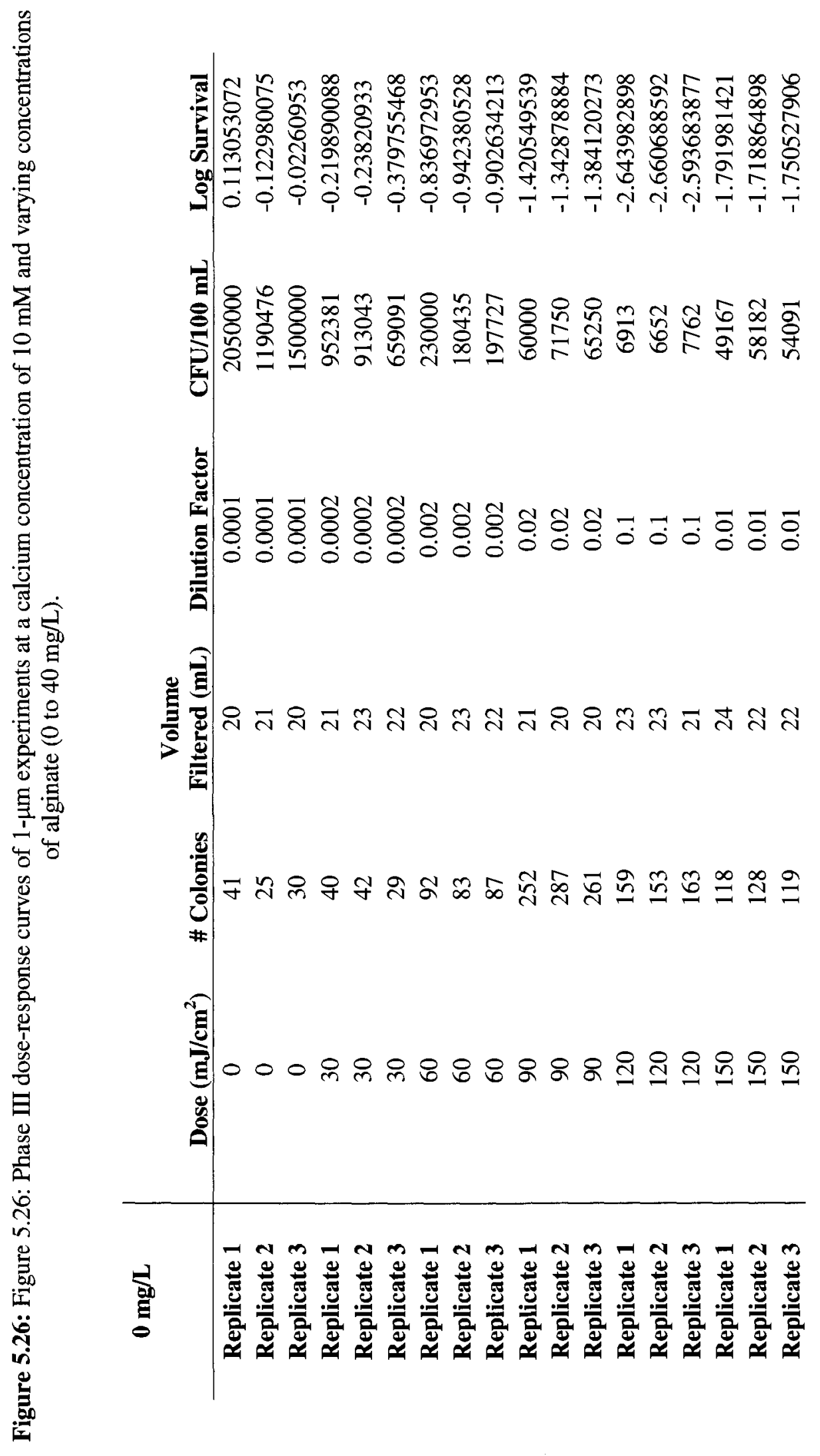




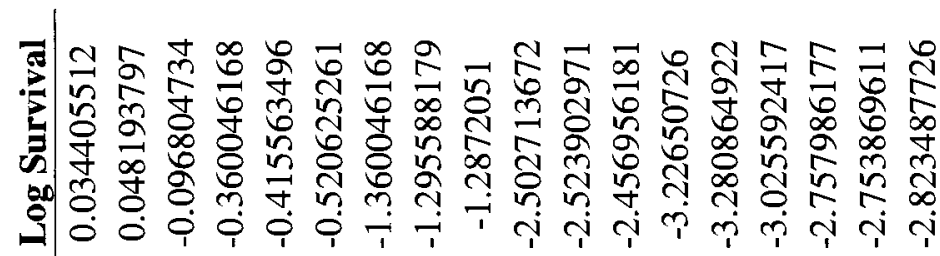

리료

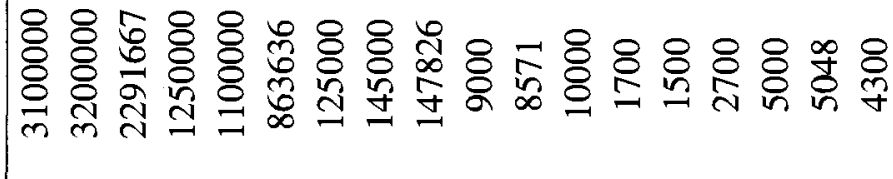

音

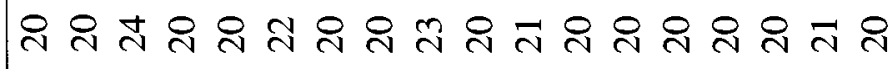

ํํㅂำ

हี

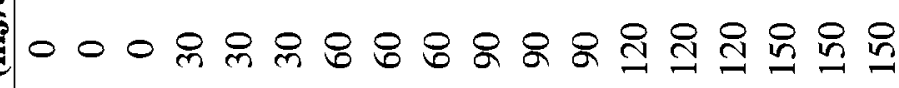


ఫ휴 ड

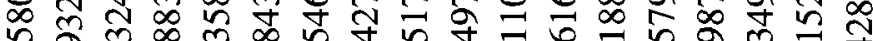

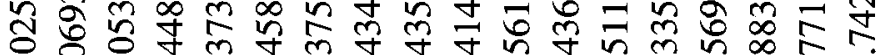

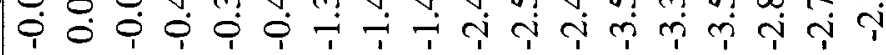

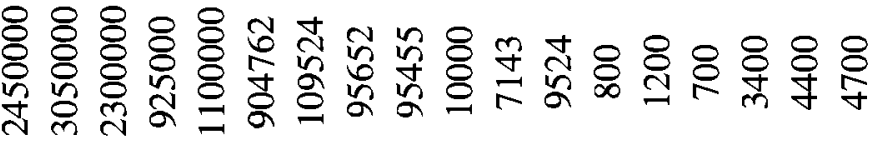

향ㅎㅇ

冚

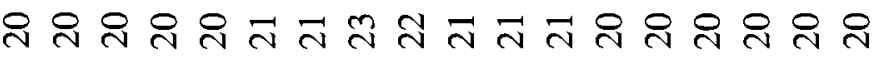

뭉ำ

"률

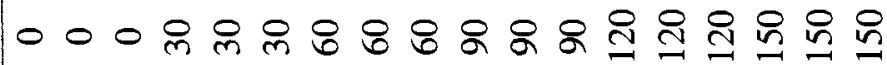

突

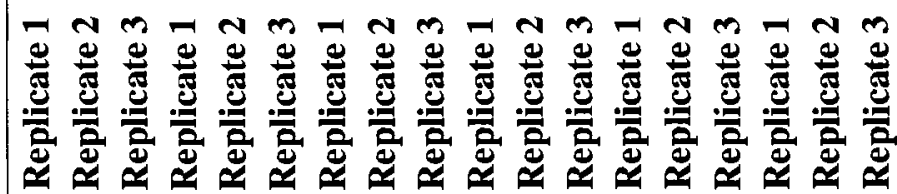




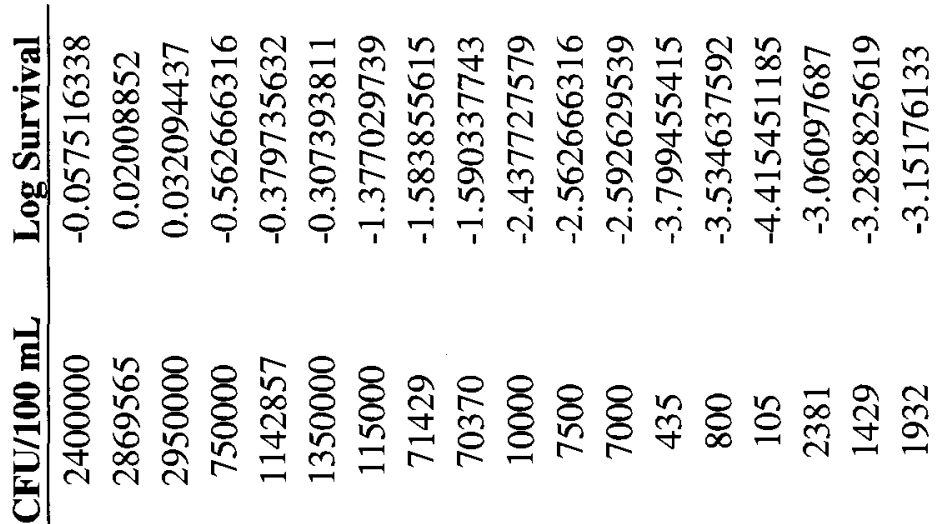

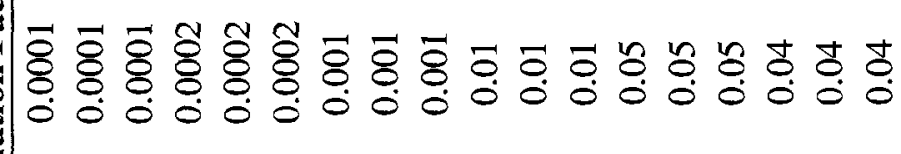

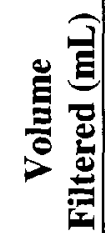

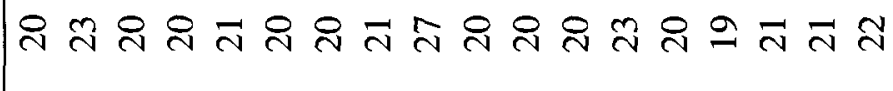

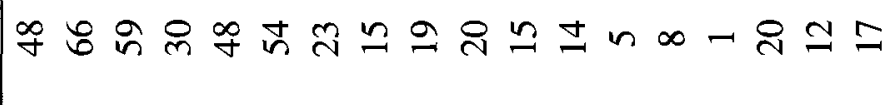

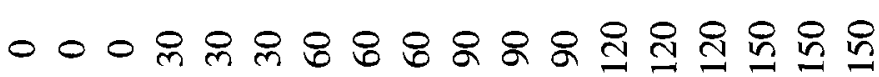

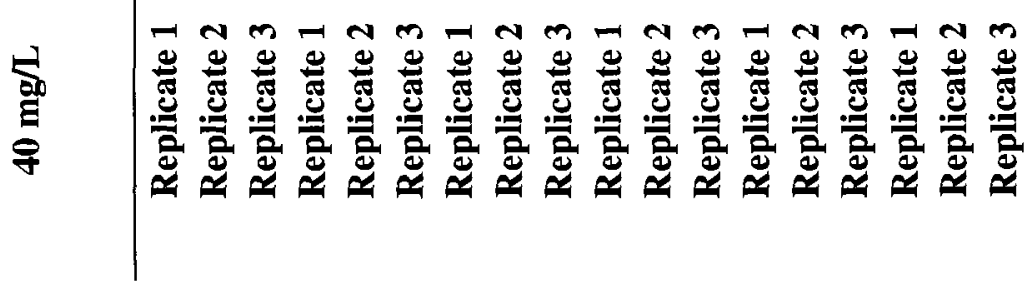




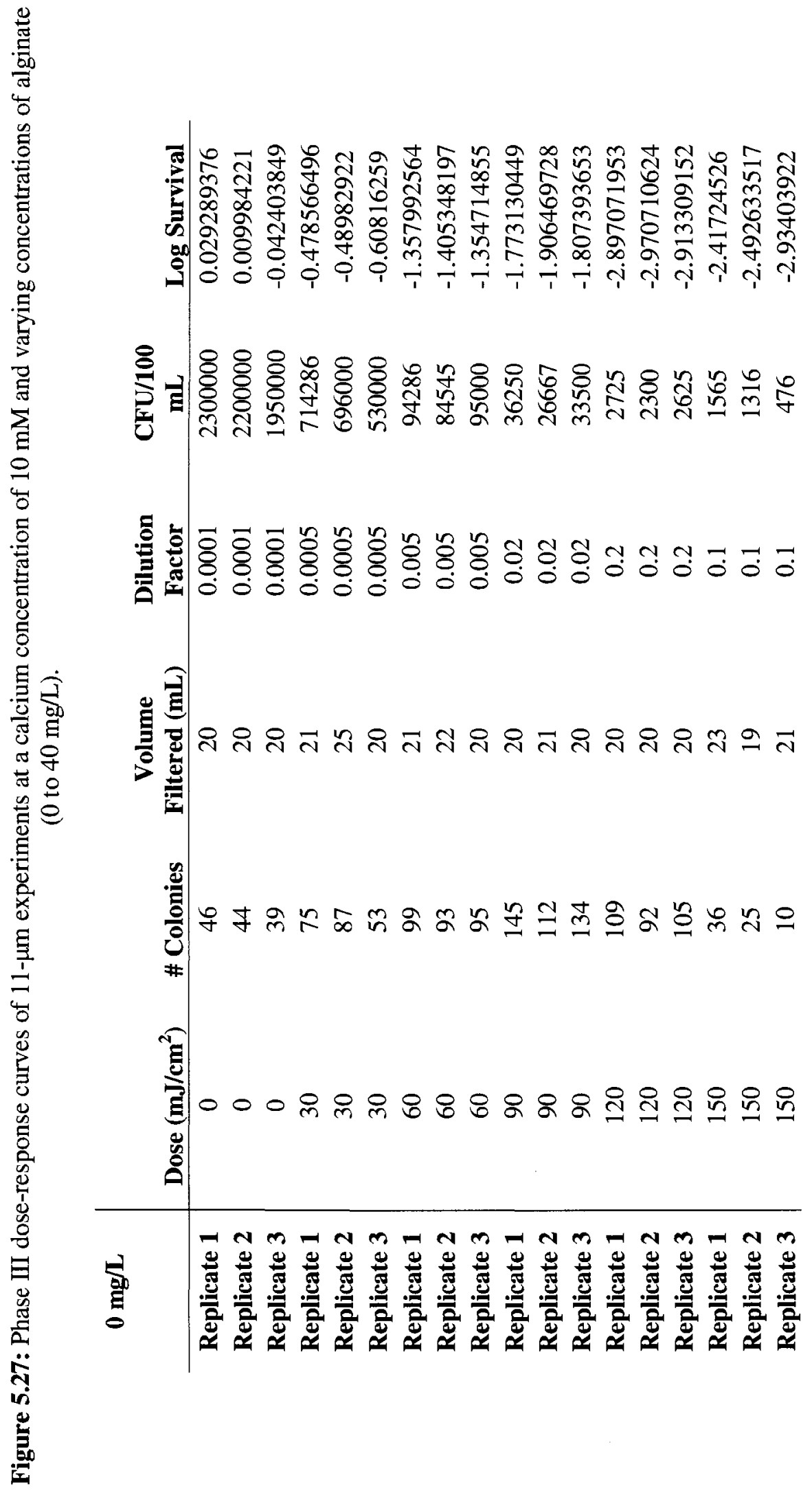




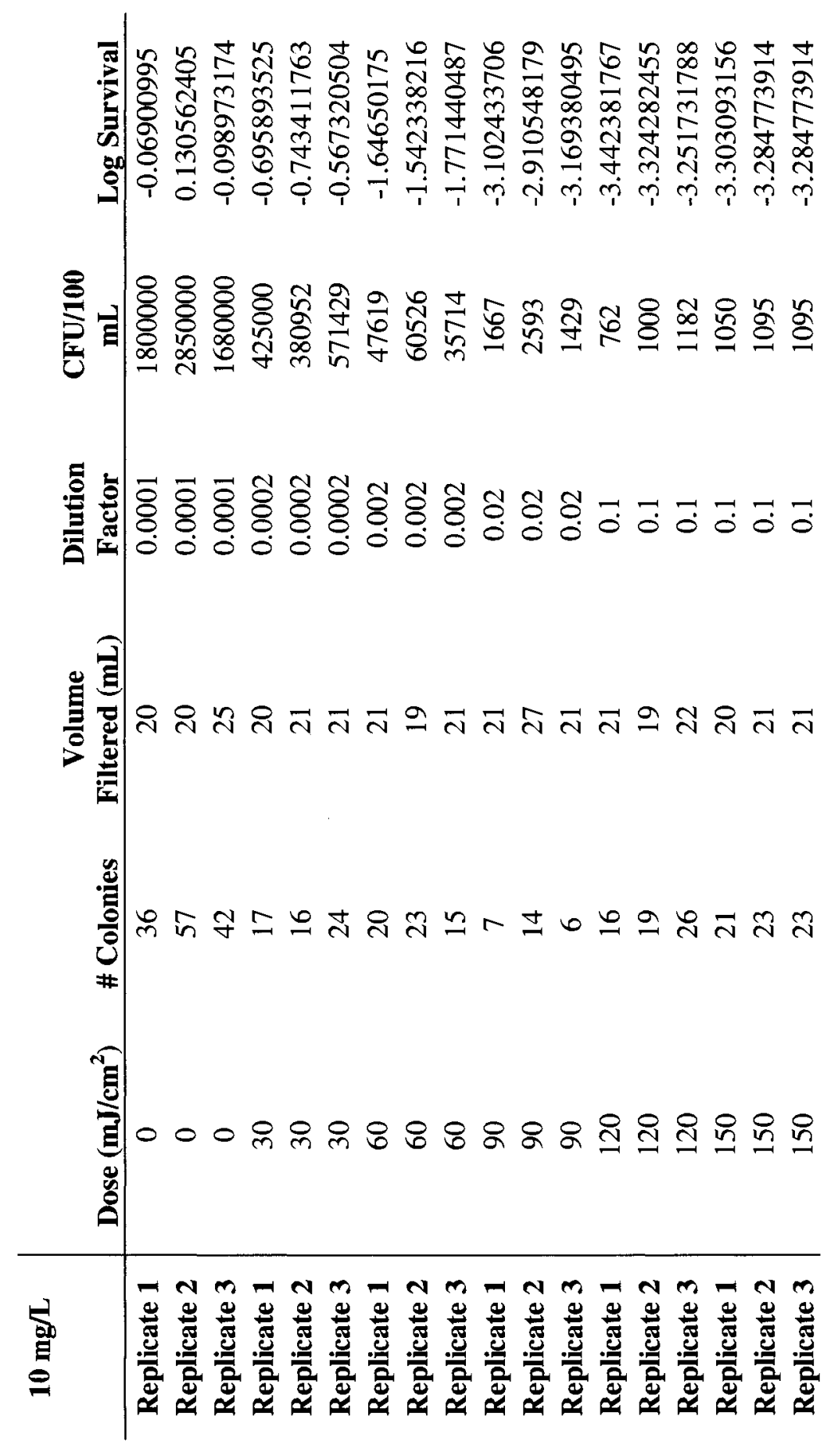




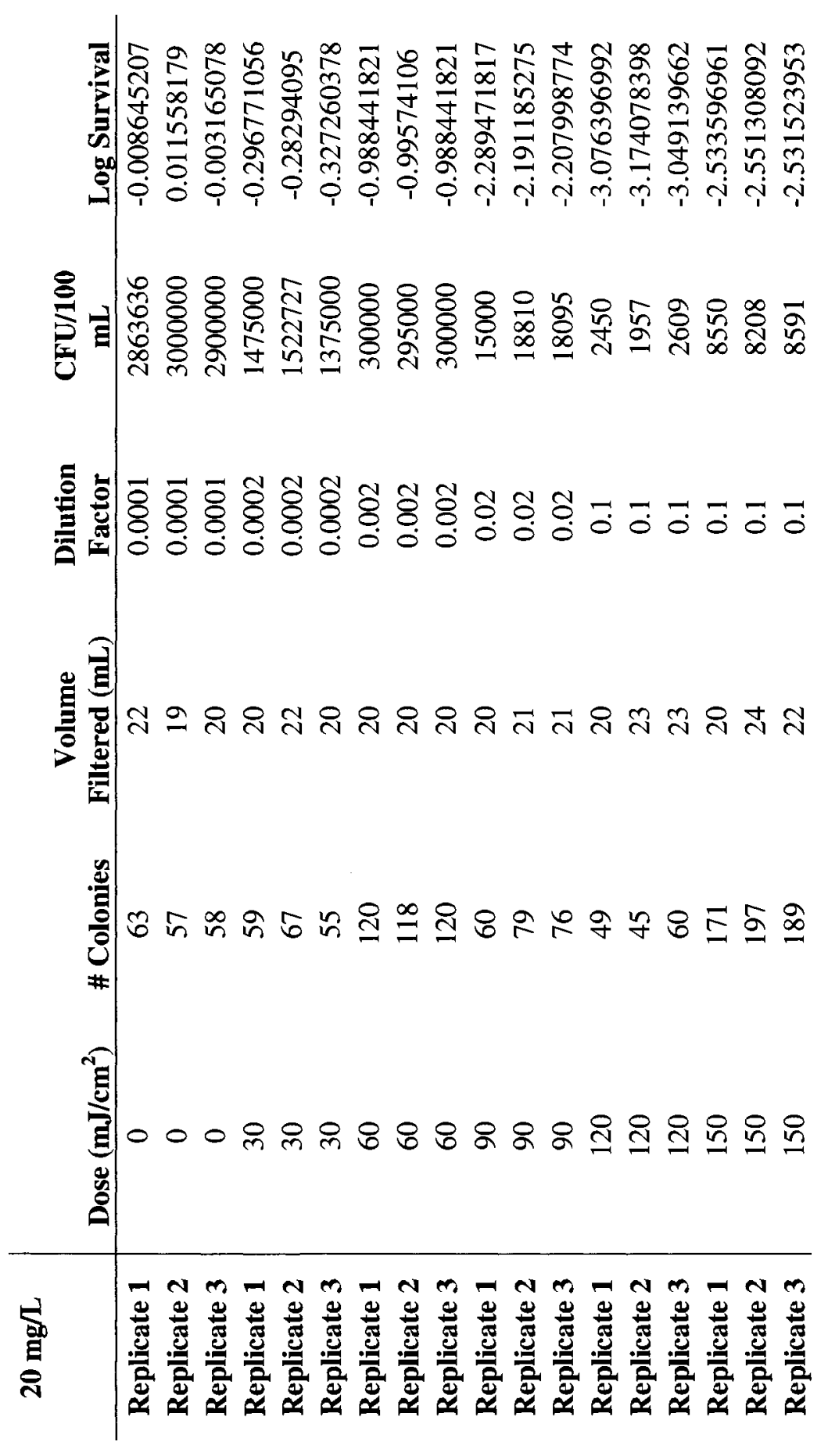




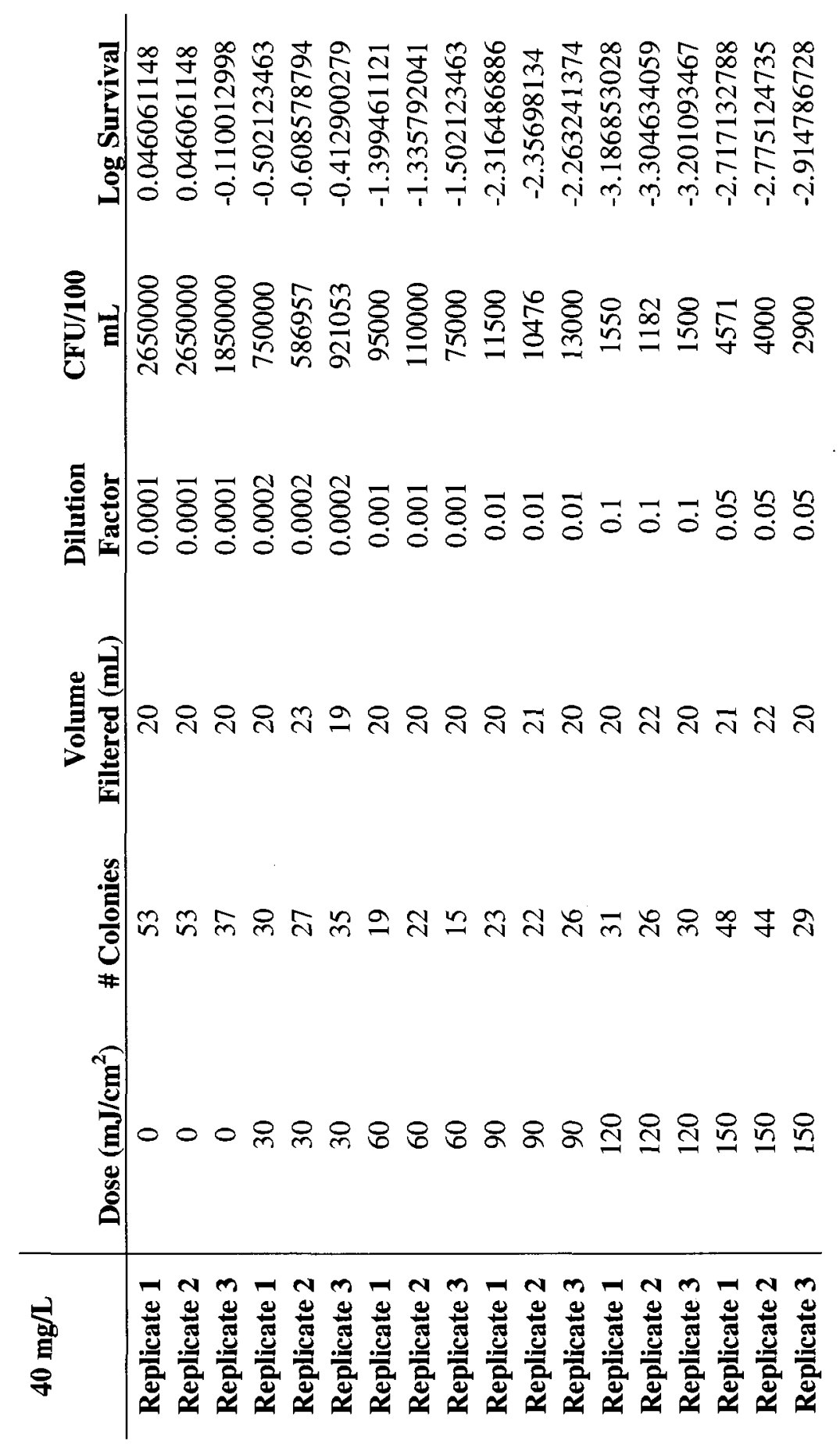




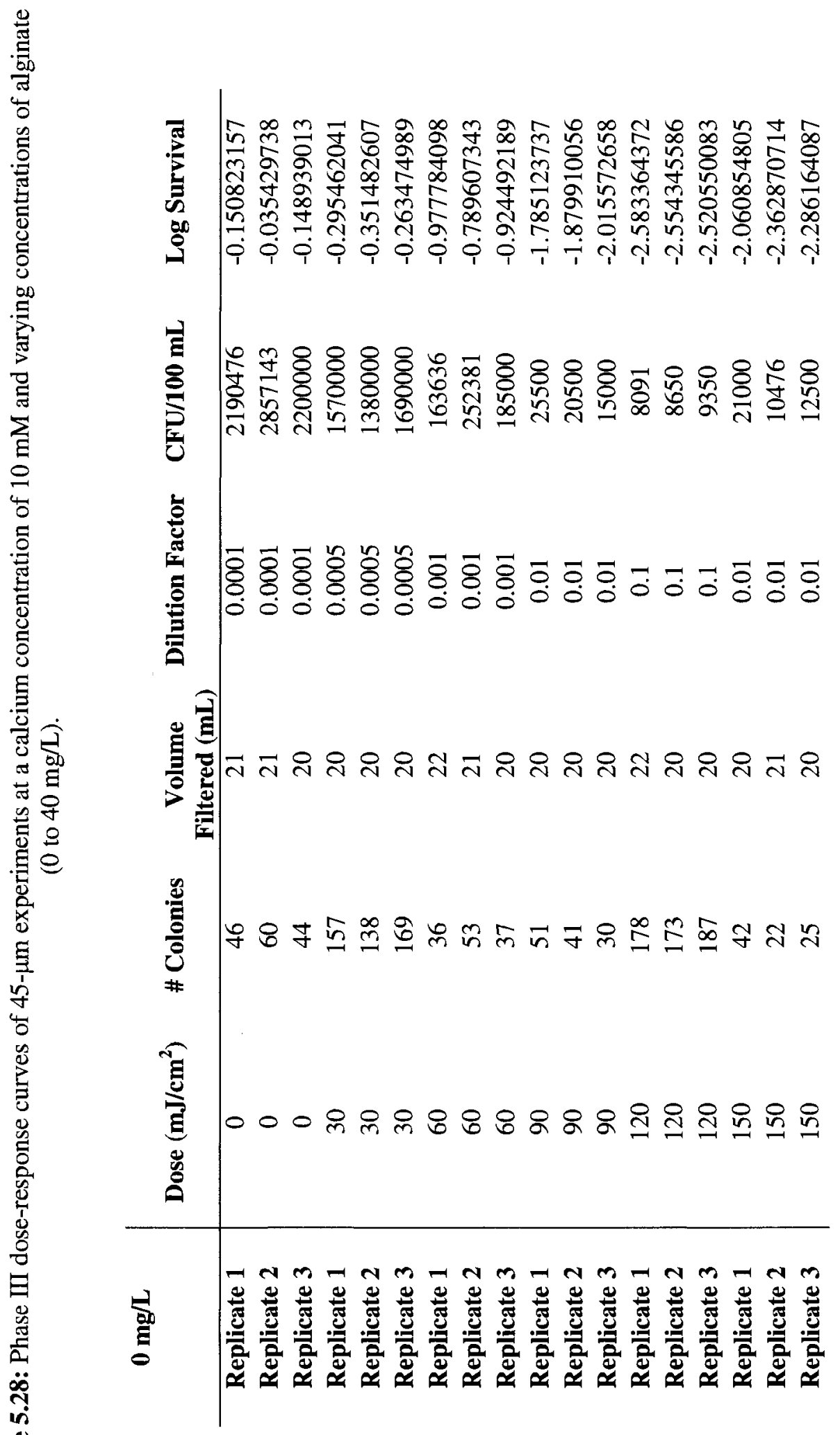




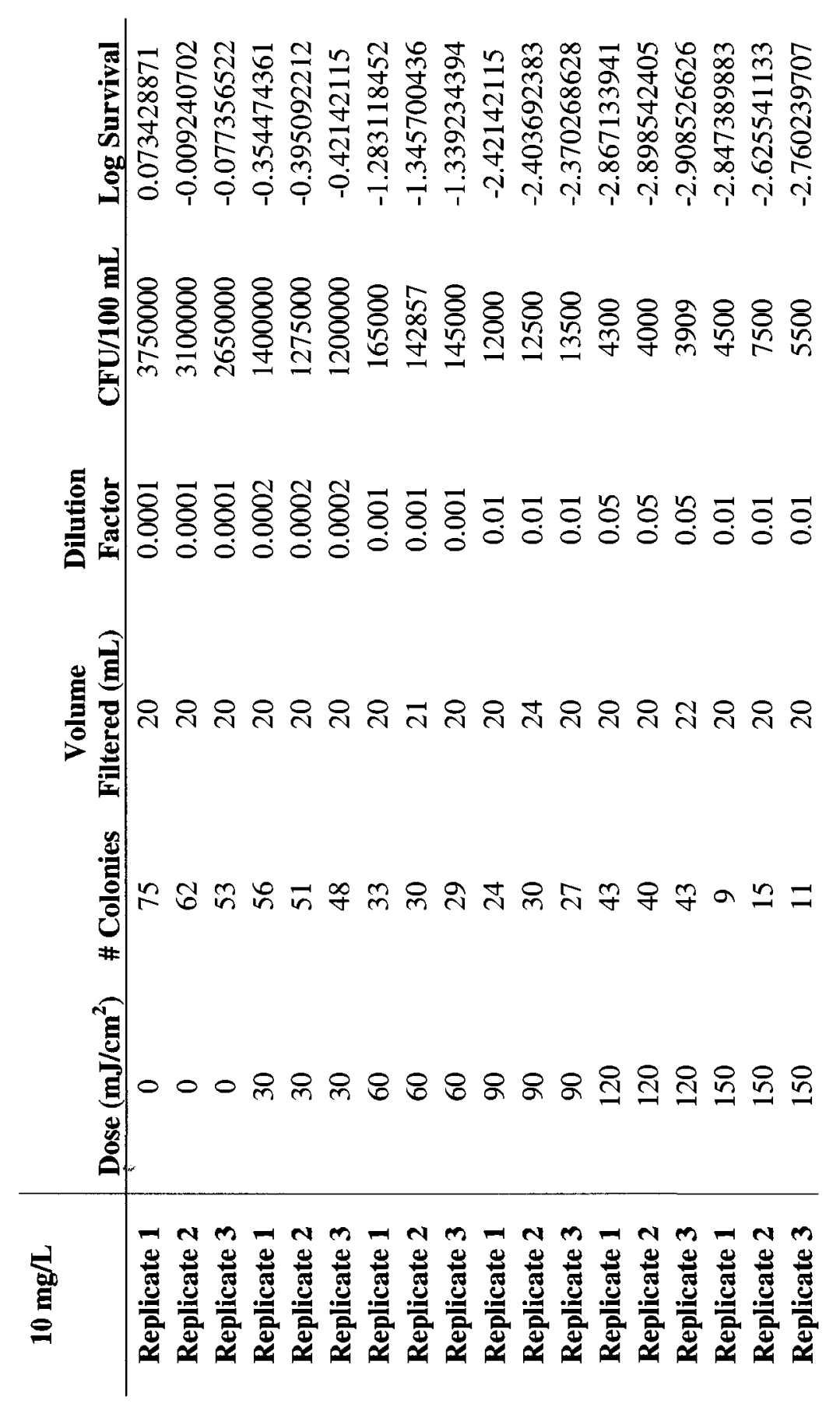




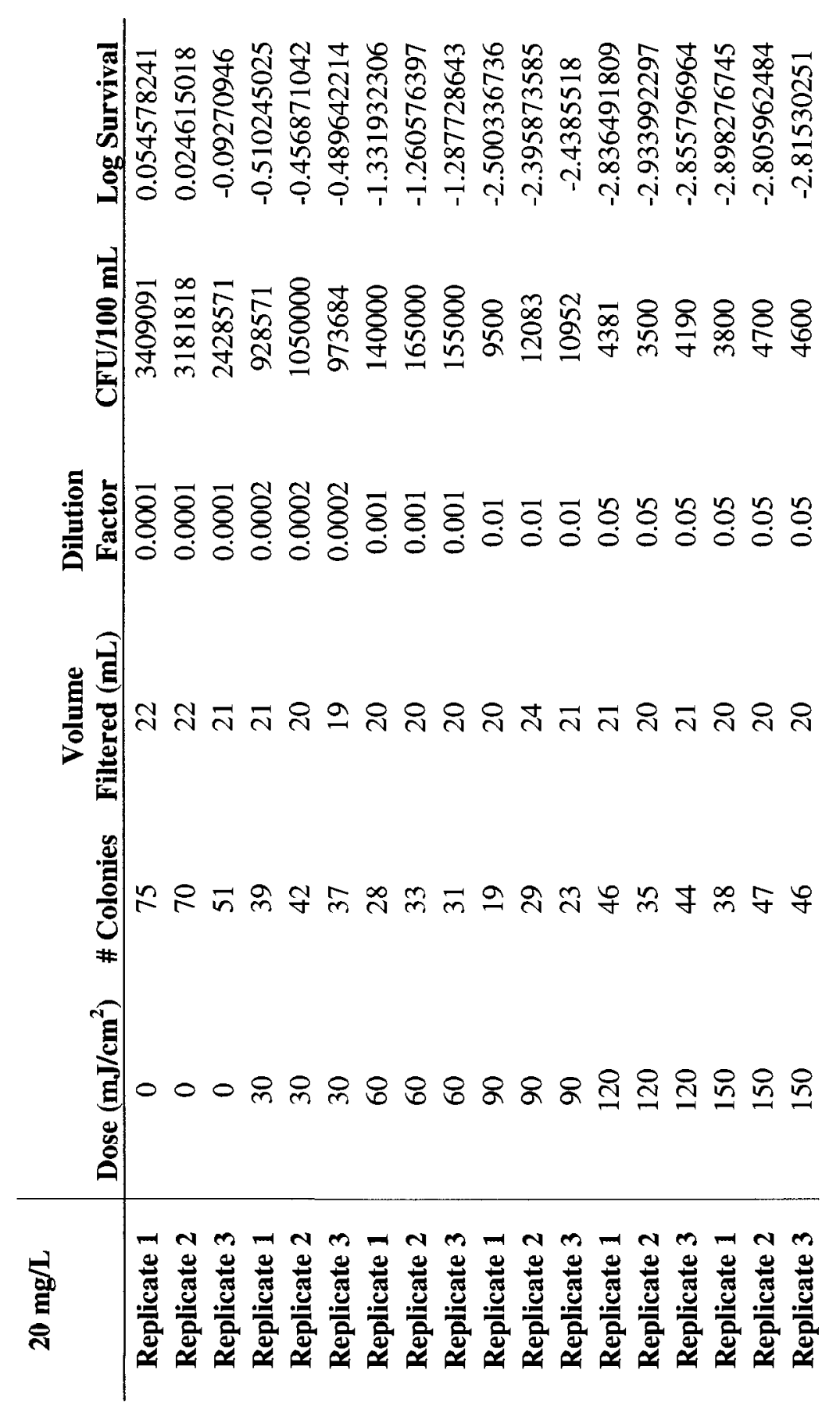




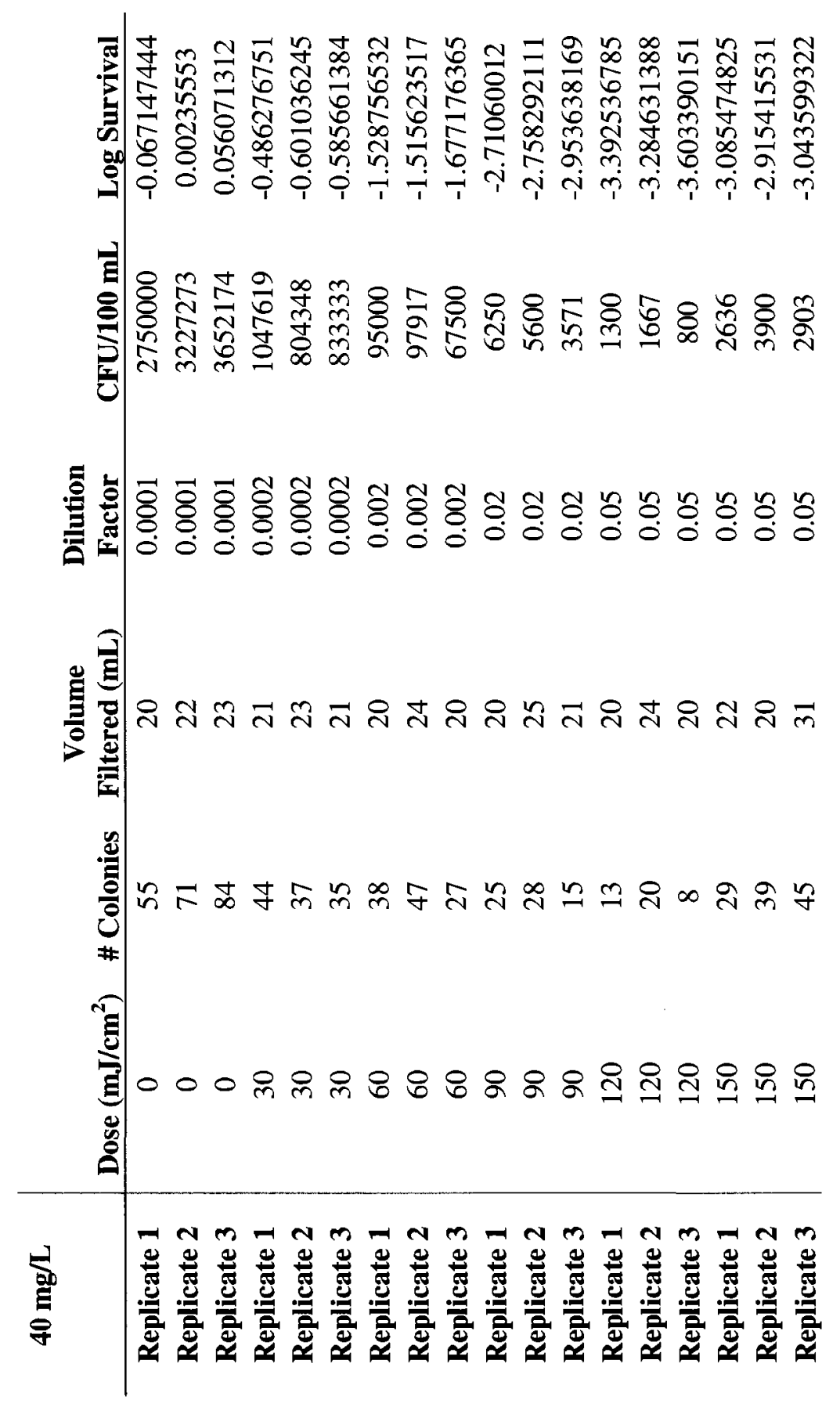




\section{APPENDIX B: LINEARIZED DOSE-RESPONSE CURVES AND \\ INACTIVATION RATE CONSTANTS}

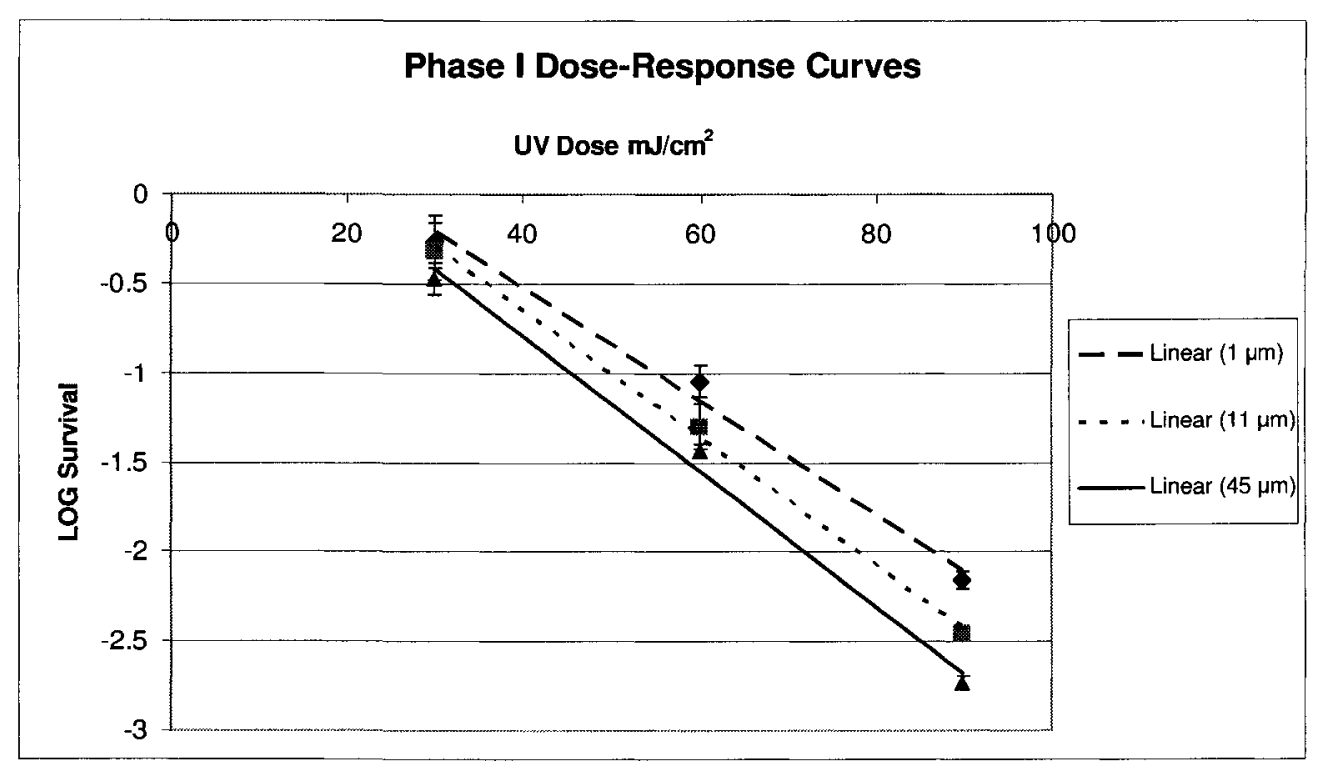

Appendix B Figure 1: Linearized dose-response curves of Phase I.

Appendix B Table 1: Inactivation rate constant (k) values for linearized doseresponse curves of Phase I

\begin{tabular}{l|ccc}
\hline & $1 \mu m$ & $11 \mu m$ & $45 \mu m$ \\
\hline$k$ & 0.0315 & 0.0356 & 0.0376 \\
\hline
\end{tabular}




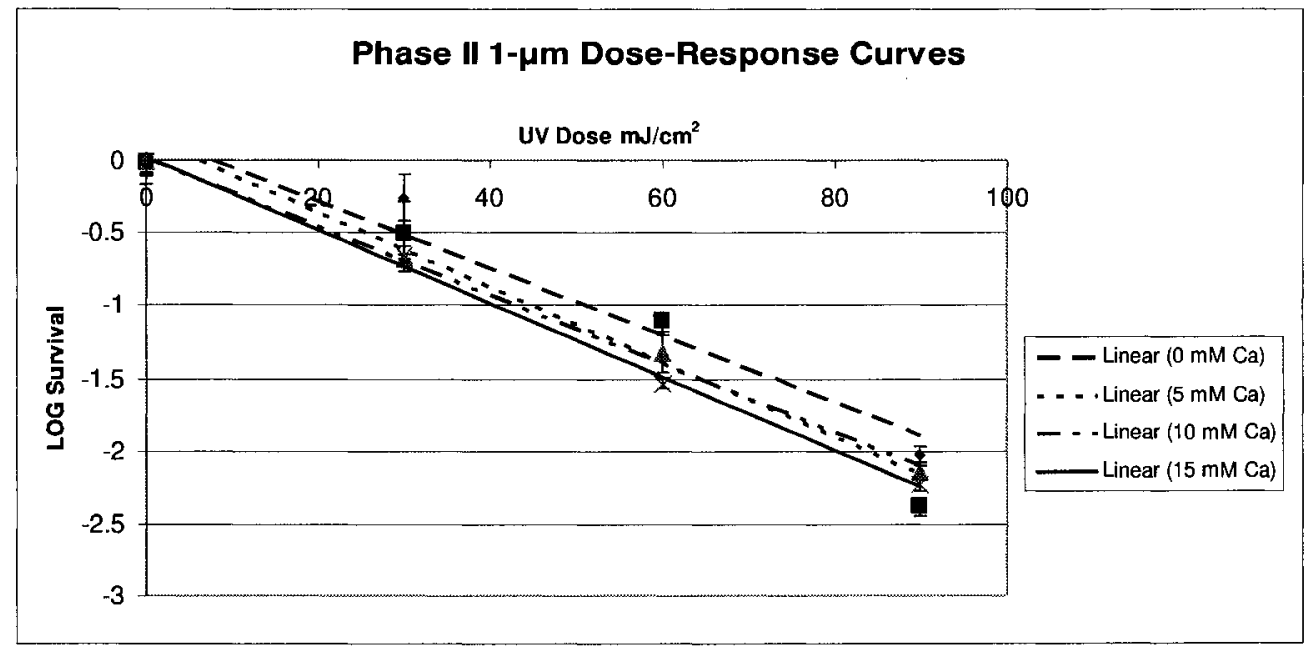

Appendix B Figure 2: Linearized dose-response curves of 1- $\mu \mathrm{m}$ experiments (Phase II).

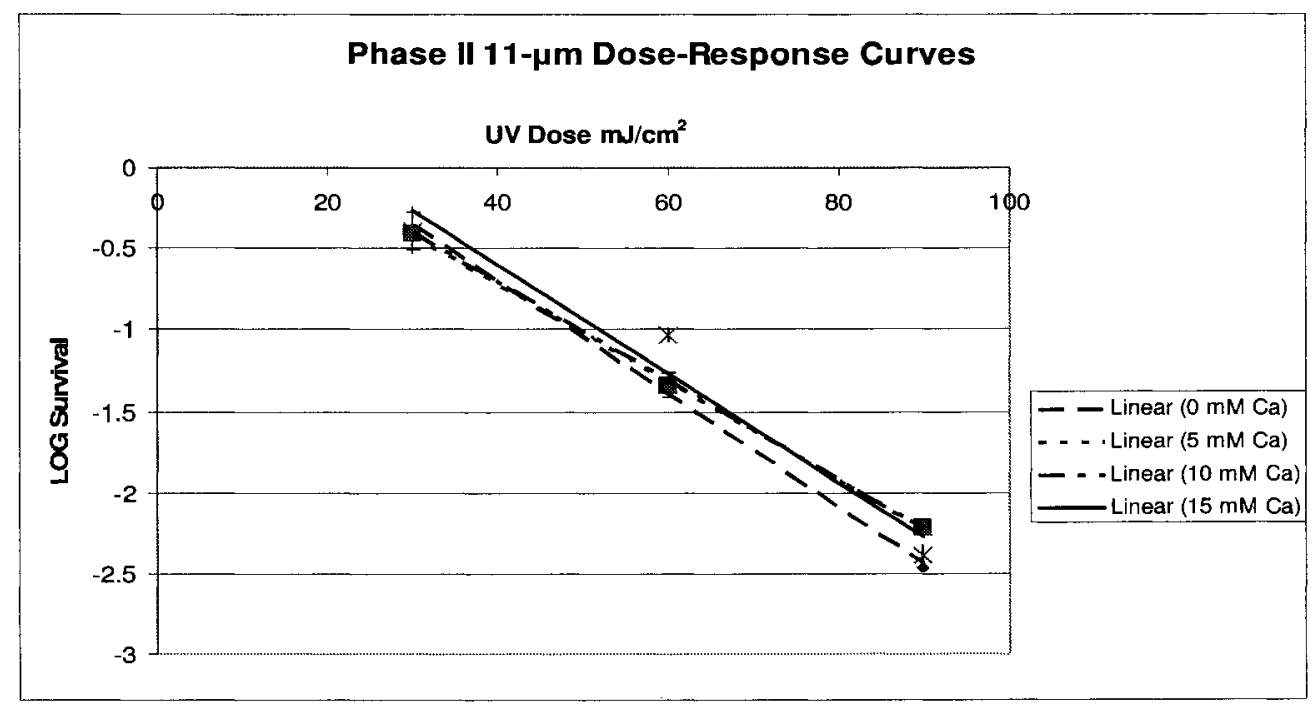

Appendix B Figure 3: Linearized dose-response curves of 11- $\mu \mathrm{m}$ experiments (Phase II). 


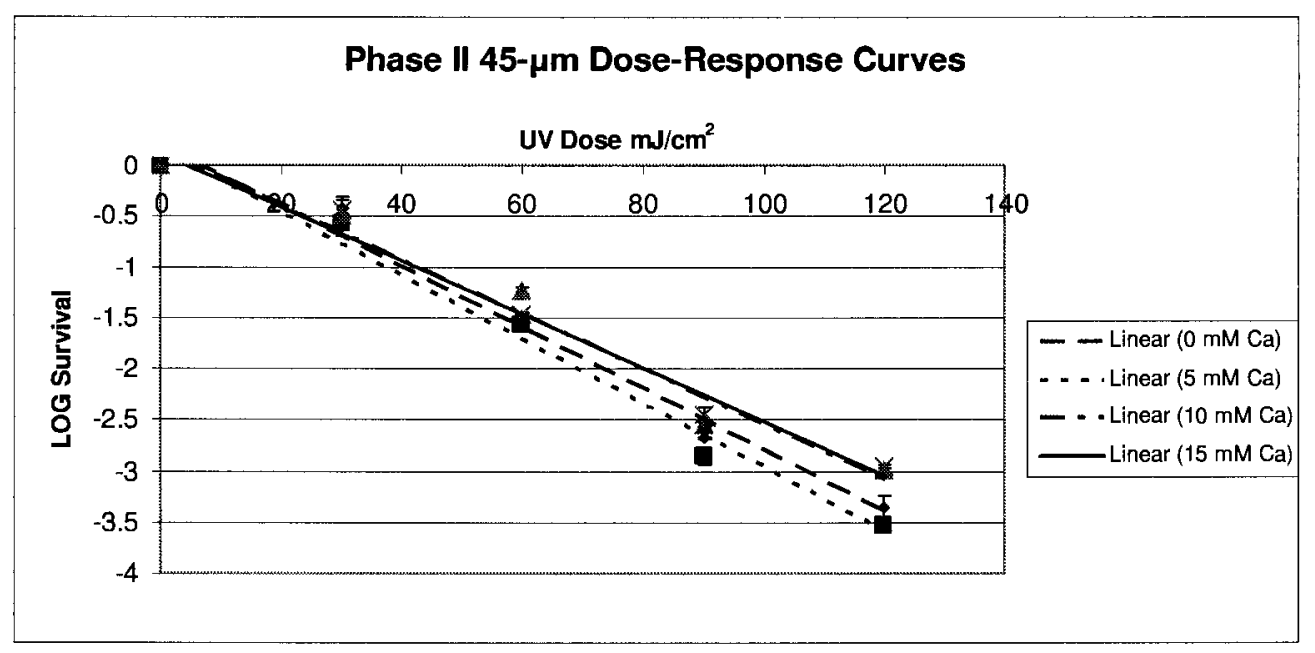

Appendix B Figure 4: Linearized dose-response curves of 45- $\mu \mathrm{m}$ experiments (Phase II).

Appendix B Table 2: Inactivation rate constant (k) values for linearized doseresponse curves of Phase II

\begin{tabular}{|c|c|c|c|}
\hline & $1 \mu m$ & $11 \mu \mathrm{m}$ & $45 \mu m$ \\
\hline $0 \mathrm{mMCa^{2+ }}$ & 0.023 & 0.0347 & 0.0299 \\
\hline $5 m M C^{2+}$ & 0.0258 & 0.0300 & 0.0313 \\
\hline $10 \mathrm{mMCa^{2+ }}$ & 0.0235 & 0.0303 & 0.0268 \\
\hline $15 m M C a^{2+}$ & 0.0251 & 0.0333 & 0.0263 \\
\hline
\end{tabular}




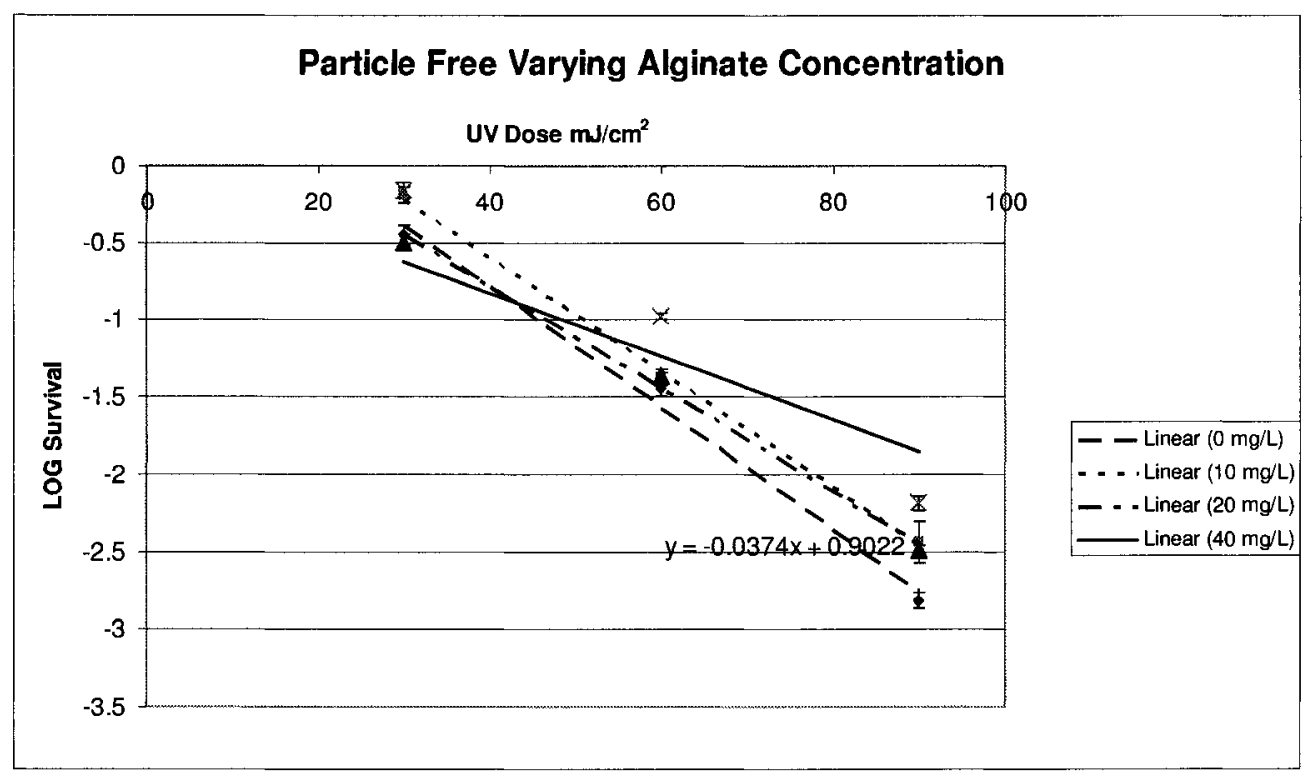

Appendix B Figure 5: Linearized dose-response curves of particle-free experiments (Phase III).

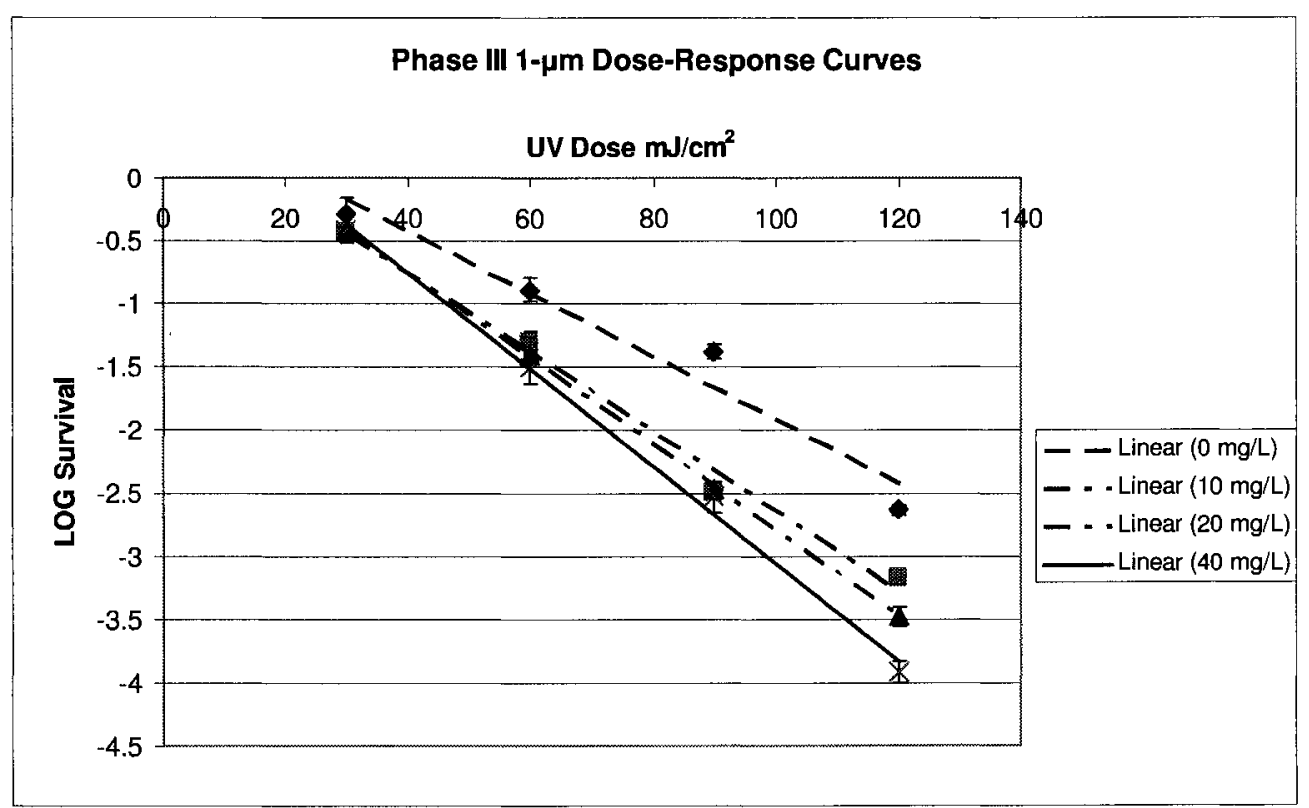

Appendix B Figure 6: Linearized dose-response curves of $1-\mu \mathrm{m}$ experiments (Phase III). 


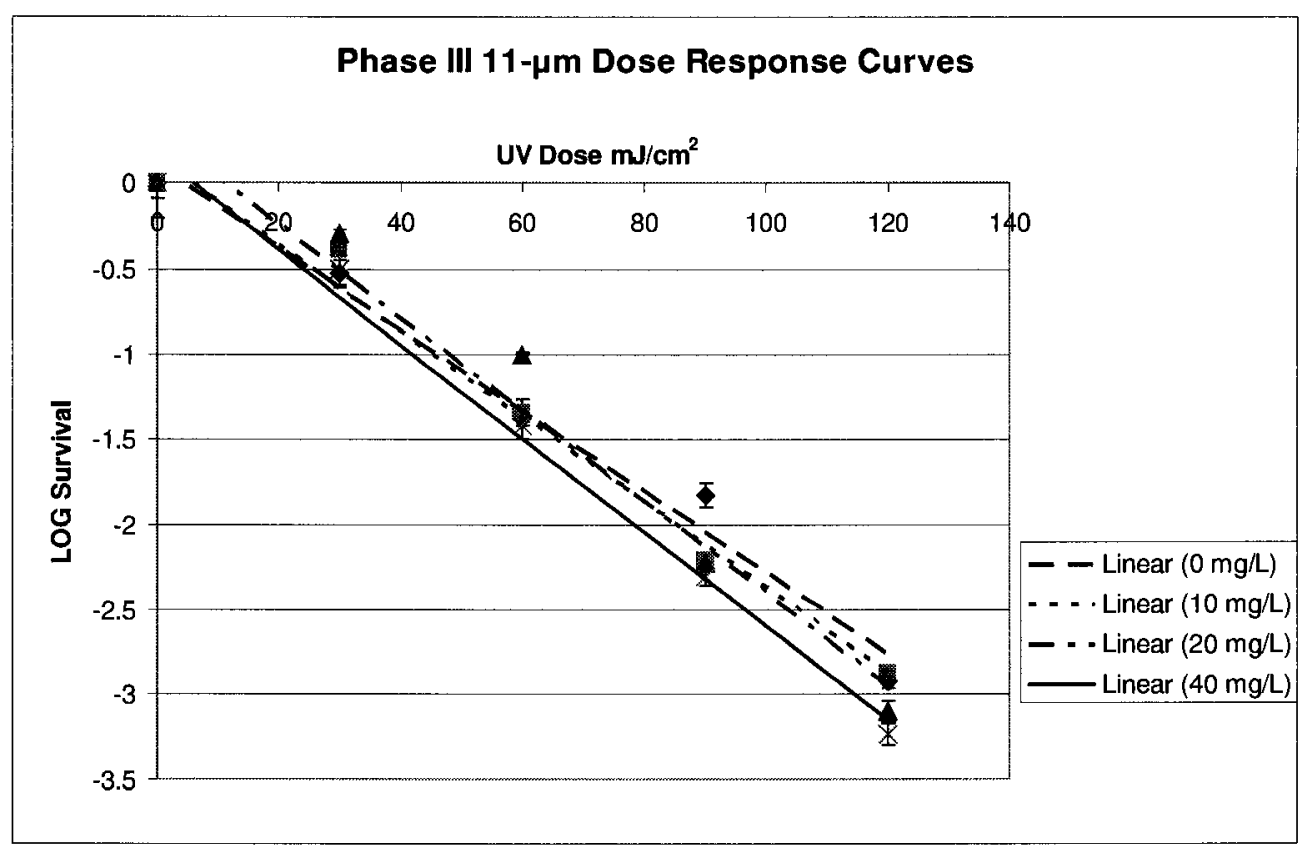

Appendix B Figure 7: Linearized dose-response curves of 11- $\mu \mathrm{m}$ experiments (Phase III).

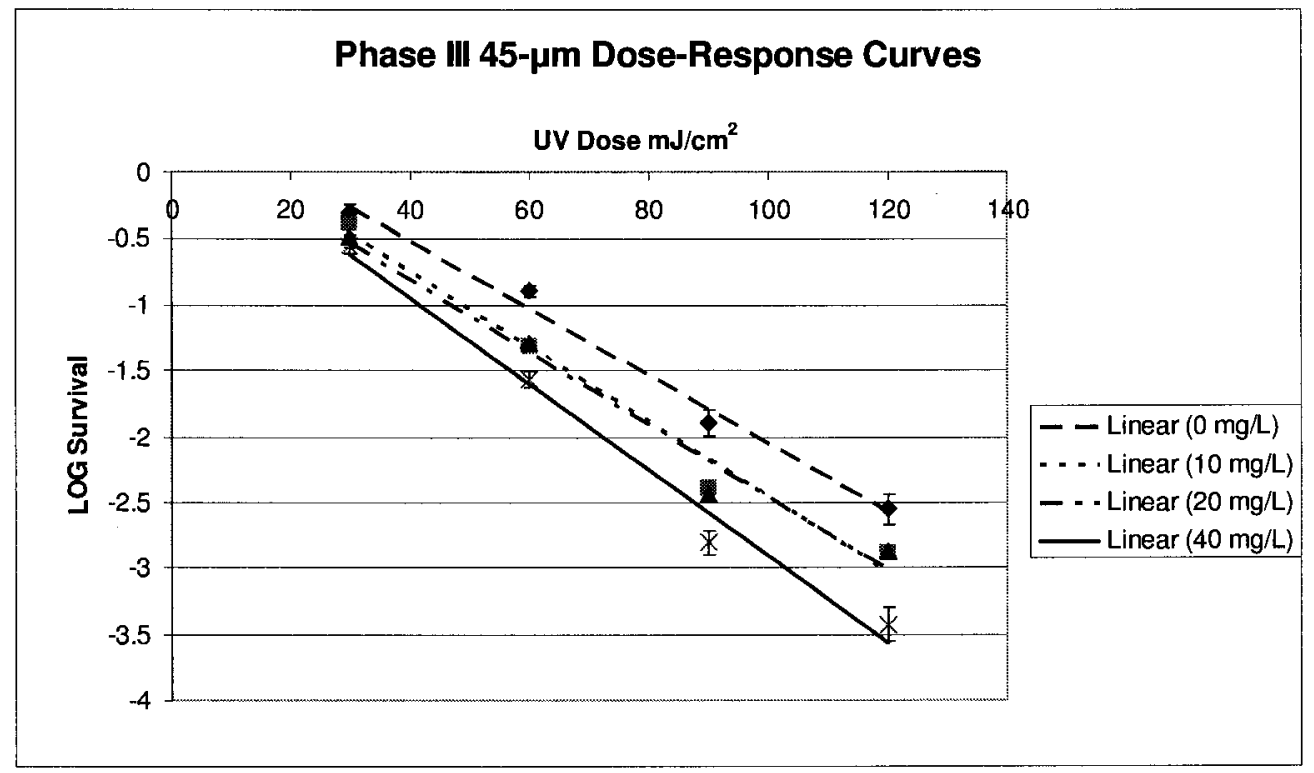

Appendix B Figure 8: Linearized dose-response curves of $45-\mu \mathrm{m}$ experiments (Phase III). 
Appendix B Table 3: Inactivation rate constant $(\mathrm{k})$ values for linearized doseresponse curves of Phase III

\begin{tabular}{|c|c|c|c|c|}
\hline & Particle-free & $1 \mu m$ & $11 \mu \mathrm{m}$ & $45 \mu m$ \\
\hline $0 \mathrm{mg} / \mathrm{L}$ Alginate & 0.0395 & 0.0252 & 0.0239 & 0.0258 \\
\hline $10 \mathrm{mg} / \mathrm{L}$ Alginate & 0.0374 & 0.0314 & 0.0252 & 0.0286 \\
\hline $20 \mathrm{mg} / \mathrm{L}$ Alginate & 0.0332 & 0.034 & 0.0271 & 0.0277 \\
\hline $40 \mathrm{mg} / \mathrm{L}$ Alginate & 0.0337 & 0.0384 & 0.0276 & 0.0328 \\
\hline
\end{tabular}

